\title{
Mechanik und Dynamik biologischer Modellsysteme am Beispiel aktingefüllter Vesikel und synchroner Zellmigration von Dictyostelium discoideum
}

\author{
Dissertation
}

zur Erlangung des mathematisch-naturwissenschaftlichen

Doktorgrades

"Doctor rerum naturalium"

der Georg-AugustUniversität Göttingen

im Promotionsprogramm Chemie

der Georg-August University School of Science (GAUSS)

vorgelegt von

Edith Elisabeth Schäfer

aus Mayen

Göttingen 2012 


\title{
Betreuungsausschuss
}

Prof. Dr. Andreas Janshoff

Institut für Physikalische Chemie, Georg-August-Universität Göttingen

Prof. Dr. Sarah Köster

Institut für Röntgenphysik, Georg-August-Universität Göttingen

\section{Mitglieder der Prüfungskommission}

\author{
Referent/in: Prof. Dr. Andreas Janshoff \\ Institut für Physikalische Chemie, Georg-August-Universität Göttingen \\ Korreferent/in: Prof. Dr. Sarah Köster \\ Institut für Röntgenphysik, Georg-August-Universität Göttingen \\ Weitere Mitglieder der Prüfungskommission: \\ Prof. Dr. Blanche Schwappach \\ Biochemie I, Universitätsmedizin Göttingen \\ Prof. Dr. Burkhard Geil \\ Institut für Physikalische Chemie, Georg-August-Universität Göttingen \\ Prof. Dr. Mikael Simons \\ Max-Planck-Institut für experimentelle Medizin \\ Prof. Dr. Volker Thiel \\ Geobiologie, Georg-August-Universität Göttingen
}

Tag der mündlichen Prüfung: 19.09.2012 

Glück entsteht oft durch

Aufmerksamkeit in kleinen Dingen, Unglück oft durch

Vernachlässigung kleiner Dinge.

- Wilhelm Busch 


\section{Inhaltsverzeichnis}

1. Einleitung ....................................................................................

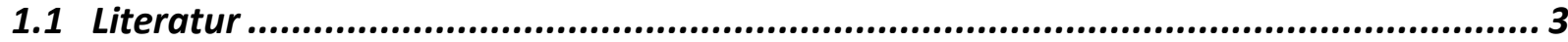

2. Kollektive Motilität von Dictyostelium discoideum ........................5

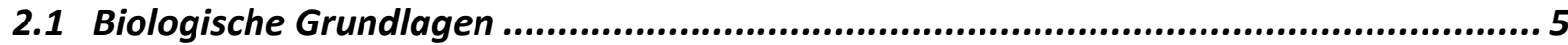

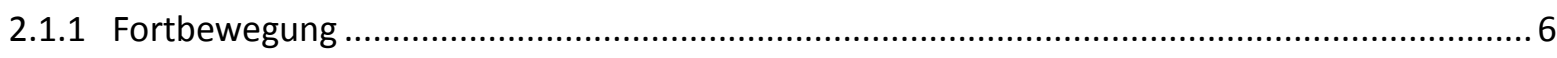

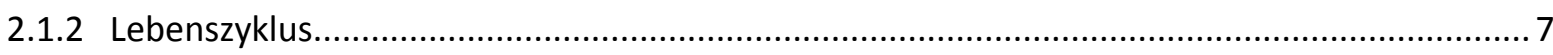

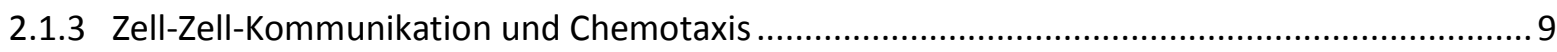

2.1.4 Beeinflussung der Oszillationsfrequenz .......................................................................... 13

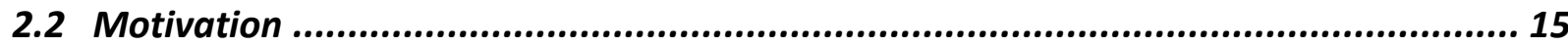

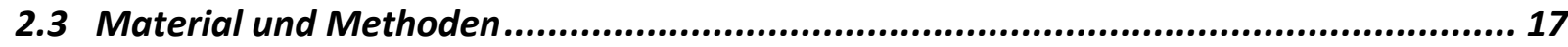

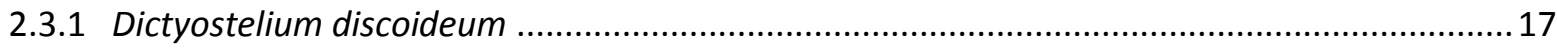

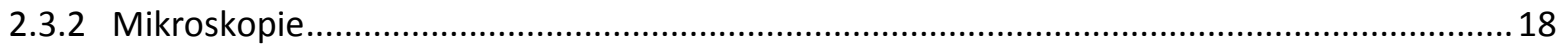

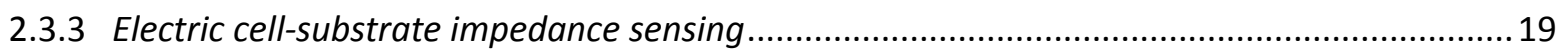

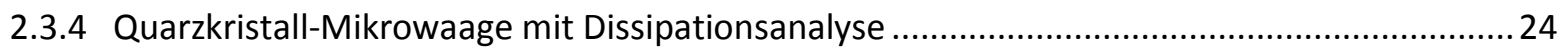

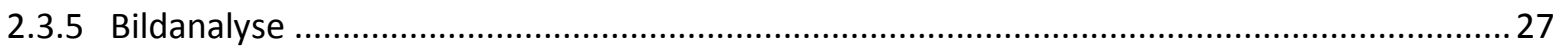

2.4 Impedanzmessungen im Mikrokanal........................................................... 29

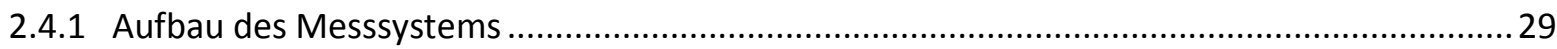

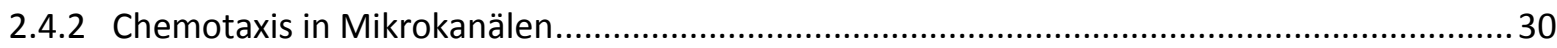

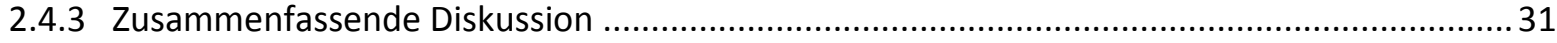

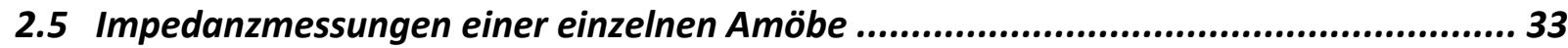

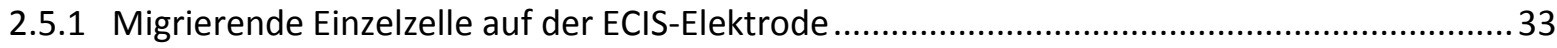

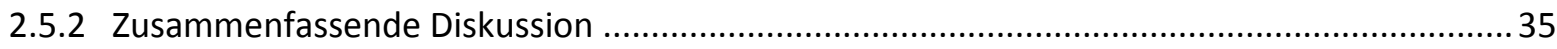

2.6 ECIS-Impedanzmessungen von zellulären Ensembles ........................................ 37

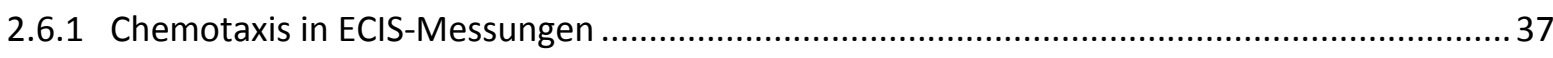




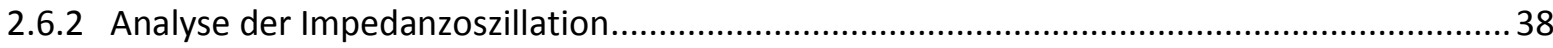

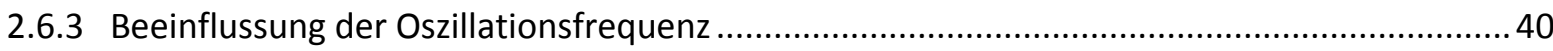

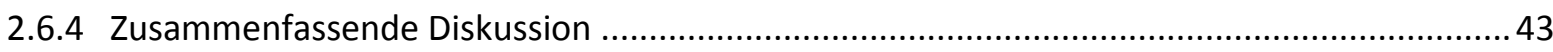

2.7 Veränderungen der Zellen auf der ECIS-Elektrode ................................................ 45

2.7.1 ECIS-Impedanzmessungen in Kombination mit Mikroskopieaufnahmen.................................. 45

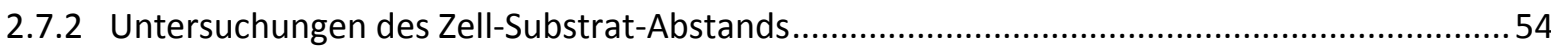

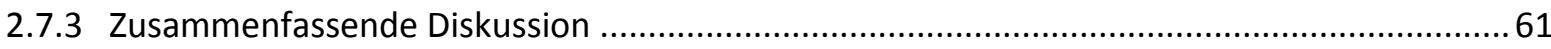

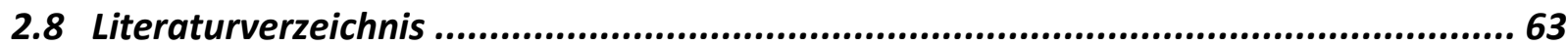

\section{Untersuchung der mechanischen Eigenschaften von Riesenvesikeln. 69}

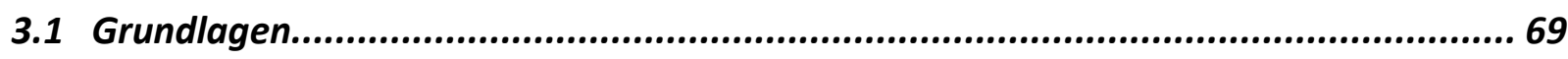

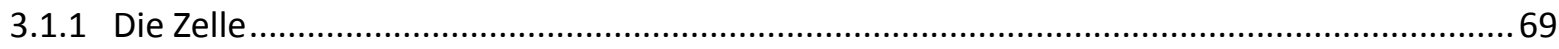

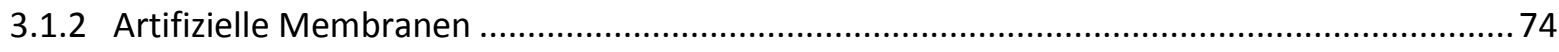

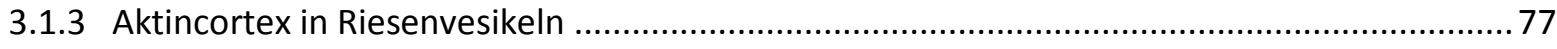

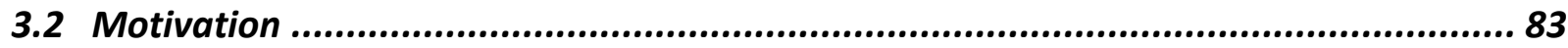

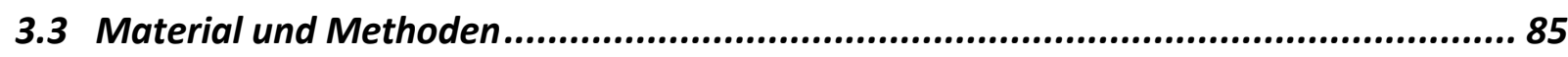

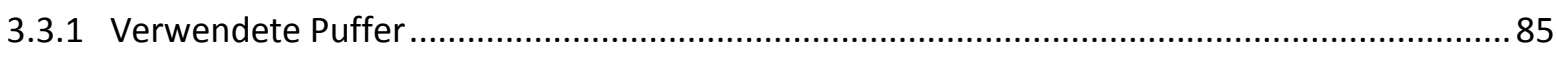

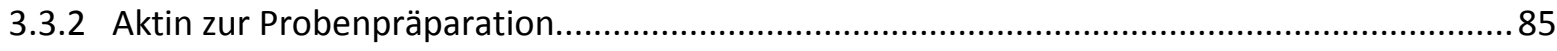

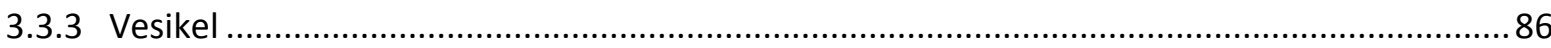

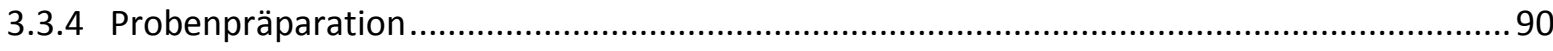

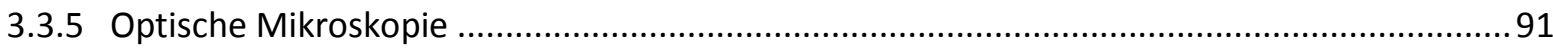

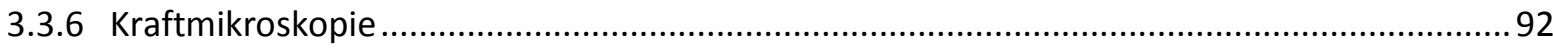

3.4 Kompression von Riesenvesikeln zwischen planparallelen Platten ......................... 97

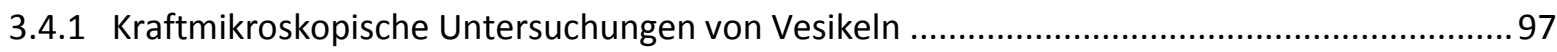

3.4.3 Berechnung der Kontur eines komprimierten Vesikels .................................................... 107

3.4.4 Bestimmung der auf das Vesikel wirkenden Kraft ...........................................................113

3.4.5 Bestimmung der Oberfläche eines komprimierten Vesikels................................................114

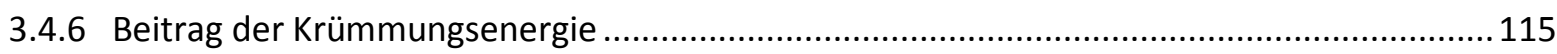

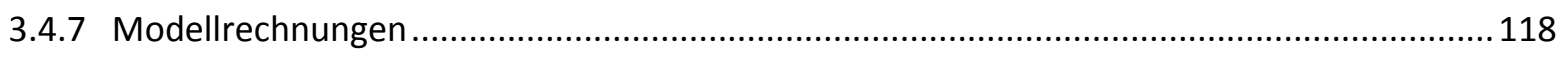

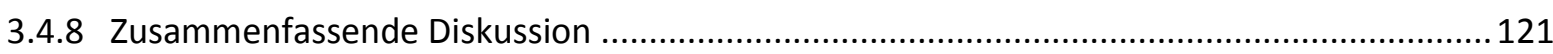

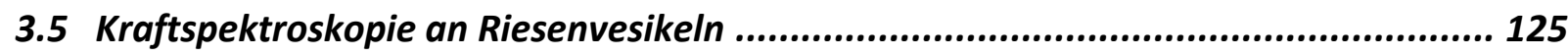

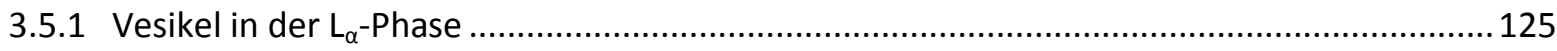




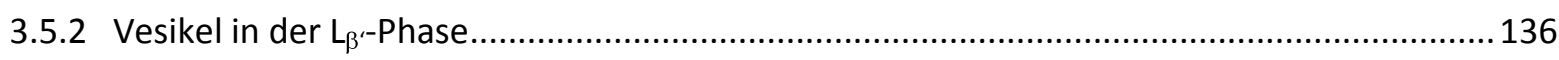

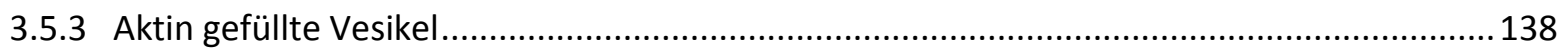

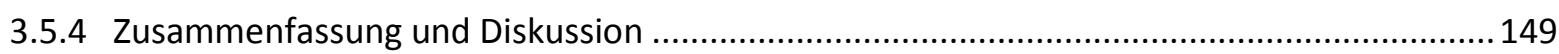

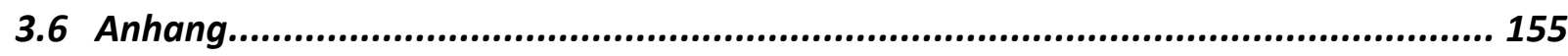

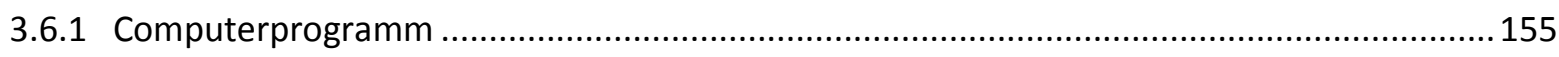

3.7 Literaturverzeichnis ............................................................................. 159

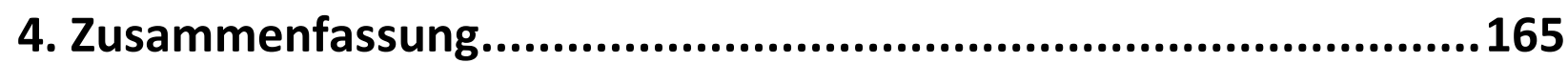

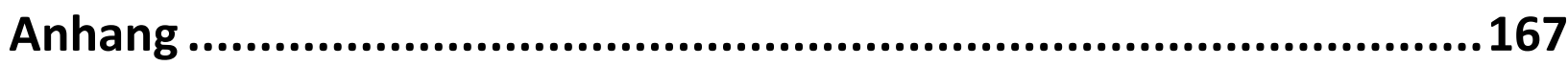

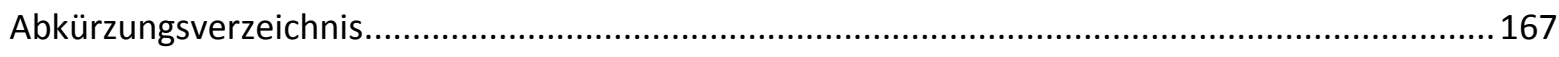

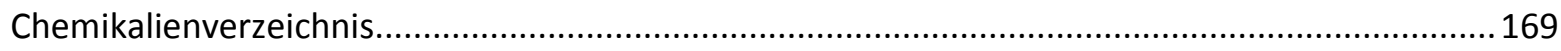

Veröffentlichungen ........................................................171 



\section{Kapitel}

\section{Einleitung}

Die mechanischen und dynamischen Eigenschaften von Zellen sind von zentraler Bedeutung für das Überleben der Zellen und daher auf die unterschiedlichen Arten von Zellen mit ihren spezifischen Funktionen und Umgebungen angepasst. Der Mechanismus, der die Stabilität einer Zelle gewährleistet, muss zum einen die Zellmembran vor möglichen Beschädigungen durch mechanische Reize schützen und zum anderen auf die wechselnden Interaktionen der Zelle mit der Umgebung reagieren. Insbesondere tierische Zellen zeigen einen hohen Grad an Deformationsmodi und nehmen ihre Umgebung mit Hilfe der Mechanosensorik wahr. Die im Zellinneren, beispielsweise durch hydrostatischen Druck oder durch Polymerisation des Cytoskeletts und der molekularen Motoren generierten Kräfte, sind entscheidend für die Form, das Wachstum, die Motilität, die Zellteilung und die Adhäsion der Zellen. Zur Aufrechterhaltung der mechanischen Stabilität und der Funktionalität der Zellen ist daher eine selektive Detektion und spezifische Reaktion auf die verschiedenen, auf die Zelle wirkenden Reize durch meist multiple, parallel laufende Signalwege nötig. [1-2]

Zur Untersuchung der mechanischen und dynamischen Eigenschaften und der dabei ablaufenden, hoch komplexen Vorgänge und Regulierungsmechanismen wird häufig auf kontrollierbare Modelle zurückgegriffen. Hierbei kann es sich sowohl um artifizielle Modellsysteme, bei denen ein mannigfaltiger, biologischer Zusammenhang auf die Basisbestandteile reduziert wird, oder um lebende Zellen handeln. Diese können entweder vom Organismus isoliert betrachtet werden oder der gesamte Organismus dient als Modellsystem. Bei Erythrocyten wird beispielsweise der Einfluss der Zellmembran und des Spektrinnetzwerks auf die großen Verformungsmöglichkeiten von roten Blutkörperchen untersucht [3], während bei Fibroblastenzellen die Dynamik der PlasmamembranCytoskelett-Adhäsion durch den sekundären Botenstoffs Phosphatidylinositol 4,5-Bisphosphat $\left(\mathrm{PIP}_{2}\right)$ studiert wird [4]. Dictyostelium discoideum Zellen und Neutrophile dienen zur Aufklärung der Signalwege während der Migration in Richtung eines chemischen Gradienten (Chemotaxis) und der Entstehung von Pseudopodien [5].

Bei artifiziellen Modellsystemen werden die für die gegebene Fragestellung entscheidenden Bestandteile der komplex aufgebauten Zelle durch definierte Modellmoleküle nachgestellt. Zum Beispiel kann das Verhalten einer Zelle während der Adhäsion auf einer extrazellulären Matrix durch in die Membran eines Riesenvesikels eingebauten Intergrine simuliert werden, die an Epitope auf einer Oberfläche binden [6], oder Pseudopodien ähnliche Strukturen können durch eine artifizielle 
Lipidmembran, Aktin und eine minimale Ausstattung mit aktinbindenden Proteinen nachgestellt werden [7].

Diese Arbeit beschäftigt sich mit zwei verschiedenen Modellsystemen, die Aufschluss über die Mechanik und die Dynamik von zellulären Systemen geben sollen. Zum Einsatz kommt zum einen der Modellorganismus Dictyostelium discoideum, dessen kollektives Migrationsverhalten analysiert wird (Kapitel 2) und zum anderen wird die Mechanik von aktingefüllten Riesenvesikeln als artifizielles Modellsystem etabliert (Kapitel 3).
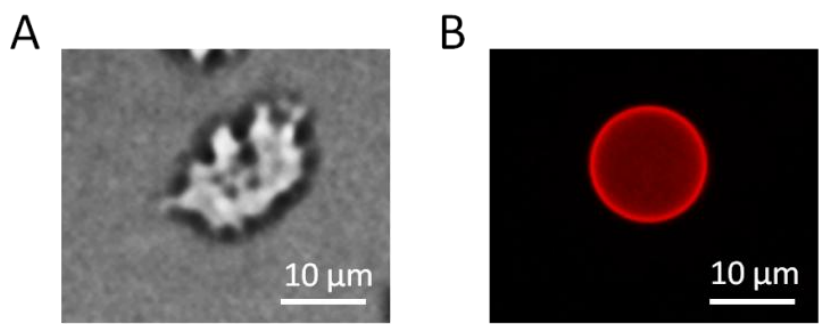

Abbildung 1.1: A) Modellorganismus Dictyostelium discoideum: Hellfeldmikroskopische Aufnahme. B) Artifizielles Modellsystem: Fluoreszenzaufnahme eines Riesenvesikels.

Im ersten Teil wird die kollektive Dynamik von Dictyostelium discoideum Zellen während der Migration mit Hilfe von elektrischen Impedanzmessungen untersucht. Konkret wird die in einem Ensemble von Zellen synchron ablaufende Chemotaxis während der Hungerphase studiert, die durch Zell-Zell-Kommunikation gesteuert wird. In den Impedanzverläufen können periodische Veränderungen des Zellensembles detektiert werden, die mit Hilfe von zeitlich parallel durchgeführter Hellfeldmikroskopie, dem akustischen Sensor der Quarzkristallmikrowaage und Interner Totalreflexionsfluoreszenzmikroskopie ein verfeinertes Modell der Chemotaxis von Dictyostelium discoideum Zellen ergeben.

Der zweite Teil befasst sich mit der mechanischen Stabilität der Zellmembran, bestehend aus einer Lipiddoppelschicht und dem cortikalen Cytoskelett. Hierzu werden die elastischen Eigenschaften von Riesenvesikeln durch Kompression zwischen planparallelen Platten bestimmt. Durch Polymerisation eines Aktincortex in den Vesikeln können die spezifischen Veränderungen der mechanischen Membraneigenschaften, die aus dem zusätzlichen Cytoskelett entstehen, bestimmt werden. 


\subsection{Literatur}

1. Lecuit, T., und Lenne, P.-F. (2007) Cell surface mechanics and the control of cell shape, tissue patterns and morphogenesis, Nat Rev Mol Cell Biol 8, 633-644.

2. Hamill, O. P., und Martinac, B. (2001) Molecular Basis of Mechanotransduction in Living Cells, Physiological Reviews 81, 685-740.

3. Lim, C. T., Zhou, E. H., und Quek, S. T. (2006) Mechanical models for living cells-a review, Journal of Biomechanics 39, 195-216.

4. Raucher, D., Stauffer, T., Chen, W., Shen, K., Guo, S., York, J. D., Sheetz, M. P., und Meyer, T. (2000) Phosphatidylinositol 4,5-Bisphosphate Functions as a Second Messenger that Regulates Cytoskeleton Plasma Membrane Adhesion, Cell 100, 221-228.

5. Parent, C. A. (2004) Making all the right moves: chemotaxis in neutrophils and Dictyostelium, Current Opinion in Cell Biology 16, 4-13.

6. Sackmann, E., und Bruinsma, R. F. (2002) Cell Adhesion as Wetting Transition?, ChemPhysChem 3, 262-269.

7. Liu, A. P., Richmond, D. L., Maibaum, L., Pronk, S., Geissler, P. L., und Fletcher, D. A. (2008) Membrane-induced bundling of actin filaments, Nat Phys 4, 789-793. 



\section{Kapitel}

\section{Kollektive Motilität von Dictyostelium discoideum}

\subsection{Biologische Grundlagen}

Die Art Dictyostelium discoideum wurde 1869 von dem Mykologen O. Brefeld entdeckt, der sie der Klasse der Schleimpilze (englisch: slime molds) zuordnete. [1] Dictyostelium discoideum zählt zu den phylogenetisch ältesten Euykarioten, die zur Verwandtschaftsgruppe der Amoebozoa zählen und dort der Untergruppe der Mycetozoa zuzuordnen ist. [2] Dictyostelium discoideum kommt in der Natur im Waldboden sowie im Dung vor und ernährt sich von Bakterien und Hefen, die es durch Phagozytose aufnimmt. [3] Ein natürlicher Fressfeind ist Nematoda (Fadenwurm). [4] Dictyostelium discoideum Zellen leben als Einzeller, wobei sie sich in Hungerphasen zu multizellulären Verbänden zusammenschließen, weswegen sie auch soziale Amöben genannt werden. [3]
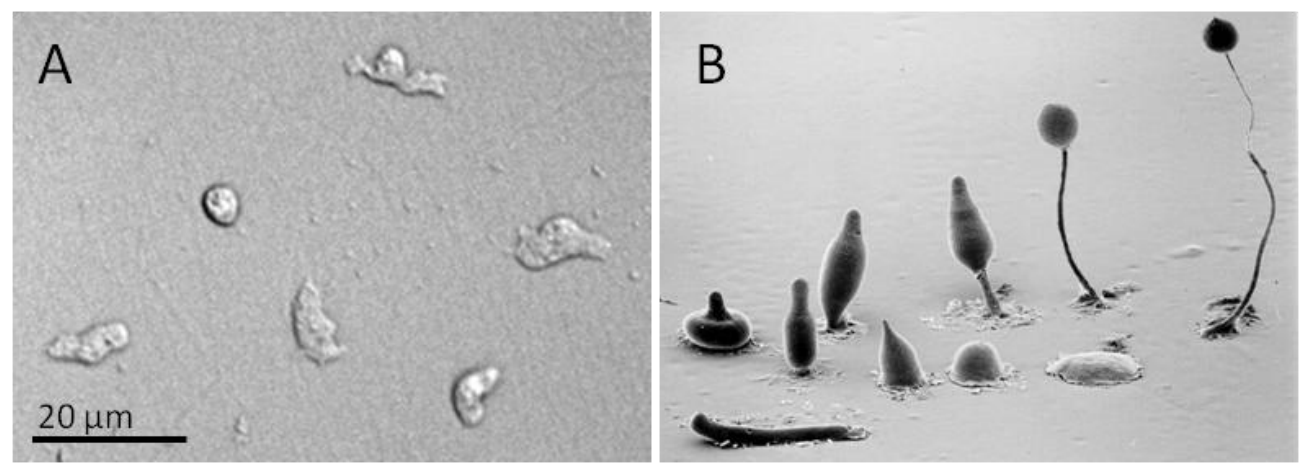

Abbildung 2.1: A) Hellfeldmikroskopische Aufnahme von Dictyostelium discoideum Zellen B) Rasterelektronenmikroskopische Aufnahme verschiedener Stadien des sozialen Zyklus von Dictyostelium. ${ }^{1}$

Dictyostelium discoideum dient als weitverbreitetes Forschungsmodell für eine Vielzahl von biologischen Prozessen wie Zellbewegung [5-7], Signaltransduktion [8-9], Chemotaxis [10-11], Phagozytose [12-13] und Zellkommunikation während der Morphogenese und Zelldifferenzierung

\footnotetext{
${ }^{1}$ Copyright:

Mark Grimson und Larry Blanton, Electron Microscopy Laboratory, Department of Biological Sciences, Texas Tech University.
} 
[14-15]. Zudem wurde das Genom von Dictyostelium discoideum im Jahr 2005 vollständig sequenziert. [16]

\subsubsection{Fortbewegung}

Für Dictyostelium discoideum ist es sowohl zur Nahrungsaufnahme wie auch zur Aggregation während der Hungerphase nötig, sich fortbewegen zu können. Bei diesen zielgerichteten Bewegungen folgen die Zellen einem Gradienten bakterieller Folsäure zur Nahrungssuche [17-18] und dem sekundären Botenstoff zyklisches Adenosinmonophosphat (cAMP) während der Zellaggregation (Kapitel: 2.1.2).

Bei der Zellbewegung findet eine Frontseiten-Rückseiten-Polarisation der Amöben statt, wobei bevorzugt Aktinfilamente, Phosphatidylinositol-(3,4,5)-trisphosphat $\left(\mathrm{PIP}_{3}\right)$ und Aktin bindende Proteine im vorderen Bereich des Cytoplasmas lokalisiert sind und die Ausbildung der Pseudopodien (Scheinfüßchen) unterstützen. [6, 19-22] Myosin II und die Kinase der schweren Myosinketten hingegen befinden sich insbesondere im mittleren und hinteren Bereich des Zellkörpers [6, 9, 21, 23 26] und steuern die Kontraktion der Rückseite von Dictyostelium discoideum Zellen [9] sowie den Abbau des rückseitigen Aktinnetzwerks und somit die Unterdrückung der Pseudopodienausbildung in diesem Bereich der Zelle [24-25].

Der Ablauf der periodischen Bewegung von Dictyostelium discoideum ist schematisch in Abbildung 2.2 gezeigt und findet wie folgt statt: Zuerst bildet sich im vorderen Teil der Zelle in Richtung eines chemischen Signals ein Pseudopodium nach oben aus. Anschließend adhäriert das Pseudopodium in Fortbewegungsrichtung an der Oberfläche und es wird eine Spannung generiert. Der hintere Bereich der Amöbe löst sich vom Substrat und wird in Richtung des Pseudopodiums gezogen. [6, 27-29]

Die Durchschnittsgeschwindigkeit eines Dictyostelium discoideum beträgt $10-15 \mu \mathrm{m} / \mathrm{min}$. [11, 30] Dabei zeigt die Kriechbewegung im Geschwindigkeitsprofil zwei Phasen, eine relativ weniger bewegte Phase (zirka $10 \mu \mathrm{m} / \mathrm{min}$ ) und eine mit relativ hoher Geschwindigkeit (> 20 $\mu \mathrm{m} / \mathrm{min}$ ). [31-32] Eine durchschnittliche Bewegungsperiode dauert zwischen 1.4 und 1.6 Minuten. [31]

In der vegetativen Phase ohne chemische Signale bilden Amöben Pseudopodien in alle Richtungen aus und bewegen sich somit ungerichtet über die Oberfläche [26] und ändern kontinuierlich ihre Zellform [9]. 

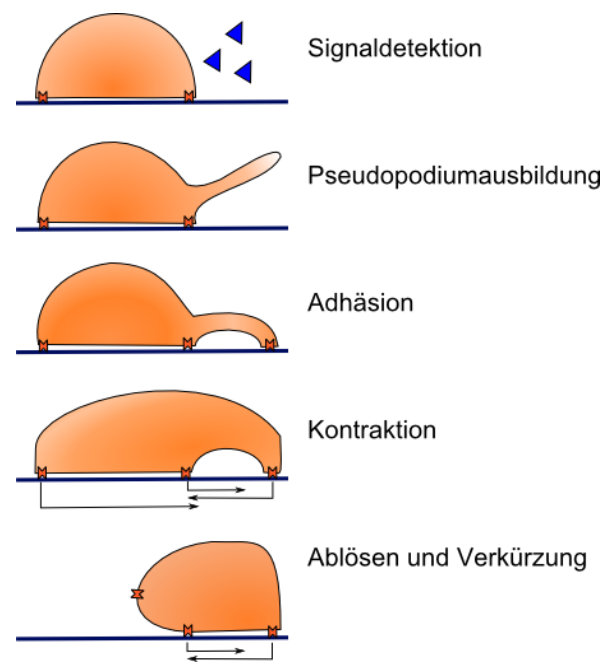

Abbildung 2.2: Schematische Zeichnung der amöboiden Kriechbewegung. Ein Pseudopodium bildet sich in Richtung des detektierten Signals aus. Nach Adhäsion des Pseudopodiums an das Substrat wird durch Kontraktion der Schwerpunkt der Zelle in Migrationsrichtung verschoben. ${ }^{2}$

\subsubsection{Lebenszyklus}

In der vegetativen Phase, oder auch Wachstumsphase genannt, bei ausreichendem Nahrungsangebot lebt Dictyostelium discoideum als Einzeller und vermehrt sich durch Zellteilung. [3] Bei zu geringem Nahrungsangebot wechselt Dictyostelium discoideum in den sexuellen Zyklus oder in den sozialen Zyklus. [3] Der sexuelle Zyklus ist an eindeutige und extreme Bedingungen der Umgebung, zum Beispiel Dunkelheit, Temperaturen im Bereich der oberen Toleranzgrenze $\left(25^{\circ} \mathrm{C}\right)$ und das Fehlen von Phosphat im Medium gebunden. [33-34] Im Folgenden wird daher nur auf den relevanteren sozialen Zyklus eingegangen.

Bei dem sozialen Zyklus vereinigen sich 10000 bis 100000 Amöben und bilden einen gemeinsamen Organismus, den sogenannten Fruchtkörper aus. [35] Hierzu sind grundlegende morphologische Veränderungen der Amöben einschließlich verschiedener Zelldifferenzierungen notwendig. [15] Der Großteil der Zellen entwickelt sich zu Sporen, die vom Ursprungsort verteilt, unter adäquaten Bedingungen keimen können und wieder in den vegetativen Zyklus übergehen. [36] Der zeitliche Verlauf des sozialen Zyklus ist in Abbildung 2.3 gezeigt.

\footnotetext{
${ }^{2}$ In Anlehnung an:

Condeelis, J.S. et al., Lamellipodia in invasion. Semin. Cancer Biol., 2001, (11), 119-128.
} 


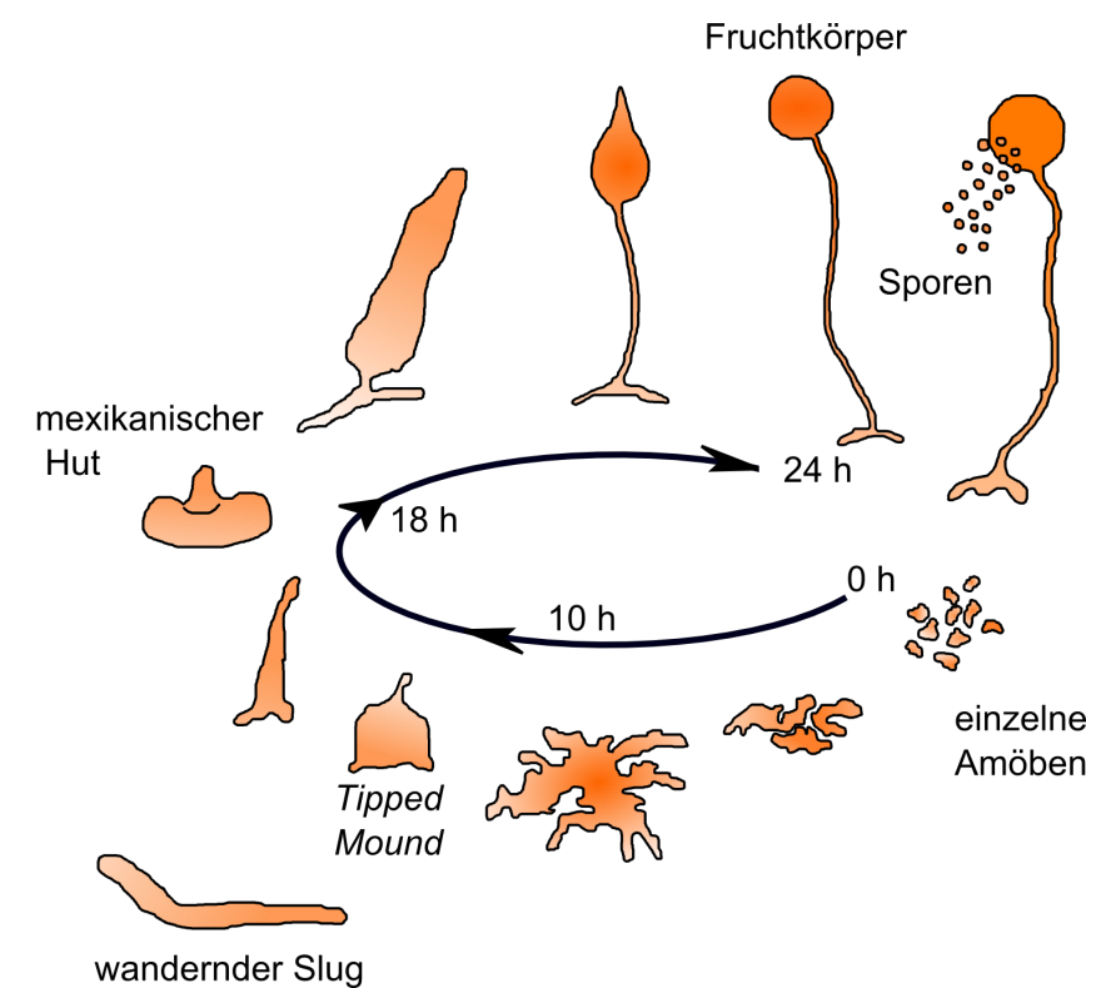

Abbildung 2.3: Schematische Darstellung des sozialen Zyklus von Dictyostelium discoideum Zellen. ${ }^{3}$

Wird ein Nahrungsmangel von den Amöben detektiert, wird der vegetative Zellzyklus gestoppt und die Transkription der Proteine für die Zellaggregation wird verstärkt. [3, 9] Durch Ausschüttung eines Acrasins (chemischer Botenstoff) strömen die Amöben aufeinander zu und bilden einen undifferenzierten, multizellulären Organismus, den sogenannten Mound. [15] Im nächsten Schritt differenzieren die Amöben zu Vorsporenzellen (englisch: prespore cells) und Vorstielzellen (englisch: prestalk cells). Die Vorstielzellen sortieren sich morphologisch über den Vorsporenzellen zu einer herausstehenden Ansammlung von Zellen und der sogenannte Tipped Mound entsteht. [35, 37] Hieraus kann sich durch Streckung ein Slug bilden, der sowohl auf phototaxische sowie thermotaxische Reize reagiert und dem Organismus ermöglicht zur Erdoberfläche zu wandern. [3839] Über weitere Zwischenstufen bildet sich schließlich nach zirka 24 Stunden ein Fruchtkörper, bestehend aus einem Stiel mit abgestorbenen Zellen und einem Sorus an der Spitze mit keimfähigen Sporen, aus. [15] Die Fruchtkörper sind bis zu $4 \mathrm{~mm}$ hoch [35] und das Verhältnis zwischen Stielzellen und Sporen beträgt ungefähr 1:4 [36].

Im Rahmen der vorliegenden Arbeit war insbesondere die erste Phase der Zellaggregation von Interesse, bei der die Amöben nach 3 bis 5 Stunden Nahrungsentzug anfangen, kollektiv über chemische Botenstoffe miteinander zu kommunizieren und aufeinander zu zuwandern.

\footnotetext{
3 In Anlehnung an:

Weiss, K. et al., The mermaid's tale: four billion years of cooperation in the making of living things. Harvard University Press, 2009.
} 


\subsubsection{Zell-Zell-Kommunikation und Chemotaxis}

Die Idee, dass Myxomyceten während der Aggregationsphase über Botenstoffe miteinander kommunizieren, wurde erstmals 1902 von W. Olive aufgebracht. [40] Doch erst 45 Jahre später konnte J. Bonner beweisen, dass die Zell-Zell-Kommunikation bei Dictyostelium discoideum Zellen über einen zunächst allgemein als Acrasin bezeichneten Botenstoff abläuft. [41] Weitere 21 Jahre später konnte dann gezeigt werden, dass es sich dabei um den sekundären Botenstoff cAMP handelt. [42]

Die Zell-Zell-Kommunikation und die Chemotaxis findet über einen periodischen Auf- und Abbau der extrazellulären cAMP-Konzentration statt. [6, 21, 43-44] Hierzu synthetisieren die Amöben cAMP und schütten dies an ihre Umgebung aus. Durch Diffusion gelangt der Botenstoff zu den Nachbarzellen, die diesen mit ihren zirka 40000 hoch spezifischen und sehr sensitiven cAMPRezeptoren (cAR) detektieren können. [9, 45-46] Die cAMP-Konzentration, die ein Dictyostelium discoideum mit den cARs detektieren kann, liegt im Bereich von $0.1 \mathrm{nM}$ bis $10 \mu \mathrm{M}$. [46-48]

Bei den vier verschiedenen cARs (CAR1-CAR4) handelt es sich um Sieben-Transmembrandomänen Rezeptoren, [49] deren extrazelluläre Bereiche eine cAMP-Bindungsdomäne besitzen und deren intrazelluläre Bereiche an heterotrimere G-Proteine gekoppelt sind, durch die Signalkaskaden innerhalb der Amöbe ausgelöst werden. [6, 8-9, 19] Während der frühen Aggregationsphase werden durch das Binden von cAMP an cAR1 zwei aufeinander abgestimmte Prozesse gestartet $[8,19]$, der stimulierende Pfad und der anpassende Pfad [35]. Durch den stimulierenden Pfad wird die Adenylylcyclase (AC) aktiviert und im Cytoplasma der Zelle wird cAMP gebildet. [5, 50] Dieses wird von der Amöbe ausgeschüttet und dient der autokatalytischen Verstärkung des CAMP-Signals und als Botenstoff für die Signalweitergabe an die Nachbarzellen. $[9,24]$ Der anpassende Pfad hingegen verursacht durch Phosphorylierung des cAMP-Rezeptors eine Möglichkeit der Desensibilisierung gegenüber cAMP und somit eine Beendigung der autokatalytischen Verstärkung. [9, 51] Des Weiteren wird die cAMP-Phosphodiesterase ausgeschüttet, die das extrazelluläre cAMP hydrophilisiert. [52] Durch anschließende Dephosphorylierung der cAR1 werden diese wieder für die nächste cAMP-Welle sensitiviert. Für eine optimale Weitergabe des CAMP-Signals benötigt ein Zyklusdurchlauf, bestehend aus cAMP-Detektion, cAMP-Signalweitergabe, Desensibilisierung und Übergang in den sensitiven Rezeptorzustand, 5-6 Minuten. [9, 47, 53] Die Reichweite des cAMPSignals von einer Zelle wurde von F. Alcantara und M. Monk auf $57 \mu \mathrm{m}$ [54] und von A. Gingle auf ungefähr $45 \mu \mathrm{m}$ [55] bestimmt. 
Unter Chemotaxis versteht man eine Bewegung, die durch Detektion eines chemischen Gradienten und gezielter Migration mit oder entgegengesetzt zur Konzentration des chemischen Botenstoffes herbeigeführt wird. [49] Durch die Verteilung der cAMP-Rezeptoren auf der gesamten Zellmembranoberfläche $[9,46,56]$ können die Amöben cAMP-Konzentrationsunterschiede von 1-5 \% zwischen dem vorderen und dem hinteren Bereich der Zelle detektieren [29, 46-48, 57], was einem Konzentrationsunterschied von $0.010 \mathrm{nM} / \mu \mathrm{m}$ [58] beziehungsweise einem Unterschied der Rezeptorbelegung zwischen dem vorderen und dem hinteren Bereich der Zelle von zirka 5 cARs [46] entspricht. Hierdurch wird eine Polarisation der Zelle mit Ausbildung von meist einem Pseudopodium an der Seite mit der höchsten cAMP-Konzentration ermöglicht. [6] Die Amöben bewegen sich somit in Richtung der höheren cAMP-Konzentration, entgegengesetzt zum chemischen Gradienten, zum Aggregationszentrum hin. [21]

Die Entstehung des synchronen Verhaltens von einem Ensemble von Dictyostelium discoideum Zellen zu Beginn der Zell-Zell-Kommunikation und der Chemotaxis ist noch nicht endgültig geklärt. Eine Möglichkeit ist, dass einige Zellen als Taktgeber fungieren und durch Ausschüttung von cAMPPulsen die Zellen in ihrer Umgebung stimulieren, wodurch es zum kollektiven, synchronen Verhalten innerhalb der Population kommt. T. Gregor et al. konnten jedoch zeigen, dass der Beginn der oszillierenden cAMP-Bildung in den Zellen ein hoch dynamischer und kollektiver Prozess ist. Die Autoren gehen davon aus, dass es durch autonome cAMP-Ausschüttungen aller Zellen in einer Population zu lokalen Erhöhungen der cAMP-Konzentration kommt. Übersteigt diese Konzentration einen kritischen Wert, kommt es zur Synchronisierung der Zellen und der kollektiven, oszillierenden cAMP-Ausschüttung innerhalb des Ensembles. [50,59] Es scheint jedoch Unterschiede in der Sensitivität der Amöben bezüglich der kritischen cAMP-Konzentration zu geben, wodurch es zu einer schrittweisen Synchronisierung innerhalb einer Population von Zellen kommt. [47]

Der chronologische Ablauf der Chemotaxis von Dictyostelium discoideum Zellen stellt sich wie folgt dar: Unmittelbar nach der Detektion eines cAMP-Pulses stoppt die Amöbe die Ausbildung von Pseudopodien und die Zellposition sowie die Zellform bleiben konstant. [6] Zwischen 6 und 20 Sekunden nach dem Stimulus durch cAMP bilden sich die vorhandenen Pseudopodien zurück und die Konzentration an filamentösem Aktin sinkt. Es bildet sich der sogenannte cringe-Zustand aus. [60-61] Anschließend kommt es im Cytoplasmabereich der Zelle, der auf der dem cAMP-Puls zugewandten Seite liegt, unter anderem zur Aktivierung der Phosphoinositid-3-Kinasen $\left(\mathrm{Pl}_{3} \mathrm{~K}\right)$, die das membrangebundene $\mathrm{PIP}_{2}$ zu PIP 3 phosphoryliert. In der Zellregion mit einem hohen $\mathrm{PIP}_{3}$-Anteil in 


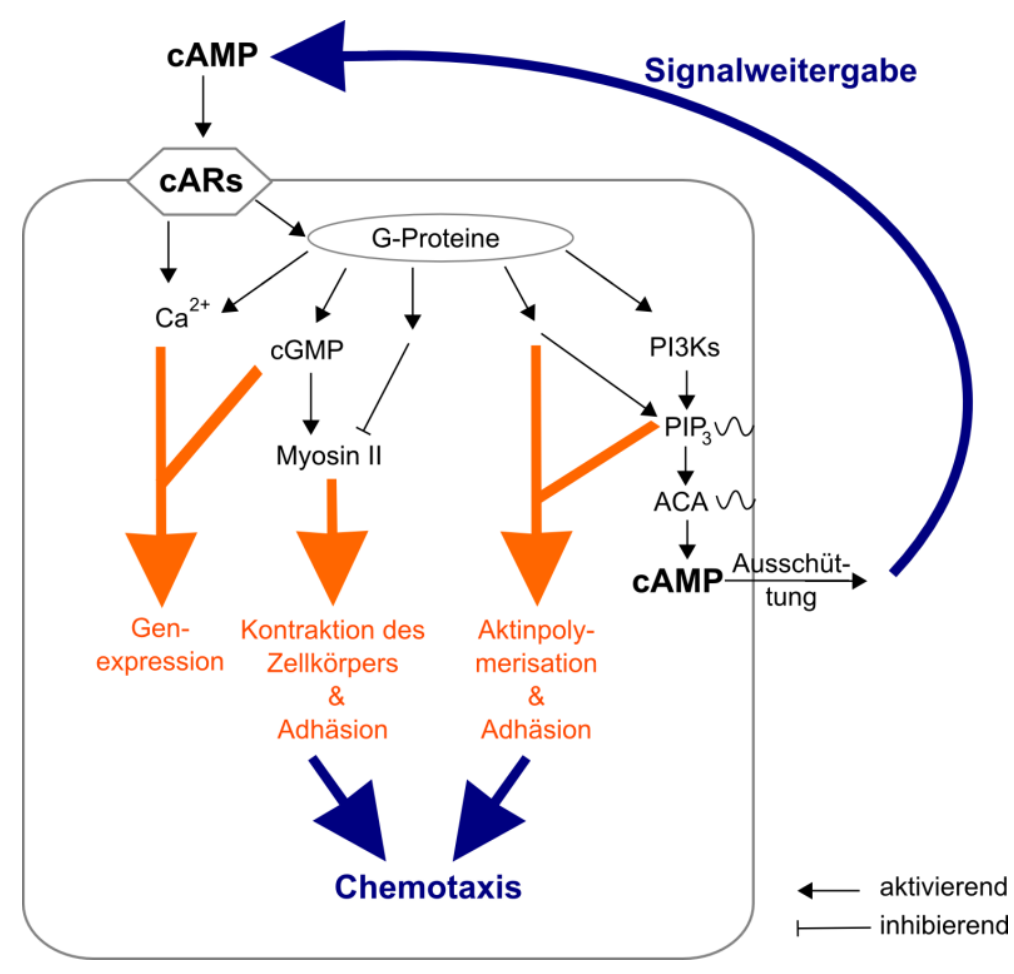

Abbildung 2.4: Übersicht über den Signal-Transduktionsweg von Dictyostelium discoideum Zellen während der frühen Aggregationsphase. ${ }^{4}$

der Membran kommt es verstärkt zur Bildung von Aktinfilamenten und es bilden sich neue Pseudopodien in Migrationsrichtung aus. [6, 19-22] An der dem cAMP-Signal abgewandten Seite wird die Ausbildung von lateralen Pseudopodien durch Dephosphorylierung von $\mathrm{PIP}_{3}$ durch die Lipid3-Phosphatase PTEN und durch kortikales Myosin II unterdrückt. [6, 23-26, 62] Nach dem die cAMPWelle die Amöbe passiert hat, bleibt die chemotaktische Antwort bestehen, wodurch eine Änderung der Wanderrichtung während der nächsten 2 Minuten auch ohne detektierbaren cAMP-Gradienten verhindert wird. $[26,61,63]$

Nach einigen gerichteten cAMP-Pulsen bilden Dictyostelium discoideum Zellen eine bleibende Polarisation in einen vorderen und hinteren Bereich der Amöben aus. Bei einem abrupten Richtungswechsel des CAMP-Pulses um $180^{\circ}$ dreht sich die Zelle ihrerseits um $180^{\circ}$ und ändert die Ausrichtung ihrer Polarisation nicht mehr. [9-10, 49]

Zu Anfang der Aggregationsphase wandern die Zellen als Individuen in Richtung des Aggregationszentrums. Nach 30-40 Zyklen bilden sich jedoch Bahnen von Dictyostelium discoideum

\footnotetext{
${ }^{4}$ In Anlehnung an:

Swaney, K.F. et al., Eukaryotic Chemotaxis: A Network of Signaling Pathways Controls Motility, Directional Sensing, and Polarity. Annu. Rev. Biophys., 2010, (39), 265-2899. und

Chen, M.-Y. et al., Signaling through chemoattractant receptors in Dictyostelium. Trends Genet., 1996, (12), 52-57.
} 
Zellen [53], bei denen die Amöben Kopf-an-Schwanz mittels calciumunabhängiger Adhäsion und seitlich mittels calciumabhängiger Adhäsion in Zellverbänden wandern [26, 64-66]. So kommt es während der Chemotaxis häufig zur Ausbildung von strahlenförmigen Bahnen aus Dictyostelium discoideum Zellen, die zu einem Zentrum wandern und dort den Mound bilden. [37, 41, 67] Bei dieser frühen Phase der Aggregation können Amöben, die entgegengesetzt zu einem cAMPGradienten wandern, eine Geschwindigkeit von $15 \mu \mathrm{m} / \mathrm{min}$ erreichen. [61]

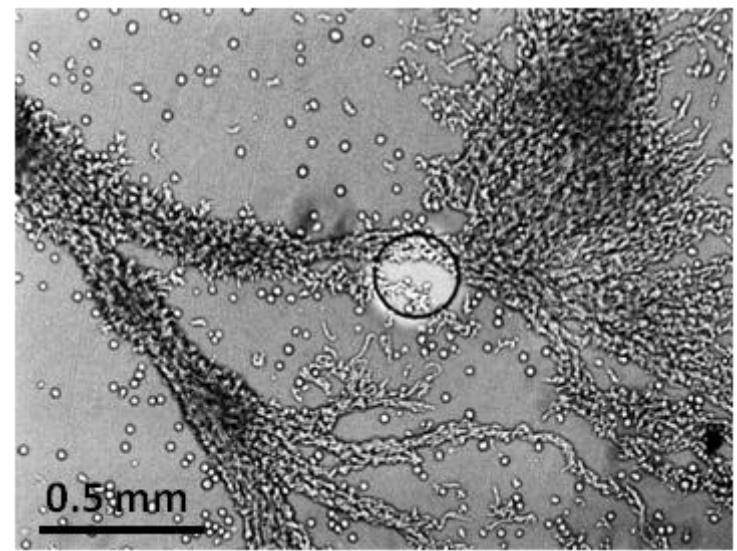

Abbildung 2.5: Mikroskopieaufnahme von in verzweigten Bahnen wandernden Dictyostelium discoideum Zellen. Die helle Kreisfläche ist eine Goldelektrode.

Mit verschiedenen Analysemethoden konnten unterschiedliche, regelmäßig wiederkehrende Vorgänge während der Aggregationsphase erfasst werden. Hierbei sind mikroskopische Methoden, bei denen einzelne Zellen analysiert werden, wie zum Beispiel deren Form [27, 68], Wandergeschwindigkeit [36] oder die Verteilung von fluoreszenzmarkierten Proteinen [69-70], von denen zu unterscheiden, die den Effekt einer großen Anzahl an Dictyostelium discoideum Zellen gleichzeitig detektieren. Zur zweiten Methode gehören zum Beispiel Lichtstreuexperimente von suspendierten Amöben in Lösung [71], Musterbildungen in Dunkelfeldmikroskopieaufnahmen [54, 72], Bestimmungen der Fluoreszenzintensität von grün fluoreszierenden Proteinen (GFP) wie zum Beispiel bei GFP-markierten Aktinfilamenten [21], Isotopen Photofluorographien von ${ }^{3} \mathrm{H}$-markiertem CAMP [44] oder Bestimmungen der intrazellulären cAMP-Konzentrationen basierend auf einem Förster-Resonanzenergietransfer (FRET) Sensor [50].

Des Weiteren gibt es eine Vielzahl von Modellen, die sich mit der Beschreibung einer gerichteten Bewegung entlang eines chemischen Gradienten befassen. [47, 73-79] Bei einem neuen Ansatz werden zwei Modellsysteme für die verschiedenen Prozesse der Detektion des Gradienten mit dem Modell der Polarisation und Bewegung der Zelle gekoppelt. Die Zellbewegung wird mit dem Modell des polarisierten, angeregten Netzwerks (englisch: biased excitable network, BEN) beschrieben, das 


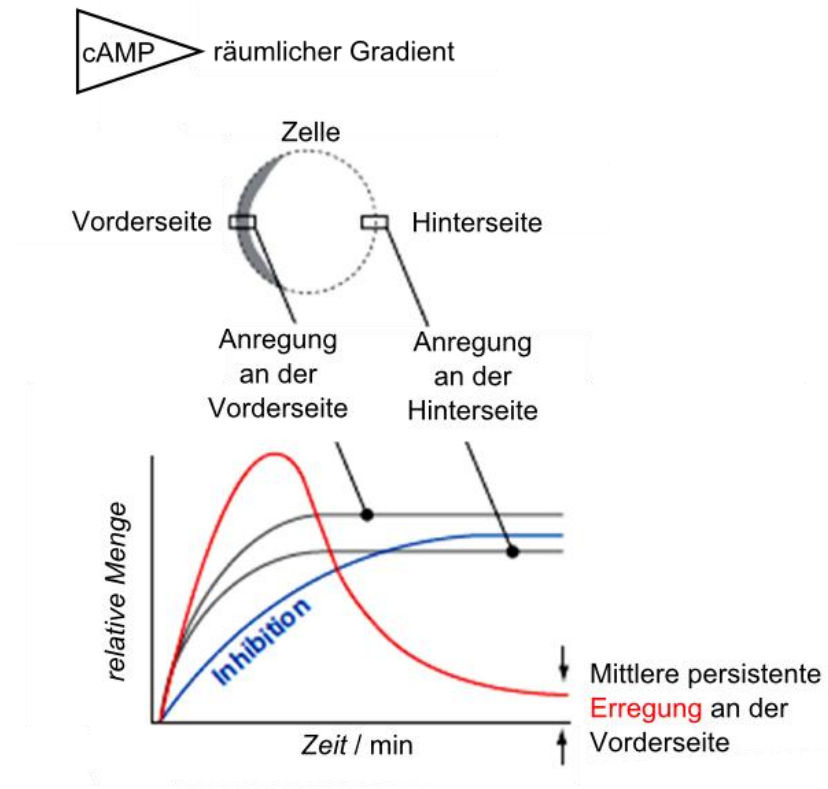

Abbildung 2.6: Räumlich und zeitlich angepasste Reaktion einer Zelle im LEGI-Modell während eines chemotaktischen Stimulus. ${ }^{5}$

sowohl die spontane Aktivierung der Zelle als auch die Zellmigration nach Detektion eines chemischen Gradienten beinhaltet. Die Erkennung des chemischen Gradienten kann mit Hilfe des lokalen Anregungs- und globalen Inhibitionsmodells (englisch: local-excitation, global-inhibition, LEGI) simuliert werden; ein Modell, das eine Balance zwischen den räumlichen und zeitlichen Einflüssen des chemischen Signals auf die Zelle mit den zwei entgegenwirkenden Prozessen des Aktivierens und Inhibierens bildet. [79]

\subsubsection{Beeinflussung der Oszillationsfrequenz}

Die cAMP-Ausschüttung sowie die Chemotaxis kann außer durch externe cAMP-Zugabe [50,71] auch durch verschiedene andere Faktoren beeinflusst werden. Eine Erhöhung der Temperatur verursacht zum Beispiel eine Frequenzerhöhung und Veränderung der Signalform bei Lichtstreuexperimenten [53] und Dunkelfeldmikroskopie [80]. Die Zugabe von Ammonium-Ionen, die als Inhibitor der cAMPAusschüttung dienen [81] und die Zellbewegung beeinflussen [82], verändern die Amplitudenhöhe der optischen Dichte-Oszillationen während Dunkelfeldmikroskopieexperimenten [83], wohingegen Koffein die Oszillationsfrequenz reduziert [83].

\footnotetext{
${ }^{5}$ Angelehnt an:

Swaney, K.F. et al., Chemotaxis: A Network of Signaling Pathways Controls Motility, Directional Sensing, and Polarity. Annu. Rev. Biophys., 2010, (39) 265-2899.
} 


\subsubsection{1 cAMP-Zugabe}

Durch externe Zugabe von cAMP kann nicht nur die Wanderrichtung von Dictyostelium discoideum Zellen während des sozialen Zyklus beeinflusst werden [11, 58, 62], sondern es werden auch Phasenverschiebungen während der Oszillationen bei Lichtstreuversuchen in Suspension beobachtet [71].

\subsubsection{Inhibition der Adenylylcyclase}

Das Membranprotein Adenylylcyclase Adenosintriphosphat (ACA), das vorwiegend im hinteren Bereich der Amöbe lokalisiert ist, wandelt Adenosintriphosphat (ATP) in CAMP und Diphosphat im Inneren der Amöben um. Sie ist daher ein wichtiger Baustein bei der Weitergabe des CAMP-Signals während der Aggregationsphase von Dictyostelium discoideum Zellen. [3, 9]

M. Brenner und S. D. Thoms konnten zeigen, dass Koffein ein schneller und reversibler Inhibitor der cAMP-abhängigen Aktivierung der ACA ist und dabei die Zellviabilität nicht beeinflusst. [45] Koffein wirkt sich somit auf die CAMP-Ausschüttung sowie die chemotaktische Bewegung von Dictyostelium discoideum Zellen aus. Die Periodenlänge aufeinanderfolgender cAMP-Wellen während des sozialen Zyklus nimmt mit steigender Koffeinkonzentration linear zu. [83] 


\subsection{Motivation}

Die verschiedenen Aspekte der Chemotaxis, wie zum Beispiel die Polarisation der Zelle, insbesondere die Ausbildung von Pseudopodien bedingt durch Aktin und aktinbindende Proteine, das Migrationsverhalten, die Signaldetektion und die Signalweitergabe durch cAMP-Pulse, stellen einen Schwerpunkt der aktuellen Forschung an Dictyostelium discoideum Zellen dar. [47, 84-88]

Hierbei wird mit optischen Methoden das Verhalten beziehungsweise die Reaktion von einer einzelnen Zelle oder von einem Ensemble während des sozialen Zyklus untersucht. Mikroskopische Methoden beeinflussen jedoch aufgrund der Phototaxis der Dictyostelium discoideum Zellen das zu untersuchende Messsystem in signifikanter Art und Weise. Licht wirkt sich sowohl auf die cAMP abhängige Zell-Zell-Kommunikation als auch auf die Chemotaxis durch Induktion der Sekretion von cAMP, sowie die Verringerung der Periodenlänge von optischen Dichtewellen und die Beschleunigung der Zellmigration aus. [39]

Die Analyse des chemotaktischen Verhaltens von Dictyostelium discoideum Zellen mit der Methode der Widerstandsmessung ist aus phototaxischer Sicht nicht-invasiv. Durch die zeitliche Detektion der Impedanz der Zellen in einem Mikrokanal oder auf einer Elektrodenfläche bei electric cell-substrate impedance sensing (ECIS) kann die Migration der Zellen erforscht werden, ohne das die Zellen durch den Messvorgang beeinflusst werden. Die Methoden sind sensitiv gegenüber dem kollektiven Verhalten von einigen hundert Zellen bei Veränderungen des zwei-dimensionalen Gruppenverhaltens und reagieren empfindlich auf Veränderungen der Zellform beziehungsweise des Zell-Substrat-Abstands.

Eine weitere Methode für die nicht-invasive Detektion der Veränderungen des Zell-SubstratAbstands ist der akustische Sensor der Quarzkristallmikrowaage (QCM). Die hohe Empfindlichkeit dieser Technik ermöglicht es, Ensembles auf einer größeren Fläche als bei der ECIS-Methode zu erfassen und zusätzliche Informationen über mechanische Parameter zu erhalten. So werden auch kollektive Änderungen der Viskoelastizität der Zellen zeitaufgelöst detektiert. Veränderungen in einzelnen Zellen bleiben bei dieser Methode jedoch verborgen. 



\subsection{Material und Methoden}

\subsubsection{Dictyostelium discoideum}

Dictyostelium discoideum Zellen sind ein häufig verwendetes Forschungsobjekt, da es ein freilebender, einzelliger Organismus ist, dessen optimale Wachstumstemperatur $22^{\circ} \mathrm{C}$ beträgt und der keine Kontrolle der Stickstoff- oder Kohlendioxidatmosphäre erfordert. [89] Der heute meist verwendete Stamm NC4 wurde 1935 von K. B. Raper et al. in einem Wald von Nordkalifornien entdeckt. [3] Aus diesem NC4-Stamm sind durch Mutationen verschiedene Dictyostelium discoideum-Stämme entstanden, die ohne lebende Organismen als Nahrungsquelle überleben können (AX-Stämme). Die Zellen werden in keimfreien Glucosemedien kultiviert, wodurch sich die Teilungsrate der AX-Stämme von zirka 4 Stunden auf alle 8 bis 12 Stunden erhöht. [89]

\subsubsection{Zelltypen}

Im Rahmen dieser Arbeit wird außer für Fluoreszenzexperimente der Wildtyp-Stamm AX3 verwendet. Für Fluoreszenzaufnahmen wird die GFP-Zelllinie HG1694 des AX2-Stamms verwendet, eine transfizierte Zelllinie, bei der das Protein GFP an kein anderes Protein gebunden ist und daher frei im Cytosol diffundiert. Das GFP wird unter der Kontrolle des Act15 Promotors exprimiert. ${ }^{6}$ [90] Beide Zelllinien wurden von der Arbeitsgruppe von Prof. Dr. E. Bodenschatz, Max Planck Institut für Dynamik und Selbstorganisation, Göttingen zur Verfügung gestellt.

\subsubsection{Zellkultivierung}

Bei $-80^{\circ} \mathrm{C}$ eingefrorene Lösungen von Dictyostelium discoideum Sporen werden aufgetaut und 100-150 $\mu \mathrm{l}$ der Lösung werden in einer Petrischale (Primaria, Falcon, USA) $(\varnothing=100 \mathrm{~mm}$ ) mit $10 \mathrm{ml}$ HL5-Nährmedium mit Glucose von ForMedium (35.5 g/l) gleichmäßig verteilt. Danach werden die Sporen in der Petrischale in einem Brutschrank bei $22^{\circ} \mathrm{C}$ bis zur vollständigen Belegung des Petrischalenbodens kultiviert (vereinzelt lösen sich Amöben ab). Zur Reduktion und Überführung der Zellen in neues Nährmedium wird die überstehende Lösung in der Petrischale abgenommen und die Amöben werden mit $10 \mathrm{ml}$ frischem Medium vom Boden gelöst. Zirka $1 \mathrm{ml}$ der Zellsuspension wird in eine neue, mit $10 \mathrm{ml}$ Nährmedium gefüllte Petrischale geben. Zur Gewährleisung, das bei der Kultivierung der cytosolischen GFP-Zellen nur transfizierte Zellen wachsen, wird das Nährmedium mit 0.05 \% Vol. des Selektionsmarkers Geneticin ${ }^{\circledR}$ (auch G418 genannt) versetzt, da zusätzlich zum

\footnotetext{
${ }^{6}$ aus der Arbeitsgruppe von Prof. Dr. G. Gerisch, Max Planck Institut für Biochemie, Martinsried.
} 
GFP-Gen in dieser Zelllinie ein Neomycin-Geniticin-Resistenzgen eingeschleust wurde. Bei neu aufgetauten Sporen wird das selektierende Antibiotikum erst nach dem Keimen der Sporen zum Medium gegeben (nach zirka 24 Stunden). Zur Vermeidung von physiologischen Veränderungen innerhalb der Kultur werden für die Experimente nur Zellen der Passagen 2 bis 6 verwendet.

\subsubsection{3 Überführung in nährstofffreien Puffer}

Zur Überführung der Zellen in den nährstofffreien Sörensen-Phosphatpuffer (S-Puffer) (14.6 mM $\mathrm{KH}_{2} \mathrm{PO}_{4}$ und $2.0 \mathrm{mM} \mathrm{Na} 2 \mathrm{HPO}_{4}, \mathrm{pH}$ 6.1) wird die Suspension aus Zellen im Nährmedium 3 min bei 200×g zentrifugiert und der Überstand abgenommen. Das zurückbleibende Pellet wird in $10 \mathrm{ml}$ S-Puffer gelöst und mit den gleichen Einstellungen erneut zentrifugiert. Der überstehende Puffer wird gegen neuen Puffer ausgetauscht und die Zellsuspension wird ein drittes Mal zentrifugiert. Nach erneutem Austauschen des S-Puffers wird die Zellzahl in der Lösung in einer NeubauerZählkammer bestimmt.

\subsubsection{Sporengewinnung}

Für die Ausbildung von Fruchtkörpern werden zirka 150 Millionen Zellen in $1 \mathrm{ml}$ S-Puffer aufgenommen und die Suspension wird gleichmäßig auf eine mit $15 \mathrm{ml}$ Agaroseagar (12 g Agarose auf 1 I S-Puffer) gefüllte Petrischale gegeben. Die Petrischale wird zum Trocknen eine Stunde mit geöffnetem Deckel stehen gelassen und anschließend für 72 Stunden im Brutschrank bei $22^{\circ} \mathrm{C}$ inkubiert, wobei nach 12 Stunden die Platte umgedreht wird. Die entstandenen Fruchtkörper mit Sporen werden mit $4 \mathrm{ml} \mathrm{S-Puffer} \mathrm{vom} \mathrm{Agar} \mathrm{abgespült} \mathrm{und} \mathrm{die} \mathrm{Sporensuspension} \mathrm{wird} \mathrm{in} \mathrm{jeweils}$ $500 \mu \mathrm{l}$ Aliquote in flüssigem Stickstoff schockgefroren und anschließend bei $-80^{\circ} \mathrm{C}$ gelagert.

\subsubsection{Mikroskopie}

\subsubsection{Hellfeldmikroskopie}

Zur Mikroskopie der Zellen simultan zu den Widerstandsmessungen wird ein inverses Lichtmikroskop von Olympus (IX 81, Olympus, Tokyo, Japan) mit CDD-Kamera (XM 10, Olympus, Tokyo, Japan) unter Verwendung eines UPLFLN 10-fach oder LUCPLFLN 40-fach Objektivs (beides Olympus, Tokyo, Japan) eingesetzt. Es wird mit einer Aufnahmerate von 6 Bildern pro Minute gearbeitet.

Für die Analyse der Migration von einzelnen Zellen auf einer Elektrode wird in einigen Fällen ein inverses Phasenkontrastmikroskop von Zeiss (Axiovert 200, Zeiss, Jena, Deutschland) mit 40-facher Vergrößerung (LD Plan-NEOFLUAR, Zeiss, Jena, Deutschland) und einer Kamera von Imaging Source 
(DFx 31AF03, The Imaging Source, Bremen, Deutschland) verwendet. Es wird alle 2 Minuten ein Bild aufgenommen.

\subsubsection{Interne Totalreflexionsfluoreszenzmikroskopie}

Die Untersuchungen der cytosolischen GFP-Zellen mit der internen Totalreflexionsfluoreszenzmikroskopie (englisch: total internal reflection fluorescence microscopy, TIRFM) werden in Kooperation mit der Arbeitsgruppe von Prof. Dr. E. Bodenschatz (Max Planck Institut für Dynamik und Selbstorganisation, Göttingen) durchgeführt. Hierzu wird ein OlympusMikroskop IX 81 (Olympus, Tokyo, Japan) mit xCellenceRT-Software, einem PlanApo N 60× Ölimmissionsobjektiv (Olympus, Tokyo, Japan) und einer 16 Bit CCD-Kamera mit 1344×1024 Pixeln (Hamamatsu Photonics, Hamamatsu, Japan) verwendet. Für die zu mikroskopierenden Proben werden Dictyostelium discoideum-Zellkonzentrationen von $4-5 \times 10^{6}$ Zellen/ml S-Puffer in eine Petrischale mit Glasboden (No. 1.5, $\varnothing=50$ mm, MaTek, Ashland, USA) gegeben. Der GFP-Fluorophor in den Zellen wird durch einen 20 mW Argon-Laser mit einer Wellenlänge von $488 \mathrm{~nm}$ angeregt. Die TIRFM-Bildaufnahmefrequenz beträgt $0.05 \mathrm{~Hz}$, wobei jeweils eine BF-Mikroskopieaufnahme zwischen den TIRFM-Aufnahmen aufgenommen wird.

\subsubsection{Electric cell-substrate impedance sensing}

Beim electric cell-substrate impedance sensing (ECIS) handelt es sich um ein Widerstandsmessverfahren, mit dem nicht-invasive, nicht optische Untersuchungen von Zellen mit hoher Zeitauflösung (<1 Sekunde) möglich sind. [91-92] Als Messgröße wird die Impedanz (komplexer Wechselstromwiderstand) als Funktion der Zeit aufgenommen. Die Impedanz wird maßgeblich von den isolierenden Eigenschaften der Zellen auf der Arbeitselektrode hervorgerufen. Fluktuationen im Impedanzsignal sind unter anderem vom Belegungsgrad der Goldelektrode, dem Zell-Substrat-Abstand und den Zell-Zell-Kontakten abhängig. [92]

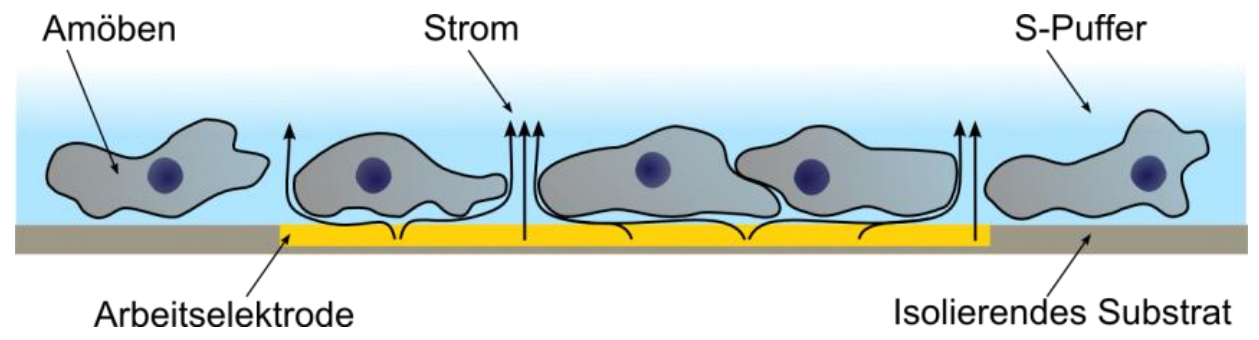

Abbildung 2.7: Schematische Darstellung des Stromflusses auf einer mit Amöben belegten ECISElektrode. 


\subsubsection{Geräte und Messmodi}

Im Rahmen dieser Arbeit werden drei verschiedene ECIS-Messaufbauten verwendet. Bei der ersten Apparatur handelt es sich um die kommerziell erhältliche ECIS Z $\theta$ (Applied BioPhysics, Troy, USA), die sowohl Einzelfrequenzmessungen als auch Multifrequenzmessungen (im Bereich von $31.25 \mathrm{~Hz}$ bis $100 \mathrm{kHz}$ ) von bis zu 16 Messkammern zulässt. Zwischen den Kammern ist ein Multiplexer (MUX) geschaltet, der quasi-simultane Messungen ermöglicht.

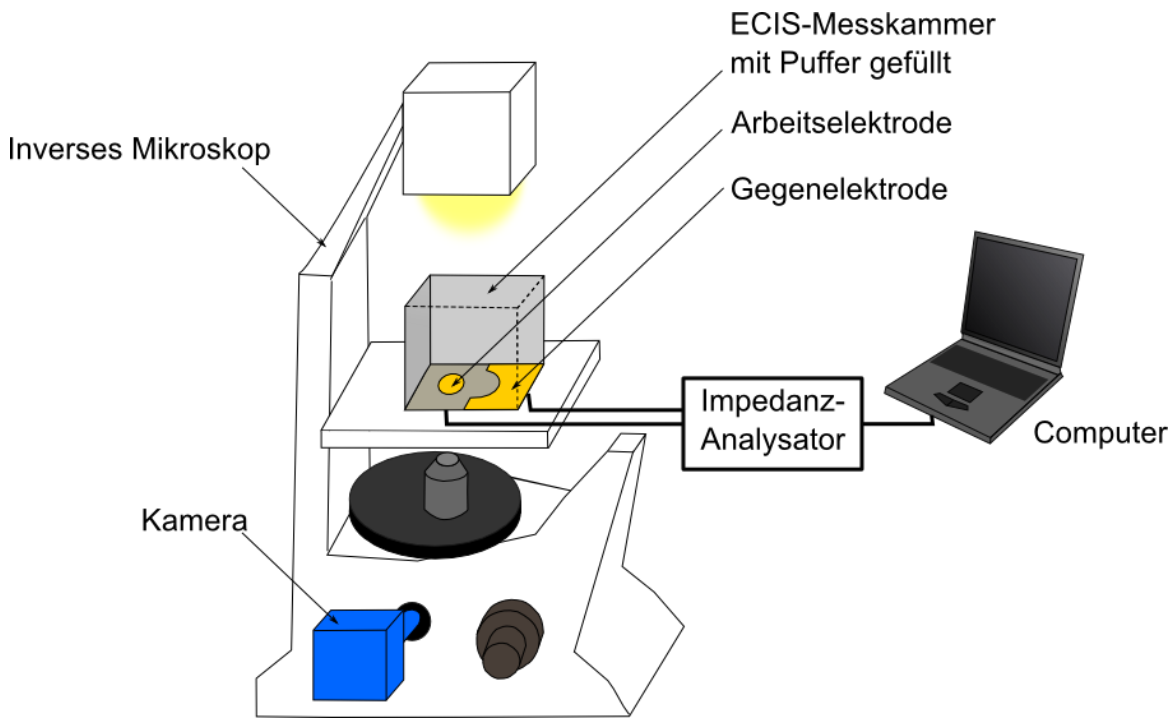

Abbildung 2.8: Schematischer Aufbau der ECIS-Apparatur mit einem Impedanz-Analysator auf einem inversen Mikroskop. ${ }^{7}$

Bei den Impedanzmessungen von Zellen in Kombination mit der Hellfeldmikroskopie wird ein Impedanz-Analysator (SI 1260, Solartron, Hampshire, UK) mit einem selbstgeschriebenen Programm auf der Basis von LabVIEW (National Instruments, München, Deutschland) betrieben. Durch die Einstellung der Anzahl der Zyklen für die Mittelung auf 1000 Durchgänge pro gespeicherten Datenpunkt, wird mit einer Abtastfrequenz von $0.7 \mathrm{~Hz}$ gemessen. Bei diesem Aufbau wird jeweils nur eine Messkammer angesteuert. Der für die Mikroskopie angepasste Probenhalter ermöglicht es während der ECIS-Messung Videos der Arbeitselektrode mit Hilfe eines inversen Mikroskops aufzunehmen (Abbildung 2.8).

Der dritte ECIS-Aufbau, der auch gleichzeitige Mikroskopieaufnahmen ermöglicht, wird neben dem zweiten Aufbau bei den Messungen einer einzelnen Zelle auf der Elektrode verwendet. Er besteht

\footnotetext{
${ }^{7}$ In Anlehnung an:

Schäfer, E. et al. Chemotaxis of Dictyostelium discoideum: Collective Oscillation of Cellular Contacts. PLos One,2013, (1), e54172.
} 
aus einem Computer, der einen Lock-in Verstärker (SR830, SRS, Inc., Sunnyvale, USA) mittels eines selbstgeschriebenen Programms auf der Basis von IGOR Pro (Wavematrix, Inc., Lake Oswego, USA) ansteuert. [93] Als Probenhalter dient derselbe Mikroskopiehalter wie im zuvor beschriebenen Aufbau.

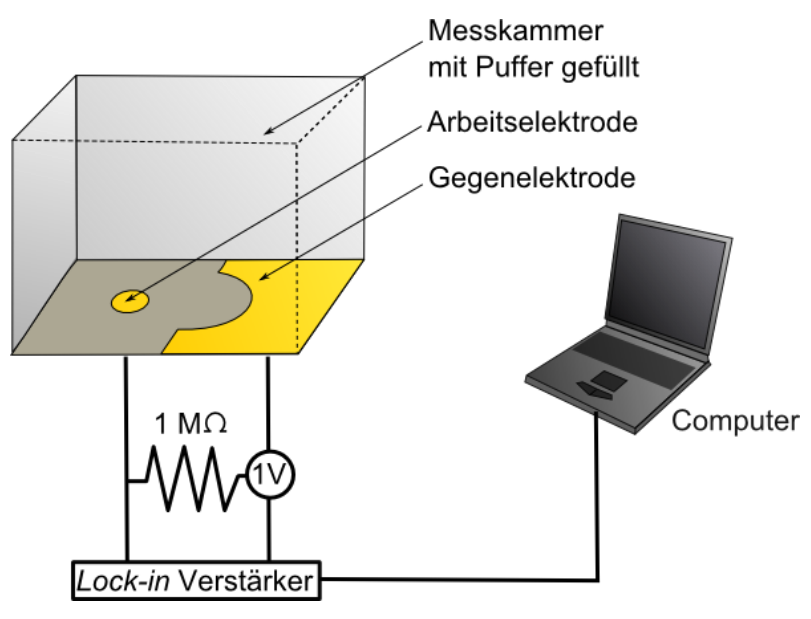

Abbildung 2.9: Schematischer Aufbau der ECIS-Apparatur bestehend aus einer Spannungsquelle, die über einen Vorwiderstand eine Spannung appliziert, und einem Lock-in Verstärker, der das Messsignal in Phase und Amplitude zerlegt und zum Computer weiterleitet. Die Messkammer bestehend aus zwei in den Boden eingelassenen Goldelektroden.

Bei den Messungen von Zellensembles werden Elektroden des Typs 8W1E von Applied BioPhysics (Troy, USA) mit einem Elektrodendurchmesser von $250 \mu \mathrm{m}$ verwendet. Für die Messungen der Migration von einzelnen Zellen auf der Elektrode werden die Elektrodenarrays des Typs 8W1EDD (Applied BioPhysics, Troy, USA) mit Elektrodendurchmessern von $25 \mu \mathrm{m}$, $50 \mu \mathrm{m}$ oder $100 \mu \mathrm{m}$ benutzt.

\subsubsection{Impedanzmessungen von zellulären Ensembles}

Bei den ECIS-Messungen von zellulären Ensembles an Dictyostelium discoideum Zellen wird der Impedanzverlauf während des sozialen Zyklus als Funktion der Zeit von einigen hundert Zellen auf einer Elektrode mit einem Durchmesser von $250 \mu \mathrm{m}$ gemessen.

\section{Messvorbereitung}

Die Messkammern des 8W1E-Arrays werden mit $400 \mu \mathrm{l}$ S-Puffer gefüllt und einer Leermessung ohne Zugabe von Zellen unterzogen. Die gewünschte Zellanzahl an Amöben wird aus der Zellsuspension von $1 \times 10^{6}$ bis $5 \times 10^{6}$ Zellen/ml hinzugeben, wobei zur Beibehaltung eines konstanten Volumens das 
entsprechende Volumen an S-Puffer zuvor aus der Messkammer entnommen wird. Die Messungen werden bei Raumtemperatur durchgeführt. Bei simultanen Mikroskopieaufnahmen der Elektrode während der ECIS-Messung wird für die spätere exakte Korrelation der Daten der Zeitpunkt der ersten Aufnahme des Mikroskopievideos notiert.

\section{Dielektrische Spektroskopie}

Zur Bestimmung der zu verwendenden Messfrequenz werden frequenzabhängige Impedanzmessungen im Bereich von $31.25 \mathrm{~Hz}-100 \mathrm{kHz}$ durchgeführt. Es werden Frequenzspektren von mit S-Puffer gefüllten Messkammern ohne Zellen und von mit Dictyostelium discoideum Zellen belegten Elektroden aufgenommen. Der Frequenzbereich, in dem die Frequenzspektren der mit Zellen belegten Elektroden von jenen der unbelegten Elektroden abweichen, ist in Abbildung 2.10 dargestellt.

Dictyostelium discoideum Zellen sind in einem Frequenzbereich von zirka 2-62 kHz detektierbar. Modellberechnungen für vollständig belegte Elektroden mit Epithelzellen zeigen, dass der Widerstand im hohen Frequenzbereich (>10 kHz) insbesondere von den Membraneigenschaften der adsorbierten

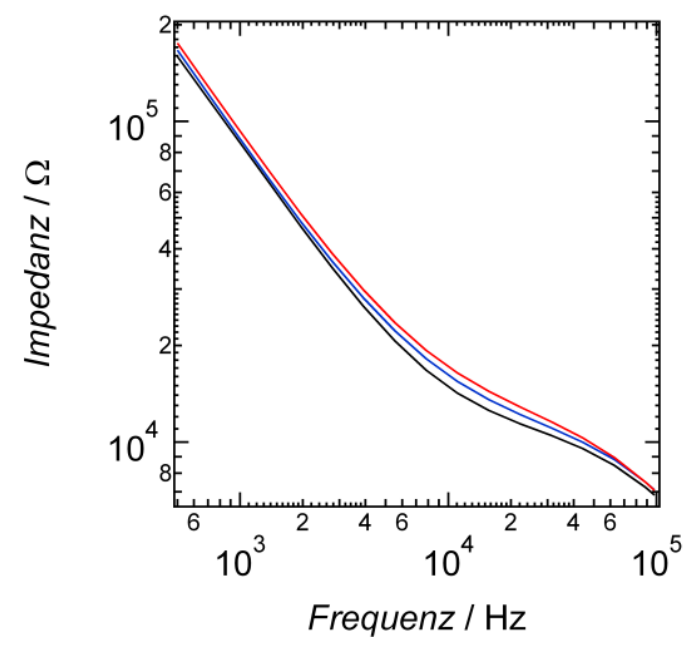

Abbildung 2.10: Auftragung der von der ECIS detektierten Impedanz als Funktion der Frequenz im Bereich von $0.5-100 \mathrm{kHz}$ mit einer Arbeitselektrode des Durchmessers von $250 \mu \mathrm{m}$. Die Messkammern sind mit $\mathbf{4 0 0} \mu \mathrm{l}$ S-Puffer (schwarze Kurve) sowie mit $3750 \mathrm{Zellen} / \mathrm{mm}^{2}$ bei dem in blau beziehungsweise mit 6250 Zellen/ $\mathrm{mm}^{2}$ bei dem in rot dargestellten Spektrum gefüllt.

Zellenschicht abhängig ist [92], wohingegen bei niedrigen Frequenzen $(0.1-10 \mathrm{kHz})$ eher ZellSubstrat-Abstände und Zell-Zell-Kontakte die gemessene Impedanz beeinflussen [94]. Da im Rahmen 
dieser Arbeit besonders die Zellbewegung von Interesse ist, werden die ECIS-Messungen demzufolge mit einer Frequenz von 4 kHz durchgeführt.

\section{Belegungsgrad der Elektrode}

Der detektierte Impedanzwert bei einer ECIS-Messung ist abhängig vom Belegungsgrad der Elektrode und dementsprechend von der Anzahl der Amöben auf der Elektrode. In Abbildung $2.11 \mathrm{~A}$ ist der Anstieg des Impedanzwertes bei $4 \mathrm{kHz}$, normiert auf den Zeitpunkt vor der Zellzugabe, als Funktion der Zeit bei verschiedenen Zellkonzentrationen dargestellt. Nach einer halben Stunde kann man einen quasi linear zur Zellanzahl verlaufenden Anstieg der Impedanz erkennen (Abbildung $2.11 \mathrm{~B}$ ).

Die Impedanzmessungen zeigen häufig einen nicht reproduzierbaren und nicht nachvollziehbaren Abfall des Impedanzwertes gegen die Zeit (Abbildung 2.11 A blaue Kurve). Daher sind Aussagen über den Belegungsgrad der Elektrode während einer Messung nicht zweifelsfrei anhand des detektierten Impedanzsignals möglich.
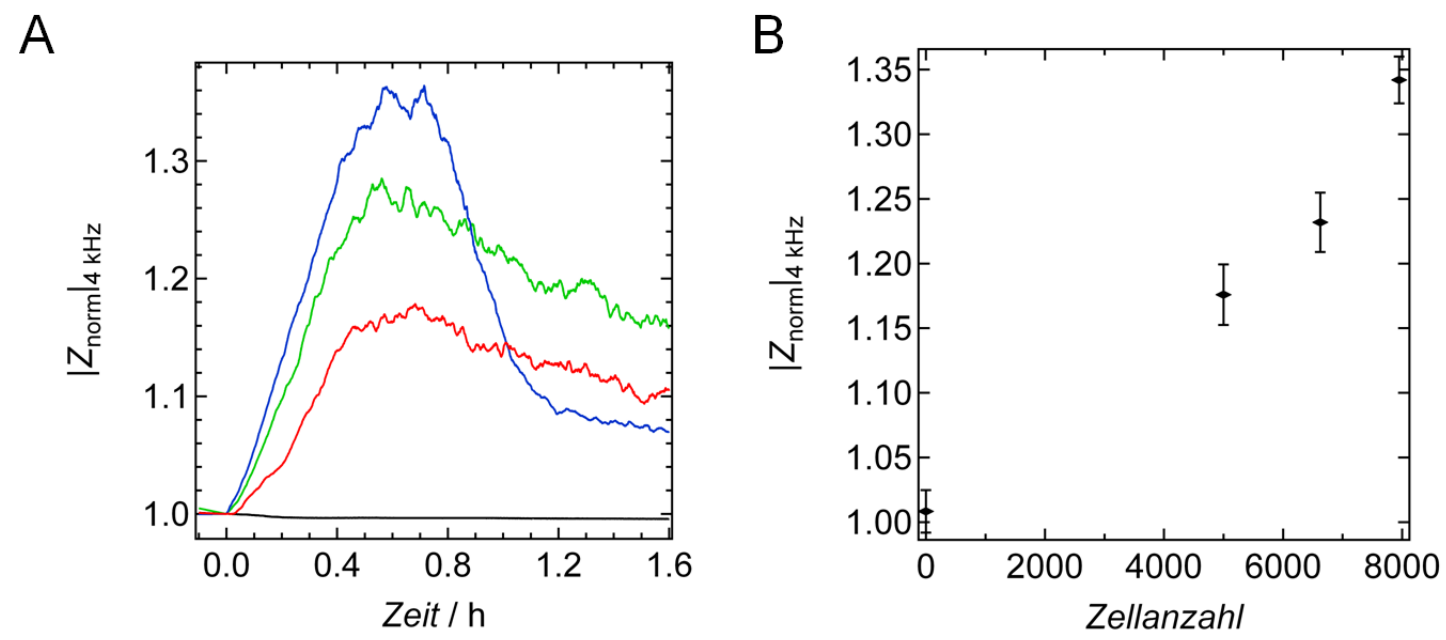

Abbildung 2.11: A) Auftragung der auf die Zellzugabe normierten Impedanz $\left(\left|Z_{\text {norm }}\right| 4 \mathrm{kHz}\right)$ als Funktion der Zeit bei verschiedenen Dictyostelium discoideum-Zellkonzentrationen auf der Elektrode $(\varnothing=250 \mu \mathrm{m})$ : blau: 7950 Zellen $/ \mathrm{mm}^{2}$; grün: 6625 Zellen $/ \mathrm{mm}^{2}$; rot: $5000 \mathrm{Zellen} / \mathrm{mm}^{2}$; schwarz: Leermessung. B) Auftragung des normierten Impedanzwertes 30 Minuten nach Zellzugabe als Funktion der Zellzahl.

\subsubsection{Impedanzmessungen einzelner Amöben}

Für Versuche mit Einzelzellen auf einer ECIS-Elektrode werden die kleinen Arbeitselektroden der 8W1EDD-Arrays ( $\varnothing: 25 \mu \mathrm{m}, 50 \mu \mathrm{m}$ und $100 \mu \mathrm{m}$ ) bei einer Messfrequenz von $4 \mathrm{kHz}$ verwendet. In die mit $400 \mu \mathrm{l}$ S-Puffer gefüllten Messkammern werden bei gleichzeitiger Impedanzwertaufnahme zirka 
500 Zellen/mm² hinzugeben. Der Belegungsgrad an Dictyostelium discoideum Zellen in der Messkammer wird solange durch Zugabe von weiteren Zellen beziehungsweise durch erneutes Füllen der Messkammer verändert, bis sich nur noch eine Zelle auf der Elektrode oder wenige Zellen in der Nähe der Elektrode befinden. Anschließend wird die Aufnahme optischer Bilder von der Arbeitselektrode gestartet. Die Messungen werden bei Raumtemperatur durchgeführt.

\subsubsection{Quarzkristall-Mikrowaage mit Dissipationsanalyse}

Bei der Quarzmikrowaage (englisch: quartz crystal microbalance, QCM) handelt es sich um eine Messtechnik, die Veränderungen des Schwingungsverhaltens von oszillierenden Quarzresonatoren detektiert. Die Quarzscheibe kann aufgrund ihrer piezoelektrischen Eigenschaft durch eine angelegte Wechselspannung im Bereich der Resonanzfrequenz angeregt werden. Durch die Anlagerung einer Fremdmasse an den Quarz wird die Resonanzfrequenz verringert. [95]

Rodahl et al. entwickelte eine Variante der Quarzmikrowaage, mit der zusätzlich die simultane Bestimmung des freien Ausschwingens des Schwingquarzes möglich ist (D-QCM). [96] Das Abklingverhalten des Quarzes nach vorheriger Anregung mit der entsprechenden Resonanzfrequenz wird abhängig von den Eigenschaften der adsorbierten Fremdmasse gedämpft. Der dabei entstehende Energieverlust kann durch den Dissipationsfaktor Delta $(\delta)$ beschrieben werden, der das Verhältnis aus der Gesamtenergie, die pro Oszillationszyklus im Quarz gespeichert wird, und der im gleichen Zeitrahmen dissipierten Energie angibt

$$
\delta=\frac{E_{\text {dissipiert }}}{2 \pi E_{\text {gespeichert }}} .
$$

Aus dem Dissipationsfaktor und der Resonanzfrequenz lassen sich zusätzliche Aussagen über die Viskoelastizität der adsorbierten Fremdmasse ableiten. [97]

H. L. Bandey et al. entwickelten ein Modell, das die Umrechnung der elektrischen Ansprechzeit des Resonators in verschiedene Beladungszustände eines Mehrschichtenmodells ermöglicht. [98] Abbildung 2.12 A zeigt das Schema eines 3-Schichtenmodells mit einer adsorbierten Schicht (Schicht 2) auf dem Goldfilm des Quarzes in einem definierten Abstand $\left(h_{\mathrm{fl}}\right)$. Die Stärke der detektierten Dämpfung ist von der Schichtdicke $\left(h_{c}\right)$, der Distanz der Schicht vom Quarz sowie der viskoelastischen Eigenschaft, ausgedrückt durch das Speichermodul $G^{\prime}$ und das Verlustmodul G", abhängig. 
A

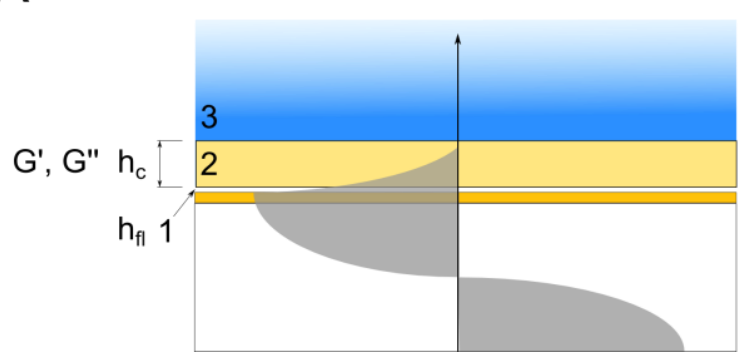

B

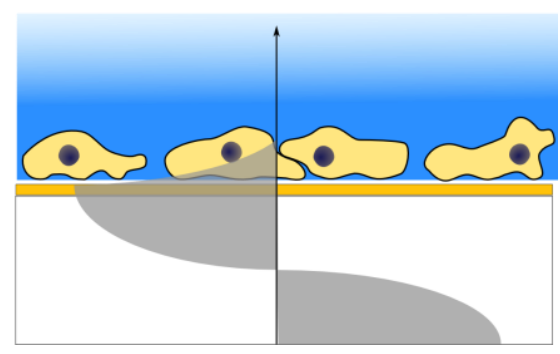

Abbildung 2.12: A) Schematische Skizze des 3-Schichtenmodellsystems bei D-QCM-Messungen mit den für den gemessenen Dissipationsfaktor und die Resonanzfrequenz wesentlichen Merkmalen: Schichtdicke $\left(h_{\mathrm{c}}\right)$, Abstand der Schicht vom Quarz $\left(h_{\mathrm{fl}}\right)$ und Viskoelastizität (Speichermodul $G^{\prime}$, Verlustmodul $\left.G^{\prime \prime}\right)$. B) Korrespondierende schematische Zeichnung mit adhärenten Amöben auf dem Quarz als Schicht 2. Schicht 1 und 3 entsprechen einer Schicht aus wässrigem Medium. ${ }^{8}$

M. Tarantola et al. nahm bei D-QCM-Versuchen eine an den Quarz adsorbierte Epithelzellenschicht als Schicht 2 im 3-Schichtenmodell von H. L. Bandey et al. an [98], mit dem Hinweis, dass die Zellschicht keine homogene Ebene darstellt. In dem Modell von H. L. Bandey et al. wird jedoch eine homogene Beladung des Quarzes angenommen. [97] .

Mit dieser Einschränkung konnten die in Abbildung 2.13 dargestellten Zusammenhänge zwischen den Veränderungen von mechanischen und geometrischen Eigenschaften einer Zellschicht und den daraus resultierenden Änderungen der berechneten Frequenz und Dissipation gezeigt werden. Abbildung 2.13 A zeigt den Einfluss von Höhenänderungen einer Zellmonolage, die in einem Bereich von zirka 0 bis $1 \mu \mathrm{m}$ detektiert werden kann. Veränderungen im Zell-Substrat-Abstand und im Verlustmodul zeigen einen gegenläufigen Kurvenverlauf für Dissipations- und Frequenzänderung, wohingegen eine Erhöhung des Speichermoduls eine Vergrößerung sowohl der Frequenz als auch der Dissipation bewirkt.

\footnotetext{
${ }^{8}$ In Anlehnung an:

Tarantola, M. et al., Toxicity of gold-nanoparticles: Synergistic effects of shape and surface functionalization on micromotility of epithelial cells. Nanotoxicology, 2011, (5), 254-268.
} 
A

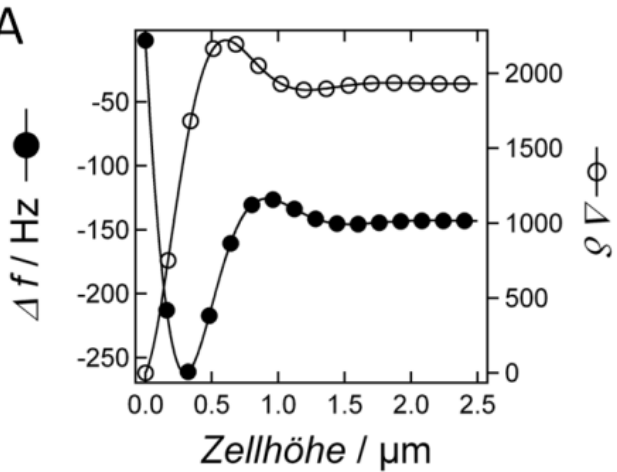

C

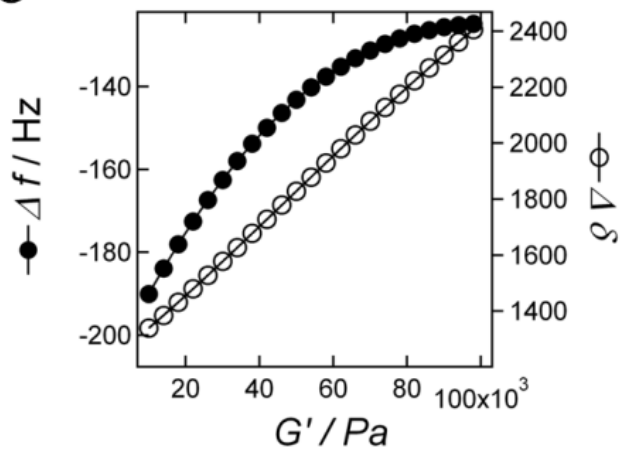

B

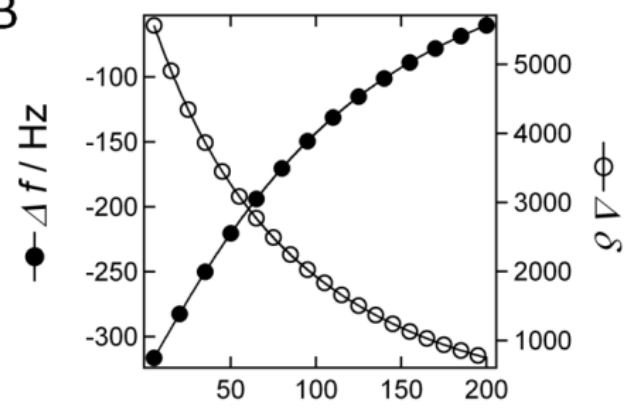

Zell-Substratabstand / nm

$\mathrm{D}$

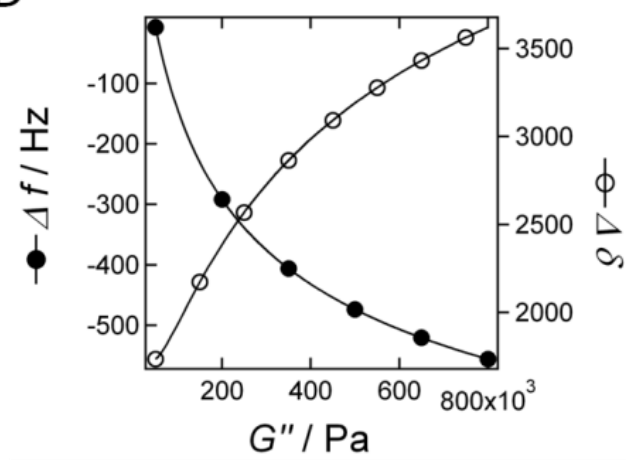

Abbildung 2.13: Berechnete Veränderungen der Frequenz $(\Delta f)$ und der Dissipation $(\Delta \delta)$ nach dem 3-Schichtenmodell für D-QCM Experimente mit einem $5 \mathrm{MHz}$ Resonator in Abhängigkeit von geometrischen und mechanischen Eigenschaften einer adhärenten Zellmonolage. Als Schicht 1 und 3 werden jeweils eine wässrige Schicht mit einer Viskosität von $\eta_{\mathrm{fl}}=0.89 \times 10^{-4} \mathrm{~Pa} \times \mathrm{S}$ und einer Dichte von $\rho_{f l}=0.997 \mathrm{~g} / \mathrm{l}$ angenommen. In den Diagrammen sind $\Delta f$ und $\Delta \delta$ in Abhängigkeit von A) der Höhe der Zellmonolage $\left.\left(h_{c}\right), B\right)$ des Abstands zwischen der Zellschicht und dem Quarz $\left.\left(h_{f l}\right), C\right)$ das Speichermodul $(G)$ und $D)$ das Verlustmodul $\left(G^{\prime}\right)$ aufgetragen. Für die jeweils nicht variablen Parameter wurden zur Berechnung folgende Einstellungen verwendet: $h_{\mathrm{c}}=6 \mu \mathrm{m}, h_{\mathrm{fl}}=100 \mathrm{~nm}$, $G^{\prime}=50 \mathrm{kPa}, G^{\prime \prime}=100 \mathrm{kPa} .{ }^{9}$

\subsubsection{Gerät und Messmodi}

Die D-QCM-Messungen werden an einem selbstgebauten System mit einem $5 \mathrm{MHz} A T$-cut Quarz (KVG, Neckerbischhofsheim, Deutschland) durchgeführt. Mit einem $80 \mathrm{MHz}$ Signal Generator (Agilent 33250A, National Instruments, Austin, USA) wird der Quarz mit der Grundresonanzfrequenz angeregt und das Abklingverhalten mit einem A/D-Wandler (NI PCI5911, National Instruments, Austin, USA) mit einer Rate von $100 \mathrm{MHz}$ detektiert. [99-100] Dieser periodische Zyklus von Anregen und Ausschwingen wird zehnmal pro Minute durchlaufen.

\footnotetext{
${ }^{9}$ In Anlehnung an:

Tarantola, M. et al., Toxicity of gold-nanoparticles: Synergistic effects of shape and surface functionalization on micromotility of epithelial cells. Nanotoxicology, 2011. 5(2): p. 254-268.
} 
Die selbst angefertigten Messkammern aus Teflon werden vollständig mit S-Puffer gefüllt und zur Vermeidung von Longitudinalwellen, die an der Luft-Wasser-Grenzfläche reflektiert werden, mit einem Teflondeckel verschlossen.

\subsubsection{Messvorbereitung}

Bei dem verwendeten $5 \mathrm{MHz}$ Quarz mit einem Elektrodendurchmesser von $3 \mathrm{~mm}$ wird eine der aufgedampften Goldzuleitungen an der Seite mit lod/Kaliumiodid-Lösung entfernt. Vor Beginn der Leermessung wird die Messkammer mit eingebautem Quarz 45 Sekunden lang in Argonplasma gereinigt und mit $1.3 \mathrm{ml}$ S-Puffer gefüllt. Nach Erreichen des thermischen Gleichgewichts, wird die

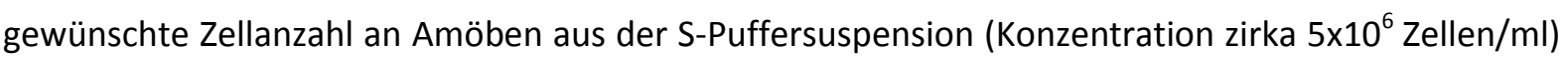
zugegeben, wobei zur Beibehaltung eines konstanten Volumens das entsprechende Volumen an S-Puffer zuvor aus der Messkammer entnommen wird. Die Messung wird mit verschlossener Messkammer und bei Raumtemperatur durchgeführt.

\subsubsection{Bildanalyse}

\subsubsection{Zellsegmentierung}

Zur Analyse der Zellform und des Belegungsgrades der Zellschicht auf der ECIS-Elektrode wird die Zellstruktur der Dictyostelium discoideum Zellen manuell auf einem Graphiktablett (Cintiq 21UX, wacom Europe, Krefeld, Deutschland) unter Verwendung der Software MyPaint (lizenzfreie Software, entwickelt von Martin Renold) auf den Hellfeldmikroskopieaufnahmen nachgezeichnet.

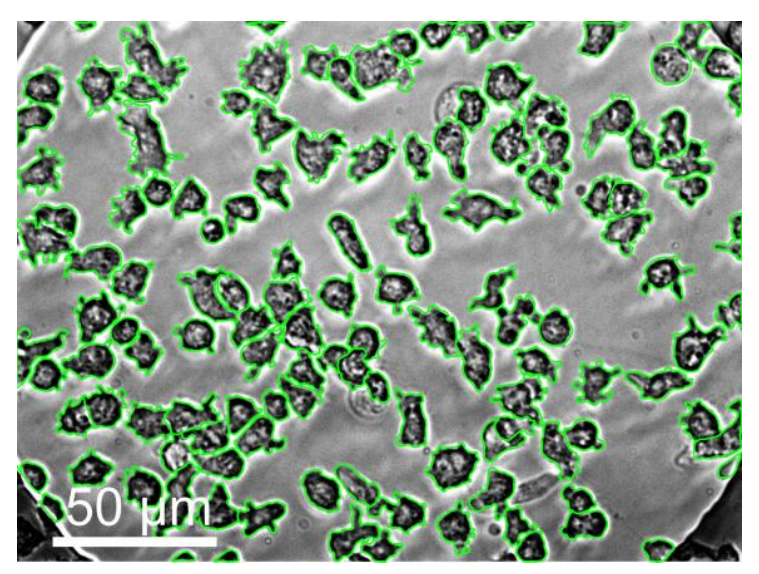

Abbildung 2.14: Hellfeldaufnahme mit in grüner Farbe nachgezeichneten Konturen von Dictyostelium discoideum Amöben auf einer ECIS-Elektrode $(\varnothing=250 \mu \mathrm{m})$. 


\subsubsection{Bildsubtraktion}

Bei den Bildreihen, die während den Experimenten mit Zellkollektiven bei ECIS- und TIRF-Messungen aufgenommen wurden, werden Überlagerungsbilder von zwei Hellfeldaufnahmen, die mit einem zeitlichen Versatz von einer Minute aufgenommen wurden, erstellt. Dazu werden die Bilder im Bildbearbeitungsprogramm ImageJ (Lizenzfreie Software, entwickelt von Wayne Rasbahnd) mit Hilfe eines Makrobefehls voneinander subtrahiert. Von diesen Überlagerungsbildern wird anschließend eine Grauwertanalyse in ImageJ durchgeführt. 


\subsection{Impedanzmessungen im Mikrokanal}

Widerstandsmessverfahren bieten die Möglichkeit, Zelleigenschaften und deren Veränderungen nicht-invasiv, in Abwesenheit einer Lichtquelle und ohne vorherige Markierung der Zellen zu untersuchen. Aufgrund der dielektrischen Eigenschaft der Zellmembran wird eine Reihe von interessanten Parametern zugänglich. So konnte E. O'Conner et al. mit der Methode des Widerstandsmessverfahrens Volumenveränderungen von Zellen detektieren. Hierzu wurde in einer speziell konstruierten Messkammer das Volumen von Astrozyten in einer Zellmonolage durch Osmose verändert. [101]

In diesem Kapitel soll untersucht werden, ob es mittels des Widerstandsmessverfahrens möglich ist, die Chemotaxis von Dictyostelium discoideum Zellen während dem Nahrungsentzug im sozialen Zyklus zu detektieren. Hierzu wird der Impedanzverlauf von mit Zellen gefüllten Mikrokanälen als Funktion der Zeit analysiert. [102] Ziel ist es, simultanes, kollektives Verhalten der Amöben anhand des Widerstands zu detektieren, wobei als mögliche Ursachen der Impedanzveränderungen Änderungen der Zellform oder der Zellanordnung im Kanal in Frage kommen.

\subsubsection{Aufbau des Messsystems}

Die verwendeten Kanäle bestehen aus dem Polymer Poly(dimethylsiloxan) (PDMS) in das eine Kanalstruktur auf der Unterseite eingeprägt ist. Durch Verbinden der Unterseite des PDMS mit einem Glasträger entsteht ein geschlossener Kanal. Die Kanäle haben eine Höhe von $18 \mu \mathrm{m}$, eine Länge von $5 \mathrm{~mm}$ und eine Breite von entweder $15 \mu \mathrm{m}$ oder $50 \mu \mathrm{m}$. Die Übertragung der Kanalstrukturen auf das PDMS geschieht mittels Abformung einer Masterstruktur, die zuvor durch Photolithographie hergestellt wird.

Der Aufbau des Messsystems für die Impedanzmessungen von Zellen in Mikrokanälen ist in Abbildung 2.15 schematisch dargestellt. An den Enden des mit Zellen gefüllten Kanals wird in die Übergangsstücke, die gleichzeitig als Pufferreservoir dienen, jeweils eine Platinelektrode getaucht, die mit einem Potentiostaten/Galvanostaten (SP-300, GAMEC Analysetechnik, Illingen, Deutschland) verbunden ist. Die Messungen werden mit Wechselstrom bei einer Frequenz von $500 \mathrm{~Hz}$ durchgeführt, da bei dieser Frequenz der Strom an den Zellen vorbei und nicht durch die Zellmembran fließt. [101] Der Aufbau des Messsystems bietet die Möglichkeit die Zellen im Kanal mit einem inversen Mikroskop zu beobachten. 


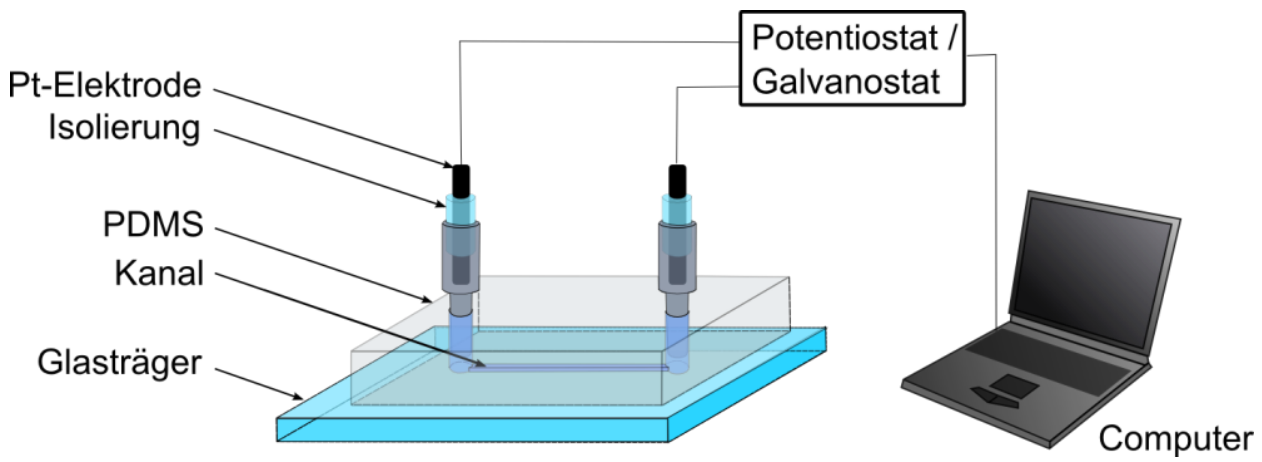

Abbildung 2.15: Schematischer Aufbau einer Apparatur zur Widerstandsmessung eines puffergefüllten PDMS-Kanals.

\subsubsection{Chemotaxis in Mikrokanälen}

In die PDMS-Mikrokanäle werden Dictyostelium discoideum Zellen im nährstofffreien S-Puffer gefüllt (Abbildung 2.16). Während des Füllvorgangs mit Amöben bilden sich Bereiche im Kanal, in denen es zur Ansammlung von Zellen kommt. Innerhalb kurzer Zeit findet eine Umorientierung der übereinander liegenden Amöben in eine nebeneinander auf der Oberfläche des Glasträgers adhärierte Monolage statt. In anderen Bereichen des Kanals ist die Zelldichte deutlich geringer.

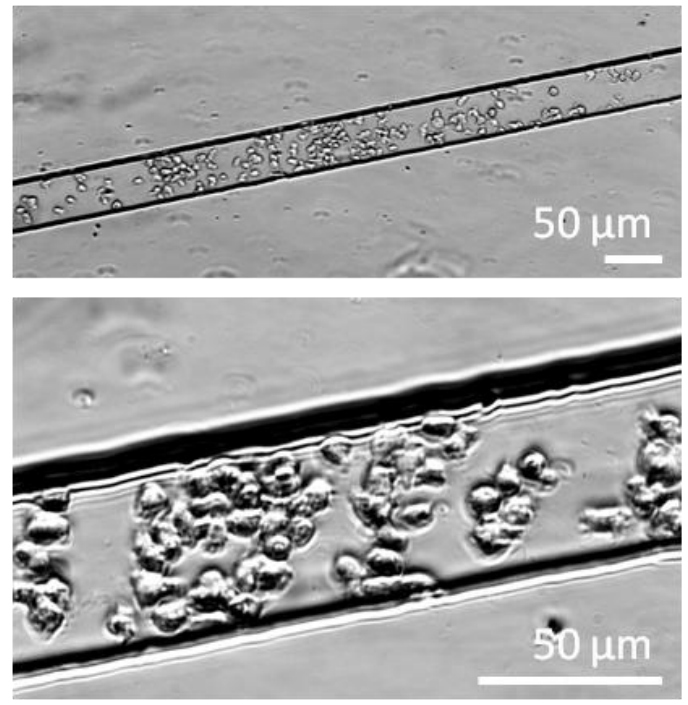

Abbildung 2.16: Hellfeldmikroskopische Aufnahmen von Dictyostelium discoideum Zellen in einem $50 \mu \mathrm{m}$ breiten PDMS-Kanal.

Der detektierte Impedanzwert des mit Zellen gefüllten Kanals steigt im Vergleich zum Impedanzwert vor Zellzugabe an, da die Amöben im Kanal den Widerstand durch Verringern des effektiven Kanaldurchmesser für den Stromfluss erhöhen. Innerhalb des Impedanzsignals lassen sich Fluktuationen erkennen, die von Zellbewegungen oder Zellformveränderungen der Amöben 
innerhalb des Kanals hervorgerufen werden. Der Anstieg des Impedanzsignals im Verlauf des Versuches ist auf die Bildung von Zellverbänden, die stellenweise den Kanaldurchmesser weiter reduzieren, zurückzuführen. Mikroskopische Untersuchungen zeigen, dass sich insbesondere im Anfangsbereich beim Übergang vom Reservoir zum Kanal Zellaggregate bilden, da die Zellzahl in diesem Bereich besonders hoch ist.

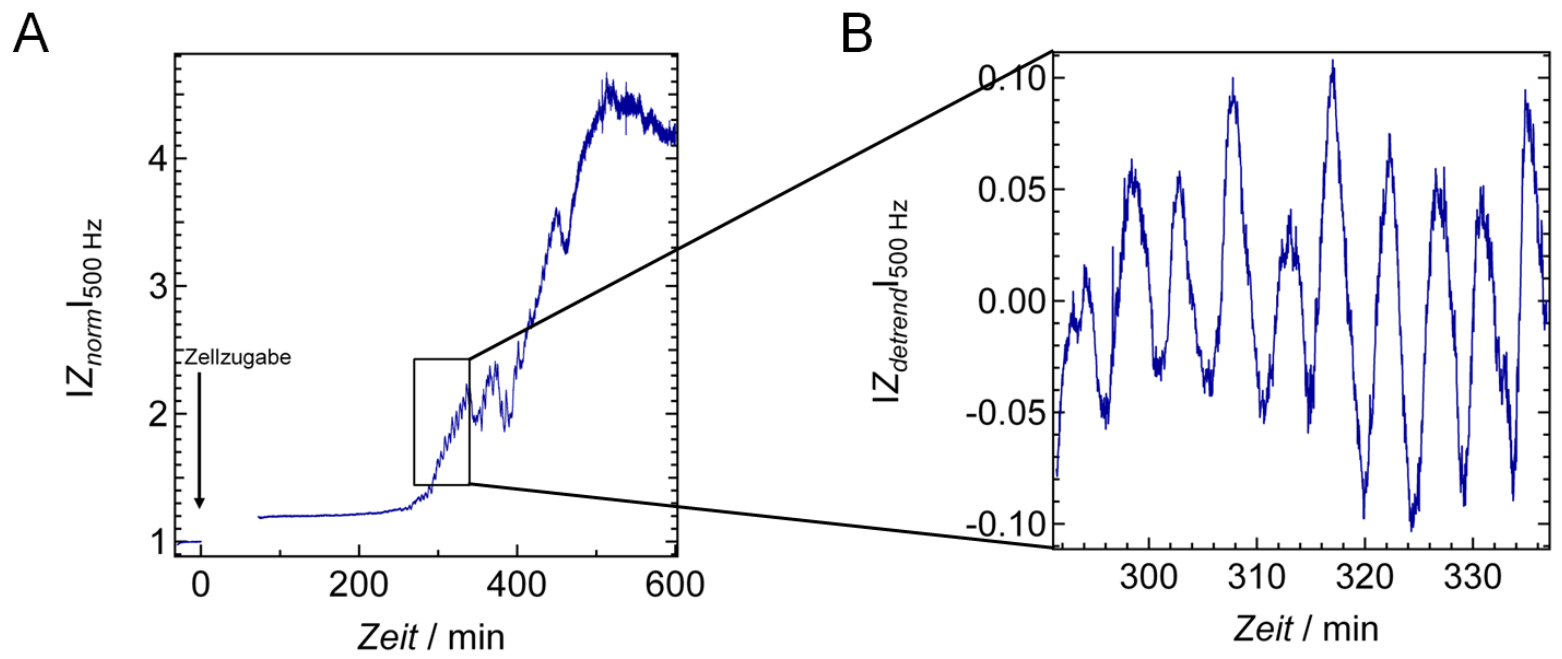

Abbildung 2.17: Impedanzverlauf von Dictyostelium discoideum Zellen in einem $15 \mu \mathrm{m}$ breiten PDMS-Kanal als Funktion der Zeit. A) Auf Zellzugabe bei $t=0$ normiertes Impedanzsignal bei $500 \mathrm{~Hz}\left(\left|Z_{\text {norm }}\right| 500 \mathrm{~Hz}\right)$ der gesamten Messung. B) Ausschnitt des oszillierenden Impedanzverlaufs nach dem Entfernen des linearen Langzeittrends $\left(\left|Z_{\text {detrend }}\right|_{500 \mathrm{~Hz}}\right)$.

Trotz des kontinuierlichen Anstieges des Impedanzwertes ist bei den Messungen der Übergang von nicht korrelierter Fluktuation in ein oszillierendes Impedanzsignal zu erkennen. Dieser tritt je nach Messung nach 4 bis 10 Stunden auf und hält 1 bis 3 Stunden an. In Abbildung 2.17 B ist dieser periodische Impedanzverlauf abzüglich des linear ansteigenden Trends für die in Abbildung 2.17 A dargestellte Messung gezeigt. Als Ursache für die Oszillation kommen periodisch wiederkehrende Veränderungen der Zellform beziehungsweise Zellgröße oder der Zellanordnung in Betracht.

Eine Schwingungsperiode der Oszillation dauert zirka 6 Minuten. Dies entspricht einer Zykluslänge der Chemotaxis beziehungsweise der Zell-Zell-Kommunikation von Dictyostelium discoideum Zellen während der Aggregation in der sozialen Zyklusphase. [9, 53]

\subsubsection{Zusammenfassende Diskussion}

Die Messungen des Impedanzverlaufs von mit Dictyostelium discoideum Zellen gefüllten Mikrokanälen zeigen, dass sich mit dieser Methode Zellbewegungen innerhalb des PDMS-Kanals 
anhand von Fluktuationen des Impedanzsignals nachweisen lassen. Des Weiteren sind die für hungernde Dictyostelium discoideum Zellen typischen Oszillationen mit einer Periodenlänge von 6 Minuten, die während der Aggregationsphase auftreten, im Impedanzverlauf zu erkennen.

Über die zyklischen, physikalischen Veränderungen im Kanal, die während der Widerstandsmessung zu dem periodisch verlaufenden Impedanzsignal führen, kann nur gemutmaßt werden. Da das Impedanzsignal von den Vorgängen im gesamten Kanal abhängig ist, werden nicht korrelierte Veränderungen von einzelnen Dictyostelium discoideum Zellen mit dieser Methode nicht erfasst. Die zwar geringe aber deutlich erkennbare Oszillation im Impedanzsignal muss daher von simultanen Veränderungen in der Messkammer stammen. Diese Veränderungen sind aufgrund des bekannten kollektiven Zellverhaltens und des 6 Minutenzyklus auf die simultane Chemotaxis der Zellen während des sozialen Zyklus zurückzuführen.

Auf den Mikroskopieaufnahmen während der Impedanzmessung sind nur kleine Bereiche des Kanals zu erkennen. Die Aufnahmen sind daher nicht repräsentativ um die Ursache der kollektiven Impedanzoszillation des gesamten Kanals zu erklären.

Aus der Literatur ist bekannt, dass es bei Dispersionsexperimenten mit Dictyostelium discoideum Zellen während der frühen sozialen Zyklusphase zur periodischer Bildung und Zerfall von Zellaggregaten im zirka 6 Minuten Rhythmus kommt. [103] Dieser Auf- und Abbau von Zellclustern könnte eine Verringerung beziehungsweise Erhöhung des freien, stromleitenden Kanaldurchmessers bewirken und somit die Ursache für das oszillierende Impedanzsignal sein. Eine weitere Möglichkeit ist eine zyklische Formveränderung von flachen zu erhöhten Strukturen der Zellen.

Da sich diese Hypothesen nicht ausschließlich durch Messungen im Mikrokanal klären lassen, werden im Folgenden Impedanzmessungen auf sehr kleinen Elektroden durchgeführt, die eine simultane optische Messung zulassen. 


\subsection{Impedanzmessungen einer einzelnen Amöbe}

Die Eigenschaft der Zellmembran für bestimmte Frequenzen des Wechselstroms einen Widerstand darzustellen, wird außer bei den Widerstandsmessungen im Mikrokanal auch beim der ECIS genutzt. $[92,104]$ Bei diesem Verfahren ist die mit Zellen belegte Goldelektrode in den Boden der Messkammer eingelassen und der Kontakt der Zellen mit der Goldoberfläche wird durch die Impedanz bestimmt. In diesem Kapitel wird untersucht, ob die Sensitivität der ECIS-Methode ausreicht um eine einzelne Dictyostelium discoideum Amöbe auf der Elektrode zu detektieren. [105]

\subsubsection{Migrierende Einzelzelle auf der ECIS-Elektrode}

In eine mit S-Puffer gefüllte ECIS-Messkammer werden Amöben gegeben und die zeitlichen Veränderungen der Impedanz bei $4 \mathrm{kHz}$ gemessen. Bei einer geringen Zellbelegung des Kammerbodens kann es zur Migration einer einzelnen Zelle über die Elektrode kommen. Simultan zu den ECIS-Messungen werden Hellfeldaufnahmen von der Elektrode durch die Goldelektrode hindurch mit einem inversen Mikroskop angefertigt. Abbildung 2.18 zeigt Mikroskopieaufnahmen während der Migration einer Zelle über eine Elektrode mit einem Durchmesser von $25 \mu \mathrm{m}$. Die geringe Elektrodengröße verbesserte das Signal-zu-Rausch-Verhältnis im Vergleich zu konventionellen ECIS-Elektroden $(\varnothing=250 \mu \mathrm{m})$. Das korrespondierende Messsignal der ECISMessung zur Bildreihe zeigt im Bereich von 1 bis 3.5 Minuten einen Peak im Impedanzverlauf.

Die Messung zeigt, dass die Detektion eines erhöhten Widerstandes zeitlich korreliert mit der Belegung der Elektrode mit der Zelle. Demzufolge ist die ECIS-Methode ausreichend sensitiv, um ein einzelnes Dictyostelium discoideum auf der Elektrode zu detektieren. Bei weiteren Messungen mit Elektroden des Durchmessers $50 \mu \mathrm{m}$ und $100 \mu \mathrm{m}$ zeigen sich ebenfalls Anstiege des Impedanzsignals pro zusätzliche Zelle auf der Arbeitselektrode. Die Signalintensität des detektierten Impedanzwertes einer Zelle nimmt jedoch antiproportional mit steigender Elektrodengröße ab $\left(\Delta Z_{\text {norm }} \propto \frac{\Delta A_{\text {Belegt }}}{\Delta A_{\text {Elektrode }}}\right)$. 


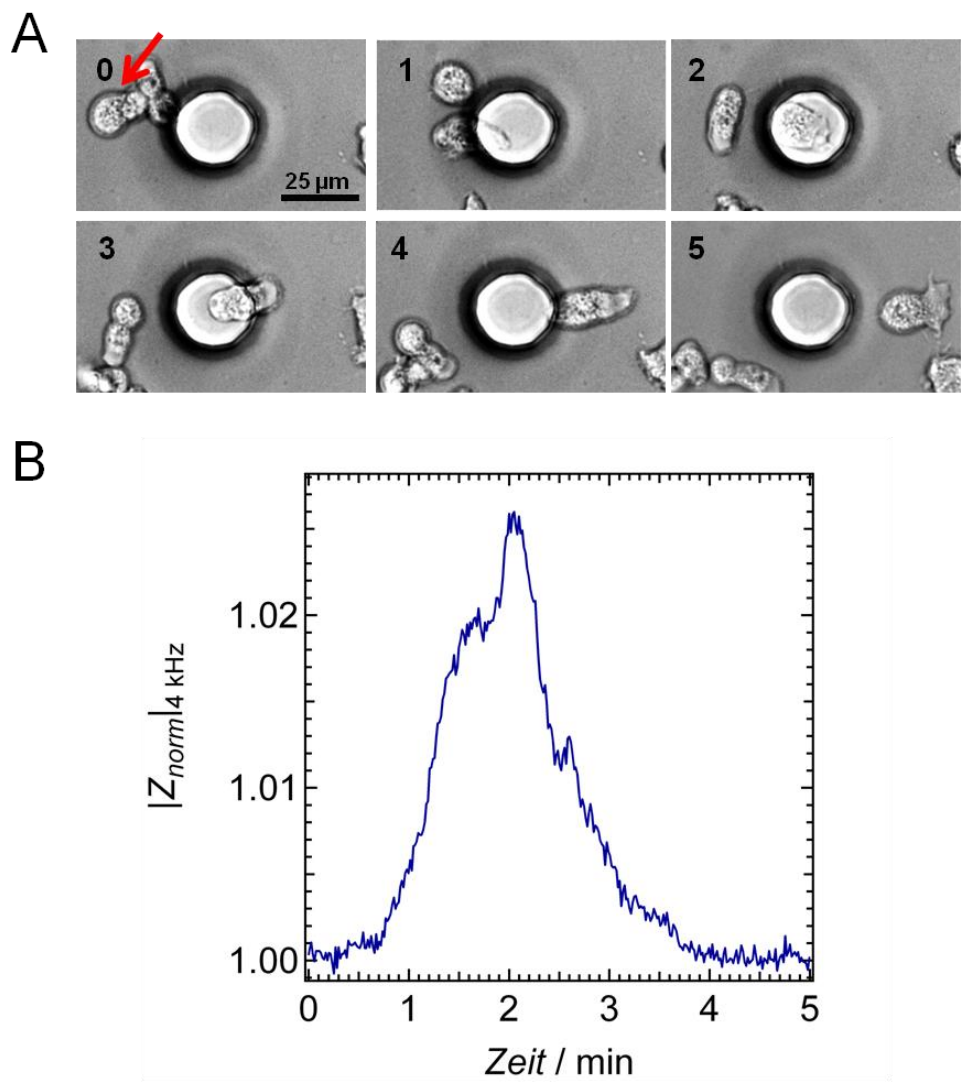

Abbildung 2.18: A) Mikroskopieaufnahmen (Olympus-Aufbau) von einer einzelnen Zelle auf einer ECIS-Elektrode $(\varnothing=25 \mu \mathrm{m})$. Die entsprechende Amöbe ist in Bild 1 mit einem roten Pfeil markiert. Die Bilder sind im Zeitabstand von einer Minute aufgenommen. B) Zeitlich korrespondierende Veränderungen des normierten Impedanzsignals (auf Initiale Impedanz bei $\boldsymbol{t}=\mathbf{0}$ normiert) bei $4 \mathrm{kHz}\left(\left|Z_{\text {norm }}\right| 4 \mathrm{kHz}\right)$ mit der in (A) dargestellten Bildreihe. Aus der Belegung der Elektrode mit einer Zelle resultiert ein höherer Impedanzwert.

Der Vorteil einer größeren Elektrode ist, dass sich die Zeit verlängert, die ein Dictyostelium discoideum zum Überqueren der Elektrode benötigt. Abbildung 2.19 zeigt die Mikroskopieaufnahmen und das korrespondierende Impedanzsignal einer einzelnen Zelle, die über die Elektrodenfläche $(\varnothing=50 \mu \mathrm{m})$ migriert. Während der zirka 15 Minuten, die sich die Zelle auf der Elektrode befindet (Abbildung 2.19 A: Bild 3-11), zeigt das Impedanzsignal regelmäßige Peaks mit einem zeitlichen Abstand von zirka 2 Minuten.

Die Ursache dieser Peaks könnten die üblichen amöboiden Kriechbewegungen der Zell sein. Aus den Zellformveränderungen während des Ausbildens von Pseudopodien und des Nachziehens des Zellkörpers könnten Größenveränderungen der Kontaktfläche oder Veränderungen des ZellSubstrat-Abstands resultieren, die die Veränderung des Impedanzwertes erzeugen. 

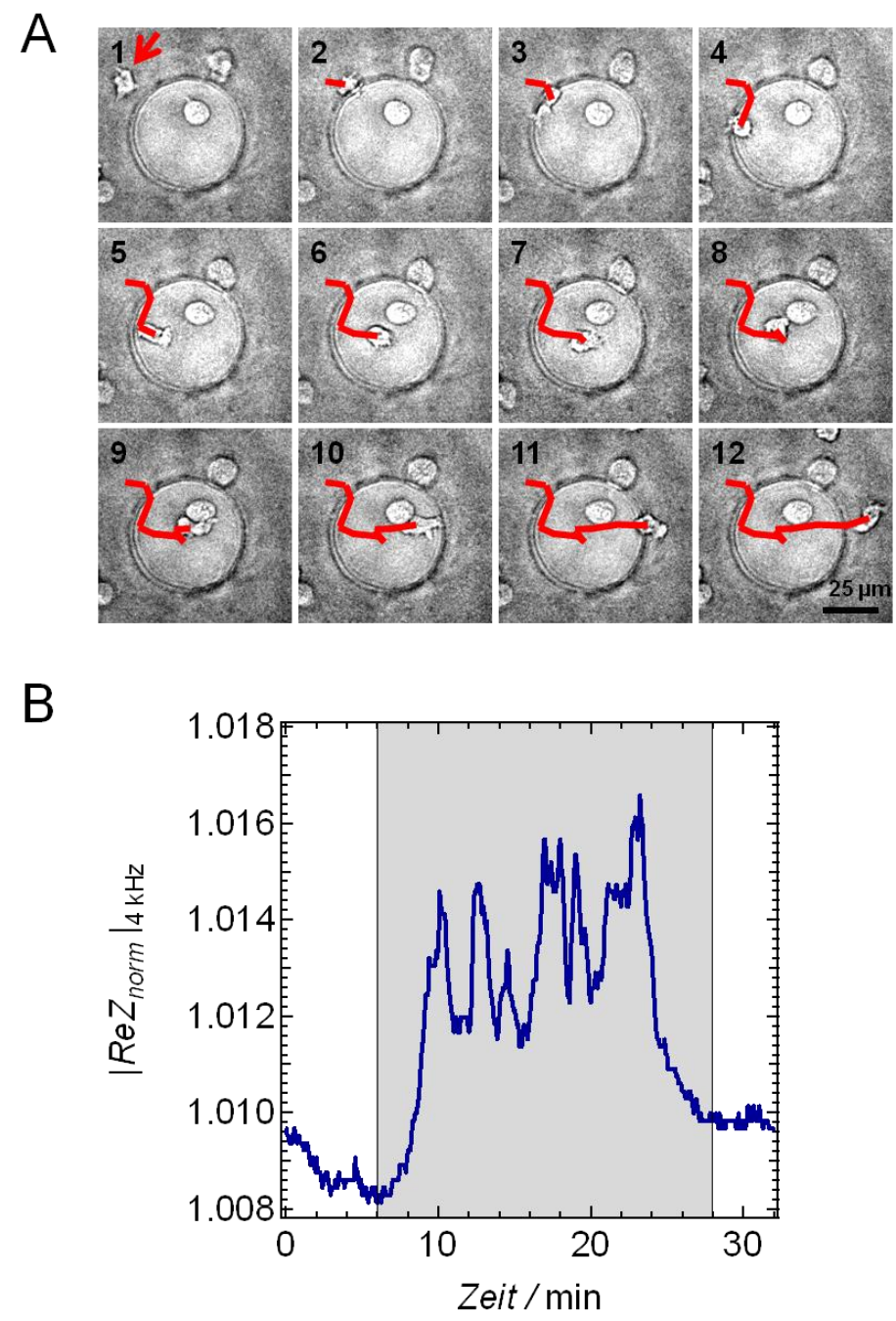

Abbildung 2.19: A) Mikroskopieaufnahmen (Zeiss-Aufbau) von einer einzelnen, wandernden Zelle auf der ECIS-Elektrode $(\varnothing=\mathbf{5 0} \mu \mathrm{m})$. Die entsprechende Amöbe ist auf Bild 1 mit einem roten Pfeil markiert. Auf den Bildern 2 bis 12 ist der von der Zelle zurück gelegte Weg als rote Linie gekennzeichnet. Die Bilder sind in einem Zeitabstand von 2 Minuten aufgenommen. B) Die korrespondierende Veränderung des normierten realen Widerstandssignals der ECIS-Messung bei $4 \mathrm{kHz}\left(\left|\operatorname{Re} Z_{\text {norm }}\right| 4 \mathrm{kHz}\right)$ zeigt ein regelmäßiges Muster von Peaks, das von der Migration der Zelle über die Elektrode verursacht wird. Die grau markierte Fläche korreliert zeitlich mit der in (A) dargestellten Bilderreihe. ${ }^{10}$

\subsubsection{Zusammenfassende Diskussion}

Es konnte gezeigt werden, dass es mit der ECIS-Methode möglich ist, einzelne Zellen auf der Arbeitselektrode zu detektieren. Die Sensitivität der Messung hängt unter anderem von der Größe der Arbeitselektrode ab. Kleinere Elektroden verursachen ein größeres Rauschen des Signals, sind jedoch sensitiver für Veränderungen des Belegungsgrades und der Zellbewegungen.

\footnotetext{
${ }^{10}$ In Anlehnung an:

Schäfer, E. et al., Shape Oscillations of Dictyostelium discoideum Cells on Ultramicroelectrodes Monitored by Impedance Analysis. Small, 2011, (7), 723-726.
} 
Des Weiteren konnte gezeigt werden, dass eine Zelle, die über die Elektrode migriert, ein Impedanzsignal mit regelmäßig wiederkehrenden Peaks verursacht. Die amöboide Kriechbewegung besteht aus der Ausbildung eines Pseudopodiums und dem anschließenden Nachziehen des Zellkörpers. [6, 28-29] Die Bewegungsanalysen von D. Wessels et al. ergaben eine durchschnittliche Bewegungsperiode bei Dictyostelium discoideum Zellen von zirka 1.5 Minuten (siehe Kapitel 2.1.1). [31] Durch die amöboide Kriechbewegung der Zelle könnte es bei jeder Bewegungsperiode zu einer zyklischen Veränderung der belegten Elektrodenfläche kommen oder durch unterschiedlich starke Adhäsionen der Zelle im Verlauf der Kriechbewegung zu Veränderungen des Zell-Substrat-Abstands. Aus beiden zuvor genannten Vorgängen könnten die periodischen Peaks im Impedanzsignal der ECIS-Messung im Abstand von einem Bewegungszyklus von Dictyostelium discoideum Zellen resultieren. 


\subsection{ECIS-Impedanzmessungen von zellulären Ensembles}

Die Widerstandsmessungen von Dictyostelium discoideum Zellen im Mikrokanal zeigen Oszillationen im Impedanzmesssignal, die mit der Chemotaxis und der Zell-Zell-Kommunikation während des sozialen Zyklus der Amöben zusammenhängen. Da es bei den Messungen im Mikrokanal verschiedene Schwierigkeiten gibt, wie zum Beispiel das nicht gleichmäßige Füllen der Kanäle mit Zellen, unregelmäßige Impedanzanstiege und ein geringes Signal-zu-Rausch-Verhältnis, wird im folgenden Kapitel das kollektive Verhalten eines Ensembles an Dictyostelium discoideum Zellen mit Hilfe der ECIS-Methode analysiert. Hierbei handelt es sich ebenfalls um ein Widerstandsmessverfahren, bei dem der Verlauf des Impedanzsignals nur von einer kleinen Gruppe an Zellen auf der am Boden angebrachten Elektrode beeinflusst wird. [105]

\subsubsection{Chemotaxis in ECIS-Messungen}

In Abbildung 2.20 A ist eine mit zirka 250 Dictyostelium discoideum Zellen bedeckte ECIS-Elektrode im nährstofffreien S-Puffer abgebildet. Die Goldelektrode $(\varnothing=250 \mu \mathrm{m})$ ist als runder Kreis in der Mitte des Bildes zu erkennen. Abbildung 2.20 B zeigt den Impedanzverlauf der dazugehörigen ECISMessung. Am Zeitpunkt $t=0$ werden zirka 7500 Zellen/mm² in S-Puffer in die Messkammer $\left(A=0.8 \mathrm{~cm}^{2}\right)$ gegeben. Durch das Belegen der Elektrode mit Zellen steigt das Impedanzsignal an. Nach zirka 4 Stunden findet ein Übergang von einer nicht korrelierten Fluktuation in ein periodisches Impedanzsignal statt. Die Periodendauer beträgt anfangs 12-20 Minuten und verringert sich in den folgenden Stunden auf 6-7 Minuten bei zirka 6 Stunden langem Nahrungsentzug der Zellen. Der Oszillation des ECIS-Impedanzsignals muss eine simultane, periodische Veränderung der Zellen auf der Elektrode zugrunde liegen. Dieses kollektive Verhalten wird in Anbetracht des Auftretens der Oszillation einige Stunden nach dem Nahrungsentzug der Amöben und der Periodendauer von zirka 6 Minuten von der Chemotaxis der Zellen stammen. 

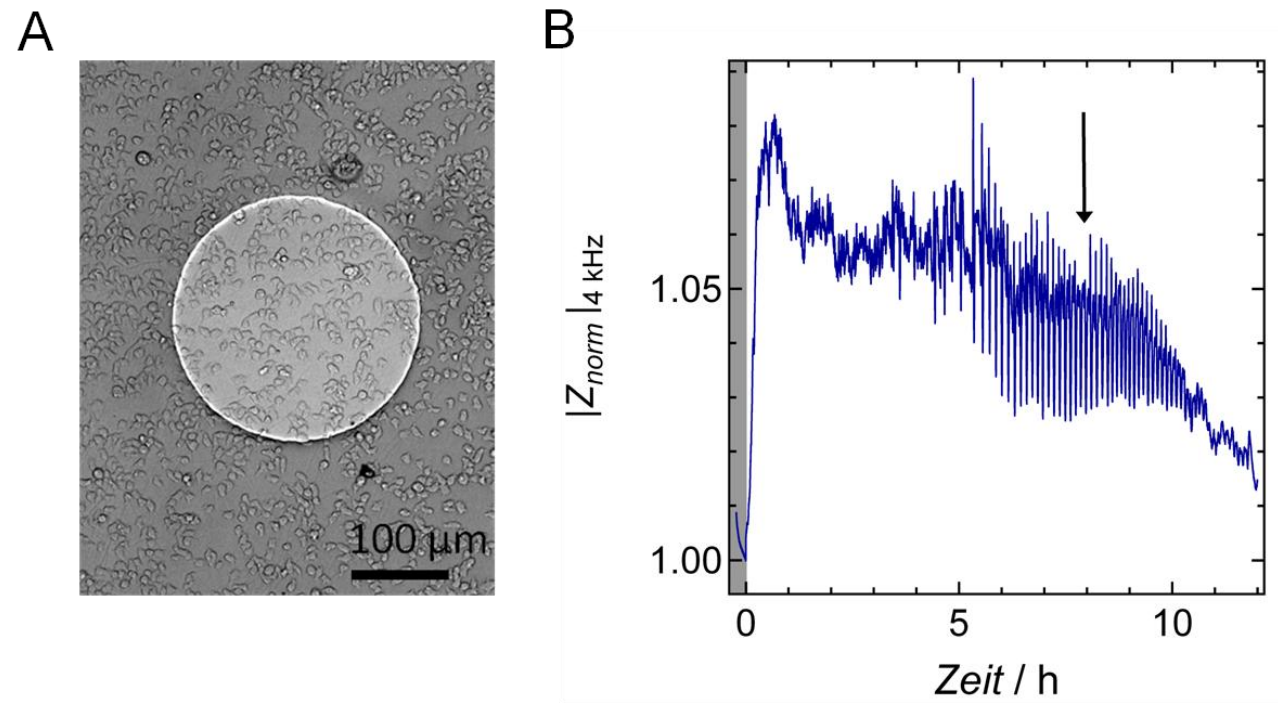

Abbildung 2.20: A) Hellfeldmikroskopische Aufnahme von zirka 8 Stunden hungernden Amöben $\left(7500\right.$ Zellen $\left./ \mathrm{mm}^{2}\right)$ in S-Puffer auf einer runden Elektrode $(\varnothing=250 \mu \mathrm{m})$. B) Veränderungen des auf die Zellzugabe normierten Impedanzsignals bei $4 \mathrm{kHz}\left(\left|Z_{\text {norm }}\right| 4 \mathrm{kHz}\right)$. Die Zellen wurden bei $t=0$ zugegeben. Der Zeitpunkt der in (A) abgebildeten Aufnahme ist mit einem Pfeil markiert.

\subsubsection{Analyse der Impedanzoszillation}

Der bei den verschiedenen Messungen auftretende oszillierende Verlauf des Impedanzsignals zeigt unterschiedliche Formen. Häufig vorkommende Oszillationsformen sind monomodale, asymmetrisch-monomodale oder gerade-bimodale Wellenformen. Die Periodendauer gegen Ende der Oszillation liegt in der Zeitspanne von 5-9 Minuten. Dieser kleine Bereich von verschiedenen Oszillationsfrequenzen ist eventuell auf unterschiedliche Zelldichten auf der Elektrode zurückzuführen. Ein geringerer Belegungsgrad der Elektrode zeigt meist eine geringere Oszillationsfrequenz. Bei der schnellen-Fourier-Transformationsanalyse (englisch: fast Fourier transform, FFT) der Oszillation zeigen sich eindeutige Peaks für die Grundschwingung des Impedanzsignals sowie für die dazu gehörigen ungeraden und geraden Obertonschwingungen.

Abbildung 2.21 A zeigt die mit der ECIS detektierten typischen Oszillationsverläufe während des kollektiven Verhaltens der 3-6 Stunden lang in S-Puffer hungernden Zellen auf der Elektrode. Bei Auftragung 1 ist der Impedanzverlauf von einer Messung gezeigt, bei der der typische Frequenz- und Amplitudenanstieg während der Anfangsphase der Oszillation bis zu einer Periodenlänge von zirka 5 Minuten und einer Amplitudenhöhe zirka 10-fach höher als die nicht korrelierte Fluktuation zu erkennen ist. Anschließend verliert die Oszillation wieder an Intensität jedoch nicht an Schnelligkeit bis sie ganz verschwindet. Die anfängliche Steigerung der Amplitude und der Frequenz wird vermutlich vom fortschreitenden Synchronisierungsprozess der Zellen verursacht, die spätere Abnahme der Amplitudenhöhe bei gleichbleibender Frequenz von Veränderungen des kollektiven 
Verhaltens der Zellen während des Fortschreitens der Aggregationsphase oder des Abwanderns der synchronisierten Zellen von der Elektrode. Die Wellenform ist asymmetrisch und besitzt eine Grundschwingung der Oszillationsfrequenz von $2.6 \mathrm{mHz}$ mit geraden und ungeraden Obertönen (Auftragung $1^{\prime}$ ). Die asymmetrische Form der Wellen wird eventuell durch zeitlich heterogene chemotaktische Reaktionen der Zellen verursacht. Neben dem asymmetrischen Kurvenverlauf in Auftragung 1 und der monomodalen Wellenform gegen Ende des Impedanzverlaufs in Auftragung 3 können auch bimodale Oszillationsstrukturen wie in Auftragung 2 auftreten. Der Grund dafür könnte sein, dass die Zellen auf der Elektrode auf unterschiedliche cAMP-pulsgebende Aggregationszentren synchronisiert sind. Das FFT-Spektrum 2' zeigt deutlich zwei Frequenzen, jeweils mit den zugehörigen Obertönen.

A

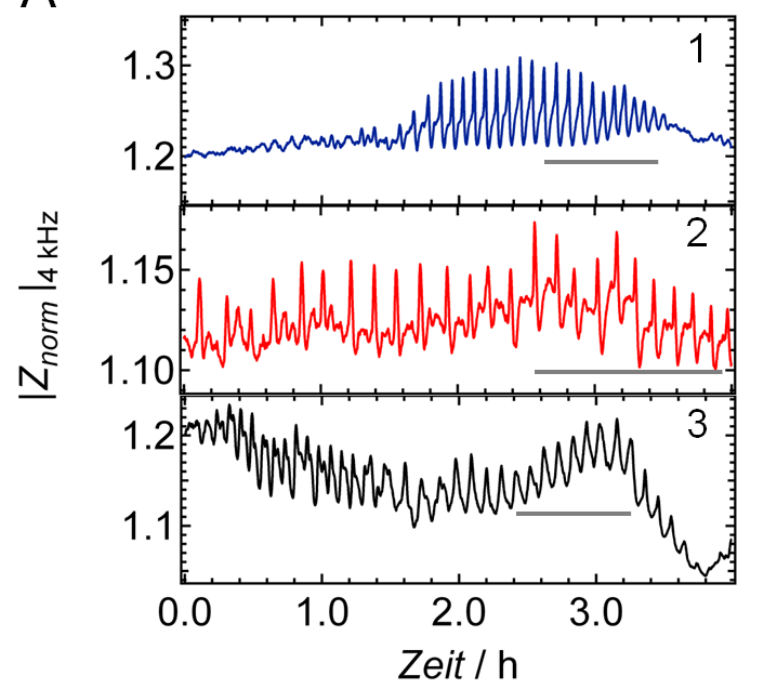

B

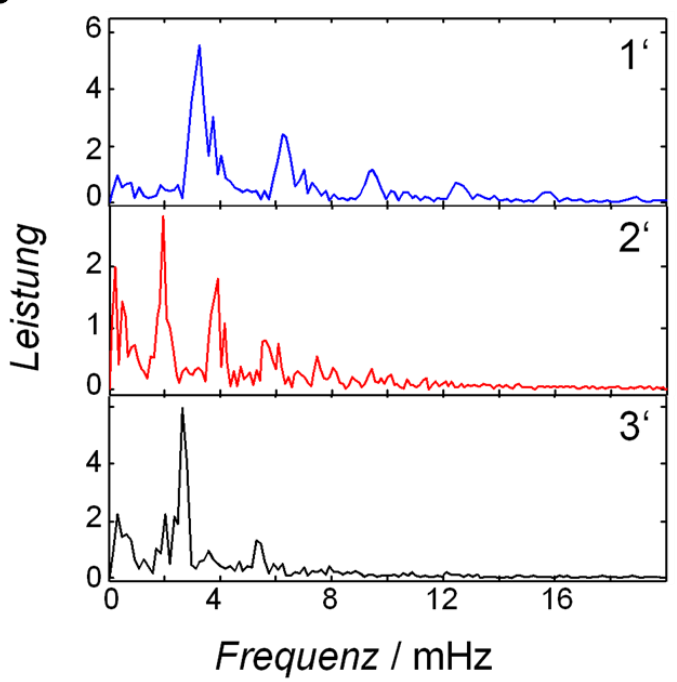

Abbildung 2.21: A) Oszillierender Bereich der normierten Impedanzverläufe als Funktion der Zeit bei $4 \mathrm{kHz}\left(\left|Z_{\text {norm }}\right| 4 \mathrm{kHz}\right)$ von drei unabhängigen ECIS-Messungen mit 10000 Zellen/mm². B) Jeweiliges FFT-Spektrum des grau-markierten Bereiches der Impedanzoszillation in (A). ${ }^{11}$

In einigen Fällen geht der bimodale Verlauf der Oszillation nach 1-2 Stunden in einen asymmetrischmonomodalen oder gar monomodalen Wellenverlauf über (Auftragung 3). Die Ursache könnte eine späte Synchronisierung der Zellen auf ein gemeinsames CAMP-Signal oder das Abwandern eines Zellensembles von der Elektrode sein. Das Auftreten von unterschiedlich verlaufenden Oszillationsmustern wurde jedoch auch bei mutierten Dictyostelium discoideum-Stämmen sowie bei Zellen, deren cAMP-Ausschüttung durch Koffein gehemmt wurde, beschrieben. [83]

\footnotetext{
${ }^{11}$ In Anlehnung an:

Schäfer, E. et al., Shape Oscillations of Dictyostelium discoideum Cells on Ultramicroelectrodes Monitored by Impedance Analysis. Small, 2011, (7), 723-726.
} 


\subsubsection{Beeinflussung der Oszillationsfrequenz}

Als Nachweis, dass die detektierte Oszillation im Impedanzsignal von der cAMP-gesteuerten Chemotaxis der Dictyostelium discoideum Zellen während der Aggregationsphase stammt, werden zwei typische Experimente zur Beeinflussung der Oszillation durchgeführt. Zum einen wird der Einfluss eines externen cAMP-Pulses auf die oszillierenden Zellen untersucht und zum anderen die Auswirkungen auf die Oszillationsfrequenz durch Hemmung der cAMP-Bildung nach Zugabe von Koffein.

\subsubsection{Zugabe von cAMP}

G. Gerisch und B. Hess konnten bei Lichtstreuexperimenten mit Zellsuspensionen zeigen, dass zirka 5 Stunden lang hungernde Dictyostelium discoideum Zellen eine Oszillation im Absorptionssignal zeigen. Eine externe Zugabe von cAMP führte zu einer raschen Reaktion im Messsignal, wobei je nach Zeitpunkt der cAMP-Zugabe entweder die Phase der Oszillation verschoben oder ein zusätzliches Peakmaximum erzeugt wurde. [71]

Um einen Bezug zwischen den Absorptionsverläufen bei den Lichtstreuexperimenten und den Impedanzsignalen der ECIS-Messung herzustellen, wird versucht, die Oszillation der Impedanz auf gleiche Weise zu beeinflussen. Hierzu wird die Auswirkung auf das oszillierende Impedanzsignal nach externer cAMP-Zugabe beobachtet. Bei der in Abbildung 2.22 A gezeigten Messung erfolgte der cAMP-Puls direkt nach einem Impedanzmaximum und verursacht das verfrühte Auftreten des nachfolgenden Maximums ( $\Delta t=4.5 \mathrm{~min}$ ). Die Phase der folgenden Oszillation verschiebt sich und ist an das neue Maximum angepasst. In Abbildung 2.22 B ist die Auswirkung der cAMP-Zugabe zu einem späteren Zeitpunkt der Schwingungsperiode gezeigt. Bei der cAMP-Zugabe in der Mitte der Periode, zirka 4 Minuten nach dem vorangegangenen Impedanzmaximum, wird ein unverzüglich auftretendes Maximum beobachtet, gefolgt von einer Verzögerung des nächsten Impedanzmaximums. Das zuvor synchronisierte System ist anschließend so gestört, dass für zirka eine halbe Stunde keine Oszillation im Impedanzsignal zu erkennen ist, bis die Oszillation spontan wieder beginnt. 
A

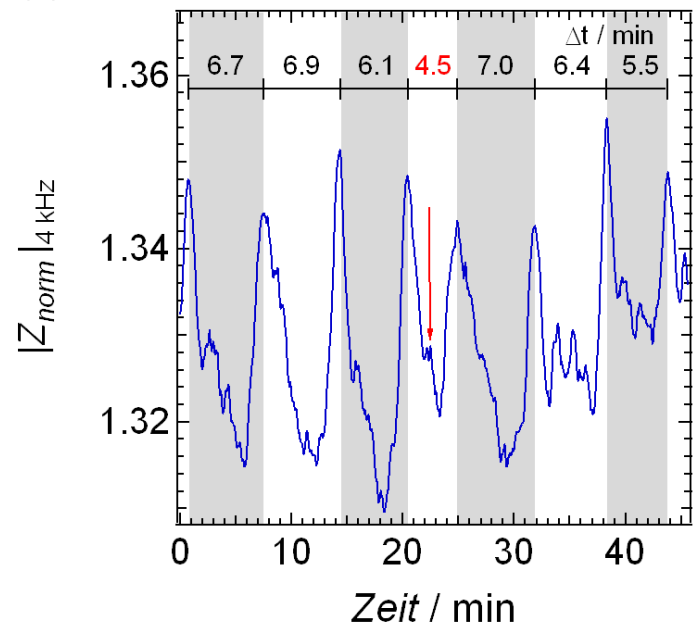

B

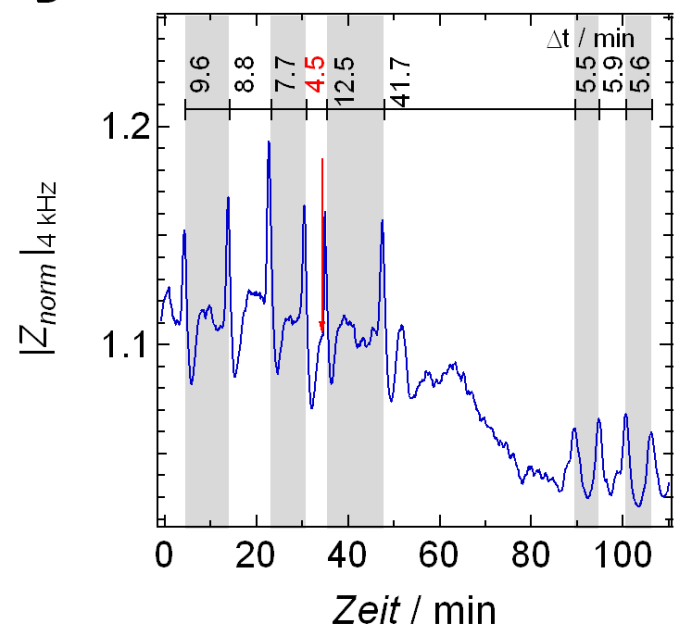

Abbildung 2.22: Impedanzmessungen während der externen Zugabe von cAMP $(2 \mu \mathrm{l}(0.1 \mathrm{~g} / \mathrm{l})$ in $400 \mu \mathrm{l} \mathrm{S-Puffer)} \mathrm{zu} \mathrm{oszillierenden} \mathrm{Dictyostelium} \mathrm{discoideum} \mathrm{Zellen} \mathrm{(zirka} 5000$ Zellen/ $/ \mathrm{mm}^{2}$ ) auf einer ECIS-Elektrode $(\varnothing=\mathbf{2 5 0} \boldsymbol{\mu m})$ zu dem mit dem roten Pfeil markierten Zeitpunkt. Der externe cAMP-Puls erfolgt A) kurz nach einem Peakmaximum der Impedanz ( $\Delta t=\mathbf{2} \mathrm{min}$ ) und B) in der Mitte der erwarteten Schwingungsperiode. ${ }^{12}$

Die während den ECIS-Messungen auftretende Oszillation im Impedanzsignal ist daher sensitiv gegenüber Veränderungen der cAMP-Konzentration in der Messkammer und zeigt eine ähnliche Beeinflussung des Oszillationsverlaufs wie bei Lichtstreuexperimenten.

\subsubsection{Zugabe von Koffein}

Koffein ist ein bekannter Inhibitor der ACA und verringert die von den Dictyostelium discoideum Zellen während der sozialen Phase gebildete und somit ausgeschüttete cAMP-Menge. [3, 9, 83] Der Inhibitor Koffein wird eine Stunde nach Zellzugabe zur Beeinflussung der cAMP-abhängigen Zell-ZellKommunikation und Chemotaxis in die ECIS-Messkammer gegeben.

In Abbildung 2.23 ist der Effekt der Koffeinzugabe auf das detektierte Impedanzsignal bei $4 \mathrm{kHz}$ gezeigt. Die kollektive Oszillation von unbehandelten Zellen (Kurve 1) beginnt zirka 4 Stunden nach Zellzugabe. Zellen in S-Puffer mit zusätzlich $0.3 \mathrm{mg} / \mathrm{ml}$ Koffein zeigen eine Oszillation im Impedanzsignal eine Stunde später als bei der Messung mit unbehandelten Zellen. Die Impedanzmessung der Zellen mit der doppelten Koffeinkonzentration im S-Puffer $(0.6 \mathrm{mg} / \mathrm{ml})$ oszilliert zuletzt. Neben der Verzögerung des Startzeitpunktes der Oszillation, beeinflusst das Koffein

\footnotetext{
12 In Anlehnung an:

Schäfer, E. et al., Shape Oscillations of Dictyostelium discoideum Cells on Ultramicroelectrodes Monitored by Impedance Analysis. Small, 2011, (7), 723-726.
} 
auch die Oszillationsfrequenz. In Abbildung 2.23 B ist die von der Koffeinkonzentration abhängige Verringerung der Frequenz zu erkennen.

A

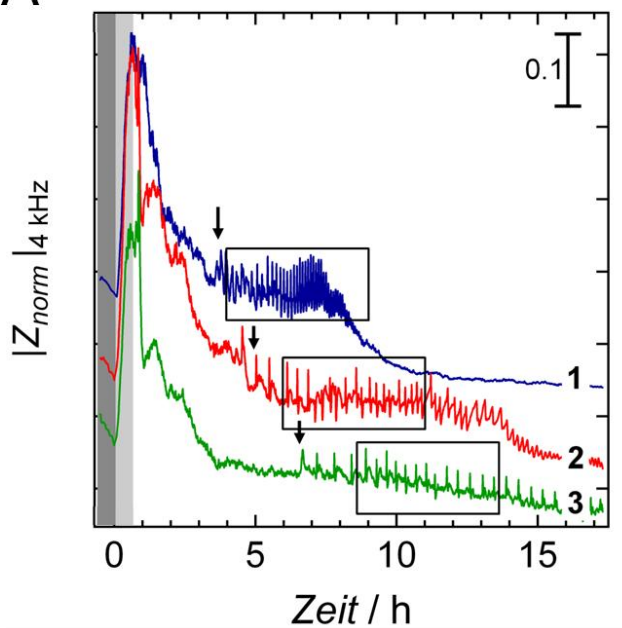

B

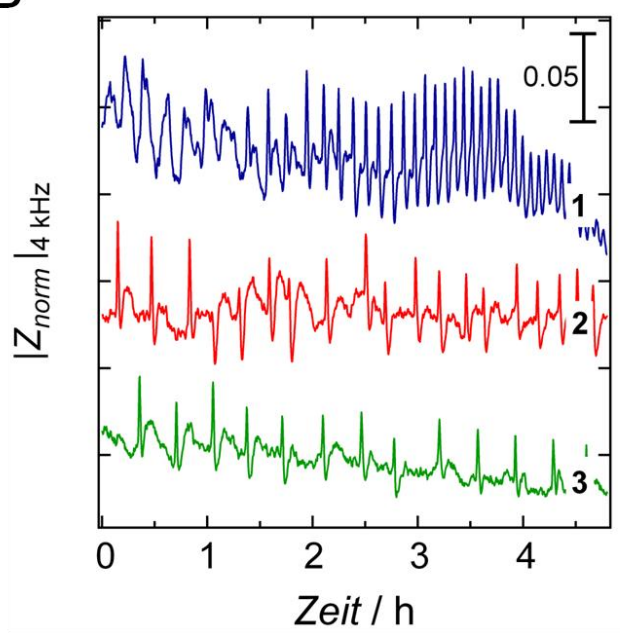

Abbildung 2.23: Einfluss von Koffein auf den Oszillationsverlauf bei ECIS-Messungen. A) Verlauf von drei Zeitspuren des normierten Impedanzsignals $\left(\left|Z_{\text {norm }}\right|_{4 \mathrm{kHz}}\right)$ von Zellen auf ECIS-Elektroden $\left(\varnothing=250 \mathrm{~mm}\right.$ ). Die Zugabe von 6250 Zellen/ $\mathrm{mm}^{2}$ an Dictyostelium discoideum Zellen erfolgte zum Zeitpunkt $t=0$. Die Pfeile markieren den Anfang der Oszillation. Kurve 1: unbehandelte Zellen; Kurve 2: Zugabe von $0.3 \mathrm{mg} / \mathrm{ml}$ Koffein; Kurve 3: Zugabe von $0.6 \mathrm{mg} / \mathrm{ml}$ Koffein jeweils eine Stunde nach Zellzugabe (Ende der hellgrauen Fläche). Der Kurvenverlauf in den schwarzen Kästen ist in (B) vergrößert dargestellt und zeigt den Bereich der Oszillation während der Aggregationsphase. Zur besseren Erkennung der Impedanzverläufe sind die Kurven beliebig im Impedanzwert (A) beziehungsweise im Impedanzwert und der Zeit (B) verschoben. ${ }^{13}$

Eine Übersicht des Effekts der Verringerungen der Frequenz durch Koffein ist zusätzlich in den Histogrammen in Abbildung 2.24 dargestellt. Für die drei Impedanzmessungen mit den verschiedenen Koffeinkonzentrationen ist jeweils die Häufigkeit der Periodendauer der einzelnen Schwingungen während der Oszillation bestimmt. Der Mittelwert der Periodendauer erhöht sich von 6.8 Minuten bei unbehandelten Zellen (Histogramm 1) auf 16.5 Minuten bei der niedrigen Koffeinkonzentration (Histogramm 2) und auf 25.3 Minuten bei der hohen Konzentration an Koffein (Histogramm 3).

\footnotetext{
${ }^{13}$ In Anlehnung an:

Schäfer, E. et al., Shape Oscillations of Dictyostelium discoideum Cells on Ultramicroelectrodes Monitored by Impedance Analysis. Small, 2011, (7), 723-726.
} 


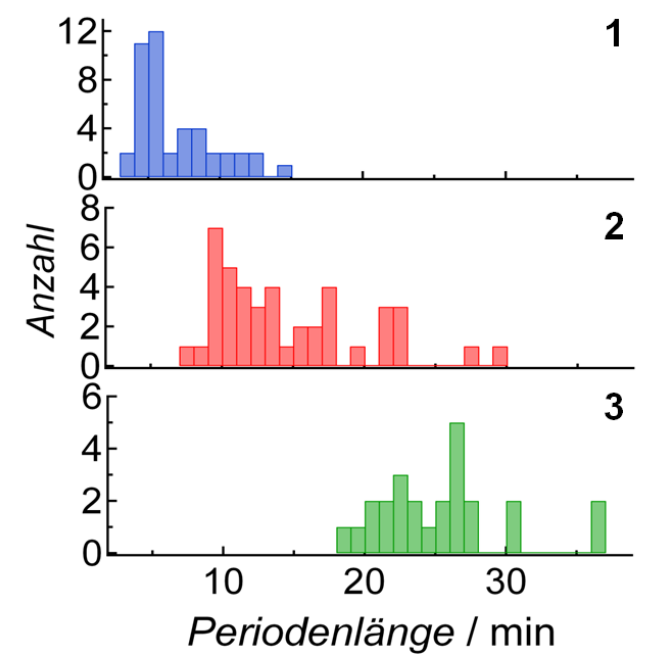

Abbildung 2.24: Einfluss von Koffein auf die Periodenlänge der Oszillationsfrequenz. Die Histogramme zeigen die Häufigkeit, mit der bestimmte Periodendauern bei den in Abbildung 2.23 A gezeigten Oszillationen auftreten. Histogramm 1: unbehandelte Zellen; Histogramm 2: Zugabe von 0.3 mg/ml Koffein; Histogramm 3: Zugabe von 0.6 mg/ml Koffein. ${ }^{14}$

Mit diesen Messungen konnte gezeigt werden, dass die bei den ECIS-Messungen detektierte Oszillation der Impedanz durch Zugabe von Koffein sowohl in ihrer Startzeit wie auch in der Frequenz konzentrationsabhängig beeinflussbar ist. Die detektierte Oszillation des Impedanzsignals ist somit von der gebildeten und ausgeschütteten cAMP-Konzentration der Zellen abhängig.

\subsubsection{Zusammenfassende Diskussion}

In diesem Kapitel konnte gezeigt werden, dass ein kleines Ensemble von einigen hundert Zellen auf der ECIS-Elektrode während der Aggregationsphase eine Oszillation des Impedanzverlaufs verursacht. Widerstandsmessverfahren bieten dabei gegenüber optischen Messmethoden den Vorteil, dass sie ohne Zufuhr von Licht durchgeführt werden. Dies ist insbesondere bei phototaktischen Zellen wie Dictyostelium discoideum entscheidend, da die Messung somit das zu vermessende System nicht beeinflusst.

Die Form und Frequenz der Oszillation des Impedanzsignals variiert zwischen den einzelnen Messungen. Typischerweise treten die Oszillationen 3-6 Stunden nach Überführung der Dictyostelium discoideum Zellen in den nährstofffreien S-Puffer auf und die Periodendauer für synchronisierte Zellen beträgt 5-9 Minuten.

\footnotetext{
${ }^{14}$ In Anlehnung an:

Schäfer, E. et al., Shape Oscillations of Dictyostelium discoideum Cells on Ultramicroelectrodes Monitored by Impedance Analysis. Small, 2011, (7), 723-726.
} 
Durch die Beeinflussung der in den ECIS-Messungen auftretenden Oszillation durch externe cAMPZugabe sowie die Koffeinexperimente konnte gezeigt werden, dass die Oszillation das kollektive Verhalten der Zellen während der cAMP-abhängigen Chemotaxis wiederspiegelt.

Die konzentrationsabhängigen Koffeinmessungen sind außerdem ein Beispiel für die Anwendungsmöglichkeit der ECIS-Methode als Analysesystem für Einflüsse von Gift- oder Wirkstoffen auf Zellen. Die Methode der Widerstandsmessung bietet gegenüber typischen biologischen Cytotoxizitätsassays den Vorteil, dass kontinuierliche, zeitliche Informationen von den Zellen erhalten werden. [93, 97] 


\subsection{Veränderungen der Zellen auf der ECIS-Elektrode}

Die biologische Grundlage für das oszillierende Impedanzsignal ist das kollektive Verhalten von hungernden Dictyostelium discoideum Zellen während der Chemotaxis. In diesem Kapitel wird untersucht, welche (bio)physikalischen Vorgänge der Zellen der Oszillation des Impedanzsignals zugrunde liegen. Eine Vielzahl an möglichen Veränderungen auf der Elektroden kommen hierbei in Frage: periodische Veränderungen der Anzahl der Amöben, Veränderungen des Belegungsgrades der Elektrodenfläche, Formveränderungen der Amöben, periodische Variationen der Anordnung von Zellen oder zyklische Änderungen des Zell-Substrat-Abstands. Zur Untersuchung der Vorgänge auf der Elektrode während der Chemotaxis der Dictyostelium discoideum Zellen bei den ECIS-Messungen werden parallel Mikroskopieaufnahmen von der Elektrode angefertigt, um so synchrone Veränderungen der Zellen zu ermitteln, die den detektierten periodischen Impedanzverlauf erklären. [106]

\subsubsection{ECIS-Impedanzmessungen in Kombination mit Mikroskopieaufnahmen}

Durch das Platzieren der ECIS-Messkammer auf einem inversen Mikroskop ist es möglich, simultan zur Impedanzmessung Hellfeldaufnahmen durch die hierzu ausreichend transparente Goldelektrode hindurch von den Amöben auf der Elektrode zu erhalten. In Abbildung 2.25 ist eine Bildreihe von einer mit Zellen belegten Elektrode $(\varnothing=250 \mu \mathrm{m})$ mit dem dazugehörigen Impedanzverlauf gezeigt. Durch die Zugabe der Zellen (7500 Zellen/ $\left./ \mathrm{mm}^{2}\right)$ zum Zeitpunkt $t=0$ wird die Elektrode gleichmäßig von Dictyostelium discoideum Zellen bedeckt und der Impedanzwert steigt aufgrund der dielektrischen Eigenschaft der Zellmembran an. Vier Stunden nach dem Nahrungsentzug sind erste Peaks im Impedanzsignal zu erkennen. Auf der Mikroskopieaufnahme ist weiterhin eine einheitliche Verteilung der Amöben auf der Elektrode zu beobachten (Zeitpunkt 1). Dies gilt in erster Näherung auch für die 2. Aufnahme, die zu einem Zeitpunkt aufgenommen wurde, an dem sich eine bimodale Oszillation mit einer Periodenlänge von 6-7 Minuten im Impedanzsignal ausgebildet hat. In Aufnahme 3 sind kleine Zellgruppen zu erkennen. Die Oszillation des Impedanzsignals ist zu diesem Zeitpunkt in eine asymmetrisch-monomodale Schwingung mit fallender Amplitudenhöhe übergegangen.

Weiteren 
A
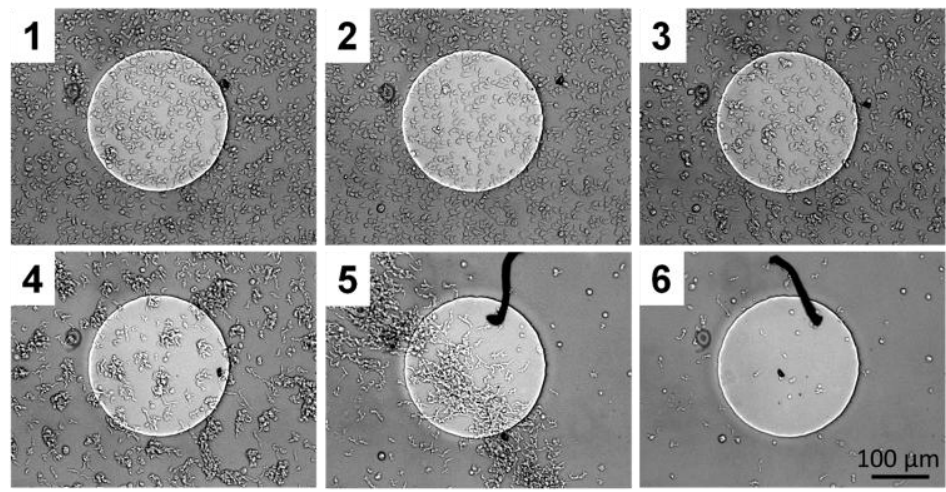

B
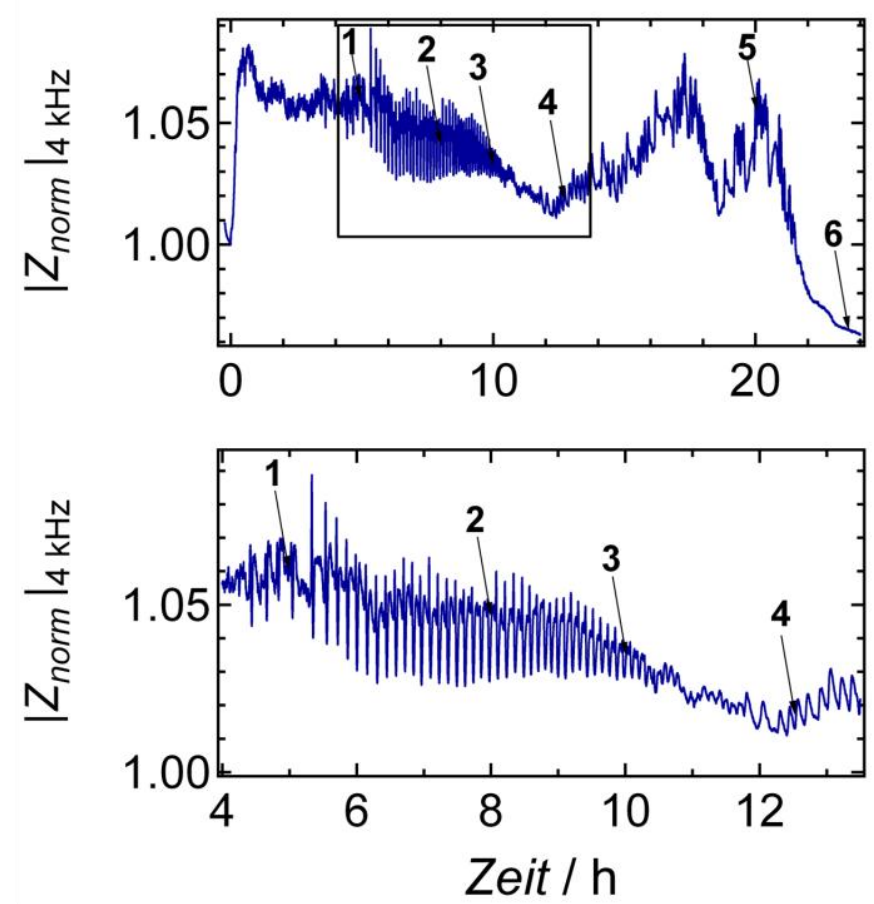

Abbildung 2.25: A) Zeitreihe von Mikroskopieaufnahmen (BF) von Dictyostelium discoideum Zellen $\left(7500\right.$ Zellen/ $\left.\mathrm{mm}^{2}\right)$ in S-Puffer in einer ECIS-Messkammer mit einer kreisförmigen Goldelektrode $(\varnothing=\mathbf{2 5 0} \mathbf{\mu m})$ in der Mitte der Bilder. B) Normierter Impedanzverlauf bei $4 \mathrm{kHz}\left(\left|Z_{\text {norm }}\right| 4 \mathrm{kHz}\right)$ zu der zu (A) korrespondierenden ECIS-Messung mit der Zellzugabe zum Zeitpunkt $t=0$. Die Pfeile markieren die Zeitpunkte, an denen jeweils ein Mikroskopiebild aufgenommen wurde. Im unteren Graph ist der Zeitabschnitt des oszillierenden Impedanzsignals (schwarzer Kasten) vergrößert dargestellt. ${ }^{15}$

Verlauf akkumulieren die Zellgruppen und bewirken die Ausbildung einer zweiten, monomodalen, harmonischen Oszillation (Zeitpunkt 4). Danach geht die Oszillation in eine starke, ungeordnete Fluktuation des Impedanzsignals über. Die Zellen migrieren in Richtung des Aggregationszentrums, das außerhalb des Bildausschnittes rechts unten liegt. Die Bildung von Bahnen an multizellulären

\footnotetext{
${ }^{15}$ In Anlehnung an:

Schäfer, E. et al., Shape Oscillations of Dictyostelium discoideum Cells on Ultramicroelectrodes Monitored by Impedance Analysis. Small, 2011, (7), 723-726.
} 
Kopf-an-Schwanz-Zellverbänden auf der Elektrodenfläche, wie in Aufnahme 5 gezeigt, erzeugt hohe Impedanzwerte in der ECIS-Messung. Gegen Ende der Messung sind die Zellverbände von der Elektrodenfläche migriert und es bleiben nur ein paar runde Zellen zurück, die in der Impedanzmessung ein kaum noch fluktuierendes Impedanzsignal erzeugen (Zeitpunkt 6).

Für die detaillierte Untersuchung, welche der Veränderungen der Zellen auf der Elektrode den oszillierenden Impedanzverlauf verursachen, wird die in Abbildung 2.26 gezeigte ECIS-Messung exemplarisch verwendet. Der Langzeittrend des Impedanzsignals wird durch Bildung des gleitenden Mittelwerts von 800 Punkten entfernt $\left(\left|Z_{\text {detrend }}\right|\right)$.

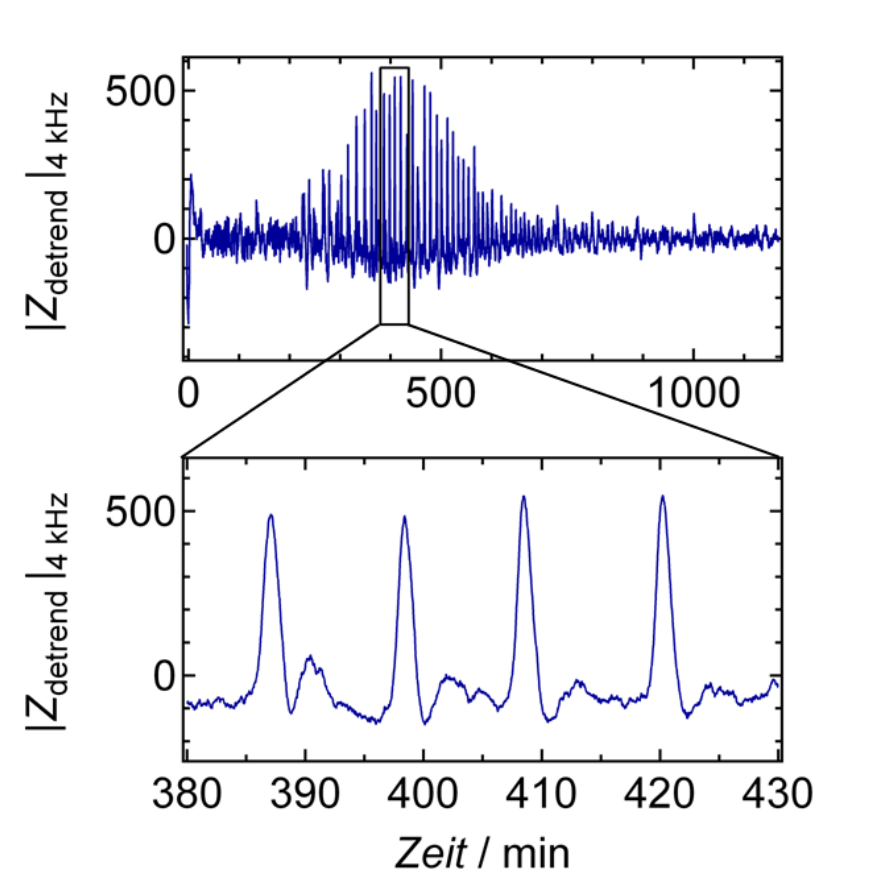

Abbildung 2.26: Vom Langzeittrend bereinigtes Impedanzsignal einer ECIS-Messung von Dictyostelium discoideum Zellen $\left(3750\right.$ Zellen $\left./ \mathrm{mm}^{2}\right)$ bei $4 \mathrm{kHz}\left(\left|Z_{\text {detrend }}\right| \mathbf{k H z}\right)$. Die Zellzugabe erfolgte bei $\boldsymbol{t}=\mathbf{0}$. Der in dem schwarzen Kasten markierte Bereich ist vergrößert in der unteren Auftragung dargestellt. ${ }^{16}$

\subsubsection{Analyse der Zellzahl und der Elektrodenbelegung}

Das detektierte Impedanzsignal der ECIS-Messung ist vom Belegungsgrad der Elektrodenfläche und somit von der Anzahl an Zellen auf der Elektrode abhängig. [92] In Kapitel 2.3.3.2 ist gezeigt, dass eine Erhöhung der von Amöben belegten Elektrodenfläche zu einem größeren Impedanzwert führt. Die zeitlich mit dem oszillierenden Impedanzbereich der ECIS-Messung korrespondierenden

\footnotetext{
${ }^{16}$ In Anlehnung an:

Schäfer, E. et al. Chemotaxis of Dictyostelium discoideum: Collective Oscillation of Cellular Contacts. PLos One, 2013, (1), e54172.
} 
Mikroskopieaufnahmen werden daher auf die Anzahl der Zellen beziehungsweise auf die von Zellen belegte Elektrodenfläche analysiert.

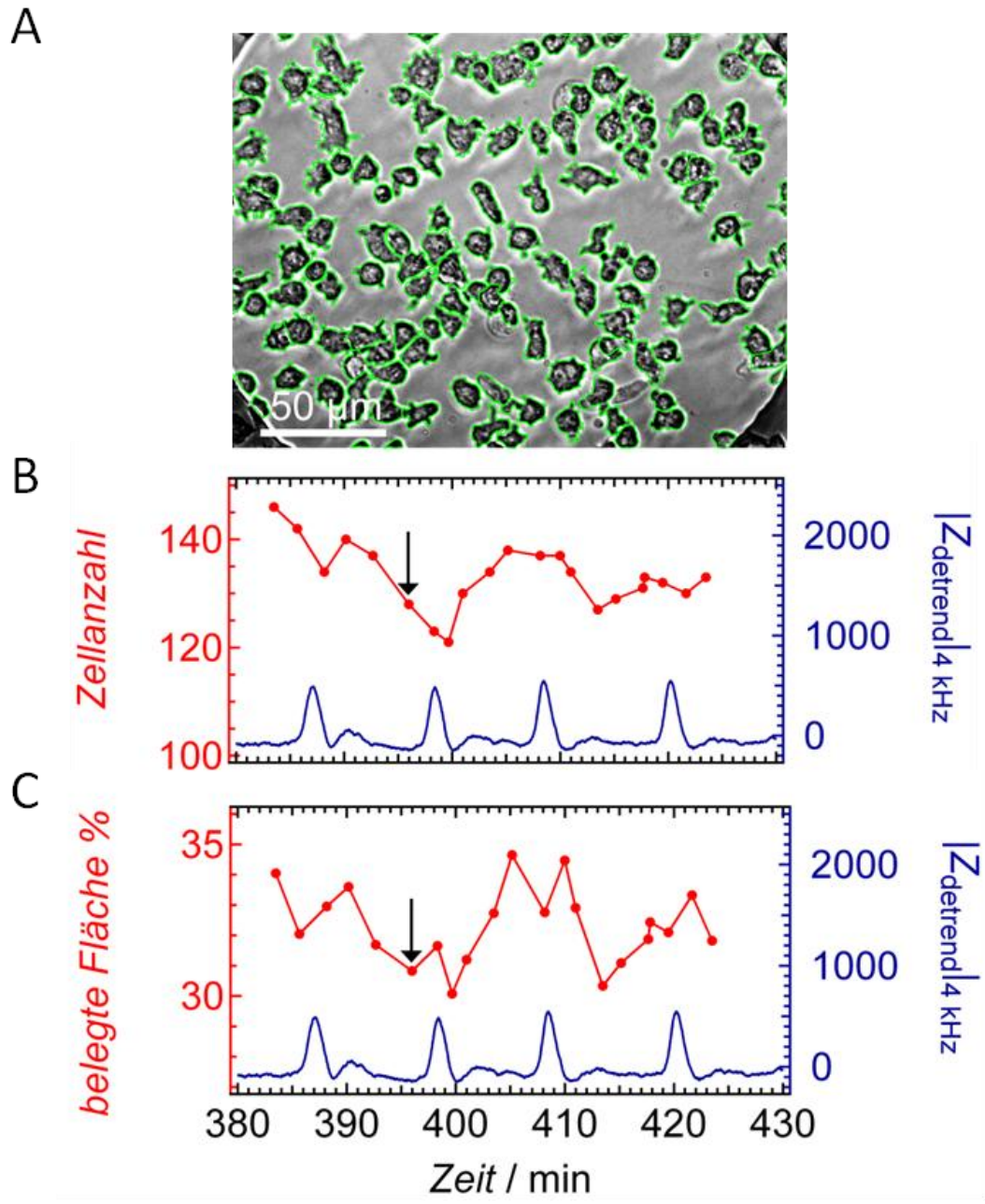

Abbildung 2.27: A) Beispiel für eine Mikroskopieaufnahme von Zellen auf einer Elektrode $(\varnothing=\mathbf{2 5 0} \mu \mathrm{m})$ deren Konturen nachträglich in grüner Farbe markiert wurden. B, C) Auftragung der zeitabhängigen Veränderung der Anzahl an Dictyostelium discoideum Zellen (B) beziehungsweise der von Zellen belegten Fläche in Prozent (C) auf der Elektrode (rote Linien). Beide Abbildungen zeigen zusätzlich den Impedanzverlauf $\left(\left|Z_{\text {detrend }}\right|_{4 \mathrm{kHz}}\right)$ des entsprechenden Zeitabschnittes (blaue Linie). Der Zeitpunkt der Mikroskopieaufnahme ist im Graph mit einem Pfeil markiert. ${ }^{17}$

In Abbildung 2.27 A ist ein Beispiel für eine Mikroskopieaufnahme gezeigt, bei der die Konturen aller auf dem Elektrodenausschnitt vorhandenen Zellen mit Hilfe eines Graphiktabletts manuell nachgezeichnet wurden. Per Computeranalyse werden von diesen Bildern die Zellzahl und der Belegungsgrad bestimmt und zusammen mit dem korrespondierenden ECIS-Impedanzsignal aufgetragen. Die Bestimmung der Anzahl an Zellen ergibt eine Fluktuation zwischen 120 und

\footnotetext{
${ }^{17}$ In Anlehnung an:

Schäfer, E. et al. Chemotaxis of Dictyostelium discoideum: Collective Oscillation of Cellular Contacts. PLos One, 2013,

(1), e54172.
} 
140 Zellen auf der Elektrode. Diese Schwankungen korrelieren jedoch nicht mit dem oszillierenden Verlauf der Impedanz. Der Belegungsgrad, der 30-35 \% beträgt, zeigt die erwartete Korrelation mit der Anzahl der Zellen auf der Elektrode und somit ebenfalls keine Korrelation mit der Oszillation des Impedanzsignals.

Die Oszillationen des Impedanzsignals werden somit nicht von einer periodischen Veränderung der Zellzahl beziehungsweise von zyklischen Änderungen der Belegung der Elektrodenfläche verursacht.

\subsubsection{Analyse der Zellform}

Das Impedanzsignal ist die Summe der Widerstände, die von den Dictyostelium discoideum Zellen auf der Elektrode verursacht werden. Daher muss das periodische Signal von einer kollektiv in den Zellen auftretenden simultanen Veränderung bewirkt werden. Aus der Literatur ist bekannt, dass es während der Chemotaxis bei Dictyostelium discoideum Zellen zu periodischen Veränderungen der Zellform und der Zellgröße kommt. [54, 68] Daher werden die auf den Mikroskopieaufnahmen abgebildeten Zellen auf zeitlich regelmäßige Veränderungen des durchschnittlichen Umfangs $\langle U\rangle$ und der durchschnittlichen Fläche $\langle A\rangle$ einer Zelle hin untersucht. Zellen, die sich nicht vollständig auf der Elektrode befinden oder deren Kontur nicht eindeutig erkennbar ist, werden nicht berücksichtigt (siehe Abbildung 2.28 A). Abbildung 2.28 B und $\mathrm{C}$ zeigen den Kurvenverlauf für den aus den Mikroskopieaufnahmen bestimmten durchschnittlichen Umfang beziehungsweise durchschnittliche Fläche, sowie den zeitlich korrespondierenden Abschnitt des Impedanzsignals. Die Auftragung von $\langle A\rangle$ zeigt keinen eindeutigen periodischen Verlauf und somit keine Korrelation zu dem oszillierenden Verlauf der Impedanz. Der Kurvenverlauf von $\langle U\rangle$ zeigt stellenweise eine geringe Korrelation mit dem oszillierenden Impedanzverlauf. Jeweils kurz nach einem lokalen Maximum des Impedanzsignals ist ein lokales Minimum im Kurvenverlauf von $\langle U\rangle$ zu erkennen.

Diese geringe aber erkennbare Korrelation der Kurvenverläufe der Impedanz mit $\langle U\rangle$ wird durch die Berechnung der durchschnittlichen Zirkularität einer Zelle $\langle C\rangle$ deutlicher

$$
\langle C\rangle=\frac{1}{n} \sum_{i=1}^{n} \frac{4 \pi A_{i}}{U_{i}^{2}} .
$$




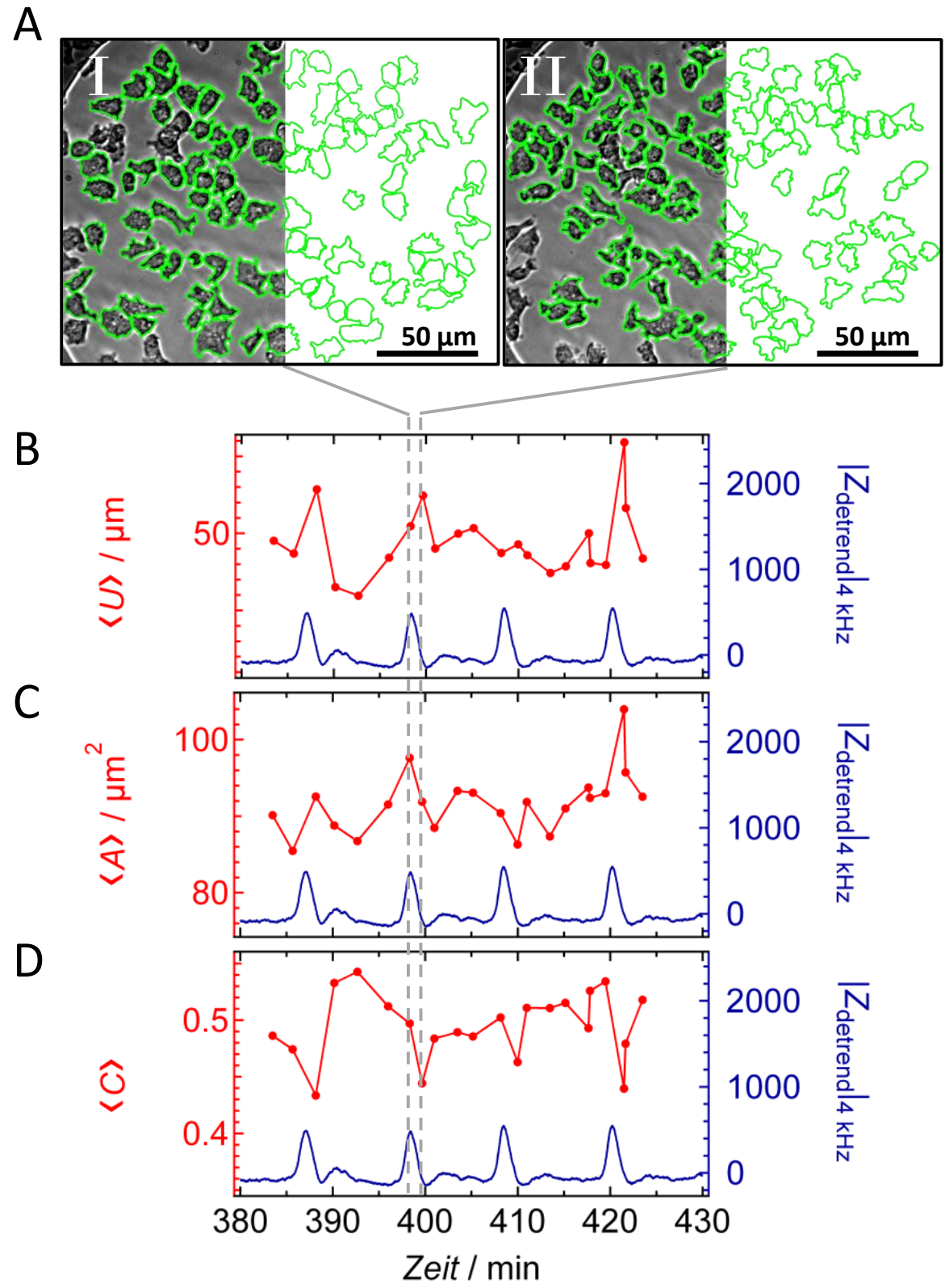

Abbildung 2.28: A) Beispielbilder von den in grüner Farbe nachgezeichneten Konturen der Zellen auf der Elektrode bei $t_{1}=398.3 \mathrm{~min}$ und $t_{\| 1}=399.7 \mathrm{~min}$. Es sind nur jene Zellen von einem grünen Rahmen umgeben, die sich vollständig auf der Elektrode befinden und deren Zellform eindeutig erkennbar ist (linken Hälfte der Bilder: original BF-Aufnahme im Hintergrund). B, C) Die Graphen zeigen den aus den manuell, umrandeten BF-Aufnahmen per Computeranalyse bestimmten durchschnittlichen Umfang $\langle U\rangle$ (B) und die durchschnittliche Fläche $\langle A\rangle(C)$ der Zellen (rote Linien). D) Aus dem Umfang und der Fläche der Zellen berechnete durchschnittliche Zirkularität einer Zelle $\langle C\rangle$ (rote Linien). Die markierten Zeitpunkte (grauen Linien) entsprechen den Bildern in (A). B) C) und D) zeigen zusätzlich das entsprechenden Impedanzsignal $\left(\left|Z_{\text {detrend }}\right| 4 \mathrm{kHz}\right)$ der korrespondierenden ECIS-Messung (blaue Linie). ${ }^{18}$

\footnotetext{
18 In Anlehnung an:

Schäfer, E. et al. Chemotaxis of Dictyostelium discoideum: Collective Oscillation of Cellular Contacts. PLos One, 2013, (1), e54172.
} 
$\langle C\rangle$ berechnet sich aus der Anzahl an Amöben $(n)$ und der Fläche $\left(A_{i}\right)$ mit dem dazugehörigen Umfang $\left(U_{i}\right)$ jeder einzelnen Zelle. Eine Zirkularität von $C=1$ steht dabei für eine runde Zelle, je kleiner der Wert wird, desto gestreckter ist die Zellform beziehungsweise desto mehr Pseudopodien sind ausgebildet.

Der in Abbildung 2.28 D dargestellte Verlauf von $\langle C\rangle$ zeigt einen periodischen Verlauf mit lokalen Minima im selben zeitlichen Abstand wie die lokalen Maxima des Impedanzsignals. Kurz vor einem lokalen Minimum der Zirkularität, also der besonders gestreckten Zellform, tritt jeweils ein Peakmaximum in der Impedanzkurve auf. Die periodische Veränderung der Zellform kann jedoch nicht die Erklärung für die Oszillation im Impedanzsignal sein. Hierzu müssten die Kurven zum selben Zeitpunkt die jeweiligen Extremwerte zeigen und nicht in den Bereichen ansteigender Impedanzwerte kaum Veränderungen der Zirkularitätswerte beziehungsweise während des gesamten Durchlaufens der Peaks der $\langle C\rangle$ einen stetigen Abfall des Impedanzsignals. Außerdem ist das Signal-zu-Rausch-Verhältnis des $\langle C\rangle$-Graphen zu gering um den sehr glatten Kurvenverlauf der Impedanz ausschließlich zu erklären.

\subsubsection{Analyse der Zellanordnung}

Aus Lichtstreuexperimenten von Zellsuspensionen ist bekannt, dass sich die Größe der Zellaggregate, die sich während der Chemotaxis von Dictyostelium discoideum Zellen in der Lösung bilden, im Verlauf einer Oszillation periodisch verändern. $[71,103]$ Zur Analyse, ob bei den ECIS-Messungen eine entsprechende periodische Veränderung der Zellanordnung auf der Elektrode stattfindet, werden jene Zellen auf den Mikroskopieaufnahmen gezählt, die keine gemeinsamen Zellgrenzen zu benachbarten Zellen haben. Abbildung 2.29 A zeigt hierzu beispielhaft Mikroskopieaufnahmen, in denen die isolierten Zellen in grüner Farbe und Zellen im Zellcluster in blauer Farbe markiert sind. Aus der Analyse der Anzahl isolierter Amöben auf der Elektrode als Funktion der Zeit ergibt sich der in Abbildung 2.29 B dargestellte Kurvenverlauf (rote Linie).

Der Kurvenverlauf der Anzahl an isolierten Zellen zeigt einen deutlich oszillierenden Verlauf. Es findet also ein periodisches Bilden und Zerfallen von Zellclustern statt. Der zyklische Verlauf der Anzahl an isolierten Zellen korreliert mit dem entsprechenden, simultan aufgenommenen Abschnitt des Impedanzsignals. Zum Zeitpunkt eines lokalen Maximums der Impedanz zeigt der Kurvenverlauf der Anzahl an isolierten Zellen ein lokales Minimum. Die Anzahl an Zellen, die sich in einem Cluster befinden, ist also maximal zum Zeitpunkt maximaler Impedanz. 


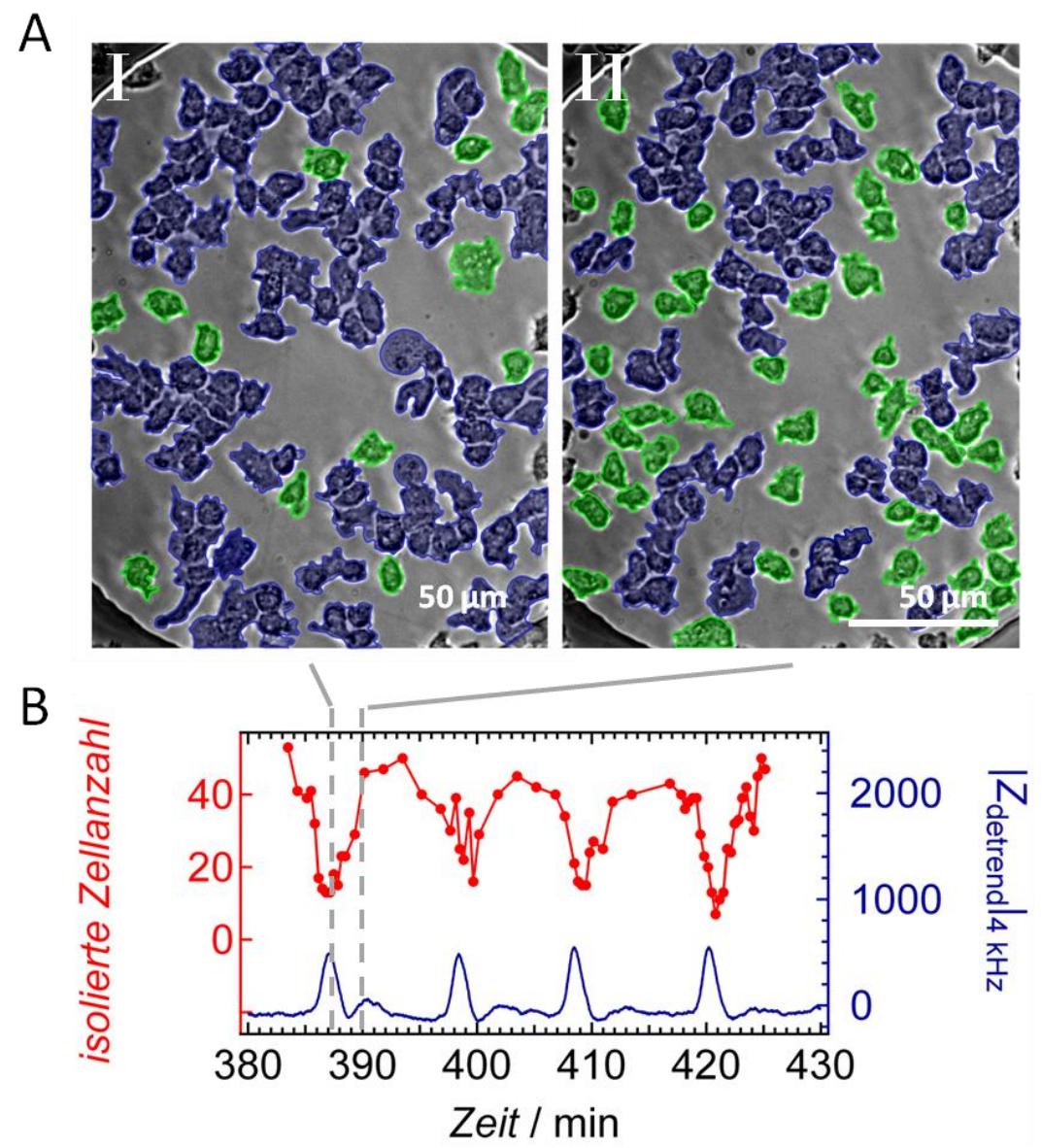

Abbildung 2.29: A) Beispielhafte Mikroskopieaufnahmen (BF) einer mit Dictyostelium discoideum Zellen belegten Elektrode $(\varnothing=250 \mu \mathrm{m})$ bei $t_{1}=387.2 \mathrm{~min}$ und $t_{11}=390.2 \mathrm{~min}$ nach Zellzugabe $\left(3750\right.$ Zellen $\left./ \mathrm{mm}^{2}\right)$. In grüner Farbe sind die Zellen markiert, die isoliert von den Nachbarzellen sind, hingegen befinden sich die blau eingefärbten Zellen in einem Zellverband. B) Zeitabhängige Veränderung der Anzahl an isolierten Zellen auf den Mikroskopieaufnahmen (rote Line) und der entsprechende Impedanzverlauf $\left(\left|Z_{\text {detrend }}\right| 4 \mathrm{kHz}\right)$ des Zeitabschnittes (blaue Linie). ${ }^{19}$

Ein einfaches Modell für die Korrelation der Impedanzoszillation mit der periodischen Aggregation der Zellen geht von folgender Situation aus. Bei den Impedanzmessungen wird durch die dielektrische Eigenschaft der Zellmembran ein Widerstand in dem leitfähigen Puffer verursacht. Durch Veränderungen der räumlichen Anordnung der Zellen auf der Elektrode verändert sich auch die Größe der leitenden Bereiche zwischen den Zellen. Bei einem konstanten Belegungsgrad der Elektrode wird durch die gleichmäßige Verteilung der isolierten Zellen ein homogenes Netzwerk leitender Bereiche ausgebildet. Das Clustern der Zellen führt hingegen zu größeren, isolierenden Flächen und gleichzeitig zu ausgedehnten, stromleitenden Bereichen. Da die Impedanz hauptsächlich von dem lonenstrom entlang der basalen Zellmembran erzeugt wird, bewirkt der Zustand mit mehr

\footnotetext{
${ }^{19}$ In Anlehnung an:

Schäfer, E. et al. Chemotaxis of Dictyostelium discoideum: Collective Oscillation of Cellular Contacts. PLos One, 2013, (1), e54172.
} 
isolierten Zellen eine geringere Impedanz als die partiell aggregierte Anordnung von Zellen auf der Elektrodenoberfläche.

Für ein eindimensionales Modell mit einfachen ohmschen Widerständen bei Gleichstrom kann die Vergrößerung des Widerstandes durch das Aggregierten der Zellen berechnet werden. Hierzu wird von den zwei in Abbildung 2.30 gezeigten Verteilungen der Zellen auf der Elektrode ausgegangen, bei denen der Belegungsgrad konstant ist. Die Anordnung der Widerstände wird von einer Verteilung mit mehreren, kleineren leitenden Zwischenräumen $(A)$ in eine Zellverteilung, mit wenigen aber dafür größeren, isolierenden Flächen in Kombination mit ebenfalls größeren, leitenden Bereichen verändert (B). Durch Summieren der eingezeichneten parallelen und in Reihe angeordneten Widerstände mit Hilfe der Kirchhoffschen-Regeln ergibt sich ein Verhältnis von dem verteilten Zustand zu dem mehr geclusterten Zustand von $\frac{Z_{\mathrm{A}}}{Z_{\mathrm{B}}}=\frac{31}{34}$.

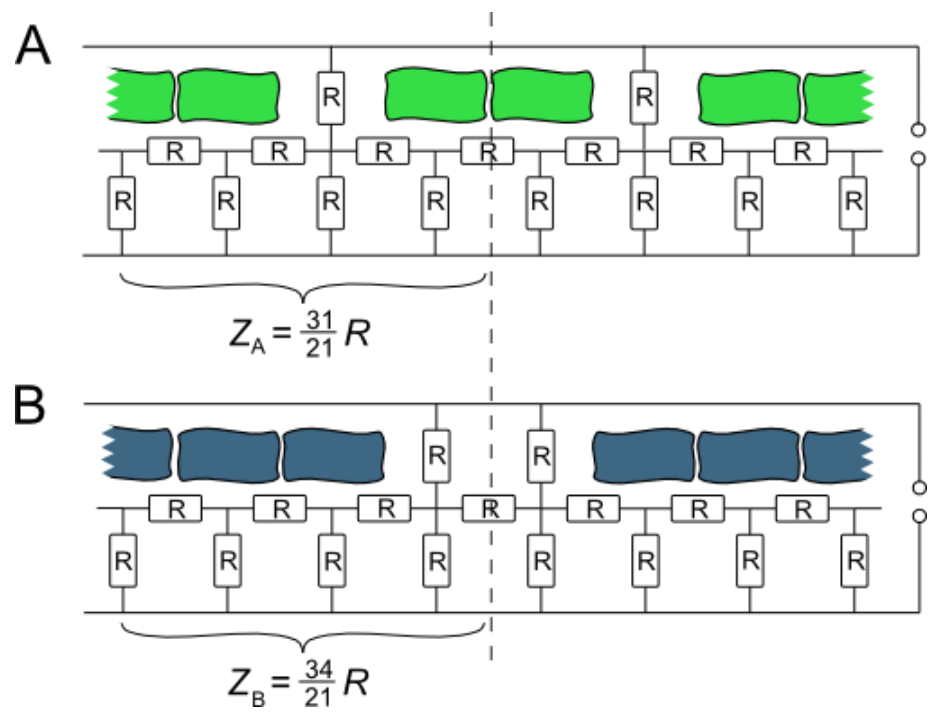

Abbildung 2.30: Schematische eindimensionale Darstellung der Beeinflussung des Widerstandes durch eine unterschiedliche Anordnung von Zellen auf der Elektrode. In (A) sind die Zellen in kleineren Clustern angeordnet als in (B). Der Gesamtwiderstand für jeweils eine sich wiederholende Anordnung von Zellen ist in Abhängigkeit des Widerstands $R$ für beide dargestellten Einteilungen berechnet. ${ }^{20}$

Das mit Hilfe von Mikroskopieaufnahmen gezeigte Aggregationsverhalten der Zellen führt somit zu einer Erhöhung des Widerstandes durch Veränderung der Zellanordnung auf der Elektrode von einem stärker isolierten Zustand in einen partiell aggregierten Zustand. Die periodische Veränderung der Verteilung der Zellen auf der Elektrode erklärt somit den oszillierenden Verlauf des

\footnotetext{
${ }^{20}$ In Anlehnung an:

Schäfer, E. et al. Chemotaxis of Dictyostelium discoideum: Collective Oscillation of Cellular Contacts. PLos One, 2013, (1), e54172.
} 
Impedanzsignals bei den ECIS-Messungen. Ob diese jedoch die alleinige Erklärung der doch erheblichen Veränderungen des Widerstands während der Chemotaxis ist, sollen die nachfolgenden Experimente zu Veränderungen des Zell-Substrat-Abstands klären.

\subsubsection{Untersuchungen des Zell-Substrat-Abstands}

Einen bedeutenden Einfluss auf den von der ECIS detektierten Widerstand in dem betrachteten Frequenzbereich hat der Abstand zwischen den Zellen und der Goldelektrode. Der gemessene Widerstand von Zellen ist umso größer, je näher sich die Zellen an der Elektrodenoberfläche befinden. [92]

Zur Untersuchung, ob es zu zyklischen Veränderungen des Zell-Substrat-Abstands während der Chemotaxis kommt, werden hungernde Dictyostelium discoideum Zellen im sozialen Zyklus mit zwei weiteren Methoden untersucht. Sowohl Messungen mit der D-QCM wie auch zeitabhängige TIRFMVideos reagieren sensitiv auf Veränderungen des Abstands zwischen den Zellen und des Substrates. $[97,107]$ Es ist jedoch nicht möglich, diese Methoden parallel zu den ECIS-Messungen auf der Elektrode durchzuführen. Für die D-QCM-Messungen ist ein unterschiedlicher Aufbau der Messkammern bezüglich der Elektroden nötig und die TIRFM-Aufnahmen können aufgrund der Löschung der Fluoreszenz auf Goldoberflächen nicht auf der Goldelektrode simultan zu den ECISMessungen durchgeführt werden. [108-109]

\subsubsection{Quarzkristall-Mikrowaage mit Dissipationsanalyse}

Durch die periodische Anregung und das freie Ausschwingen des Schwingquarzes bei D-QCMMessungen können die Resonanzfrequenz des Quarzes und das Dissipationsverhalten gleichzeitig bestimmt werden. Die Belegung des Quarzes mit einer Fremdmasse verändert beide Messgrößen und zwar abhängig von der Masse, der Elektrodenbelegung, der Viskoelastizität, der Schichtdicke und dem Abstand der Fremdmasse zur Quarzoberfläche. [97]

In Abbildung 2.31 ist eine D-QCM-Messung mit Dictyostelium discoideum Zellen im nährstofffreien S-Puffer gezeigt. Beim Zeitpunkt $t=0$ werden die Zellen zugeben, wodurch es zu einem Frequenzabfall und einem Dissipationsanstieg kommt. Nach 3 Stunden sind in beiden Messsignalen erste periodische Schwingungen erkennbar. Die Periodendauer beträgt zirka 9 Minuten. Die Oszillationen zeigen erst einen steigenden, dann einen abnehmenden Verlauf der Amplitudenhöhe, ähnlich zu den Impedanzverläufen der ECIS-Messungen. Die Oszillation in den Messsignalen ist wie 
bei den ECIS-Messungen auf das kollektive Verhalten von Dictyostelium discoideum Zellen während der Chemotaxis zurück zu führen.

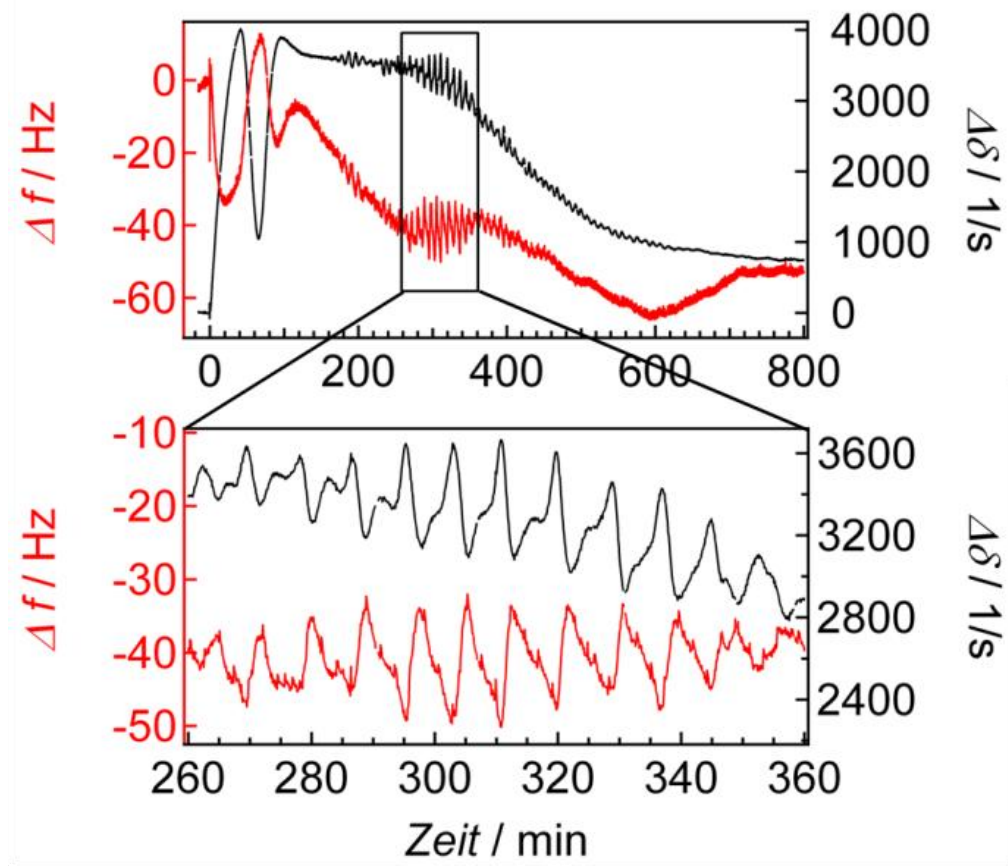

Abbildung 2.31: Veränderungen der Resonanzfrequenz ( $\Delta f$ ) (rote Linie) und der Dissipation $(\Delta \delta)$ (schwarze Linie) eines oszillierenden Quarzkristalls während einer D-QCM-Messung mit Dictyostelium discoideum Zellen (10000 Zellen/ $\left./ \mathrm{mm}^{2}\right)$. Die Zellzugabe erfolgte bei $\boldsymbol{t}=\mathbf{0}$. Der durch den schwarzen Kasten markierte Bereich ist im unteren Graphen vergrößert dargestellt. ${ }^{21}$

Die lokalen Extremwerte der Dissipation und der Frequenz treten zum selben Zeitpunkt der Messung auf, jedoch verlaufen die Kurven gegenläufig. Bei einem lokalen Maximum der Frequenzkurve zeigt die Dissipationskurve ein lokales Minimum und umgekehrt. Modellberechnungen von einem 3-Schichten-Modell zeigen, dass eine Abnahme des Zell-Substrat-Abstands zu einem niedrigeren Wert der Resonanzfrequenz und zu einem größeren Dissipationswert führt (Kapitel 2.3.4). [97] Die Modellberechnungen zeigen außerdem, dass Veränderungen im Speicher- oder Verlustmodul der adsorbierten Masse auf dem Quarz zu anderen Veränderungen im Schwingungsverhalten des Quarzes führen. Eine Veränderung des Verlustmoduls zeigt zwar einen ähnlichen Trend des Frequenz- und Dissipationskurvenverlaufs, jedoch sind solche dramatischen Veränderungen des Verlustmoduls äußerst unwahrscheinlich, sodass davon ausgegangen werden kann, dass die detektierten Veränderungen der Resonanzfrequenz und der Dissipation durch Variationen des ZellSubstrat-Abstands hervorgerufen werden.

\footnotetext{
${ }^{21}$ In Anlehnung an:

Schäfer, E. et al. Chemotaxis of Dictyostelium discoideum: Collective Oscillation of Cellular Contacts. PLos One, 2013, (1), e54172.
} 
Die D-QCM-Messungen zeigen also, dass es höchstwahrscheinlich zu periodischen Veränderungen des Zell-Substrat-Abstands kommt. Im Verlaufe der Aggregationsphase der hungernden Dictyostelium discoideum Zellen verringert und vergrößert sich der Zell-Substrat-Abstand einmal innerhalb eines Zyklus der Chemotaxis.

\subsubsection{Interne Totalreflexionsfluoreszenzmikroskopie}

Die TIRF-Mikroskopie ist eine besondere Form der Fluoreszenzmikroskopie, bei der selektiv der Bereich nahe an der Glasoberfläche des Probenträgers abgebildet wird. Dieses ist durch Ausbildung eines evaneszenten Feldes des unter Totalreflexion eingestrahlten Lichts möglich, wodurch nur die Fluorophore in der Probe angeregt werden, die sich maximal in einem Abstand von zirka $100 \mathrm{~nm}$ zum Glasträger befinden. Die Hintergrundfluoreszenz ist stark minimiert, da die Anregung der Fluorophore mit dem Abstand zum Probenträger exponentiell abfällt. [107] Mit Hilfe der TIRFM ist es dementsprechend möglich, die Kontaktregionen zwischen Zellen und Glassubstrat genauer zu untersuchen. [107]

Für die TIRFM von Dictyostelium discoideum Zellen werden Amöben verwendet, deren Cytosol GFP-markiert ist. In Abbildung 2.32 A und B ist jeweils eine Zeitreihe von hellfeldmikroskopischen beziehungsweise fluoreszenzmikroskopischen Aufnahmen von Amöben gezeigt, die seit zirka 5 Stunden ohne Nahrung sind. Der zeitliche Abstand zwischen Bild I und II beträgt 40 Sekunden, der Abstand zu Bild III weitere 80 Sekunden. Der Versatz zwischen den untereinander abgebildeten Hellfeld- und Fluoreszenzaufnahmen beläuft sich auf 10 Sekunden. Bei der ersten Aufnahme der Fluoreszenzreihe (I) sind nur kleine fluoreszierende Flächen zu erkennen. Im Laufe der nächsten zwei Bilder (II und III) vergrößert sich der fluoreszierende Bereich stetig und einzelne Pseudopodien der Zellen sind zu erkennen. Dies ist besonders deutlich in Abbildung $2.32 \mathrm{~B}$ bei der Zelle zu beobachten, die mit dem Pfeil markiert ist. Der Anstieg der fluoreszierenden Fläche ist mit einer höheren Konzentration an Fluorophoren in einem für die TIRFM relevanten Abstand zum Glassubstrat von unter $100 \mathrm{~nm}$ zu interpretieren und daher mit einer Vergrößerung der Kontaktfläche der Zellen auf der Oberfläche identisch. 

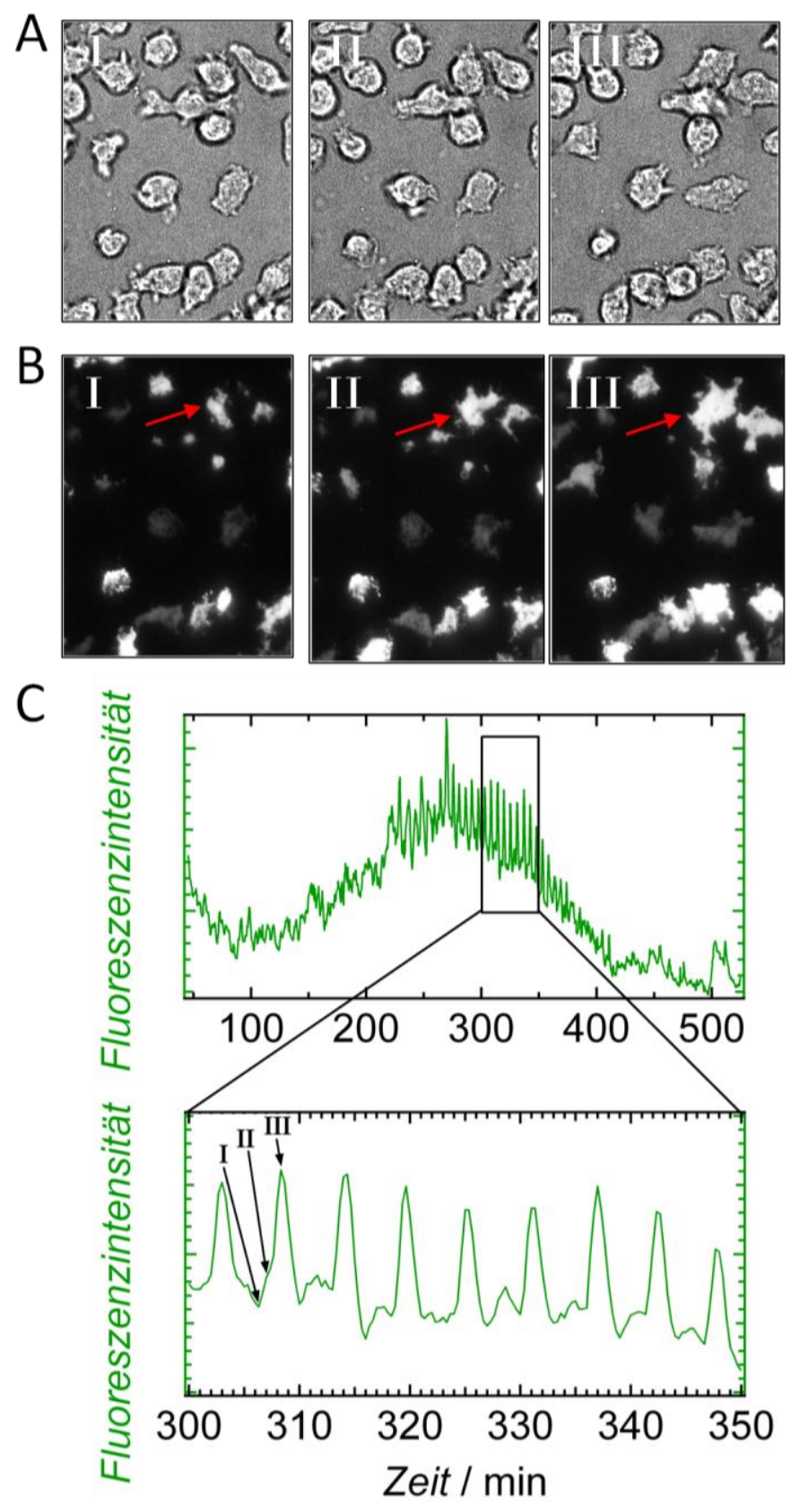

Abbildung 2.32: A) BF- und B) TIRF-Mikroskopieaufnahmen von Dictyostelium discoideum Zellen, deren Cytosol GFP-markiert ist auf einer Glasoberfläche. Die TIRFM-Aufnahmen sind jeweils 10 Sekunden nach den darüber abgebildeten BF-Aufnahmen aufgenommen. C) Zeitliche Veränderung der gesamten Fluoreszenzintensität (integriert über das gesamte Bild) der TIRFAufnahmen. Der mit dem schwarzen Kasten markierte Bereich ist im unteren Graphen vergrößert dargestellt, in dem zusätzlich die Zeitpunkte der TIRF-Mikroskopieaufnahmen aus (B) mit Pfeilen dargestellt sind. ${ }^{22,23}$

\footnotetext{
22 Messungen durchgeführt in Kooperation mit Dr. M. Tarantola, Arbeitsgruppe Prof. Dr. E. Bodenschatz, Max Planck Institut für Dynamik und Selbstorganisation, Göttingen.

${ }^{23}$ In Anlehnung an:

Schäfer, E. et al. Chemotaxis of Dictyostelium discoideum: Collective Oscillation of Cellular Contacts. PLos One, 2013,

(1), e54172.
} 
Bei den hellfeldmikroskopischen Aufnahmen ist im Verlauf der Zeitreihe ein geringer Verlust des Zellkontrastes auf den Bildern zu beobachten. Dies ist ebenfalls zurückzuführen auf eine Veränderung der Position der Zelle aus der Fokusebene heraus.

Durch zeitliche Auftragung der Fluoreszenzintensität der TIRFM-Aufnahmen ergibt sich der in Abbildung 2.32 C dargestellte Graph. Die Fluktuation des Intensitätsverlaufs geht bei zirka 220 Minuten in ein periodisches Signal über. Die Periodendauer dieser Oszillation beträgt zirka 6 Minuten. Der Kurvenverlauf zeigt einen asymmetrischen Schwingungsverlauf, welcher starke Ähnlichkeit zum oszillierenden Impedanzsignal hat.

Anhand der Bestimmungen der durchschnittlichen Fläche eines Dictyostelium discoideum während der Chemotaxis mittels Hellfeldaufnahmen ist bekannt, dass sich die Fläche einer Zelle im Verlauf einer Periode nicht zyklisch verändert (Kapitel 2.7.1.2). Dies bedeutet, dass die während der TIRFMMessungen detektierte Zunahme der fluoreszierenden Fläche der Amöben, aus einer Verlagerung des Zellkörpers zum Substrat hin und nicht aus einer generellen Vergrößerung der Zellausdehnung resultiert (Abbildung 2.33).

Veränderungen des minimalen Abstands zwischen Zellmembran und Substrat während der Oszillation können anhand des zeitlichen Verlaufs der maximalen Fluoreszenzintensität einer Zelle analysiert werden. Dabei zeigt sich, dass die maximale Fluoreszenzintensität einer Zelle während eines Zyklus kaum zunimmt zum Zeitpunkt der lokalen Maxima in Abbildung 2.32 C. Der minimale Abstand der Zellen zum Substrat erhöht sich demzufolge nur geringfügig. Die verschiedenen maximalen Fluoreszenzintensitäten zwischen den abgebildeten Zellen einer Aufnahme werden maßgeblich durch unterschiedlich starke Expression des GFPs in den einzelnen Zellen bestimmt und nicht durch unterschiedliche, minimale Abstände zum Substrat.

Die in der D-QCM vorgefundene periodische Veränderung des Zell-Substrat-Abstands während der Chemotaxis der Dictyostelium discoideum Zellen kann also auch mit der TIRF-Mikroskopie bestimmt werden. Des Weiteren lässt sich anhand der Mikroskopieaufnahmen feststellen, dass es sich hauptsächlich um eine Umverteilung des Zellkörpers zum Substrat hin handelt und nur zu einem geringen Teil um eine Verringerung des minimalen Zell-Substrat-Abstands. 


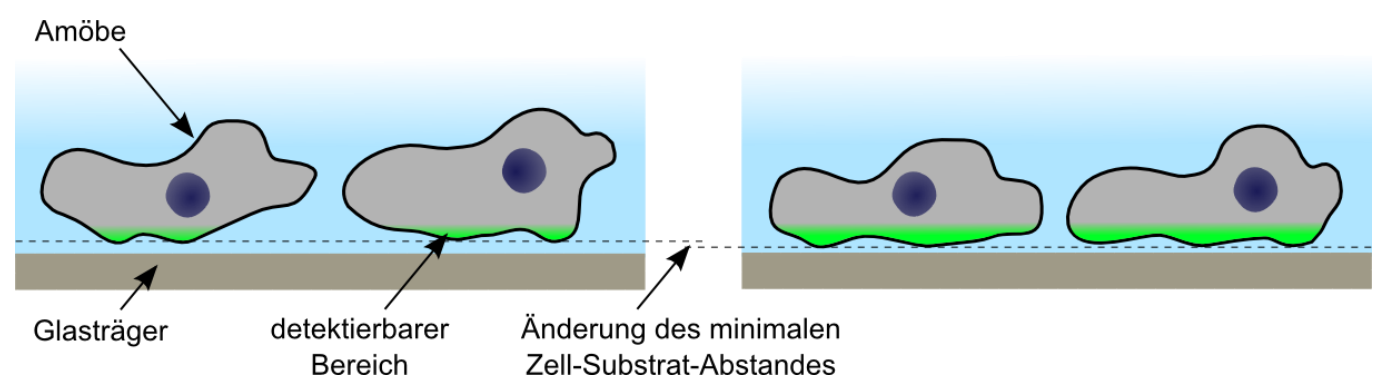

Abbildung 2.33: Schematische Darstellung des detektierbaren Fluoreszenzbereichs (grüne Fläche) während TIRFM-Messungen von Dictyostelium discoideum Zellen, deren Cytosol GFP-markiert ist. Zum Zeitpunkt der minimalen Fluoreszenzintensität (Abbildung $2.32 \mathrm{BI}$ ) ist nur ein geringer Bereich des Cytoplasmas in der von der TIRFM detektierbaren Zone (linke Seite). Während der maximalen Fluoreszenzintensität (Abbildung 2.32 B III) findet eine Verlagerung des Zellkörpers in Richtung Substrat und folglich in den detektierbaren Bereich hinein statt (rechte Seite). Der minimale Zell-Substrat-Abstand verringert sich hierbei nur geringfügig (gestrichelte Linie). ${ }^{24}$

\subsubsection{Zeitliche Korrelation zu den ECIS-Messungen}

Die beiden beschriebenen Methoden, mit denen die periodischen Veränderungen des Zell-SubstratAbstands während der Chemotaxis detektierbar sind, können nicht mit ECIS-Messungen kombiniert werden. Um dennoch eine zeitliche Korrelation der detektierten Veränderungen der Größe der Zellkontaktfläche auf der Oberfläche bei den TIRFM-Messung mit dem Impedanzsignal der ECIS zu erzielen, werden die während den Messungen aufgenommenen hellfeldmikroskopischen Aufnahmen verwendet. Dazu werden die zeitabhängigen, hellfeldmikroskopischen Bildreihen, die während den separaten ECIS- und TIRFM-Experimenten aufgenommen wurden, die eine auf der Goldelektrode simultan zur Impedanzmessung und die andere auf dem Glas quasi-simultan während der Fluoreszenzmessung, getrennt voneinander aber identisch bearbeitet. Von jeweils zwei Hellfeldaufnahmen einer Bildreihe mit einem zeitlichen Versatz von einer Minute wird durch Subtraktion ein überlagertes Bild erstellt. Durch Bestimmung der Helligkeit dieser überlagerten Bilder werden die in Abbildung 2.34 rot dargestellten Intensitätsverläufe der Helligkeit für die subtrahierten Hellfeldaufnahmen während der ECIS-Messung (A) und TIRF-Messung (B) erhalten.

Die Intensitätsverläufe der Helligkeit von den überlagerten Bildern zeigen in den Bereichen des oszillierenden Impedanzsignals der ECIS-Messung beziehungsweise im Bereich der Oszillation im Verlauf der Fluoreszenzintensität der TIRFM-Messung ebenfalls eine Oszillation. Die Peaks des Intensitätsverlaufs der Helligkeit der überlagerten Bilder zeigt in beiden Fällen eine charakteristische

\footnotetext{
${ }^{24}$ In Anlehnung an:

Schäfer, E. et al. Chemotaxis of Dictyostelium discoideum: Collective Oscillation of Cellular Contacts. PLos One, 2013, (1), e54172.
} 
Doppelspitze (Pfeile in Abbildung 2.34 A und B).Die Periodendauer entspricht der jeweiligen Periodendauer der Oszillation der Impedanz- beziehungsweise der Fluoreszenzintensitätsmessung.
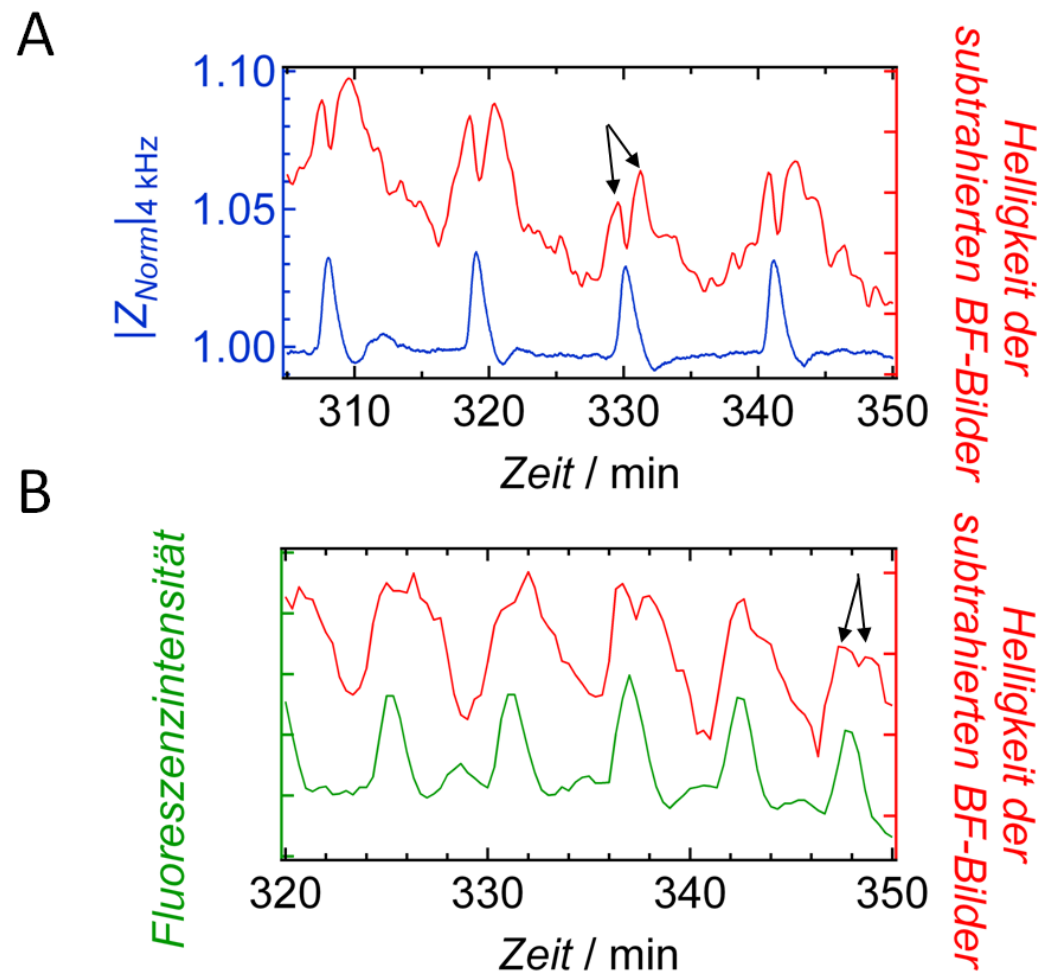

Abbildung 2.34: Oszillation des Impedanzsignals $\left(\left|Z_{\text {detrend }}\right| 4 \mathrm{kHz}\right)$ der ECIS-Messung (A: blaue Linie) beziehungsweise der Fluoreszenzintensität von TIRF-Mikroskopieaufnahmen (B: grüne Linie) mit jeweils der Helligkeitsintensität der zeitlich korrelierenden, subtrahierten Hellfeldaufnahmen der entsprechenden Messung (rote Linien). Die charakteristische Doppelspitze der Peakmaxima der Helligkeitsintensität der subtrahierten BF-Aufnahmen ist mit Pfeilen markiert. ${ }^{2526}$

Durch Vergleich der Positionen der lokalen Extremwerte des Impedanzverlaufs und des Verlaufs der Fluoreszenzintensität mit dem Signalverlauf der Intensität der Helligkeit der überlagerten Hellfeldaufnahmen ist es möglich, eine zeitliche Korrelation zwischen der ECIS- und der TIRFMOszillation zu erstellen. In beiden Fällen liegen die Spitzen der Maxima des ECIS- beziehungsweise des TIRFM-Signals im Bereich der ersten Doppelspitze der überlagerten Bilder. Dies bedeutet, dass zum Zeitpunkt der höchsten Impedanzwerte auch die größten Intensitäten bei den Fluoreszenzaufnahmen vorliegen und demzufolge der höchste Impedanzwert zeitlich mit der größten Kontaktfläche der Zellen auf der Oberfläche korreliert.

\footnotetext{
${ }^{25}$ TIRF-Messung durchgeführt in Kooperation mit Dr. M. Tarantola, Arbeitsgruppe Prof. Dr. E. Bodenschatz, Max Planck Institut für Dynamik und Selbstorganisation, Göttingen.

${ }^{26}$ In Anlehnung an:

Schäfer, E. et al. Chemotaxis of Dictyostelium discoideum: Collective Oscillation of Cellular Contacts. PLos One, 2013, (1), e54172.
} 


\subsubsection{Zusammenfassende Diskussion}

In diesem Kapitel wurde untersucht, welche (bio)physikalischen Veränderungen während der ECISMessungen mit hungernden Dictyostelium discoideum Zellen die Oszillationen im Impedanzsignal verursachen.

Die entdeckten, periodischen Veränderungen der Zellform sind nicht die Ursache für die Oszillation des Impedanzsignals der ECIS-Messung. Das zyklische Abrunden und Stecken einer Zelle während einer Periode der Chemotaxis, detektiert durch die Zirkularität einer Zelle, ist zeitlich verschoben zum oszillierenden Impedanzverlauf. Zudem ist das Fehlen einer Korrelation der Signalform zwischen der Impedanzzeitreihe und der zeitlichen Änderung der Zirkularität sowie das unterschiedliche Signal-zu-Rausch-Verhältnis der beiden Messungen zu erwähnen. Dennoch ist davon auszugehen, dass die Formveränderung auch die Impedanz beeinflusst.

Die Untersuchung der Anordnung der Zellen auf der Elektrode zeigt, dass es einen periodischen Aufund Abbau von Zellclustern während der Aggregationsphase gibt. Der Zeitpunkt stärkster Clusterbildung, also wenn sich viele Zellen in Zellverbänden befinden, korreliert mit dem Zeitpunkt der lokalen Maxima des Impedanzverlaufs der ECIS-Messung. Modellberechnungen zeigen, dass durch die Bildung von großen, isolierenden Flächen auf der Elektrode, ein größerer Widerstand erzeugt wird, als wenn bei gleichem Belegungsgrad mehrere kleine, isolierende Flächen auf der Elektrode existieren.

Für die Analyse, ob es während der Chemotaxis der Dictyostelium discoideum Zellen zu zyklischen Veränderungen des Zell-Substrat-Abstands kommt, wurden D-QCM-Experimente und zeitabhängige TIRFM-Messungen durchgeführt. Die detektierten Signalverläufe der D-QCM-Messungen einige Stunden nach dem Nahrungsentzug der Zellen zeigen Oszillationen in der Resonanzfrequenz und dem Dissipationsfaktor. Die gemessenen, gegenläufigen Oszillationen der Frequenz- und der Dissipationsänderung können aufgrund von Modellberechnungen auf zyklische Veränderung des Zell-Substrat-Abstands und nicht auf Veränderungen der Viskoelastizität der Zellen zurückgeführt werden.

Die Veränderung der zeitabhängigen Fluoreszenzintensität der TIRFM-Videos zeigt ebenfalls eine Oszillation. Mit Hilfe der Fluoreszenzaufnahmen lässt sich zusätzlich bestimmen, dass die Zunahme der detektierten, gesamten Fluoreszenzintensität hauptsächlich aus einer Umverteilung des Zellkörpers zum Substrat hin resultiert und nur geringfügig aus einer Verringerung des minimalen Zell-Substrat-Abstands. 
Über die Hellfeldaufnahmen bei den ECIS- und TIRFM-Messungen kann zudem eine zeitliche Korrelation der größten Kontaktflächen der Zellen mit dem Substrat und den maximalen Impedanzwerten hergestellt werden.

Eine prozentuale Gewichtung der Oszillation des Impedanzsignals bezüglich den periodischen Veränderungen der Zellclustergröße und den Veränderungen des Zell-Substrat-Abstands, lässt sich nicht bestimmen. Die auch in Details sehr ähnliche Kurvenform der Oszillation der Fluoreszenzintensitäten mit jener des Impedanzsignals lässt jedoch vermuten, dass der Einfluss des Zell-Substrat-Abstands überwiegt. 


\subsection{Literaturverzeichnis}

1. Brefeld, O. (1869) Dictyostelium mucoroides. Ein neuer Organismus aus der Verwandtschaft der Myxomyceten, Abhandlungen der Senckenbergischen Naturforschenden Gesellschaft Frankfurt 7, 85-107.

2. Baldauf, S. L., Roger, A. J., Wenk-Siefert, I., und Doolittle, W. F. (2000) A Kingdom-Level Phylogeny of Eukaryotes Based on Combined Protein Data, Science 290, 972-977.

3. Kessin, R. H. (2001) Dictyostelium Evolution, Cell Biology, und the Development of Multicellularity, Cambride University Press 1.

4. Kessin, R. H., Gundersen, G. G., Zaydfudim, V., und Grimson, M. (1996) How cellular slime molds evade nematodes, Proc. Natl. Acad. Sci. U.S.A. 93, 4857-4861.

5. Parent, C. A. (2004) Making all the right moves: chemotaxis in neutrophils and Dictyostelium, Curr. Opin. Cell Biol. 16, 4-13.

6. Van Haastert, P. J. M., und Devreotes, P. N. (2004) Chemotaxis: signalling the way forward, Nat. Rev. Mol. Cell Biol. 5, 626-634.

7. Weijer, C. J. (2009) Collective cell migration in development, J. Cell Sci. 122, 3215-3223.

8. Parent, C. A., und Devreotes, P. N. (1996) Molecular Genetics of Signal Transduction in Dictyostelium, Annu. Rev. Biochem. 65, 411-440.

9. Swaney, K. F., Huang, C.-H., und Devreotes, P. N. (2010) Eukaryotic Chemotaxis: A Network of Signaling Pathways Controls Motility, Directional Sensing, and Polarity, Annu. Rev. Biophys 39, 265-289.

10. Manahan, C. L., Iglesias, P. A., Long, Y., und Devreotes, P. N. (2004) Chemoattractant signaling in Dictyostelium Discoideum, Annu. Rev. Cell Dev. Biol. 20, 223-253.

11. McCann, C. P., Kriebel, P. W., Parent, C. A., und Losert, W. (2010) Cell speed, persistence and information transmission during signal relay and collective migration, J. Cell Sci. 123, 17241731.

12. Titus, M. A. (2000) The Role of Unconventional Myosins in Dictyostelium Endocytosis, J. Eukaryotic Microbiol. 47, 191-196.

13. Clarke, M., Engel, U., Giorgione, J., Müller-Taubenberger, A., Prassler, J., Veltman, D., und Gerisch, G. (2010) Curvature recognition and force generation in phagocytosis, BMC Biol. 8, 154-176.

14. Williams, H. P., und Harwood, A. J. (2003) Cell polarity and Dictyostelium development, Curr. Opin. Microbiol. 6, 621-627.

15. Chisholm, R. L., und Firtel, R. A. (2004) Insights into morphogenesis from a simple developmental system, Nat. Rev. Mol. Cell Biol. 5, 531-541.

16. Eichinger, L., Pachebat, J. A., Glockner, G., Rajandream, M. A., Sucgang, R., Berriman, M., Song, J., Olsen, R., Szafranski, K., Xu, Q., Tunggal, B., Kummerfeld, S., Madera, M., Konfortov, B. A., Rivero, F., Bankier, A. T., Lehmann, R., Hamlin, N., Davies, R., Gaudet, P., Fey, P., Pilcher, K., Chen, G., Saunders, D., Sodergren, E., Davis, P., Kerhornou, A., Nie, X., Hall, N., Anjard, C., Hemphill, L., Bason, N., Farbrother, P., Desany, B., Just, E., Morio, T., Rost, R., Churcher, C., Cooper, J., Haydock, S., van Driessche, N., Cronin, A., Goodhead, I., Muzny, D., Mourier, T., Pain, A., Lu, M., Harper, D., Lindsay, R., Hauser, H., James, K., Quiles, M., Madan Babu, M., Saito, T., Buchrieser, C., Wardroper, A., Felder, M., Thangavelu, M., Johnson, D., Knights, A., Loulseged, H., Mungall, K., Oliver, K., Price, C., Quail, M. A., Urushihara, H., Hernandez, J., Rabbinowitsch, E., Steffen, D., Sanders, M., Ma, J., Kohara, Y., Sharp, S., Simmonds, M., Spiegler, S., Tivey, A., Sugano, S., White, B., Walker, D., Woodward, J., Winckler, T., Tanaka, Y., Shaulsky, G., Schleicher, M., Weinstock, G., Rosenthal, A., Cox, E. C., Chisholm, R. L., Gibbs, R., Loomis, W. F., Platzer, M., Kay, R. R., Williams, J., Dear, P. H., Noegel, A. A., Barrell, B., und Kuspa, A. (2005) The genome of the social amoeba Dictyostelium discoideum, Nature 435, 43-57. 
17. Pan, P., Hall, E. M., und Bonner, J. T. (1972) Folic Acid as Second Chemotactic Substance in the Cellular Slime Moulds, nature new biology 237, 181-182.

18. Kesbeke, F., van Haastert, P. J. M., De Wit, R. J. W., und Snaar-Jagalska, E. B. (1990) Chemotaxis to cyclic AMP and folic acid is mediated by different $\mathrm{G}$ proteins in Dictyostelium discoideum, J. Cell Sci. 96, 668-673.

19. Chen, M.-Y., Insall, R. H., und Devreotes, P. N. (1996) Signaling through chemoattractant receptors in Dictyostelium, Trends Genet. 12, 52-57.

20. Condeelis, J. (1993) Life at the Leading Edge: The Formation of Cell Protrusions, Annu. Rev. Cell Biol. 9, 411-444.

21. Vicker, M. G., und Grutsch, J. F. (2008) Dual chemotaxis signalling regulates Dictyostelium development: Intercellular cyclic AMP pulses and intracellular F-actin disassembly waves induce each other, Eur. J. Cell Biol. 87, 845-861.

22. Wessels, D., Schroeder, N. A., Voss, E., Hall, A. L., Condeelis, J., und Soll, D. R. (1989) cAMPmediated inhibition of intracellular particle movement and actin reorganization in Dictyostelium, J. Cell Biol. 109, 2841-2851.

23. Abu-Elneel, K., Karchi, M., und Ravid, S. (1996) Dictyostelium Myosin II Is Regulated during Chemotaxis by a Novel Protein Kinase C, J. Biol. Chem. 271, 977-984.

24. Kimmel, A. R., und Parent, C. A. (2003) The Signal to Move: D. discoideum Go Orienteering, Science 300, 1525-1527.

25. Stites, J., Wessels, D., Uhl, A., Egelhoff, T., Shutt, D., und Soll, D. R. (1998) Phosphorylation of the Dictyostelium myosin II heavy chain is necessary for maintaining cellular polarity and suppressing turning during chemotaxis, Cell Motil. Cytoskeleton 39, 31-51.

26. Weijer, C. J. (2004) Dictyostelium morphogenesis, Curr. Opin. Genet. Dev. 14, 392-398.

27. Alonso-Latorre, B., del Álamo, J., Meili, R., Firtel, R., und Lasheras, J. (2011) An Oscillatory Contractile Pole-Force Component Dominates the Traction Forces Exerted by Migrating Amoeboid Cells, Cell. Mol. Bioeng. 4, 603-615.

28. Condeelis, J. S., Wyckoff, J. B., Bailly, M., Pestell, R., Lawrence, D., Backer, J., und Segall, J. E. (2001) Lamellipodia in invasion, Semin. Cancer Biol. 11, 119-128.

29. Ridley, A. J., Schwartz, M. A., Burridge, K., Firtel, R. A., Ginsberg, M. H., Borisy, G., Parsons, J. T., und Horwitz, A. R. (2003) Cell Migration: Integrating Signals from Front to Back, Science 302, 1704-1709.

30. Varnum, B., und Soll, D. R. (1984) Effects of cAMP on single cell motility in Dictyostelium, J. Cell Biol. 99, 1151-1155.

31. Wessels, D., Vawter-Hugart, H., Murray, J., und Soll, D. R. (1994) Three-dimensional dynamics of pseudopod formation and the regulation of turning during the motility cycle of Dictyostelium, Cell Motil. Cytoskeleton 27, 1-12.

32. Wessels, D., Voss, E., Von Bergen, N., Burns, R., Stites, J., und Soll, D. R. (1998) A computerassisted system for reconstructing and interpreting the dynamic three-dimensional relationships of the outer surface, nucleus and pseudopods of crawling cells, Cell Motil. Cytoskeleton 41, 225-246.

33. Erdos, G. W., Raper, K. B., und Vogen, L. K. (1973) Mating Types and Macrocyst Formation in Dictyostelium discoideum, Proc. Natl. Acad. Sci. U.S.A. 70, 1828-1830.

34. Saga, Y., Okada, H., und Yanagisawa, K. (1983) Macrocyst development in Dictyostelium discoideum. II. Mating-type-specific cell fusion and acquisition of fusion-competence, J. Cell Sci. 60, 157-168.

35. Dormann, D., Vasiev, B., und Weijer, C. J. (1998) Propagating waves control Dictyostelium discoideum morphogenesis, Biophys. Chem. 72, 21-35.

36. Dormann, D., und Weijer, C. J. (2006) Imaging of cell migration, EMBO J 25, 3480-3493.

37. Dormann, D., und Weijer, C. J. (2001) Propagating chemoattractant waves coordinate periodic cell movement in Dictyostelium slugs, Development 128, 4535-4543. 
38. Bonner, J. T., Clarke, W. W., Neely, C. L., und Slifkin, M. K. (1950) The orientation to light and the extermely sensitive orientation to temperature gradients in the slime mold Dictyostelium discoideum, J. Cell. Comp. Physiol. 36, 149-158.

39. Miura, K., und Siegert, F. (2000) Light affects CAMP signaling and cell movement activity in Dictyostelium discoideum, Proc. Natl. Acad. Sci. U.S.A. 97, 2111-2116.

40. Olive, E. W. (1902) Monograph of the Acrasieae, Proceedings of the Boston Society of Natural History 30, 451-513.

41. Bonner, J. T., und Savage, L. J. (1947) Evidence for the formation of cell aggregates by chemotaxis in the development of the slime mold Dictyostelium discoideum, J. Exp. Zool. 106, 1-26.

42. Konijn, T. M., Barkley, D. S., Chang, Y. Y., und Bonner, J. T. (1968) Cyclic Amp: A Naturally Occurring Acrasin in the Cellular Slime Molds, The American Naturalist 102, 225-233.

43. Shaffer, B. M. (1975) Secretion of cyclic AMP induced by cyclic AMP in the cellular slime mould Dictyostelium discoideum, Nature 255, 549-552.

44. Tomchik, K. J., und Devreotes, P. N. (1981) Adenosine 3',5'-monophosphate waves in Dictyostelium discoideum: a demonstration by isotope dilution-fluorography, Science 212, 443-446.

45. Brenner, M., und Thoms, S. D. (1984) Caffeine blocks activation of cyclic AMP synthesis in Dictyostelium discoideum, Dev. Biol. 101, 136-146.

46. van Haastert, P. J. M., und Postma, M. (2007) Biased Random Walk by Stochastic Fluctuations of Chemoattractant-Receptor Interactions at the Lower Limit of Detection, Biophys. J. 93, 1787-1796.

47. Wang, C. J., Bergmann, A., Lin, B., Kim, K., und Levchenko, A. (2012) Diverse Sensitivity Thresholds in Dynamic Signaling Responses by Social Amoebae, Sci. Signaling 5, ra17-.

48. Mato, J. M., Losada, A., Nanjundiah, V., und Konijn, T. M. (1975) Signal input for a chemotactic response in the cellular slime mold Dictyostelium discoideum, Proc. Natl. Acad. Sci. U.S.A. 72, 4991-4993.

49. Affolter, M., und Weijer, C. J. (2005) Signaling to Cytoskeletal Dynamics during Chemotaxis, Dev. Cell 9, 19-34.

50. Gregor, T., Fujimoto, K., Masaki, N., und Sawai, S. (2010) The Onset of Collective Behavior in Social Amoebae, Science 328, 1021-1025.

51. Caterina, M. J., Devreotes, P. N., Borleis, J., und Hereld, D. (1995) Agonist-induced Loss of Ligand Binding Is Correlated with Phosphorylation of CAR1, a G Protein-coupled Chemoattractant Receptor from Dictyostelium, J. Biol. Chem. 270, 8667-8672.

52. Garcia, G. L., Rericha, E. C., Heger, C. D., Goldsmith, P. K., und Parent, C. A. (2009) The Group Migration of Dictyostelium Cells Is Regulated by Extracellular Chemoattractant Degradation, Mol. Biol. Cell 20, 3295-3304.

53. Nanjundiah, V. (1998) Cyclic AMP oscillations in Dictyostelium discoideum: models and observations, Biophys. Chem. 72, 1-8.

54. Alcantara, F., und Monk, M. (1974) Signal Propagation during Aggregation in the Slime Mould Dictyostelium discoideum, J. Gen. Microbiol. 85, 321-334.

55. Gingle, A. R. (1976) Critical density for relaying in Dictyostelium discoideum and its relation to phosphodiesterase secretion into the extracellular medium, J. Cell Sci. 20, 1-20.

56. Ueda, M., Sako, Y., Tanaka, T., Devreotes, P., und Yanagida, T. (2001) Single-Molecule Analysis of Chemotactic Signaling in Dictyostelium Cells, Science 294, 864-867.

57. Endres, R. G., und Wingreen, N. S. (2008) Accuracy of direct gradient sensing by single cells, Proc. Natl. Acad. Sci. U.S.A. 105, 15749-15754.

58. Song, L., Nadkarni, S. M., Bödeker, H. U., Beta, C., Bae, A., Franck, C., Rappel, W.-J., Loomis, W. F., und Bodenschatz, E. (2006) Dictyostelium discoideum chemotaxis: Threshold for directed motion, Eur. J. Cell Biol. 85, 981-989. 
59. Mehta, P., und Gregor, T. (2010) Approaching the molecular origins of collective dynamics in oscillating cell populations, Curr. Opin. Genet. Dev. 20, 574-580.

60. Futrelle, R. P., Traut, J., und McKee, W. G. (1982) Cell behavior in Dictyostelium discoideum: preaggregation response to localized cyclic AMP pulses, J. Cell Biol. 92, 807-821.

61. Tani, T., und Naitoh, Y. (1999) Chemotactic responses of Dictyostelium discoideum amoebae to a cyclic AMP concentration gradient: evidence to support a spatial mechanism for sensing cyclic AMP, J. Exp. Biol. 202, 1-12.

62. Janetopoulos, C., und Firtel, R. A. (2008) Directional sensing during chemotaxis, FEBS Lett. 582, 2075-2085.

63. Devreotes, P. N., Potel, M. J., und MacKay, S. A. (1983) Quantitative analysis of cyclic AMP waves mediating aggregation in Dictyostelium discoideum, Dev. Biol. 96, 405-415.

64. Gerisch, G. (1968) Cell aggregation and differentiation in dictyostelium, Curr. Top. Dev. Biol. A. A. Moscona and A. Monroy, Eds., 157197.

65. Wong, E., Yang, C., Wang, J., Fuller, D., Loomis, W. F., und Siu, C.-H. (2002) Disruption of the gene encoding the cell adhesion molecule DdCAD-1 leads to aberrant cell sorting and celltype proportioning during Dictyostelium development, Development 129, 3839-3850.

66. Coates, J. C., und Harwood, A. J. (2001) Cell-cell adhesion and signal transduction during Dictyostelium development, J. Cell Sci. 114, 4349-4358.

67. Palsson, E., und Othmer, H. G. (2000) A model for individual and collective cell movement in Dictyostelium discoideum, Proc. Natl. Acad. Sci. U.S.A. 97, 10448-10453.

68. Satoh, H., Ueda, T., und Kobatake, Y. (1985) Oscillations in cell shape and size during locomotion and in contractile activities of Physarum polycephalum, Dictyostelium discoideum, Amoeba proteus and macrophages, Exp. Cell Res. 156, 79-90.

69. Parent, C. A., und Devreotes, P. N. (1999) A Cell's Sense of Direction, Science 284, 765-770.

70. Sasaki, A. T., Chun, C., Takeda, K., und Firtel, R. A. (2004) Localized Ras signaling at the leading edge regulates PI3K, cell polarity, and directional cell movement, J. Cell Biol. 167, 505-518.

71. Gerisch, G., und Hess, B. (1974) Cyclic-AMP-Controlled Oscillations in Suspended Dictyostelium Cells: Their Relation to Morphogenetic Cell Interactions, Proc. Natl. Acad. Sci. U.S.A. 71, 2118-2122.

72. Sawai, S., Thomason, P. A., und Cox, E. C. (2005) An autoregulatory circuit for long-range self-organization in Dictyostelium cell populations, Nature 433, 323-326.

73. FitzHugh, R. (1961) Impulses and Physiological States in Theoretical Models of Nerve Membrane, Biophys. J. 1, 445-466.

74. Nagumo, J., Arimoto, S., und Yoshizawa, S. (1962) An active pulse transmission line simulating nerve axon, Proceedings of the institute of radio engineers 50, 2061-2070.

75. Levine, H., Kessler, D. A., und Rappel, W.-J. (2006) Directional sensing in eukaryotic chemotaxis: A balanced inactivation model, Proc. Natl. Acad. Sci. U.S.A. 103, 9761-9766.

76. Xiong, Y., Huang, C.-H., Iglesias, P. A., und Devreotes, P. N. (2010) Cells navigate with a localexcitation, global-inhibition-biased excitable network, Proc. Natl. Acad. Sci. U.S.A. 107, 17079-17086.

77. Hecht, I., Skoge, M. L., Charest, P. G., Ben-Jacob, E., Firtel, R. A., Loomis, W. F., Levine, H., und Rappel, W.-J. (2011) Activated Membrane Patches Guide Chemotactic Cell Motility, PLoS Comput. Biol. 7, e1002044.

78. Iglesias, P. A. (2012) Chemoattractant Signaling in Dictyostelium: Adaptation and Amplification, Sci. Signaling 5, 8.

79. Iglesias, P. A., und Devreotes, P. N. (2012) Biased excitable networks: how cells direct motion in response to gradients, Curr. Opin. Cell Biol. 24, 245-253.

80. Gross, J. D., Peacey, M. J., und Trevan, D. J. (1976) Signal emission and signal propagation during early aggregation in Dictyostelium discoideum, J. Cell Sci. 22, 645-656. 
81. Williams, G. B., Elder, E. M., und Sussman, M. (1984) Modulation of the cAMP relay in Dictyostelium discoideum by ammonia and other metabolites: Possible morphogenetic consequences, Dev. Biol. 105, 377-388.

82. Bonner, J. T., Chiang, A., Lee, J., und Suthers, H. B. (1988) The possible role of ammonia in phototaxis of migrating slugs of Dictyostelium discoideum, Proc. Natl. Acad. Sci. U.S.A. 85, 3885-3887.

83. Siegert, F., und Weijer, C. (1989) Digital image processing of optical density wave propagation in Dictyostelium discoideum and analysis of the effects of caffeine and ammonia, J. Cell Sci. 93, 325-335.

84. Amselem, G., Theves, M., Bae, A., Bodenschatz, E., und Beta, C. (2012) A Stochastic Description of Dictyostelium Chemotaxis, PLOS ONE 7, e37213.

85. Cooper, R. M., Wingreen, N. S., und Cox, E. C. (2012) An Excitable Cortex and Memory Model Successfully Predicts New Pseudopod Dynamics, PLoS ONE 7, e33528.

86. Driscoll', M. K., McCann, C., Kopace, R., Homan, T., Fourkas, J. T., Parent, C., und Losert, W. (2012) Cell Shape Dynamics: From Waves to Migration, PLoS Comput Biol 8, e1002392.

87. Jaiswal, P., Soldati, T., Thewes, S., und Baskar, R. (2012) Regulation of aggregate size and pattern by adenosine and caffeine in cellular slime molds, BMC Dev. Biol. 12.

88. Pfannes, E., Theves, M., Wegner, C., und Beta, C. (2012) Impact of the carbazole derivative wiskostatin on mechanical stability and dynamics of motile cells, J. Muscle Res. Cell Motil. 33, 95-106.

89. Fey, P., Kowal, A. S., Gaudet, P., Pilcher, K. E., und Chisholm, R. L. (2007) Protocols for growth and development of Dictyostelium discoideum, Nat. Protoc. 2, 1307-1316.

90. Gabriel, D., Hacker, U., Kohler, J., Muller-Taubenberger, A., Schwartz, J. M., Westphal, M., und Gerisch, G. (1999) The contractile vacuole network of Dictyostelium as a distinct organelle: its dynamics visualized by a GFP marker protein, J. Cell Sci. 112, 3995-4005.

91. Giaever, I., und Keese, C. R. (1984) Monitoring fibroblast behavior in tissue culture with an applied electric field, Proc. Natl. Acad. Sci. U.S.A. 81, 3761-3764.

92. Wegener, J., Keese, C. R., und Giaever, I. (2000) Electric Cell-Substrate Impedance Sensing (ECIS) as a Noninvasive Means to Monitor the Kinetics of Cell Spreading to Artificial Surfaces, Exp. Cell Res. 259, 158-166.

93. Tarantola, M., Schneider, D., Sunnick, E., Adam, H., Pierrat, S., Rosman, C., Breus, V., Sönnichsen, C., Basché, T., Wegener, J., und Janshoff, A. (2009) Cytotoxicity of Metal and Semiconductor Nanoparticles Indicated by Cellular Micromotility, ACS Nano 3, 213-222.

94. Lo, C.-M., und Ferrier, J. (1998) Impedance analysis of fibroblastic cell layers measured by electric cell-substrate impedance sensing, Phys. Rev. E 57, 6982-6987.

95. Janshoff, A., Galla, H.-J., und Steinem, C. (2000) Piezoelectric Mass-Sensing Devices as Biosensors-An Alternative to Optical Biosensors?, Angew. Chem., Int. Ed. 39, 4004-4032.

96. Rodahl, M., Höök, F., Fredriksson, C., Keller, C. A., Krozer, A., Brzezinski, P., Voinova, M., und Kasemo, B. (1997) Simultaneous frequency and dissipation factor QCM measurements of biomolecular adsorption and cell adhesion, Faraday Discuss. 107, 229-246.

97. Tarantola, M., Pietuch, A., Schneider, D., Rother, J., Sunnick, E., Rosman, C., Pierrat, S., Sönnichsen, C., Wegener, J., und Janshoff, A. (2011) Toxicity of gold-nanoparticles: Synergistic effects of shape and surface functionalization on micromotility of epithelial cells, Nanotoxicology 5, 254-268.

98. Bandey, H. L., Martin, S. J., Cernosek, R. W., und Hillman, A. R. (1999) Modeling the Responses of Thickness-Shear Mode Resonators under Various Loading Conditions, Anal. Chem. 71, 2205-2214.

99. Reiss, B., Janshoff, A., Steinem, C., Seebach, J., und Wegener, J. (2002) Adhesion Kinetics of Functionalized Vesicles and Mammalian Cells: A Comparative Study, Langmuir 19, 18161823. 
100. Tarantola, M., Marel, A.-K., Sunnick, E., Adam, H., Wegener, J., und Janshoff, A. (2010) Dynamics of human cancer cell lines monitored by electrical and acoustic fluctuation analysis, Integr. Biol. 2, 139-150.

101. O'Connor, E. R., Kimelberg, H. K., Keese, C. R., und Giaever, I. (1993) Electrical resistance method for measuring volume changes in monolayer cultures applied to primary astrocyte cultures, Am. J. Physiol.: Cell Physiol. 264, C471-C478.

102. Aue, D. (2010) Untersuchung zur Motilität von Dictyostelium Discoideum mit elektroschemischen Methoden.

103. Wurster, B., und Kurzenberger, W. (1989) Periodic cell aggregation in suspensions of Dictyostelium discoideum, Differentiation 41, 1-4.

104. Giaever, I., und Keese, C. R. (1993) A morphological biosensor for mammalian cells, Nature 366, 591-592.

105. Schäfer, E., Westendorf, C., Bodenschatz, E., Beta, C., Geil, B., und Janshoff, A. (2011) Shape Oscillations of Dictyostelium discoideum Cells on Ultramicroelectrodes Monitored by Impedance Analysis, Small 7, 723-726.

106. Schäfer, E., Tarantola, M., Polo, E., Westendorf, C., Oikawa, N., Bodenschatz, E., Geil, B., und Janshoff, A. (2013) Chemotaxis of Dictyostelium discoideum: collective oscillation of cellular contacts PLOS ONE 1, e54172.

107. Mattheyses, A. L., Simon, S. M., und Rappoport, J. Z. (2010) Imaging with total internal reflection fluorescence microscopy for the cell biologist, J. Cell Sci. 123, 3621-3628.

108. Anger, P., Bharadwaj, P., und Novotny, L. (2006) Enhancement and Quenching of SingleMolecule Fluorescence, Phys. Rev. Lett. 96, 113002.

109. Dubertret, B., Calame, M., und Libchaber, A. J. (2001) Single-mismatch detection using goldquenched fluorescent oligonucleotides, Nat. Biotechnol. 19, 365-370. 


\section{Kapitel}

\section{Untersuchung der mechanischen Eigenschaften von Riesenvesikeln}

\subsection{Grundlagen}

Zur Untersuchung von komplexen biologischen Systemen werden in der Biophysik häufig bottom-upModelle verwendet. Hierbei wird versucht, einen mannigfaltigen, natürlichen Zusammenhang auf die Basisbestandteile zu reduzieren und anhand der Analyse des Modellsystems Erkenntnisse über die Aufgaben und Funktionsweisen im realen, komplexen System zu erlangen. [1-3]

Zum Beispiel kann die Plasmamembran einer Zelle mit dem darunter lokalisiertem Cytoskelett im bottom-up-Modell durch eine artifizielle Lipidmembran nachgestellt werden, die sich über ein Aktinnetzwerk streckt. Mit Hilfe dieses Modells kann eine Aussage über die viskoelastischen Eigenschaften einer Zellmembran und die Wechselwirkung zwischen der Membran und dem Cytoskelett erhalten werden. [4-6] Durch Nachahmung der Topologie einer Zelle durch Verwendung von Riesenvesikeln werden zudem die natürlichen, räumlichen Dimensionen einer Zelle in das Modell mit einbezogen. [7-9]

\subsubsection{Die Zelle}

Eine Zelle ist ein komplexes System, bestehend aus einer fluiden Hülle, der Zellmembran, die die verschiedenen Organellen, das Cytoskelett und das Cytosol umschließt. Neben der Plasmamembran sind Membranen in der Zelle überall dort vorzufinden, wo es zur Abgrenzung von verschiedenen funktionellen Kompartimenten kommt. Unabhängig davon, ob es sich um ein Kompartiment innerhalb des Cytosols oder die Abgrenzung des gesamten Zellinnenraums nach außen handelt, bestehen Membranen aus verschiedenen Lipiden und Steroiden, die in einer Doppelschicht angeordnet sind. Eingebettet in diese flüssig-kristalline Matrix sind Membranproteine, die als funktionelle Einheiten den Transport über die dielektrische Barriere gewährleisten, als Rezeptor fungieren und enzymatische Wirkung zeigen. Die Zusammensetzung ist von der Art der Zelle und von der jeweiligen Funktion der Membran abhängig, da die Membran nicht nur die Funktion der Abgrenzung sondern auch für den selektiven Transport von Molekülen und für die Signalweitergabe 
über die Membran hindurch verantwortlich ist. Bei tierischen Zellen ist die Zellmembran zudem zusammen mit dem Cytoskelett für die mechanischen Eigenschaften und die Form der Zelle verantwortlich. [10-11]

\subsubsection{Cytoskelett}

Das Cytosol durchdringend oder an die Plasmamembran gebunden, ist es das Cytoskelett einer tierischen Zelle, das dieser mechanische Stabilität verleiht, die Zellform beeinflusst, die Beweglichkeit der Zelle steuert und den gerichteten Transport von Material innerhalb der Zelle ermöglicht. Es gibt drei verschiedene Arten von Faserstrukturen in einer Zelle, die unterschiedliche Funktionen innerhalb dieser übernehmen. Sie bilden jeweils ein separates Netzwerk aus und unterscheiden sich in der Anordnung, der Länge und dem Durchmesser der Fasern und somit in der Steifigkeit des aufgebauten Netzwerks. Alle drei Arten von Filamenten bestehen aus Proteinuntereinheiten, die durch schwache, nichtkovalente Bindungen zusammengehalten werden. Diese Konstruktion ermöglicht den hochdynamischen Auf- und Abbau, der für den Ablauf der komplexen Vorgänge innerhalb der Zelle unentbehrlich ist. Die Filamentart mit der höchsten Steifigkeit stellen die Mikrotubuli dar, die vom Mikrotubuli-Organisationszentrum nahe dem Zellkern in die Zelle ausstrahlen und hauptsächlich für den Transport innerhalb der Zelle, die Lokalisierung der Zellorganellen und für die Ausbildung des Spindelapparates, zur korrekten Aufteilung des Erbgutes während der Zellteilung, zuständig sind. Intermediärfilamente sind zwischen den Zellseiten durch das Cytosol hindurch aufgespannt und sind vorwiegend für die Stabilität der Zelle verantwortlich. Die schlanken Aktinfilamente bilden den sogenannten Zellcortex und sind nahe der

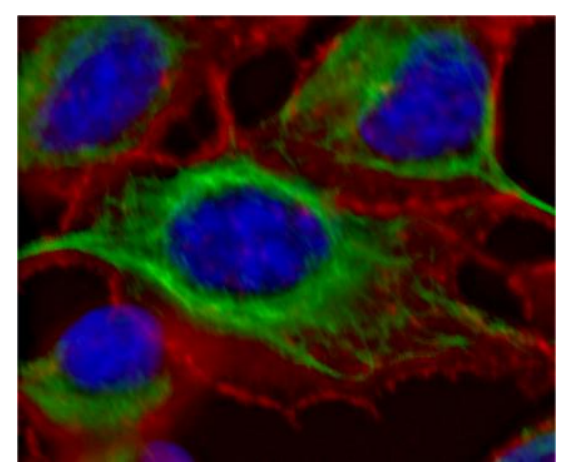

Abbildung 3.1: Fluoreszenzaufnahme einer Zelle, bei der die Aktinfilamente in roter Farbe und die Mikrotubuli in grüner Farbe angefärbt sind. Der Zellkern ist in blauer Farbe gefärbt. ${ }^{27}$

\footnotetext{
${ }^{27}$ Von Anna Pietuch zu Verfügung gestellt.
} 
Plasmamembran angereichert, wo sie ein dreidimensionales Netzwerk ausbilden. Sie sind maßgeblich an der Stabilität, der Form der Oberfläche und der Beweglichkeit der Zelle beteiligt. [1011]

Da im Rahmen dieser Arbeit die Untersuchung des Einflusses von Aktin im Fokus steht, wird im Folgenden auf diesen Bestandteil des Cytoskeletts näher eingegangen.

\subsubsection{Aktin}

Aktin ist eines der häufigsten Proteine in eukaryotischen Zellen [12] und bildet je nach Zelltyp und Funktion hoch geordnete Strukturen, lockere Netzwerke oder fest verankerte Bündel aus. Auf die Polymerisation von globulären Molekülen des Proteins Aktin (G-Aktin) zu Aktinfilamenten (F-Aktin) wird im Folgenden genauer eingegangen. [10, 13]

\section{Aktinpolymerisation}

Bevor ein Aktinmonomer in ein Filament eingebaut wird, müssen die zwei Bindungsstellen, eine für ein Adenosintriphosphat (ATP) und eine für ein zweiwertiges Kation, des G-Aktins besetzt werden. $[10,14]$ Durch das assoziierte ATP wird die Bindungsaffinität des G-Aktins zum Aktinfilament erhöht. Im Filament findet die Hydrolyse des ATPs zu Adenosindiphosphat (ADP) und Phosphat statt, wodurch wiederum die Dissoziation des Filaments in die Untereinheiten begünstigt wird. [10, 13, 15] Die Bindung von zweiwertigen Kationen, zum Beispiel eines Magnesiumions, reduziert die negative Nettoladung des G-Aktins, wodurch die Polymerisation durch Verringerung der elektrostatischen Abstoßung begünstig wird. [16]

Der geschwindigkeitsbestimmende Schritt der Polymerisation ist die Bildung eines filamentösen Keimes, bestehend aus einem Aktintrimer. Die nachfolgende Elongation erfolgt schnell, wobei die zwei Enden des Aktinfilaments nicht identisch sind. Das eine Ende des Filaments zeigt eine deutlich höhere Affinität zum G-Aktin und es lagern sich bis zu 10-mal schneller Monomere an dieses Ende an. Dieses Filamentende wird das Plus-Ende (englisch: barbed end) genannt. Das langsam wachsende Filamentende heißt dementsprechend Minus-Ende (englisch: pointed end). Für die Polymerisation des Aktinfilaments muss die Konzentration an Aktinmonomeren oberhalb der kritischen Monomerkonzentration liegen, die für das jeweilige Filamentende charakteristisch ist und in vitro von der Temperatur, der ATP-Konzentration und der zweiwertigen Kationenkonzentration abhängig ist. Wird die kritische Monomerkonzentration unterschritten, wird das Filament von den Enden her abgebaut. Bei einer Monomerkonzentration von zirka $0.1 \mu \mathrm{M}$ stellt sich ein Fließgleichgewicht ein, das heißt das Plus-Ende wächst mit der gleichen Geschwindigkeit mit der das Minus-Ende durch 
Depolymerisation von Aktin-ADP-Untereinheiten schrumpft. Man spricht daher auch von einem Tretmühlenmechanismus. [10, 13-14]

A

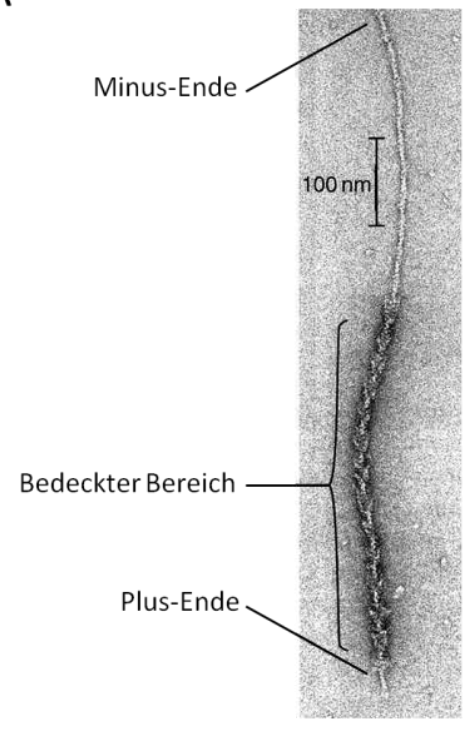

B

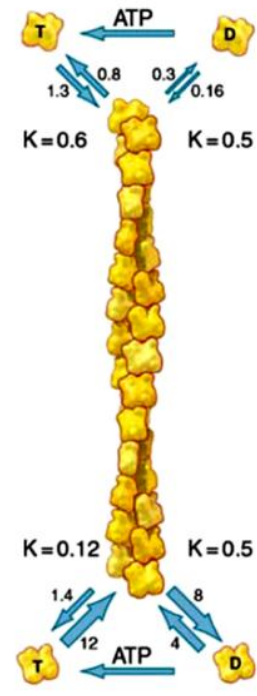

Abbildung 3.2: A) Elektronenmikroskopieaufnahme von einem Aktinfilament, das im mittleren Bereich mit Myosin-Köpfen bedeckt ist. B) Schematische Zeichnung eines Aktinfilaments mit Angaben der Bindungskonstante (in $1 / \mu \mathrm{Ms}$ ) und Dissoziationskonstante (in $1 / \mathrm{s}$ ) von $\mathrm{Mg}^{2+}-\mathrm{ATP}$ Aktin (T) und $\mathrm{Mg}^{2+}$-ADP-Aktin (D) an das Plus-Ende und das Minus-Ende. Zusätzlich ist die Gleichgewichtskonstante $(K$ in $\mu \mathrm{M})$ für die kritischen Konzentrationen an $T$ beziehungsweise $D$ für die Polymerisation an dem jeweiligen Ende angegeben. ${ }^{28}$

\section{Struktur}

Es gibt sechs verschiedene Isoformen von G-Aktin beim Menschen, welche eine hohe Homologie der Aminosäurensequenz aufweisen. [17-18] Ein Aktinmonomer hat ein Gewicht von 43 kDa. [19-20] Durch die Polymerisation entstehen biegsame, spiralförmige Filamente mit einem Durchmesser von $8 \mu \mathrm{m}$ und einer Persistenzlänge von zirka 10-20 $\mu \mathrm{m}$. [20] Der Aktincortex nahe der Plasmamembran besteht vorwiegend aus kurzen Filamenten (einige hundert Nanometer), die ein isotopisch querverknüpftes Netzwerk bilden. [21] Etwas längere Filamente (zirka $1 \mu \mathrm{m}$ ) sind in der Lage, stark quervernetzte Aggregate und Filamentbündel mit einer deutlich höheren Stabilität als die von Einzelfilamenten auszubilden. Besonders lange Aktinfilamente (in der Größenordnung von $10 \mu \mathrm{m}$ ) bilden einen wesentlichen Bestandteil des kontraktilen Systems der Muskelzellen und der Stressfasern (englisch: stress fibers) bei nicht-muskulären, adhärierten Zellen. [22-23]

\footnotetext{
${ }^{28}$ Copyright: Pollard, T.S. und Borisy, G. G., Cellular Motility Driven by Assembly and Disassembly of Actin Filaments. Cell, 2003, (112), 453-465.
} 
Aufgrund der verschiedenen Funktionen des Aktins innerhalb der Zelle, bildet sich eine Vielzahl an verschiedenen Architekturen des Aktinnetzes aus. Dies wird in vivo durch eine große Anzahl an Proteinen erreicht, die das Wachstum und die Struktur des Aktinnetzwerks kontrollieren wie zum Beispiel Aktindepolymerisationsfaktoren (ADF), Moleküle die als Startproteine für die Polymerisation dienen wie Arp 2/3, Aktinfilament-quervernetzende Proteine wie $\alpha$-Actinin oder Filamin, und filamentverzweigende Proteine wie Gelsolin. $[10,13]$ Hinzu kommen Proteine, die eine Verknüpfung mit dem Zellcortex herstellen. Eine direkte Verbindung zwischen in der Membran befindlichem Phosphoinositid und Aktin wird über die Proteinklasse der Ezrin-Radixin-Moesin-Familie (ERMFamilie) ermöglicht. Es bilden sich aber auch Membranverknüpfungen über die Proteine der Spectrinfamilie, die Wiskott-Aldrich-Syndrom Proteinfamilie (WASP) und über Vinculin aus. [19, 2425] Bei adhärenten Zellen wir über die Fokalkontakte der Zelle eine Verknüpfung der extrazellulären Matrixproteine über die Transmembranproteine, die sogenannten Integrine zum intrazellulären F-Aktin gebildet. [26-27]

Das molekulare Motorprotein Myosin bindet an Aktinfilamente und wandert in Richtung des PlusEndes der Filamente. Myosin ist sowohl bei der Kontraktion des Skelettmuskelgewebes von Säugetieren (Myosin II) von entscheidender Bedeutung als auch für den gerichteten Vesikeltransport innerhalb der Zellen (Myosin I). [10]

Die Auswirkungen des Aktincortex der Zelle auf die mechanischen Eigenschaften der Zelle sind markant, jedoch nicht trivial zu bestimmen und stark abhängig vom Zelltyp. [24] Die Kraft, die Aktinfilamente mit Hilfe von aktinbindenden Proteinen beim Drücken gegen die Membran erzeugen können, ist ausreichend, um Ausstülpungen innerhalb der Membran zu verursachen. Dies wird bei der Fortbewegung von einzelnen Zellen genutzt, bei denen sich aktinfilamentgefüllte Ausstülpungen der Membran an der Vorderseite der Zelle (Pseudopodien) ausbilden und eine gezielte Zellbewegung ermöglichen. [28] Bei in-vitro Experimenten mit polymerisiertem Aktin unter physiologischen Bedingungen konnten je nach Präparationsmethode und Konzentrationen innerhalb des physiologischen Bereiches von Aktin, ATP und Ionen Schubmodule von $<1 \mathrm{~Pa}$ bis zu $>1 \mathrm{kPa}$ bestimmt werden. [29-30] Das Verhältnis zwischen Verlustmodul ( $\left.G^{\prime \prime}\right)$ und Speichermodul (G) liegt im Bereich von 0.1 (festkörperartig) bis > 1 (fluidartig). [31-32]

Kraftspektroskopische Versuche mit dem Rasterkraftmikroskop auf einer konfluenten Zellschicht zeigten, dass durch die Zugabe von Cytochalasin D, einem Toxin, das den Abbau von Aktinfilamenten verursacht, die Zellviskoelastizität verändert wird. Bei MDCK II-Zellen wird zum Beispiel eine Erniedrigung der Membranspannung bei Zugexperimenten von zirka $0.21 \mathrm{nN} / \mathrm{m}$ auf $0.05 \mathrm{nN} / \mathrm{m}$ detektiert. [33] 


\subsubsection{Artifizielle Membranen}

Eine Membran ist eine zweidimensionale, fluide Struktur, die aus amphiphilen Molekülen wie zum Beispiel Lipiden, aufgebaut ist. Der amphiphile Charakter, der in natürlichen Membranen häufig vorkommenden Phospholipide, resultiert aus einer polaren oder geladenen, phosphattragenden Kopfgruppe, die über ein Glycerin mit zwei unpolaren Kohlenwasserstoffketten (Fettsäuren) verbunden ist. Durch die Selbstorganisation der Lipide in polaren Medien wird eine Lipiddoppelschicht ausgebildet. $[10,20]$ Diese Selbstorganisation zu einer geordneten Struktur findet aufgrund des sogenannten hydrophoben Effektes statt. Damit wird der Gewinn an Energie beschrieben, der in dem System, trotz Anordnung der Lipide in eine definierte Struktur (Abnahme der Entropie der Lipidmoleküle), durch das Auflösen der Solvathülle um die Kohlenwasserstoffketten (Zunahme der Entropie der Wassermoleküle) entsteht. Die hieraus resultierenden Schichten aus Phospholipiden bestehen daher aus polaren Kopfgruppen auf beiden Seiten der Membran und den hydrophoben Fettsäureketten, die in der Mitte der Doppelschicht zusammengelagert sind. [20, 34] Die Selbstorganisation der Lipide in geordnete Strukturen findet erst ab einer bestimmten Konzentration an gelösten Amphiphilen im wässrigen Medium statt. Diese Konzentration wird allgemein als kritische Mizellbildungskonzentration (englisch: critical micelle concentration CMC) bezeichnet. Für in der Natur vorkommende Phospholipide liegt die CMC im nanomolaren Bereich. $[20,35]$

Neben den Doppelschichten können, je nach Größenverhältnis der hydrophilen Kopfgruppe zu dem hydrophoben Rest der amphiphilen Moleküle, verschiedene Überstrukturen bei der Selbstorganisation der oberflächenaktiven Moleküle entstehen. Anhand des kritischen Packungsparameters, der von dem Volumen und der Länge des hydrophoben Restes ( $V_{K}$ beziehungsweise $L_{K}$ ) und der Durchschnittsfläche der Kopfgruppe $A_{K G}$ abhängig ist, kann bestimmt werden, in welcher Struktur sich Amphiphile bevorzugt anordnen.

$$
N_{\mathrm{P}}=\frac{V_{\mathrm{K}}}{L_{\mathrm{K}} A_{\mathrm{KG}}}
$$

Bei Tensiden beispielsweise mit nur einer Kohlenwasserstoffkette ist die Kopfgruppe sehr viel größer als der hydrophobe Rest $\left(N_{p}<1 / 2\right)$ und die kegelförmigen Amphiphile lagern sich zu Mizellen, also kleinen Aggregaten mit den hydrophoben Ketten in der Mitte, zusammen. Liegt der kritische Packungsparameter zwischen $1 / 2$ und 1 sind die Moleküle im Längsschnitt zylinderförmig. Es können sich planare Lipiddoppelschichten oder Vesikel, also eine kugelförmige Lipiddoppelschicht mit wässrigem Medium Innen und Außen, bilden. Bei inversen Kegelstrukturen von oberflächenaktiven 
Molekülen $\left(N_{p}>1\right)$ wird eine hexagonale Phase aus zylinderförmig angeordneten Amphiphilen gebildet. [20, 35-36]
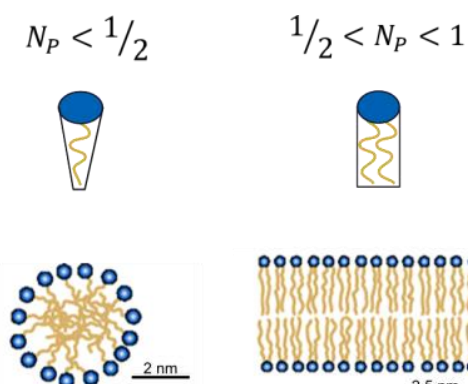

$N_{P}>1$
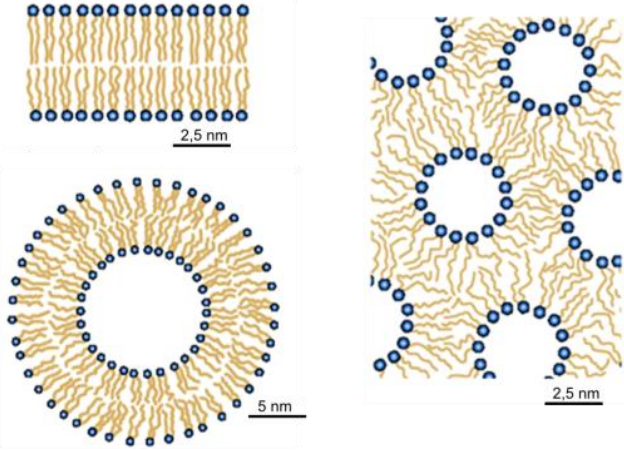

Abbildung 3.3: Schematische Darstellung von den bevorzugten Anordnungen von Amphiphilen in polaren Medien in Abhängigkeit des kritischen Packungsparameters $\left(N_{P}\right)^{29}$

Das Verhältnis zwischen der Kopfgruppe und den Kohlenwasserstoffketten kann durch den Austausch verschieden großer Kopfgruppen oder aber durch die Struktur der hydrophoben Ketten beeinflusst werden. [20,36] In der Natur werden hierzu ungesättigte Fettsäurereste verwendet, bei denen durch Doppelbindungen Knicke in den Kohlenwasserstoffketten generiert werden, die den Platzbedarf der Ketten erhöhen. Durch die Verwendung von ungesättigten Fettsäuren ist es zudem schwieriger, die Lipide in einer dichtesten Packung in der Membran anzuordnen. Es erhöht sich die Elastizität innerhalb der Lipidschicht und die Hauptumwandlungstemperatur der Lipiddoppelschicht von der Gelphase in die flüssig-kristalline Phase wird reduziert. [20, 34] Damit wird unter anderem die Fluidität und Flexibilität von Biomembranen gewährleistet. Da die einzelnen Schichten der Lipiddoppelschicht friktionsfrei zueinander verschiebbar sind, ist das Schermodul einer Membran sehr gering. [20,34]

\subsubsection{Eigenschaften von Phospholipidvesikeln}

Ein Vesikel kann man sich als einen mit Wasser gefüllten Ballon, jedoch mit einer fluiden Membran als Grenzfläche vorstellen. [20] Vesikel, die aufgrund der Krümmung der Lipidschicht nicht den thermodynamisch stabilsten Zustand darstellen, bilden sich spontan durch Schließen der

\footnotetext{
${ }^{29}$ In Anlehnung an:

http://open.jorum.ac.uk/xmlui/bitstream/handle/123456789/1024/Items/T356_3_section2.html\#FIG001_003 (20.07.2012).
} 
Lipiddoppelschicht, da hierdurch kein Kontakt der zuvor freien, hydrophoben Enden mit dem polaren Medium mehr besteht. $[20,34,37]$ Die Dicke einer Lipiddoppelschicht aus Dioleoylphosphatidylcholin (DOPC) beträgt zirka $4 \mathrm{~nm}$ und ein DOPC-Lipid nimmt im Querschnitt eine Fläche von zirka $72 \AA^{2}$ in der Membran ein. [38-39] Ein Austausch von Wasser oder lonen ist durch die semipermeable Membran mit dem hydrophoben inneren Bereich stark eingeschränkt. Der Permeabilitätskoeffizent ist von der Zusammensetzung der Lipidmembran und der Temperatur abhängig. Für eine DOPC-Membran beträgt der Koeffizient für Wasser bei $21^{\circ} \mathrm{C}$ zirka $45 \mu \mathrm{m} / \mathrm{s}$. [4041] Je größer oder polarer ein Molekül ist, desto unwahrscheinlicher wird die Diffusion durch die Membran. [37] So genannte große unilamellare Vesikel (GUV), also Vesikel mit einem Durchmesser von 10-100 $\mu \mathrm{m}$ [37] und nur einer einzelnen Lipiddoppelschicht als Grenzfläche, werden aufgrund ihrer Ähnlichkeit in Größe und Aufbau zu biologischen Zellmembranen als Modellsystem für Zellen verwendet. [42-45]

Ein kugelförmiges Vesikel schließt das maximale Volumen im Verhältnis zur Membranoberfläche des Vesikels ein. Bei genauerer Betrachtung der Vesikeloberfläche sind jedoch Ondulationen der Membran erkennbar. [20, 34, 46] Diese transversalen, thermischen Fluktuationen der Lipidschicht bei keiner oder sehr geringen Spannungen $\left(\sigma_{0}<0.5 \mathrm{mN} / \mathrm{m}\right)$ der Membran bewirken, dass der mittlere Durchmesser des Vesikels kleiner ist als die zu Verfügung stehende Lipidfläche des Vesikels es ermöglichen würde. [46] Die Ondulationen entstehen aufgrund des Energiegewinns durch die zusätzliche Entropie der sich bewegenden Lipidmoleküle. [20,34] Wird eine Spannung auf den Vesikel appliziert, werden die Ondulationen zu Gunsten der dadurch frei zur Verfügung gestellten Fläche unterdrückt. [20, 46] Die Vorspannung $\left(\sigma_{0}\right)$ eines flüssig-kristallinen Vesikels der nicht auf der Oberfläche adhäriert ist, konnte durch Fluktuationsanalyse bestimmt werden und liegt im Bereich von $0.001-0.1 \mathrm{mN} / \mathrm{m}$. [47]

Durch Einwirken einer äußeren Kraft auf eine Membran kann es zu verschiedenen Arten von Membrandeformationen kommen: Scherung, Biegung, Dehnung. Die Scherung innerhalb einer fluiden Lipiddoppelschicht benötigt keine Energie und das Schermodul ist dementsprechend Null. $[34,48]$ 


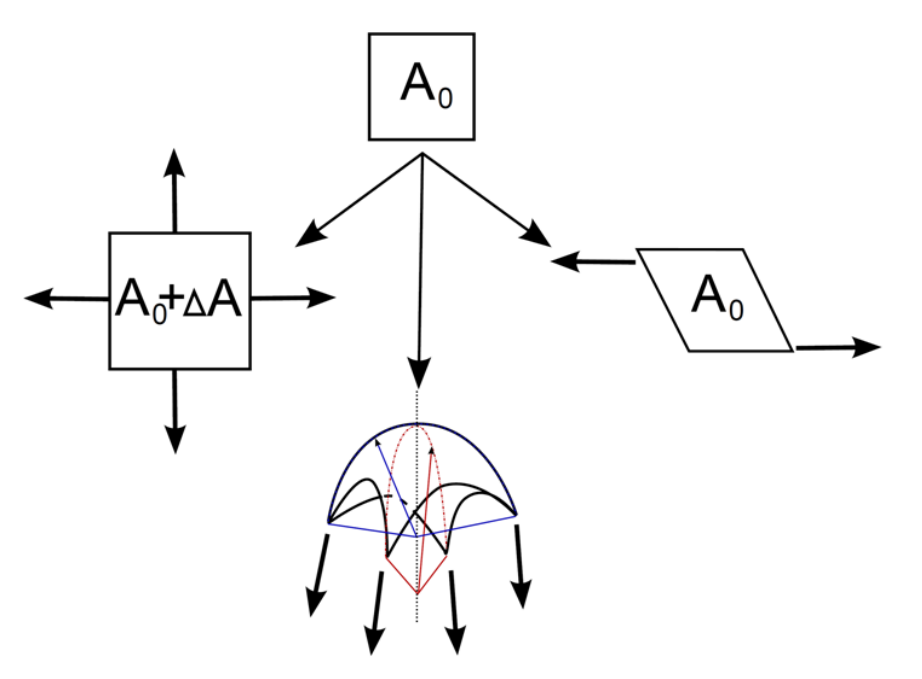

\section{Abbildung 3.4: Schematische Darstellung der möglichen Deformationen durch Dehnung/Kompression, Biegung oder Scherung einer Membran mit der ursprünglichen Fläche $A_{0}{ }^{30}$}

Die Energie, die zur Krümmung einer Lipiddoppelschicht benötigt wird, kann unter anderem mit Mikropipetten-Aspirationstechnik bestimmt werden. Das hieraus ermittelte Biegemodul $(\kappa)$ nimmt mit steigender Kettenlänge der Lipide, die eine Zunahme der Dicke der Lipidschicht bewirken, zu und für eine steigende Anzahl an Doppelbindungen in den Fettsäureketten der Lipide ab. [20, 46] Für DOPC mit zwei ungesättigten $\mathrm{C}_{18}$-langen Fettsäureketten beträgt das Biegemodul zirka $8.5 \times 10^{-20} \mathrm{~J}$. [46]

Durch Anlegen einer homogenen Spannung an den Rändern der Membran wird eine Dilatation der Lipiddoppelschicht verursacht, die durch Vergrößerung der intermolekularen Abstände der Lipide in der Membran erreicht wird. Die Membraneigenschaft, die die Dehnung der Lipidschicht beschreibt, ist das elastischen Flächenkompressionsmodul $\left(K_{A}\right)$, das nur eine geringe Abhängigkeit von der Kettenlänge oder von der Anzahl an Doppelbindungen der Fettsäureketten in der Membran zeigt. $[20,46]$ Das elastische Flächenkompressionsmodul ist abhängig von der Oberflächenspannung der Grenzfläche zwischen Wasser und Amphiphil $\gamma \quad K_{\mathrm{A}}=4 \gamma$ und beträgt zum Beispiel für eine DOPCMembran in Wasser zirka $0.265 \mathrm{~N} / \mathrm{m}$. [46]

\subsubsection{Aktincortex in Riesenvesikeln}

Die Plasmamembran einer Zelle wird von einem Polymernetzwerk gestützt, das unmittelbar unter der Zellmembran lokalisiert ist. Hierdurch werden die mechanischen Eigenschaften und die Form der Zelle maßgeblich beeinflusst und wichtige Zellprozesse wie Zellteilung, Bewegung und Entwicklung gesteuert. Bei den meisten Säugetierzellen, aber auch bei anderen eukaryotischen Zellen, geschieht

${ }^{30}$ Aus:

Ingo P. Mey, Elastizität prorenüberspannender Membranen: Eine kraftmikroskopische Studie, Dissertation, 2009. 
dies über einen Cortex aus dynamischen Aktinfilamenten. [9, 24] Die spezifischen Auswirkungen des Zellcortexes und seinen Einfluss in einen gegebenen zellulären Prozess zu untersuchen, ist aufgrund der Komplexität einer Zelle am lebenden Organismus schwierig. [5, 49] Um quantitative Untersuchungen der Wechselwirkung des Zellcortexes mit der Plasmamembran und daraus resultierende mechanische Eigenschaften der Zelle in Einzelheiten zerlegt zu bestimmen, werden cortexnachbildende Modellsysteme aus Lipidvesikeln und Bestandteilen des Cytoskeletts aufgebaut. Durch die Verwendung von großen unilamellaren Vesikeln, mit einem Durchmesser von zirka $10 \mu \mathrm{m}$, kann die natürliche Kompartimentierung der Zellen nachgestellt werden. Zusätzlich lassen sich Solute und Proteine einschließen, um der nativen Situation möglichst nahe zu kommen. [49]

Die Umsetzung des biophysikalischen Modells eines Lipidvesikels mit Aktinfilamenten im Inneren gelang erstmals J. D. Cortese et al. 1989, als sie G-Aktin, das sich in großen Vesikeln ( $\varnothing=5-10 \mu \mathrm{m})$ befand, polymerisierten. [8] Die Polymerisation wurde durch Erhöhung der Calciumkonzentration gesteuert, nachdem zuvor die Permeabilität der Membran für Calciumionen durch Zugabe des lonophors Valinomycin gewährleistet wurde. Mit Hilfe von Hellfeldmikroskopie untersuchten J. D. Cortese etal. die Morphologie der Zellmembran und zeigten, dass die ursprünglich kugelförmigen Vesikel durch Ausbildung von Aktinfilamenten eine unsymmetrische, unregelmäßige Form einnahmen. Sie konnten ebenfalls bereits zeigen, dass die Stärke der Verformung der Vesikel von der Länge der Aktinfilamente abhängig ist, die sie durch Zugabe von Gelsolin, ein an Aktin bindendes Protein das Aktinfilamente zerschneidet, manipulierten. [8]

Die Vesikelformen, die durch die Ausbildung von Aktinfilamenten innerhalb der Vesikel entstehen, wurden von H. Miyata etal. durch Untersuchungen mittels Dunkelfeldmikroskopie und Differentialinterferenzkontrast-Mikroskopie (DIC-Mikroskopie) als Scheiben oder Hanteln beschrieben. [50] In weiteren Studien konnte gezeigt werden, dass die Verformung der Vesikel durch Erhöhung der verwendeten G-Aktinkonzentration [51-54] und durch einen schnelleren Polymerisationsprozess verstärkt wird [53-54]. Des Weiteren wurde gezeigt, dass Cytochalasin D Aktinnetzwerke abbaut, da sich die Verformung der Vesikel nach Zugabe des Toxins zu den Vesikeln mit F-Aktin verringerte. [55] Zudem wurden die Auswirkungen von verschiedenen aktinfilamentvernetzenden Proteinen untersucht, wodurch eine höhere Komplexität des Filamentnetzwerks innerhalb der Vesikel erzeugt wird. $[8,51,56]$ Insbesondere die Zugabe von Fascin, ein Protein das die Filamente des Aktins eng miteinander zu parallelen Filamentbündeln verknüpft, zeigte einen deutlichen Einfluss auf die Morphologie der Vesikel. Es entstanden längliche, aktinfilamentgefüllte Ausstülpungen der Membran. [51] Ähnliche Ausstülpungen wurden auch bei der Verwendung von hohen Kationenkonzentrationen gefunden. [53] 
Die Dimension des begrenzten Reaktionsraums ist jedoch nicht nur für die Morphologie der Vesikel entscheidend, sondern auch für die Struktur des polymerisierten Atkinnetzwerks im Inneren der Vesikel. [53, 57] Der Durchmesser der untersuchten Vesikel liegt je nach Studie im gleichen Größenbereich oder nahe der Persistenzlänge von Aktinfilamenten (10-20 $\mu \mathrm{m})$ [20]. Je nach Reaktionsbedingungen können enge Aktinfilamenthüllen direkt unter der inneren Lipidschicht entstehen, diffuse Netzwerke entlang der Membran gebildet werden oder sich im gesamten Innenraum des Vesikels ein gleichmäßig polymerisiertes Netzwerk aus F-Aktin entwickeln. Dies ist abhängig davon, aus welcher Struktur eine minimale Verbiegung der Filamente resultiert. $[51,54,57]$

Einen entscheidenden Einfluss auf die Struktur des entstehenden Netzwerks aus Aktinfilamenten haben die Wechselwirkungen zwischen der inneren Lipidmembran der Vesikel und dem Aktin. G-Aktin, das in einem Vesikel bestehend aus dem Lipid Dimyristoylglycerophosphocholin (DMPC) in Anwesenheit von zweiwertigen Kationen polymerisiert, bildet eine Aktinhülle unter der Vesikelmembran aus. Die Lokalisation der Aktinfilamente an der Lipidmembran findet über elektrostatische Wechselwirkungen über die Kationen statt, sie sind jedoch nicht fest an die Lipiddoppelschicht gekoppelt. [57-58] Durch Analyse der aktincortexunterstützten Vesikelmembran mit Hilfe von Fluktuationsspektroskopie konnte der mittlere Abstand zwischen dem Aktinnetzwerk und der Membran auf 0.4-0.5 $\mu \mathrm{m}$ abgeschätzt werden. [58] Die Dicke des Aktincortex hängt von der G-Aktinkonzentration und dem Durchmesser der Vesikel ab. [58] Je größer die Vesikel sind, desto diffuser ist die Aktinhülle in Fluoreszenzaufnahmen mit fluoreszenzmarkiertem Aktin zu erkennen, was auf eine lockere Netzstruktur zurück geführt wird. [57] Durch Aufwärmen solcher Vesikel um 1-2 ${ }^{\circ} \mathrm{C}$ kann es zur Entstehung von Blistern kommen. [7] Dies sind Ausstülpungen in der Lipidmembran, die nur mit Flüssigkeit nicht aber mit F-Aktin gefüllt sind. Bulbitch et al. zufolge entstehen die für die Blisterausbildung notwendigen Instabilitäten in der Membran an lokalen Defektstellen des Aktinnetzwerks unter der Lipiddoppelschicht. [7]

Die elektrostatischen Wechselwirkungen zwischen Aktin und der Membran kann durch Einbau von PEGylierten (PEG: Poly(ethylenglycol)) Lipiden in die DMPC-Lipidmembran verringert werden. Statt einer Aktinhülle an der Membraninnenseite bildet sich dann ein Aktinnetzwerk im gesamten Lumen des Vesikels aus. [57]

Im Gegensatz dazu konnte D. Merkle et al. eine gezielte Anbindung von Aktinfilamenten an die Innenseite der Membran zeigen. [59] Die Aktinfilamente wurden hierzu über einen Komplex aus Spectrin/Ankyrin-Proteinen an Transmembranproteine in der Membran gekoppelt. Die Membran wurde aus nativen Lipiden und Proteinen gebildet, die aus Zellen des Schweinehirns extrahiert wurden. Der gebildete Aktincortex bestand aus dichtgepackten Bündeln aus F-Aktin, die an die Innenseite der Vesikel gebunden waren. [59] Eine weitere Möglichkeit für die Bindung von Aktin an 
die Membran wurde über das aktinbindende Protein Arp 2/3 realisiert, welches wiederum an Fragmente des an die Membran gekoppelten WASP-Proteins gebunden war. Auch hierbei kam es zur Bildung von Hüllen aus gebündeltem F-Aktin entlang der inneren Lipiddoppelschicht. [60]

Zur Untersuchung des Einflusses des Motorproteins Myosin auf die Dynamik des Aktinnetzwerks, wurden zunächst erfolgreich die schweren Ketten des Myosins II zusätzlich zum Aktin in die Vesikel eingeschlossen [61], und später das gesamte Myosin-II-Protein [9]. Beides führte zur Ausbildung von Bündeln an Aktinfilamenten. Eine erfolgreiche Kontraktion der Vesikelmembran aufgrund einer von den Motorproteinen generierten Kraft, über die an die Membran gebundenen Aktinfilamente, konnte bisher jedoch noch nicht nachgewiesen werden.

Zudem wurden verschiedene Eigenschaften von Vesikeln mit Aktincortex untersucht. Zum Beispiel wurde der Einfluss des Aktins auf die Wasserpermeabilität von Membranen analysiert. Hierzu wurde die Ausstromgeschwindigkeit von Wasser aus den Vesikeln nach Erhöhung der Osmolarität der die Vesikel umgebenden Lösung bestimmt. Es konnte gezeigt werden, dass der Ausstrom von Wasser bei Vesikeln mit G-Aktin schneller abläuft als bei Vesikeln, in denen polymerisiertes Aktin vorlag. [41] Dieses Verhalten wird mit verschiedenen chemischen Potenzialen für Wasser bei G-Aktin und F-Aktin erklärt. [41, 62]

Für Untersuchungen des Spreitverhaltens von Vesikeln mit Aktinfilamenten wurden die untersuchten Vesikel mit Aktincortex in zwei Gruppen eingeteilt. Die eine Gruppe bestand aus Vesikeln, in denen nur eine geringe, inhomogene Aktinhülle vorlag. Der Diffusionskoeffizient des Aktins betrug in diesen Vesikeln zirka $2 \times 10^{-3} \mu \mathrm{m}^{2} / \mathrm{s}$. Für die zweite Population an Vesikel mit einem engen, ausgeprägten Aktincortex verringerte sich der Diffusionskoeffizent auf zirka $9 \times 10^{-5} \mu^{2} / \mathrm{s}$. Die Vesikel mit der ungleichmäßigen Aktinhülle zeigten einen zirka 100-mal schnelleren Adhäsionsprozess als die Vesikel mit einem dichteren Aktincortex. Die Adhäsionsfläche der Vesikel nach Erreichen eines Gleichgewichtszustandes ohne oder nur mit einer geringen Aktinhülle war dabei deutlich größer als bei Vesikeln mit einem aktinreichen Cortex. [49]

Das Einschließen von Cytoskelettproteinen in großen Liposomen stellt zudem eine technische Herausforderung für die Herstellung von Vesikeln dar. Vesikel, die G-Aktin einschließen, können zwar über verschiedene Methoden hergestellt werden, wie zum Beispiel Gentle Hydration [8, 41, 50-51, 53-54], Elektroformation [7, 57-59], inverse Emulsionstechnik [49, 60-61] sowie Gentle Hydration auf Agarosegel [9], hohe Ausbeuten an großen unilamellaren Vesikeln sind dabei jedoch im Allgemein inkompatibel mit der Verwendung von physiologischen Salzkonzentrationen in der Pufferlösung. [9] Durch die Zugabe von zusätzlichen Proteinen wird die Ausbeute an Vesikeln weiter verringert, wobei 
es innerhalb der in einer Präparation hergestellten Vesikelpopulation zudem zu variablen Konzentrationen der eingeschlossenen Proteine in den Vesikeln kommt. $[9,57]$ 



\subsection{Motivation}

Die Plasmamembran und das Cytoskelett stellen ein komplexes System in der Zelle dar, das sowohl die mechanische Stabilität und Dynamik der Zelle, als auch die Interaktionen mit der Umgebung reguliert. Aufgrund der mannigfaltigen Zellprozesse in die die Zellmembran mit dem darunter liegenden Aktinnetzwerk involviert ist, wird der Aufbau und die Interaktionen der Membran mit dem Cytoskelett durch eine Vielzahl an Mechanismen gesteuert. $[10,13,15]$ Die daraus resultierende Komplexität und Dynamik des Systems erschwert es jedoch, die Wechselwirkungen des Zellcortexes mit der Plasmamembran und die daraus resultierenden mechanischen Eigenschaften der Zelle in ihren Einzelheiten quantitativ zu untersuchen.

Daher wird in bottom-up-Modellen versucht, die Wechselwirkungen zwischen der Plasmamembran und dem Cytoskelett durch definierte, regulierbare Voraussetzungen nachzustellen und somit unabhängig von den komplexen Kontrollmechanismen in der Zelle die Interaktionen auf wenige Parameter zu reduzieren. $[7,49,57]$ Wichtig ist es dabei, die Topologie der Zelle durch ein geeignetes Modellsystem nachzugestellen, welches die natürliche Dimension und die Kompartimentierung der Zelle zusätzlich erfasst. [49] Aus diesem Grund sollten unilamellare Riesenvesikel mit einer artifiziellen Lipiddoppelschicht und einem Aktincortex im Lumen etabliert und mechanisch charakterisiert werden.

Die spezifischen Eigenschaften einer elastischen Membran lassen sich sehr kontrolliert durch Kompressionsexperimente analysieren, bei denen die Vesikel mit Hilfe eines Rasterkraftmikroskops zwischen einem Cantilever ohne Spitze und einer parallel dazu stehenden Probenoberfläche zusammengedrückt werden. Aus den resultierenden Kraft-Abstandskurven werden mit Hilfe der Theorie für die Kompression eines Vesikels zwischen planparallelen Platten die Vorspannung und das Flächenkompressionsmodul der flüssig-kristallinen Vesikelmembranen berechnet. Durch Vergleich des Verhaltens von Vesikeln mit und ohne Aktincortex im Inneren wird ein Einblick in die Funktionsweise des stabilisierenden Cytoskeletts in einer Zelle erlangt. 



\subsection{Material und Methoden}

\subsubsection{Verwendete Puffer}

Zur Herstellung der Vesikel mit Aktincortex wird ein Puffer mit physiologischer Salzkonzentration verwendet, der es ermöglicht, das G-Aktin nach der Vesikelpräparation durch Erhöhung der Konzentration an Magnesiumionen zu polymerisieren. Das verwendete Puffersystem ist von W. Häckl et al. übernommen und geringfügig modifiziert. [58] Vesikel ohne Aktin werden mit identischen Puffern hergestellt.

\subsubsection{Vesikellumen}

Der Puffer, der zur Elektroformation verwendet wird, befindet sich anschließend innerhalb der Vesikel. Er besteht aus Tris(hydroxymethyl)aminomethan Hydrochlorid (Tris $\mathrm{HCl}: 2 \mathrm{mM}$ ), Magnesiumchlorid $\left(\mathrm{MgCl}_{2}: 0.2 \mathrm{mM}\right.$ ), Adenosintrisphosphat (ATP: $0.2 \mathrm{mM}$ ) und Dithiothreitol (DTT: $0.25 \mathrm{mM}$ ). Zur Sicherstellung, dass sich die Vesikel an der Oberfläche des Glassubstrats absetzen, wird die Dichte der Pufferlösung durch Zugabe von Sucrose $(50 \mathrm{mM})$ erhöht. Der Puffer wird auf einen pH-Wert von 7.5 eingestellt und Schwebstoffe in der Lösung werden durch einen $0.2 \mu \mathrm{m}$ Filter (Minisart, Satorius, Göttingen, Deutschland) entfernt. Im Folgenden wird dieser Puffer als S-A-Puffer (S: Sucrose; A: Aktinpolymerisation möglich) bezeichnet. Die Osmolarität des Puffers wird mit einem Osmometer (Osmomat 030, Gonotec, Berlin, Deutschland) bestimmt und beträgt zirka $0.060 \mathrm{osmol} / \mathrm{kg}$.

\subsubsection{2 Äußere Umgebung}

Der Puffer für die Vesikel umgebende Lösung besteht aus Tris $\mathrm{HCl}(2 \mathrm{mM})$ und $\mathrm{MgCl}_{2}(0.2 \mathrm{mM})$. Zur Einstellung der gleichen Osmolarität wie der des S-A-Puffers werden diesem Puffer 50 mM Glucose zugesetzt. Der Puffer wird ebenfalls auf einen pH-Wert von 7.5 eingestellt und durch einen $0.2 \mu \mathrm{m}$ Filter filtriert. Dieser Puffer wird als G-B-Puffer (G: Glucose; B: Basis) bezeichnet.

\subsubsection{Aktin zur Probenpräparation}

Aktin eines der wichtigsten Proteine der Muskelzellen und des Cytoskeletts existiert in verschiedenen, hoch konservierten Isoformen, deren Verteilung in Wirbeltieren gewebespezifisch ist. [17-18] Die Isoformen werden anhand der Aminosäurensequenz am Amino-Terminus in zwei Klassen eingeteilt. Zur Klasse 1 gehören die Isoformen: Non-muscle $\beta$, Non-muscle $\gamma$ und Smooth-muscle $\gamma$ 
Aktin, die Klasse 2 besteht aus den drei Muskelaktinisoformen: Cardiac $\alpha$, Skeletal $\alpha$ und Vascular $\alpha$. $[18,63]$ Durch die hohe Homologie der Isoformen untereinander, sind die Strukturen der Kationenund Nukleotidbindungsstellen nahezu identisch. [63] Unter physiologischen Bedingungen sind die kritischen Konzentrationen für den Aufbau von Filamentstrukturen bei den muskulären Aktinisoformen und den nicht-muskulären Aktinisoformen quasi nicht zu unterscheiden [63], die Aktinfilamente der Skelettmuskulatur sind jedoch stabiler als die Aktinisoformen des Cytoskeletts. [64] Die verschiedenen Isoformen zeigen zudem unterschiedliche Affinitäten zu aktinbindenden Proteinen. $[18,63]$

Im Rahmen dieser Arbeit wird mit Aktin gearbeitet, das aus der Skelettmuskulatur von Kaninchen isoliert wird und eine Reinheit von über $95 \%$ aufweist. Das lyophilisierte Aktin wird in destilliertem Wasser gelöst $(10 \mathrm{mg} / \mathrm{ml})$ und anschließend in der Proteinmenge aliquotiert, die für einen Versuch benötigt wird. Die Aliquote werden in flüssigem Stickstoff schockgefroren und bei $-80^{\circ} \mathrm{C}$ gelagert.

\subsubsection{Fluoreszenzmarkiertes Aktin}

Zur Markierung des Aktins für die Fluoreszenzmikroskopie wird Alexa Fluor ${ }^{\circledR} 488$ konjungiertes Aktin vom Kaninchen verwendet. Das Absorptionsmaximum des Fluorophors liegt bei einer Wellenlänge von 495 nm, die maximale Emissionswellenlänge bei $519 \mathrm{~nm}$. [65] Das fluoreszenzmarkierte Aktin wird ebenfalls in Aliquote überführt, die die Proteinmenge für einen Versuch beinhalten und nach dem Einfrieren in flüssigem Stickstoff bei $-80^{\circ} \mathrm{C}$ gelagert.

\subsubsection{Aktinkonzentrationen}

Für die Vesikelpräparation werden je nach Versuch Aktinkonzentrationen im S-A-Puffer von 5-7 $\mu \mathrm{M}$ verwendet. Zur Fluoreszenzmarkierung werden in diese Lösung 0.5-1 $\mu \mathrm{M}$ Alexa Fluor ${ }^{\circledR} 488$ konjungiertes Aktin gegeben.

\subsubsection{Vesikel}

Als biophysikalisches Modell einer Zellemembran werden im Rahmen dieser Arbeit große, unilamellare Vesikel (GUV) verwendet. Die Zusammensetzung der Membran und die Herstellungsweise sind an die physiologischen Bedingungen des in die Vesikel eingeschlossenen Aktins, die Möglichkeit, das Aktin über Variation der Kationenkonzentration zu polymerisieren und die Anbindung der Vesikel an den Probenträger angepasst. 


\subsubsection{Lipide}

\section{Phosphoglyceride}

Für den Aufbau der Lipiddoppelschicht der Vesikel werden verschiedene Phosphoglyceride verwendet. Die Hauptphasenumwandlungstemperatur von Lipiden hängt maßgeblich von der Länge und Sättigung der zwei Fettsäureketten des Amphiphils ab. Lipidmembranen mit gesättigten Palmitinsäuren $\left(C_{16}\right)$ liegen bei Raumtemperatur in der Gelphase $\left(L_{\beta}, P_{\beta^{\prime}}\right)$ vor, also in der dichtesten Packung der Lipide. Hingegen befinden sich die Membranen von Lipiden mit Ölsäureketten, also mit einfach ungesättigten $\mathrm{C}_{18}$-Acylresten, bei Raumtemperatur in der flüssig-kristallinen, lamellaren Phase, der sogenannten $\mathrm{L}_{\alpha}$-Phase. [20] Zur Herstellung von Gelphasenvesikeln wird das Lipid 1,2-Dipalmitoyl-sn-glycero-3-phosphocholin (DPPC) mit einer Umwandlungstemperatur von $41^{\circ} \mathrm{C}$ verwendet. [66] Die Lipide 1,2-Dioleoyl-sn-glycero-3-phosphocholin (DOPC) und 1,2-Dioleoyl-snglycero-3-phosphoethanolamin (DOPE) mit Umwandlungstemperaturen von $-20^{\circ} \mathrm{C}$ [67] beziehungsweise $-16{ }^{\circ} \mathrm{C}$ [68] werden zur Herstellung von Vesikeln mit einer flüssig-kristallinen Membran verwendet. Die Vesikel werden in einem Lipidverhältnis DOPC/DOPE von zirka 7:3 hergestellt, da durch die Mischung der Lipide mit einer Phophocholin-Kopfgruppe und der kleineren Phophoethanolamin-Kopfgruppe eine Lipidzusammensetzung entsteht, die bevorzugt stabile Vesikel ausbildet und nicht planare Lipiddoppelschichten. [36]

Zur Verankerung der Vesikel an der Glasoberfläche der Probenträger wird die nicht-kovalente AvidinBiotin-Bindung ausgenutzt. [69] Hierzu werden in die Vesikelmembran Lipide eingebracht, deren Kopfgruppe mit Biotin funktionalisiert ist. Es werden 5-10 mol\% des Lipids 1,2-Dioleoyl-sn-glycero-3phosphoethanolamin-N-(cap biotinyl) (DOPE-Biotin) verwendet.

\section{Fluoreszenzmarkiertes Lipid}

Zur Markierung der Vesikel für die Fluoreszenzmikroskopie wird das an der Kopfgruppe mit dem Fluorophor funktionalisierte Lipid Texas Red ${ }^{\circledR}$-1,2-Dihexadecanoyl-sn-glycero-3-phosphoethanolamin (TR-DHPE) verwendet. Die maximale Anregungswellenlänge des rot fluoreszierenden Fluorophors liegt bei $595 \mathrm{~nm}$ und die maximale Emissionswellenlänge bei $615 \mathrm{~nm}$. [70]

\subsubsection{Ionophor}

In die Membran der Vesikel wird neben den Phospholipiden der lonophor A23187 (Calimycin) eingebaut. Zwei Moleküle des lonophors bilden einen stabilen, vierfach koordinierten Komplex mit einem zweiwertigen Kation. Hierdurch können insbesondere Mangan- und Calciumionen, aber auch 
die für diese Arbeit entscheidenden Magnesiumionen, durch die Lipiddoppelschicht hindurch transportiert werden. [71]

\subsubsection{Zusammensetzung der Vesikelmembran}

Die Membran der Vesikel in der Gelphase hat eine molare Zusammensetzung der Lipide DPPC/A23187/TR-DHPE von 94.5:5:0.5. Die flüssig-kristallinen Vesikel bestehen aus DOPC/DOPE/DOPE-Biotin/A23187/TR-DHPE in einem molaren Mischungsverhältnis von $59.5: 30: 5: 5: 0.5$ beziehungsweise $54.5: 30: 10: 5: 0.5$. Zur Herstellung der Stammlösungen für die Vesikelpräparation, werden die entsprechenden Stoffmengen der in Chloroform gelösten Lipide beziehungsweise des in Ethanol gelösten lonophors zusammengegeben und mit Chloroform bis zu einer Konzentration von $1 \mathrm{mg} / \mathrm{ml}$ verdünnt.

\subsubsection{Herstellung unilamellarer Riesenvesikel}

GUVs werden mit der Methode der Elektroformation hergestellt. Bei dieser Methode, die erstmals von M. I. Angelova und D. S. Dimitrov 1986 angewendet wurde [72], werden hohe Ausbeuten an meist unilamellaren, großen Vesikeln innerhalb von wenigen Stunden durch Hydratation von getrockneten Lipidfilmen bei gleichzeitig angelegtem Wechselstrom erhalten. [73-75] Die verwendete Frequenz und Spannung sind von der Ionenkonzentration des eingesetzten Puffers und der Größe der Elektroformationskammer abhängig. [73]

Für die Elektroformation wird der in Abbildung 3.5 gezeigte Elektroformationsaufbau verwendet. Auf zwei Glasträgern, die mit einer stromleitenden Indium-Zinn-Oxidschicht (ITO) bedampft sind (Präzisions Glas \& Optik, Iserlohn, Deutschland), wird auf gegenüberliegenden Flächen von $12 \times 12 \mathrm{~mm}^{2}$ die gewünschte Lipidstammlösung $(8 \mu \mathrm{l})$ aufgetragen. Nach dem Verdunsten des Lösungsmittels wird der Lipidfilm gleichmäßig verteilt und zur vollständigen Entfernung des Lösungsmittels die ITO-Platten danach für mindestens 3 Stunden bei $50{ }^{\circ} \mathrm{C}$ im Vakuum getrocknet. Anschließend wird die Elektroformationskammer wie folgt zusammengebaut: Auf jede ITO-Platte wird an der Seite ein Kupferband angebracht, das später den Kontakt zu der ITO-Beschichtung gewährleistet. Auf einer Platte wird um den Lipidfilm die aus Silicon zugeschnittene Begrenzung der Reaktionskammer gelegt. Anschließend wird die zweite ITO-Platte so über die andere Platte gelegt, dass jeweils die Lipidfilme gegenüber voneinander zu liegen kommen und sich jeweils ein Kupferband rechts und links der Reaktionskammer befindet. Zwischen den Kupferbändern und der Glasplatte auf der gegenüberliegenden Seite werden Abstandshalter in den Dicken der Reaktionskammer $(2 \mathrm{~mm})$ eingebaut. Die Elektroformationskammer wird durch Klammern an den Seiten zusammengehalten. Über einen Spalt in der Begrenzung der Reaktionskammer wird der S-A-Puffer beziehungsweise das G-Aktin im S-A-Puffer eingefüllt. Ein Frequenzgenerator (Agilent 33220A, Santa Clara, USA) wird an 
die Kupferbänder angeschlossen und eine Frequenz von $70 \mathrm{~Hz}$ und eine Spitzenspannung (englisch: Peak to Peak voltage) von 2.4 V angelegt. Dies entspricht einer Feldstärke von 1200 V/m.

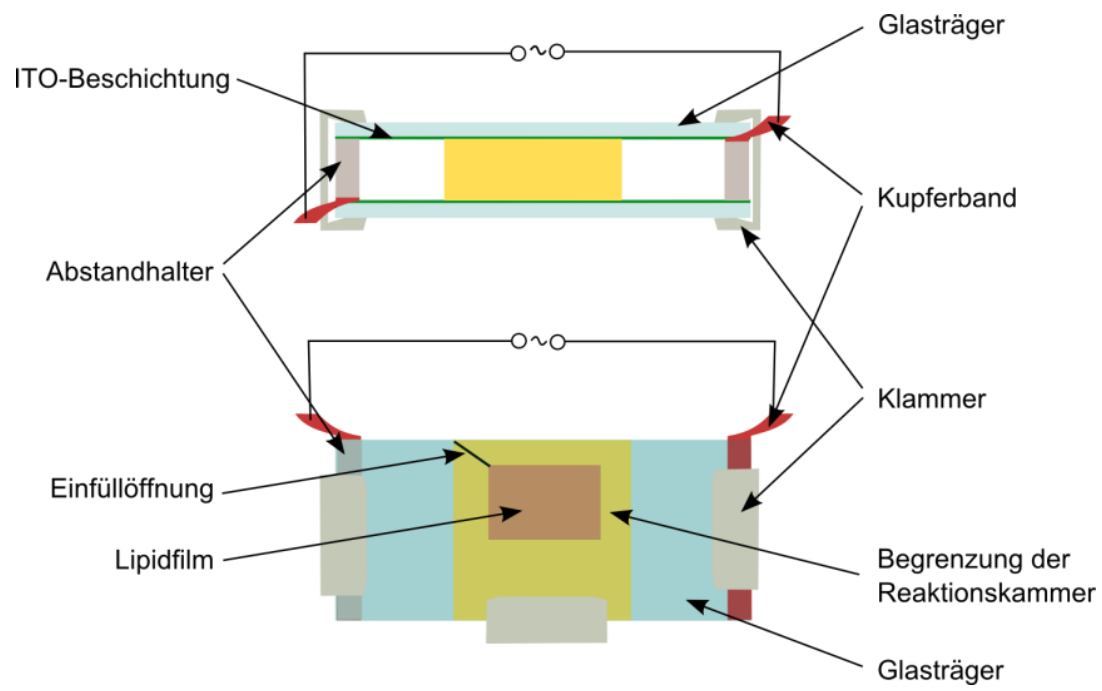

Abbildung 3.5: Schematische Zeichnungen einer Elektroformationskammer aus zwei verschiedenen Ansichten (oben: Aufsicht, unten: Seitenansicht).

Die Bildung von großen, unilamellaren Vesikeln findet nur bei einer Temperatur oberhalb der Phasenumwandlungstemperatur der Lipide statt. Daher wird die Elektroformation der Vesikel mit der Zusammensetzung DPPC/A23187/TR-DHPE bei $50{ }^{\circ} \mathrm{C}$ durchgeführt. Die DOPC/DOPE/DOPE-Biotin/A23187/TR-DHPE-Vesikel werden bei Raumtemperatur dargestellt.

Nach 3 Stunden wird die Kammer vom Frequenzgenerator getrennt und die Lösung mit den Vesikeln aus der Reaktionskammer entnommen. Die Vesikellösungen werden bis zur Probenpräparation bei 4-8 ${ }^{\circ} \mathrm{C}$ gelagert. Die Vesikel mit G-Aktin werden höchstens bis zu zwei Tagen nach der Herstellung verwendet.

Die Elektroformationskammer wird nach der Entnahme der Vesikellösung auseinander gebaut und mit Ethanol und Wasser vorgereinigt. Danach werden die ITO-Platten und die Siliconkammer 15 Minuten im Ultraschallbad in einer 2 \% Hellmanex-II-Lösung gereinigt und anschließend zwei Mal 15 Minuten im Ultraschallbad in destilliertem Wasser klargespült. Die sauberen Bestandteile der Kammer werden mit Ethanol gespült und im Stickstoffstrom getrocknet. 


\subsubsection{Probenpräparation}

Die Vesikel werden für die fluoreszenzmikroskopischen und kraftspektroskopischen Untersuchungen mittels Avidin-Biotin-Bindung auf Glasträgern fixiert. Vor der Vesikelzugabe werden die Glasträger hydrophilisiert und mit Avidin und Casein funktionalisiert.

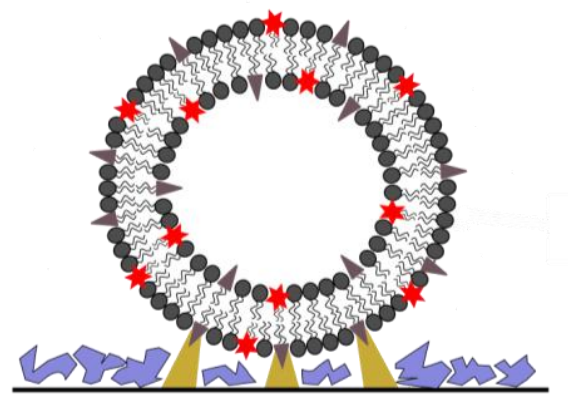

\$ Phospholipide

TR-DHPE

\& DOPE-Biotin

Avidin

Casein

\section{Abbildung 3.6: Schematische Darstellung der Anbindung eines DOPE-Biotin-funktionalisierten Vesikels an eine Avidin beschichtete Oberfläche.}

Die mit Ethanol und Wasser gereinigten Glasträger $\left(22 \times 22 \mathrm{~mm}^{2}\right)$ werden zunächst in einer Lösung aus Wasser / Wasserstoffperoxid (35\% Gew.) / Ammoniak (28\% Vol.) im Verhältnis $5: 1: 1$ bei $70{ }^{\circ} \mathrm{C}$ für 20 Minuten hydrophilisiert. Die oxidierte Glasoberfläche wird gründlich mit Wasser gespült und die Glasplatte in eine Petrischale $(\varnothing=11 \mathrm{~mm})$ gelegt. Anschließend wird die Glasoberfläche mit $300 \mu \mathrm{l}$ einer $1 \mu \mathrm{M}$ Avidinlösung (in $50 \mathrm{mM} \mathrm{Na} \mathrm{HPO}_{4}, \mathrm{pH}$ 6.8) für mindestens 30 Minuten inkubiert. Zur Gewährleistung einer vollständigen Belegung der Glasoberfläche mit Proteinen werden danach auf die Avidin funktionalisierte Oberfläche $300 \mu$ l eine $100 \mu \mathrm{M}$ Casein-Lösung (in Wasser) gegeben. Nach 30 Minuten wird die Lösung abgenommen und die Probe mit G-B-Puffer gründlich gespült.

In die mit zirka $2 \mathrm{ml} \mathrm{G-B-Puffer} \mathrm{gefüllte} \mathrm{Petrischale} \mathrm{werden} 40 \mu \mathrm{l}$ der Vesikellösung gegeben. Nach zirka 10 Minuten wird die Konzentration an Magnesiumionen in der Lösung durch Zugabe einer wässrigen Magnesiumchloridlösung auf mindestens $2 \mathrm{mM}$ erhöht. Bei Vesikeln mit Aktin wird durch die Erhöhung der Konzentration an Magnesiuminonen, die durch die lonophore in der Membran ins Innere der Vesikel gelangen, die kritische Konzentration des G-Aktins für die Aktinpolymerisation gesenkt und das Aktin polymerisiert in den Vesikeln. [58] Zusätzlich werden die elektrostatischen Wechselwirkungen zwischen den Vesikeln und der Oberfläche verstärkt, sodass die Vesikel fester an der Oberfläche adhärieren. [52]

Die gesamte Probenpräparation einschließlich der Elektroformation ist in Abbildung 3.7 schematisch dargestellt. 


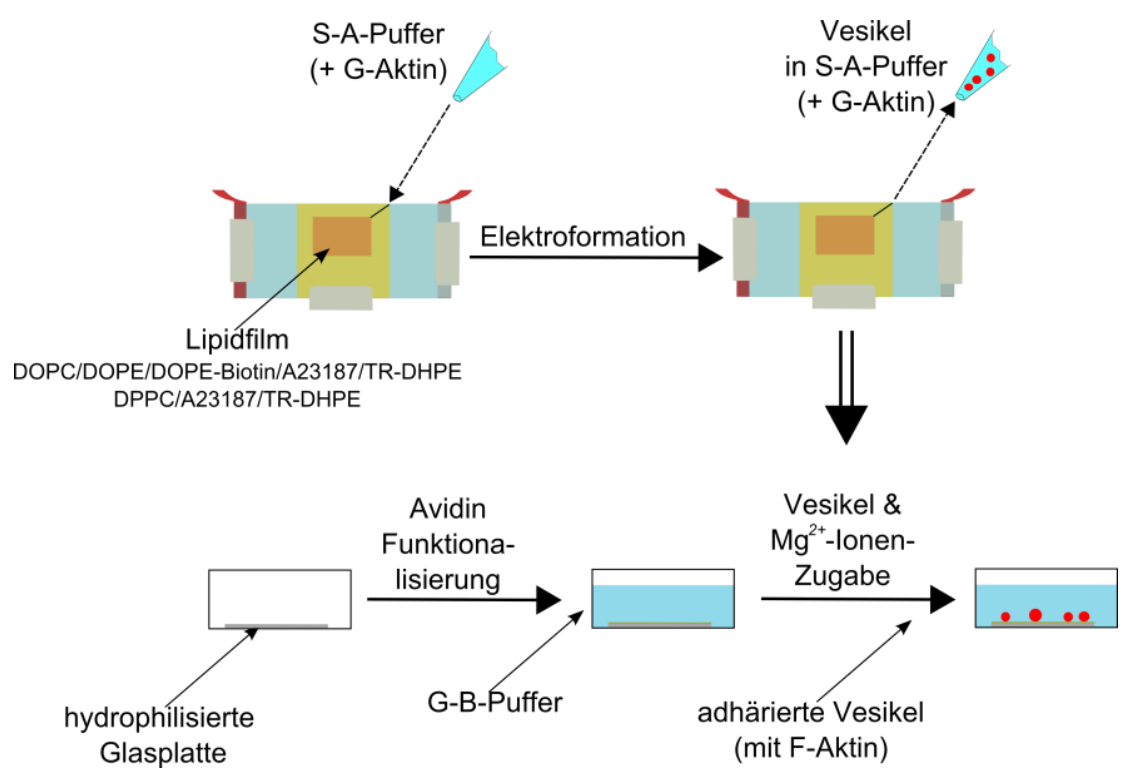

Abbildung 3.7: Schematische Darstellung der einzelnen Schritte, um fixierte Vesikel auf einer Glasoberfläche zu erhalten.

\subsubsection{Optische Mikroskopie}

Im Rahmen dieser Arbeit werden drei verschiedene Fluoreszenzmikroskope verwendet. Zur mikroskopischen Untersuchung der rot fluoreszierenden Vesikelmembran und gegebenenfalls des grün fluoreszierenden Aktins in den Vesikeln wird das aufrechte Mikroskop BX 51 (Olympus, Tokio, Japen) mit CDD-Kamera (DP 71, Olympus, Tokio, Japan) unter Verwendung eines LUMPlanFL N 40-fachen Wasserimmersionsobjektivs (Olympus, Tokio, Japan) und einer Quecksilberdampflampe (X-Cite 120Q, Lumen Dynamics Group, Ontario, Kanada) eingesetzt. Für die Kompressionsexperimente der Vesikel ist ein Rasterkraftmikroskop mit einem inversen Fluoreszenzmikroskop kombiniert. Es handelt sich dabei um ein IX 81 von Olympus (Tokyo, Japan) mit CDD-Kamera (XM 10, Olympus, Tokyo, Japan) unter Verwendung eines UPLFLN 10-fachen oder LUCPLFLN 40-fachen Objektivs (beides Olympus, Tokyo, Japan). Als Lichtquelle dient eine XenonGasentladungslampe (CellR MT 20, Olympus, Tokio, Japan).

Für hochaufgelöste Fluoreszenzaufnahmen wird ein aufrechtes konfokales Laserrastermikroskop (englisch: confocal laser scanning microsope, CLSM) verwendet. Durch zwei mit der zu untersuchenden Probenebene konfokale Lochblenden im Strahlengang wird vor allem eine bessere Tiefenschärfe der Abbildungen erzielt. Durch Scannen der einzelnen Fokusebenen lassen sich dreidimensionale Objekte am Computer anhand sogenannter z-stacks (Stapel) rekonstruieren. Des Weiteren werden mit diesem Mikroskopieaufbau FRAP-Messungen (englisch: fluorescence recovery after photobleaching) durchgeführt. Bei dieser Mikroskopiemethode werden über einen kurzen Laserpuls mit hoher Lichtintensität die Fluorophore in einem begrenzten Bereich zerstört. Durch 
Diffusion kommt es anschließend zum Austausch der Moleküle der gebleichten Stelle mit den fluoreszierenden Molekülen in der Umgebung. Anhand der Bestimmung der Fluoreszenzintensität des photooxidierten Bereiches als Funktion der Zeit lassen sich Diffusionsgeschwindigkeiten und immobile Anteile in den Proben bestimmen. [76-78] Die Software ZEN (Zeiss, Jena, Deutschland) berechnet die mobile Fraktion $(I)$ aus der Fluoreszenzintensität vor dem Bleichen $\left(I_{0}\right)$, direkt nach dem Bleich $\left(I_{\mathrm{i}}\right)$ und der Intensität nach Erreichen des Gleichgewichtszustandes $\left(I_{\mathrm{G}}\right)[78]$

$$
I=\frac{I_{\mathrm{G}}-I_{0}}{I_{\mathrm{i}}-I_{0}}
$$

Der verwendete CLSM-Aufbau besteht aus einem AXIO LSM 710 (Zeiss, Jena, Deutschland) und einem W Plan Apochromat 63-fachen Wasserimmersionsobjektiv (Zeiss, Jena, Deutschland). Als Lichtquelle wird ein Argonlaser (Lasos Lasertechnik, Jena, Deutschland) mit folgenden Einstellungen verwendet: Das Alexa Fluor ${ }^{\circledR}$ 488-Aktin wird mit einer Wellenlänge von $488 \mathrm{~nm}$ angeregt und die Emission wird im Wellenlängenbereich von 493-560 nm detektiert. Bei dem Fluorophor TexasRed ${ }^{\circledR}$-DHPE wird zur Absorption eine Wellenlänge von $594 \mathrm{~nm}$ verwendet, während das emittierte Fluoreszenzlicht in einem Wellenlängenbereich von 598-690 nm aufgenommen wird.

\subsubsection{Kraftmikroskopie}

Ein Rasterkraftmikroskop (englisch: atomic force microsope, AFM) kann sowohl zum Abbilden von Oberflächentopographien mit einer Auflösung im Bereich von Ångström als auch für kraftspektroskopische Untersuchungen zur Charakterisierung von Materialeigenschaften verwendet werden. [79-82]

Das Rasterkraftmikroskop besteht aus einem Federbalken (englisch: Cantilever), von dessen Spitze ein Laserstrahl zu einer 4-Quadranten-Photodiode reflektiert wird. Die Position des Cantilevers kann über Piezoelemente in $\mathrm{x}, \mathrm{y}$, und z-Richtung gesteuert werden. Wird der Cantilever in Kontakt zur Oberfläche gebracht, kommt es zur Verbiegung des Cantilevers, die mit Hilfe des Lichtzeigerprinzips durch die Reflektion des Lasers von der Rückseite des Cantilevers auf die geteilte Photodiode detektiert wird. [79] 


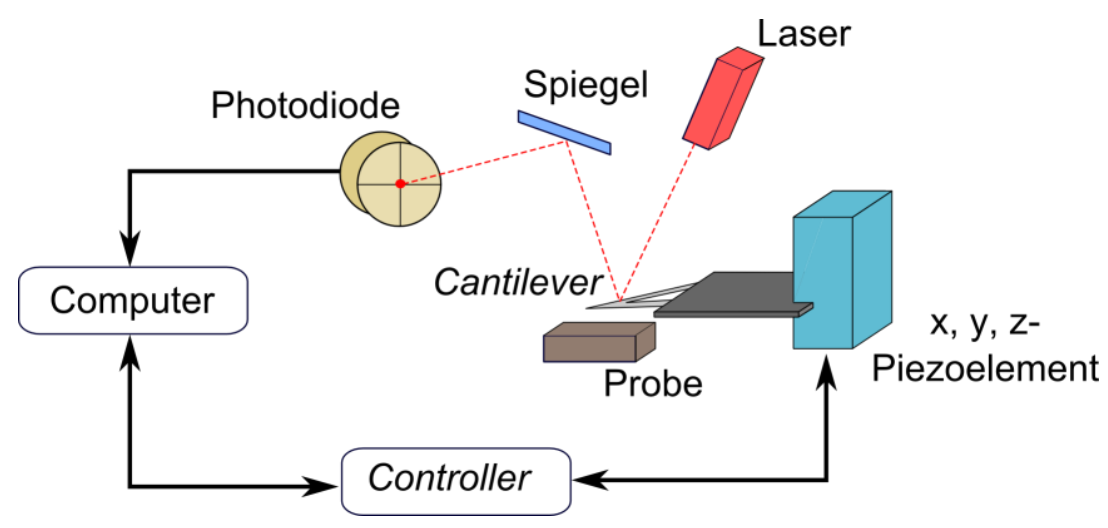

Abbildung 3.8: Schematische Darstellung des Messprinzips der Rasterkraftmikroskopie.

Der Cantilever gehorcht dabei dem Hookschen Gesetz und die Verbiegung ist proportional zur Kraft. Daher kann die vertikale Auslenkung des Cantilevers $\left(Z_{C}\right)$ durch eine Kraft $(F)$ über folgende Gleichung bestimmt werden

$$
Z_{\mathrm{C}}=\frac{4 F L^{3}}{E w d_{\mathrm{c}}^{3}} .
$$

Der Cantilever besitzt dabei das Elastizitätsmodul $E$, die Breite $w$, die Länge $L$ und die Dicke $d_{c \text {. }}$ [79]

\subsubsection{Kraftspektroskopie}

Mit Hilfe von Kraft-Abstandskurven ist es möglich, die mechanischen Eigenschaften einer Probe detailliert zu untersuchen. [83-84] Bei einer Kraftkurve wird die Spitze des Cantilevers mit einer definierten Geschwindigkeit zur Probe und wieder zurück gefahren. Die Spitze durchläuft hierbei den gesamten Bereich des Wechselwirkungspotentials, das sowohl attraktive als auch repulsive Kräfte beinhaltet. Vorherrschend sind attraktive van-der-Waals Wechselwirkungen und repulsive elektrostatische Interaktionen. [79]

Das Messprinzip beruht auf einer Veränderung der Position des Cantilevers in z-Richtung und der Detektion des Signals der Photodiode als Funktion der z-Piezobewegung. Die so erhaltene Messkurve des Photodiodensignals gegen die z-Piezobewegung kann bei bekannter Sensitivität und Federkonstante des Cantilevers in eine Kraft-Piezobewegungskurve umgerechnet werden. Die z-Piezobewegung ist eine Kombination aus der Bewegung des z-Piezos und der Verbiegung des Cantilevers. Wird von der Piezobewegung diese Verbiegung des Cantilevers subtrahiert, erhält man eine Kraftkurve als Funktion des Abstands zwischen der Spitze und der Probe. 


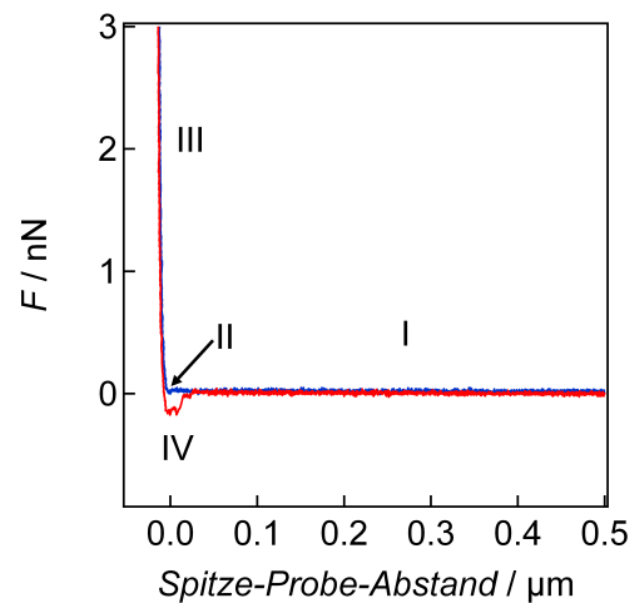

Abbildung 3.9: Kraft-Abstandskurve auf einem Avidin und Casein funktionalisiertem Glassubstrat. Die Annäherungskurve ist als blaue Linie und die Rückkurve ist als rote Linie dargestellt. Es sind die Bereiche Basislinie (I), Kontaktpunkt (II), Anstieg (III) und Adhäsion bei der Rückkurve (IV) markiert.

In Abbildung 3.9 ist eine typische Kraft-Abstandskurve auf einem harten Substrat gezeigt. Von der in rot dargestellten Annäherungskurve wird der konstante Anfangsbereich (I) als Basislinie erachtet und auf eine wirkende Kraft von im Mittel 0 gesetzt. An dem Punkt, an dem die Kurve in den quasi senkrechten Anstieg (III) übergeht, liegt der Kontaktpunkt (II) mit einem Spitze-Probe-Abstand der auf 0 gesetzt wird. Der in blau dargestellte Rückweg zeigt ein ähnliches Verhalten, jedoch haftet die Spitze durch adhäsive Kräfte an der Oberfläche (IV). Durch weiteres zurückziehen des Cantilevers reißen diese Bindungen und die Rückkurve kehrt zur die Basislinie zurück.

\subsubsection{Geräte und Messmodi}

Zur Aufnahme der Kraftkurven werden Rasterkraftmikroskope von JPK (NanoWizard 2 oder NanoWizard 3, JPK Instruments, Berlin, Deutschland) und trianguläre Siliziumnitrid-Cantilever von Bruker (Camarillo, USA) mit einer vom Hersteller angegebenen Federkonstante von $0.03 \mathrm{~N} / \mathrm{m}$ oder $0.1 \mathrm{~N} / \mathrm{m}$ verwendet. Für die Kompression der Vesikel werden Cantilever ohne Spitze (MLCT-O), bei den Versuchen mit Spitze werden Cantilever mit pyramidalen Indenter (MLCT) eingesetzt. Das Kraftmikroskop ist kombiniert mit einem inversen Fluoreszenzmikroskop zum Auffinden der Vesikel in der Probe.

\subsubsection{Durchführung}

Bei den Versuchen zur Kompression von Vesikeln zwischen zwei parallelen Platten kann der Cantilever nicht mit der sonst verwendeten Metalfeder am JPK-Cantileverhalter befestigt werden, da sie beim Annähern an die Probenoberfläche die Probe vor dem Cantilever berühren würde. Daher 
wird bei diesen Experimenten der Cantilever mit Hochvakuumfett an den aus Glas bestehenden Cantileverhalter befestigt (Abbildung 3.10).

Vor jeder Messung wird die Sensitivität und die Federkonstante des verwendeten Cantilevers durch die Methode von Hutter und Bechhofer bestimmt, bei der über das thermische Rauschspektrum das mittlere Verschiebungsquadrat ermittelt wird. Aus dem Gleichverteilungssatz wird dann die Federkonstante erhalten. [79, 85]

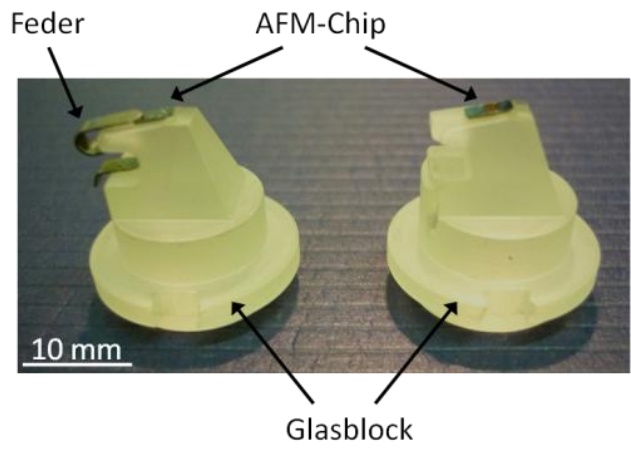

Abbildung 3.10: Aufnahme eines AFM-Chips mit Cantilever, der herkömmlich mit einer Metallfeder (links) beziehungsweise mit Hochvakuumfett (rechts) an einem JPK-Cantileverhalter aus Glas befestigt ist.

Mit Hilfe des Fluoreszenzmikroskops wird anschließend in der Probe das gewünschte Vesikel ausgesucht und ein Fluoreszenzbild des Vesikels zur Bestimmung des Radius aufgenommen. Durch gleichzeitige Hellfeld- und Fluoreszenzbeleuchtung ist es danach möglich, den Cantilever über die xund y-Piezos mittig über dem Vesikel zu positionieren. Es werden mehrere Kraftkurven auf einem Vesikel mit einer Geschwindigkeit von $1 \mu \mathrm{m} / \mathrm{s}$ aufgenommen. Die Vesikel werden dabei mit einer Normalkraft von 5 - $15 \mathrm{nN}$ komprimiert. 



\subsection{Kompression von Riesenvesikeln zwischen planparallelen Platten}

Ziel der Untersuchungen der Membraneigenschaften von Riesenvesikeln ist es, die Vorspannung $\sigma_{0}$ und das Flächenkompressionsmodul $K_{\mathrm{A}}$ der Membran von Vesikeln mit und ohne Aktincytoskelett zu bestimmen. Hierzu werden die GUVs mit Hilfe eines Kraftmikroskops zwischen zwei parallelen Platten zusammengedrückt und die dabei erhaltenen Kraft-Abstandskurven mit Hilfe eines Flüssigkeitstropfen-Modells analysiert (KVPP-Modell). Im Folgenden soll zuerst dargestellt werden, welche Vorteile die Kompression eines Vesikels mit einem Cantilever ohne Spitze gegenüber Indentationsexperimenten mit einem spitzen Indenter bietet. Anschließend wird die Membrantheorie der Kompression eines Vesikels zwischen planparallelen Platten (KVPP-Theorie) zusammengefasst.

\subsubsection{Kraftmikroskopische Untersuchungen von Vesikeln}

Bei der Rasterkraftspektroskopie werden meist Cantilever mit einer Spitze verwendet, die einen Radius von nur wenigen Nanometern besitzt. Nur diese Spitze am Ende des Federbalkens kommt bei der Aufnahme von Kraft-Abstandskurven mit der Probenoberfläche in Berührung. Im Gegensatz dazu wird durch die Verwendung eines Cantilevers ohne Spitze das Vesikel zwischen zwei Platten auf einer großen Fläche komprimiert. Im Folgenden werden die Vor- und Nachteile der Verwendung der zwei verschiedenen Cantileverarten bei der Untersuchung von Riesenvesikeln aufgezeigt.

\subsubsection{Indentation mit einem spitzen Indenter}

Bei kraftmikroskopischen Untersuchungen von Vesikeln mit einem Cantilever mit Spitze ist es entscheidend, dass die Spitze des Federbalkens exakt mittig über dem Vesikel positioniert wird. Abbildung 3.11 zeigt eine kombinierte Fluoreszenz-Hellfeldaufnahme, in der sowohl die Kontur des Vesikels als auch die Spitze des Cantilevers zu erkennen ist. 


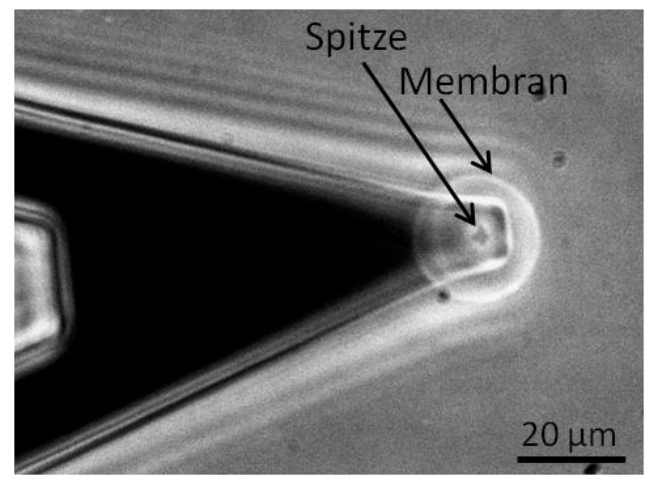

Abbildung 3.11: Fluoreszenz- und gleichzeitige Hellfeldaufnahme eines Vesikels über dem ein Cantilever mit Spitze positioniert ist. Die Membran ist als heller Kreis zu erkennen, die Spitze als dunklerer Punkt in der Mitte des Vesikels.

Bei der Aufnahme einer Kraft-Abstandskurve ist bei einer in der Mitte über dem Vesikel positionierten Spitze keine Verschiebung des Vesikels in den Fluoreszenzaufnahmen während der Indentation zu erkennen. Mehrfache Aufnahmen einer Kraft-Abstandskurve ohne Verstellen der Position des Cantilevers führen zu quasi identischen Verläufen der Kraft-Abstandskurve. Eine exemplarische Kraft-Abstandskurve ist für das oben gezeigte Vesikel in Abbildung 3.12 dargestellt.

A

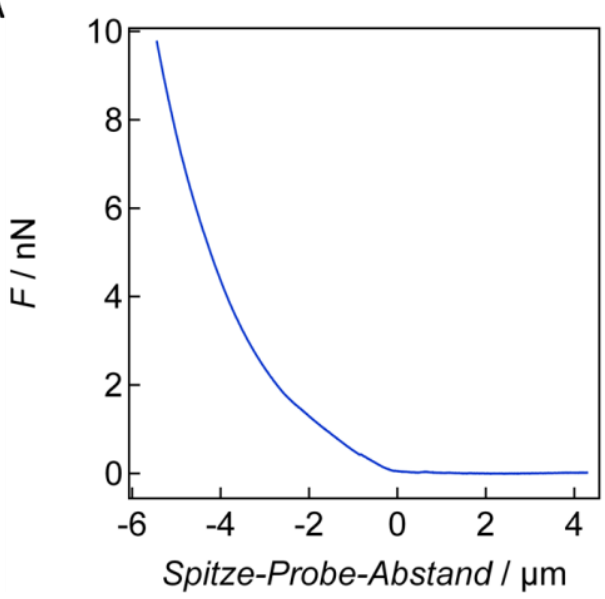

B

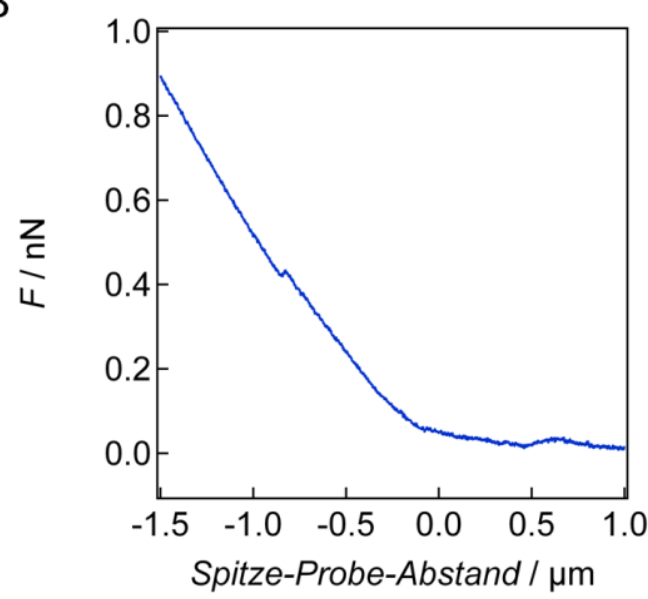

Abbildung 3.12: A) Kraft-Abstandskurve mit einem Cantilever mit Spitze auf einer Vesikelmembran in der flüssig-kristallinen Phase. B) Vergrößerter Ausschnitt des Anfangsbereiches der Steigung von der in (A) gezeigten Kraftkurve. Der Radius des indentierten Vesikels beträgt $11.4 \mu \mathrm{m}$.

Die Kraftkurven werden mit Hilfe eines Flüssigkeitstropfen-Modells [86] analysiert. Dabei handelt es sich um eine Vereinfachung des Modells von Maxwell-Fluiden mit konstanter Oberflächenspannung [87-88], und kann verwendet werden, wenn es sich aufgrund von kleinen Deformationen um ein linear elastisches Verhalten handelt. [86, 88-89] M. J. Rosenbluth et al. haben dieses Flüssigkeitstropfen-Modell für AFM-Experimente mit einem pyramidalen Indenter zur Untersuchung 
von runden, nicht-adhärenten Zellen weiterentwickelt. [88] Anhand dieses Modells ist es möglich, die Vorspannung und das Flächenkompressionsmodul einer runden Zelle bei bekannter Geometrie des Indenters und Radius der Zelle zu bestimmen.

Nach diesem Modell ergibt sich die Rückstellkraft des Cantilevers mit pyramidaler Spitze aus

$$
F=8 T S^{2}\left(\frac{1}{R_{\mathrm{V}}}+\frac{\cos \alpha}{S}\right)
$$

mit $T$ der Spannung der Vesikelmembran, $R_{\vee}$ dem Vesikelradius, $S$ der Entfernung vom Fußpunkt der mit dem Vesikel in konformen Kontakt stehenden Pyramide zur Mitte der Seite der quadratischen Grundfläche und $\alpha$ dem halben Öffnungswinkel der Pyramide. [88]

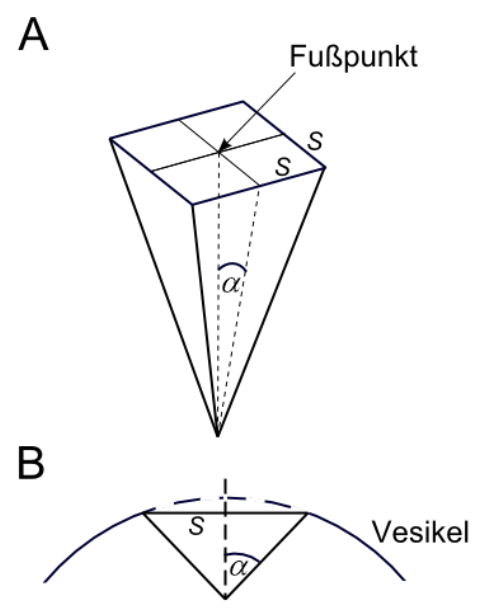

\section{Abbildung 3.13: A) Geometrie der pyramidalen Spitze des Cantilevers. B) Pyramidale Spitze die in ein Vesikel indentiert wird.}

Die Spannung setzt sich aus der Vorspannung $\left(\sigma_{0}\right)$ und dem Flächenkompressionsmodul $\left(K_{\mathrm{A}}\right)$ in Abhängigkeit der prozentualen Flächenausdehnung $\left(\frac{\Delta A}{A_{\mathrm{V}}}\right)$ des Vesikels zusammen [89]

$$
T=\sigma_{0}-K_{\mathrm{A}} \frac{\Delta A}{A_{\mathrm{V}}}
$$

Mit diesem Modell werden die Kraft-Abstandskurven untersucht, die auf den Vesikeln mit einer pyramidalen Spitze am Cantilever erhalten werden. Hierbei zeigt sich, dass der experimentell bestimmte Kurvenverlauf über weite Bereiche genau mit dem über eine Ausgleichsrechnung angepassten Kurvenverlauf übereinstimmt. Die Ausgleichsrechnung für die Kraft-Abstandskurve 
ergibt eine Vorspannung von $0.165 \mathrm{mN} / \mathrm{m}$ und ein Flächenkompressionsmodul von $0.022 \mathrm{~N} / \mathrm{m}$. Für 6 vermessene Vesikel beträgt der Mittelwert und die jeweilige Standartabweichung für $\left\langle\sigma_{0}\right\rangle=0.18 \pm 0.14 \mathrm{mN} / \mathrm{m}$ und $\left\langle K_{\mathrm{A}}\right\rangle=0.030 \pm 0.031 \mathrm{~N} / \mathrm{m}$.

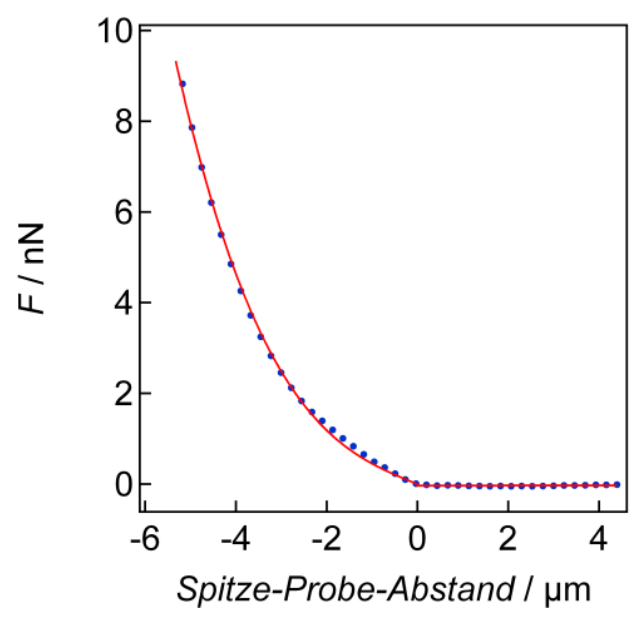

Abbildung 3.14: Experimentell bestimmte Kraft-Abstandskurve (blaue Punkte) und Kurvenverlauf, der mit Hilfe der Ausgleichsrechnung erhalten wird (rote Linie), für ein Vesikel in der flüssigkristallinen Phase mit einem Radius von $11.4 \mu \mathrm{m}$. Die mit dem Flüssigkeitstropfen-Modell berechnete Kraft-Abstandskurve ergibt: $\sigma_{0}=0.17 \mathrm{mN} / \mathrm{m}$ und $K_{\mathrm{A}}=0.022 \mathrm{~N} / \mathrm{m}$.

Der Wert der Vorspannung liegt somit über dem in der Literatur beschriebenen Bereich für nicht adhärente Vesikel auf einem Glassubstrat von $0.001-0.08 \mathrm{mN} / \mathrm{m}$. [47] Das Flächenkompressionsmodul ist zirka eine Zehnerpotenz geringer als das für DOPC-Membranen bestimmte Flächenkompressionsmodul $\left(K_{\mathrm{A}}=0.265 \mathrm{~N} / \mathrm{m}\right)$. [20, 46]

Bei genauerer Betrachtung der Kraft-Abstandskurve im Bereich des Kontaktpunktes (Abbildung 3.12 B) ist zu erkennen, dass es wahrscheinlich bereits vor dem gewählten Kontaktpunkt zu einer Berührung des Cantilevers mit der Membran kommt (bei zirka $0.8 \mu \mathrm{m}$ ). Nach diesem Kontakt ist jedoch der Anstieg der Kraft nicht stetig. Eine Ursache dafür könnte ein Ausweichen beziehungsweise minimales Verschieben des Vesikels durch den vom Cantilever applizierten Druck auf die Membran sein. Dies könnte insbesondere bei Vesikeln passieren, bei denen der Indenter nicht exakt mittig über dem Vesikel positioniert ist und somit der applizierte Druck nicht gleichmäßig auf alle Seiten der Membran übertragen wird. 
A

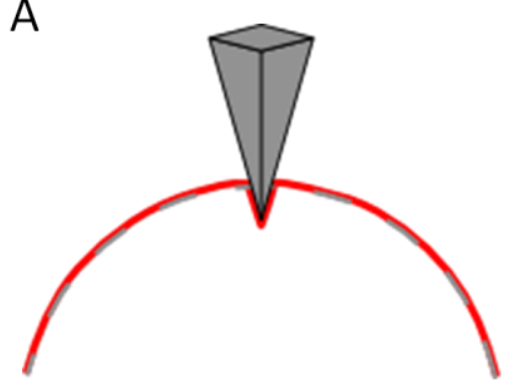

B

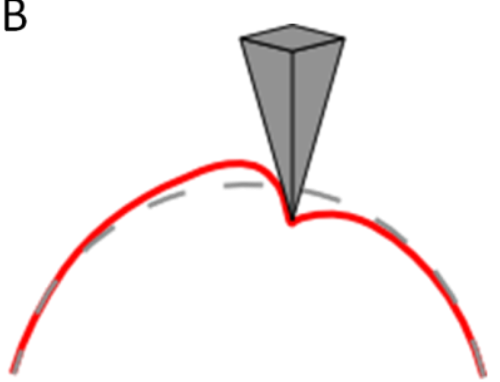

Abbildung 3.15: Schematische Darstellung eines indentierten Vesikels (rote Linie) mit einem pyramidalen Indenter. In (A) wird das Vesikel in der Mitte eingedrückt und weicht dem Indenter nicht aus im Gegensatz zu dem in (B) dargestellten Vesikel, das nicht mittig indentiert wird. Die ursprüngliche Vesikelkontur ist in grau skizziert.

Die späte Kontaktpunktwahl führt zu Überbestimmung der Anfangssteigung bei der Ausgleichsrechnung. Durch die vom Indenter bereits applizierte Spannung vor dem gesetzten Kontaktpunkt wird eine größere Vorspannung durch die Ausgleichsrechnung bestimmt als tatsächlich vorhanden. Ein Ausweichen beziehungswiese Verschieben des Vesikels bewirkt andererseits eine zu geringe Steigung in der gemessenen Kraft-Abstandskurve und führt somit zu einer Unterbestimmung des Flächenkompressionsmoduls.

\subsubsection{Kompression mit einem Cantilever ohne Spitze}

Um ein eventuelles Ausweichen des Vesikels bei der Indentation zu vermeiden, wird vom Cantilever mit Spitze zu einem Cantilever ohne Spitze gewechselt. Das Vesikel wird somit direkt zwischen dem Federbalken und der Probenoberfläche komprimiert. Bei der Kompression des Vesikels zwischen zwei parallelen Platten kann das Vesikel dem auf ihn applizierten Druck von oben nicht einseitig ausweichen.
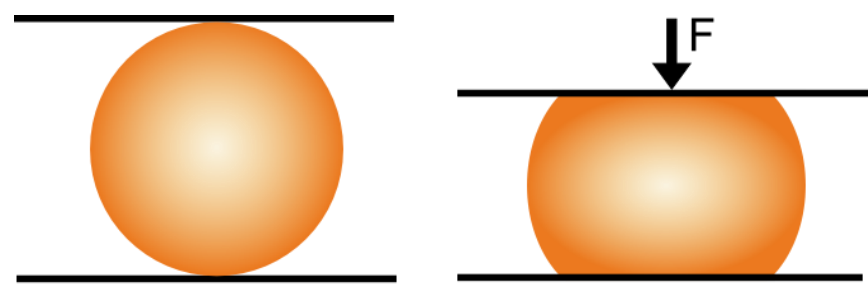

Abbildung 3.16: Schematische Darstellung der Kompression eines Vesikels zwischen zwei parallelen Platten.

Bei der Kompression eines Vesikels mit einem Cantilever ohne Spitze zeigt sich jedoch, dass sich das Vesikel verschiebt und zwar in Richtung der Halterung des Federbalkens. Dies ist bedingt durch den 
Aufbau des Rasterkraftmikroskops, in dem der Cantilever mit einer Neigung von $10-11^{\circ}$ zur Probenoberfläche steht um die Auslenkung des Cantilevers mit dem Lichtzeigerprinzip auszulesen. Diese Schrägstellung erzeugt eine laterale Kraftkomponente auf die Vesikeloberfläche und verursacht dadurch das Ausweichen des Vesikels zur Seite (Abbildung 3.17).

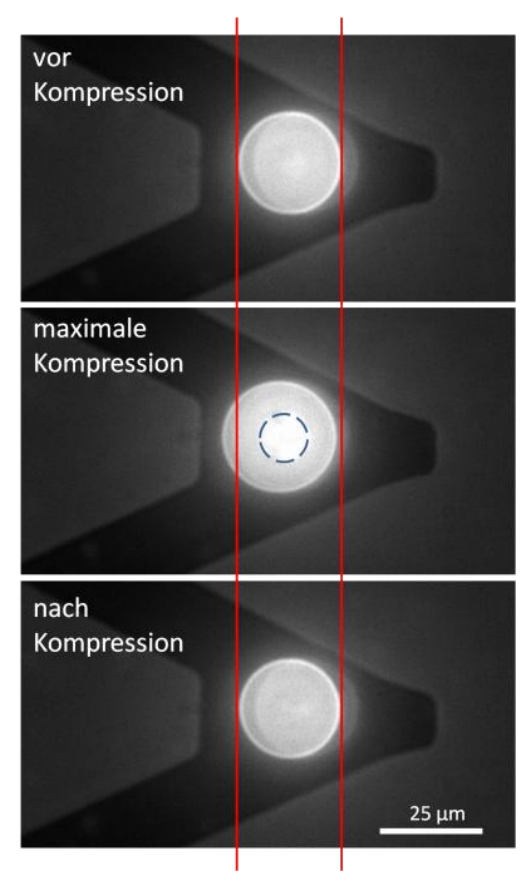

Abbildung 3.17: Fluoreszenz- und gleichzeitige Hellfeldaufnahmen, die die Verschiebung eines Vesikels durch die Kompression mit einem Cantilever ohne Spitze zeigen. Die Vesikelmembran ist als heller Kreis zu erkennen. In der mittleren Aufnahme ist die Adhäsionsfläche des Vesikels mit der Probenoberfläche anhand des hell leuchtenden Bereiches, der mit einem blauen Kreis markiert ist, zu erkennen.

Die Adhäsionsfläche des Vesikels an der Probenoberfläche liegt in der Mitte des nicht komprimierten Vesikels (blauer Kreis in Abbildung 3.17 Mitte) und nach dem Zurückfahren des Cantilevers befindet sich das Vesikel wieder in derselben Ausgangsposition, wie vor der Kompression (Abbildung 3.17, zwischen den roten Linien). Das Vesikel ist also an der Oberfläche adhäriert und verschiebt sich daher nicht im Ganzen, sondern nur der obere Teil des Vesikels weicht zur Seite aus. Charakteristisch für die so erhaltenen Kraft-Abstandskurven ist ab dem Kontaktpunkt eine langgezogene, geringe Steigung, welche durch die Auslenkung des Vesikels aus seiner Ruheposition resultiert. Aus diesem Grund ist die Position des Kontaktpunktes zwischen Vesikel und Cantilever in der Kraft-Abstandskurve nicht exakt zu bestimmen. 
A

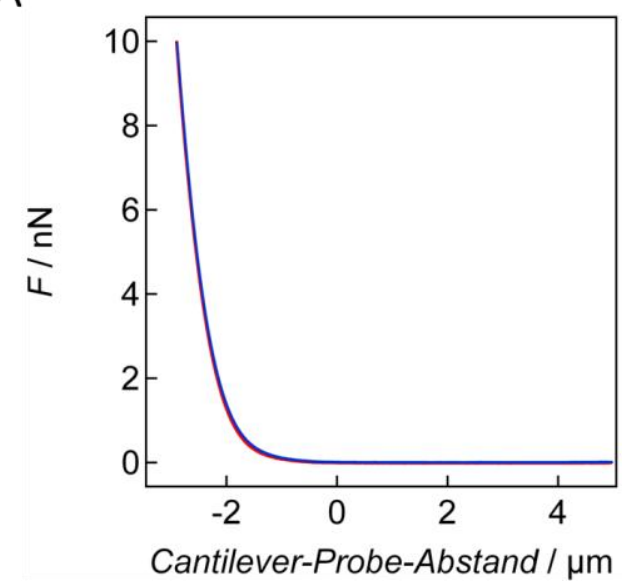

B

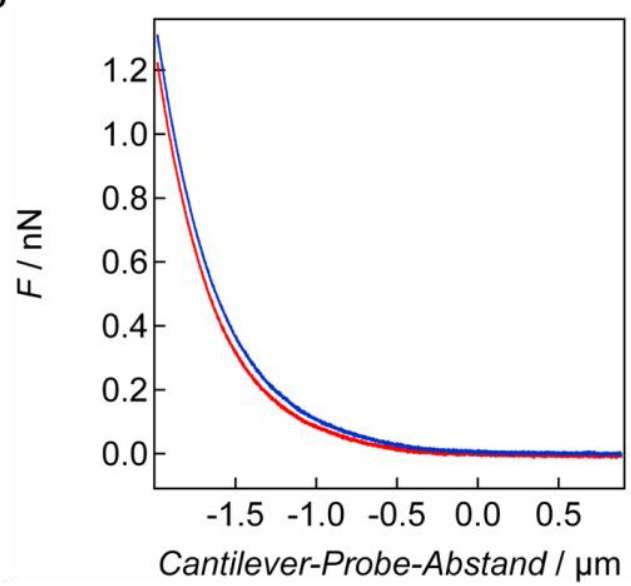

Abbildung 3.18: A) Kraft-Abstandskurven bei der Kompression eines Vesikels (Annäherung in blau und Rückweg in rot dargestellt) mit einem Cantilever ohne Spitze, der in einem $9^{\circ}$ Winkel zur Probenoberfläche steht. B) Vergrößerter Ausschnitt des Anfangsbereiches der Steigung von der in (A) gezeigten Kraftkurve. Der Radius des untersuchten Vesikels beträgt $12.2 \mu \mathrm{m}$.

Bei der Ausgleichsrechnung für eine solche Kraft-Abstandskurve unter Verwendung der Theorie der Vesikelkompression zwischen zwei parallelen Platten (siehe nächste Kapitel) gibt die ermittelte KraftAbstandskurve den gemessenen Kurvenverlauf nicht gut wieder (Abbildung 3.19). Die erhaltenen Werte für die Vorspannung und das Flächenkompressionsmodul sind daher nicht aussagekräftig.

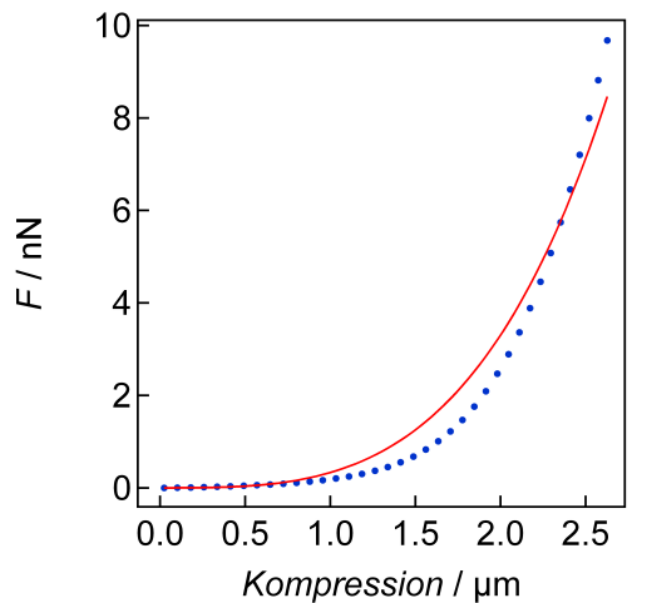

Abbildung 3.19: Experimentell bestimmte Kraft als Funktion der Kompression (blaue Punkte) bei der Kompression eines Vesikels und an die Kurve angepasster Kurvenverlauf mit dem KVPP-Modell (rote Linie). Der Radius des vermessenen Vesikels beträgt $12.2 \mu \mathrm{m}$. Die aus der Ausgleichsrechnung für die Kompression zwischen zwei parallelen Platten ermittelten Werte sind $\sigma_{0}=4.010^{-9} \mathrm{mN} / \mathrm{m}$ und $K_{\mathrm{A}}=1.4 \mathrm{~N} / \mathrm{m}$.

Durch Schrägstellung der Probe in einem $9^{\circ}$-Winkel zum Ausgleich der Verkippung des Cantilevers wird die Kompression des Vesikels zwischen zwei parallelen Platten ermöglicht. Hierdurch wird die 
Problematik der Verschiebung des Vesikels bei der Kompression verringert und das praktische Experiment in Einklang mit der in der Theorie getroffenen Annahme der symmetrischen Kompression des Vesikels gebracht.

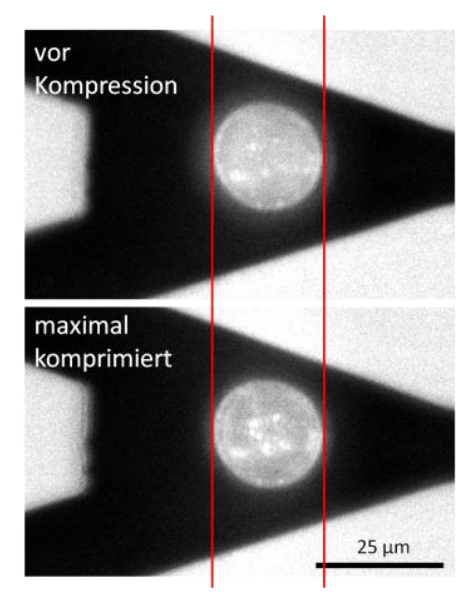

Abbildung 3.20: Fluoreszenz- und gleichzeitige Hellfeldaufnahmen eines Vesikels vor und bei zirka $10 \%$-iger Kompression mit einem Cantilever ohne Spitze auf einer um $9^{\circ}$-geneigten Probenoberfläche.

Allerdings wird die Qualität der Fluoreszenzaufnahmen der Vesikel während der Experimente durch das Schrägstellen der Probe verringert. In Abbildung 3.20 ist jedoch zu erkennen, dass das Vesikel während der Kompression bei der Verwendung einer schräg gestellten Probe nicht ausweicht.

Eine typische Kraft-Abstandskurve einer erfolgreichen Kompression eines Vesikels in der flüssigkristallinen Phase (DOPC/DOPE/DOPE-Biotin/A23187/TR-DHPE) zwischen einem Cantilever ohne Spitze und einer parallel dazu angeordneten Probenoberfläche ist in Abbildung 3.21 gezeigt.

Der Rückweg der Kraft-Abstandskurve verläuft im Bereich des Kontaktpunktes nicht entlang der Annäherungskurve. Dies liegt an attraktiven Wechselwirkungen zwischen Cantilever und Vesikel. Erst bei größerer Entfernung des Cantilevers von der Oberfläche lösen sich diese unspezifischen Bindungen. Je größer die Fläche zwischen der Kurve der Annäherung und dem Rückweg ist, desto größer sind die Wechselwirkungen zwischen Vesikel und Cantilever. Das Auftreten von Adhäsion wird durch die größere Fläche, die bei der Kompression des Vesikels mit einem Cantilever ohne Spitze in Kontakt steht, begünstigt. 
A

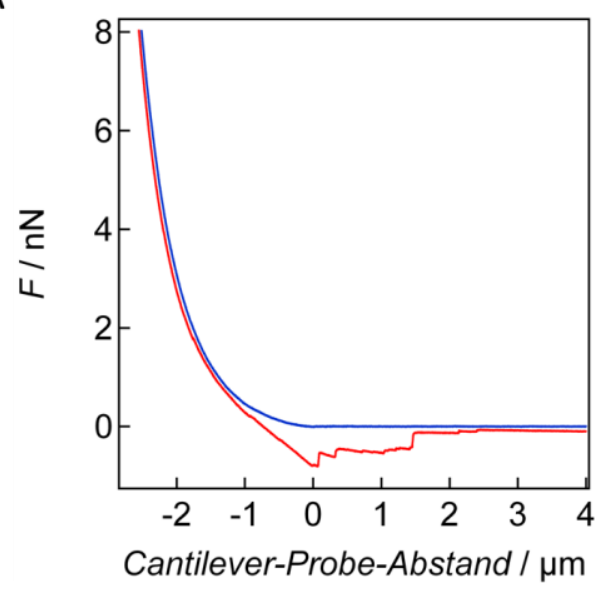

B

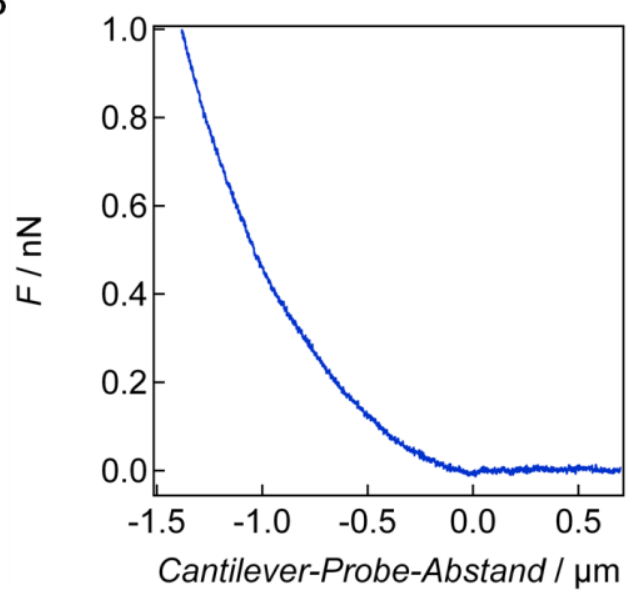

Abbildung 3.21: A) Kraft-Abstandskurven bei der Kompression eines Vesikels (Annäherung in blau und Rückweg in rot dargestellt) zwischen zwei parallelen Platten mit einem Cantilever ohne Spitze. B) Vergrößerter Ausschnitt des Kontaktpunktbereiches von der in (A) gezeigten Kraftkurve. Der Radius des untersuchten Vesikels beträgt $6.1 \mu \mathrm{m}$.

Der Kurvenverlauf, der aus der Kurvenanpassung mit dem KVPP-Modell beschrieben wird, stimmt weitestgehend mit der experimentell gemessenen Kraft-Abstandskurve überein (Abbildung 3.22). Im Folgenden wird das Eindrücken der Vesikel zwischen planparallelen Platten als Kompression bezeichnet.

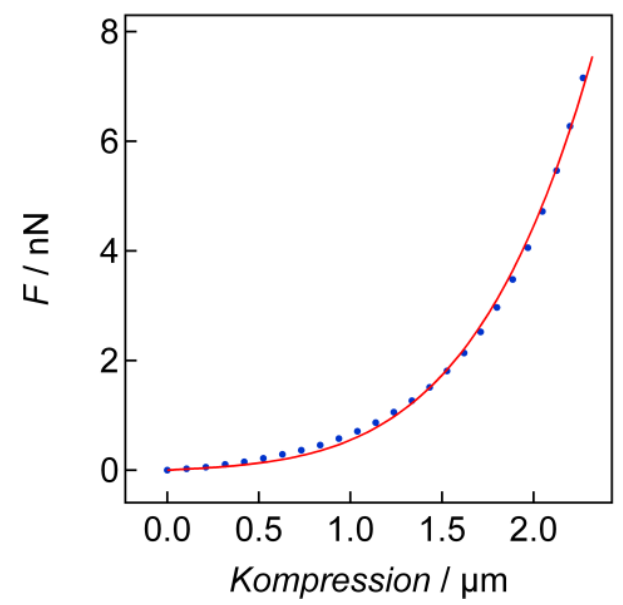

Abbildung 3.22: Experimentell bestimmter Kurvenverlauf der Kraft als Funktion der Kompression (blaue Punkte) während dem Komprimieren eines Vesikels mit spitzenlosem Cantilever und an die Kraft-Abstandskurve mit dem KVPP-Modell angepasster Kurvenverlauf (rote Linie). Der Radius des vermessenen Vesikels beträgt $6.1 \mu \mathrm{m}$. Die aus dem KVPP-Modell ermittelten Werte sind für die Vorspannung $\sigma_{0}=0.11 \mathrm{mN} / \mathrm{m}$ und für das Flächenkompressionsmodul $K_{\mathrm{A}}=0.12 \mathrm{~N} / \mathrm{m}$.

Die Versuche zur Bestimmung des Flächenkompressionsmoduls der Membranen werden daher durch Kompression zwischen dem Cantilever ohne Spitze und der parallel dazu geneigten Probenoberfläche durchgeführt. Hierdurch wird vermieden, dass das Vesikel der Quelle der applizierten Kraft 
ausweicht. Des Weiteren ist die Ausdehnung der Membranfläche, die entscheidend ist für die Bestimmung des Flächenkompressionsmoduls, durch die verwendete größere Fläche zum Eindrücken im Gegensatz zur spitzen Indentergeometrie vergrößert.

\subsubsection{Einführung in die Theorie zum KVPP-Modell}

Mit Hilfe der Membrantheorie, angewendet auf die Kompression von Vesikeln zwischen zwei parallelen Platten, soll ein Weg gefunden werden, mit dem sowohl die Vorspannung $\left(\sigma_{0}\right)$ als auch das Flächenkompressionsmodul $\left(K_{\mathrm{A}}\right)$ von Membranen bestimmt werden kann. Abbildung 3.23 zeigt schematisch die angenommene Geometrie des komprimierten Vesikels zwischen planparallelen Platten als orangefarbende Linie und die daraus resultierenden Radien im Vesikel. Der ursprüngliche Radius des Vesikels vor der Kompression beträgt $R_{\mathrm{v}}$.

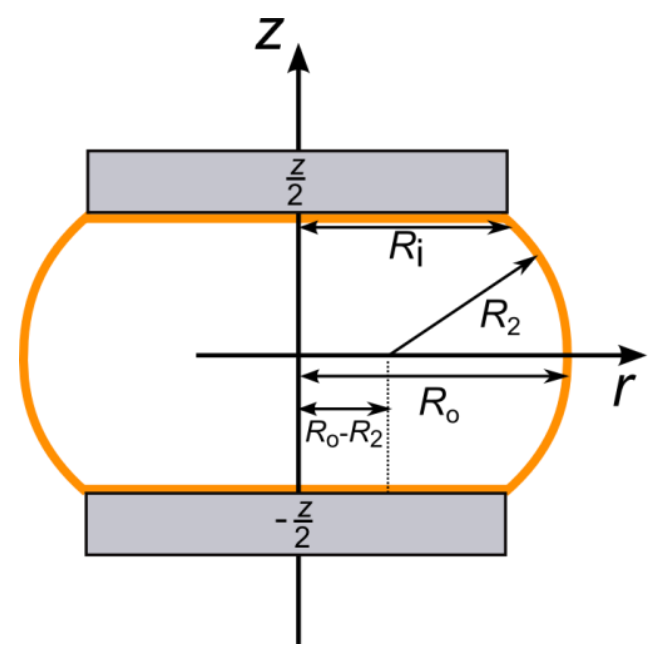

Abbildung 3.23: Schematische Zeichnung eines komprimierten Vesikels (orange Linie) zwischen zwei parallelen Platten. Zusätzlich sind die Radien eingezeichnet, die zur Bestimmung der Vesikelkontur verwendet werden $\left(\boldsymbol{R}_{\mathrm{i}}\right.$ : Kontaktradius, $\boldsymbol{R}_{\mathbf{2}}$ : meridianer Radius der freien Membranfläche, $R_{0}$ : äquatorialer Radius).

Das Flächenkompressionsmodul steht mit dem Elastizitätsmodul, das auch Youngsches Modul $\left(E_{\mathrm{Y}}\right)$ genannt wird, und mit dem Volumenkompressionsmodul $\left(K_{\mathrm{v}}\right)$ über die Dicke der Membran in Beziehung: $K_{\mathrm{A}} \propto E_{\mathrm{Y}} d \propto K_{\mathrm{V}} d$. [20, 34] Unter der Annahme, dass das Youngsche Modul einer Membran zirka bei $20 \mathrm{MPa}$ liegt, resultiert daraus ein Wert für das Flächenkompressionsmodul im Bereich von $0.1 \mathrm{~N} / \mathrm{m}$. Aus den Flächenkompressionsmodul kann das Biegemodul $(\kappa)$ über $\kappa=K_{\mathrm{A}} d^{2}$ bestimmt werden. [20] Der Einfluss der Krümmungsenergie ist jedoch bei dünnen Schalen sehr gering, so dass sie bei der Theorie für die Vesikelkompression vernachlässigt werden kann (Kapitel 3.4.6). 


\subsubsection{Berechnung der Kontur eines komprimierten Vesikels}

Die Form eines komprimierten Vesikels kann beschrieben werden mit Hilfe der Annahme, dass die Spannung $(T)$ einheitlich (isotrop) über der gesamten Oberfläche ist und der Druck $(P)$ Konstant bleibt. Allgemein verhält sich der Druck zur Spannung nach dem Young-Laplace Gesetz

$$
\Delta P=T\left(\frac{1}{\rho_{1}}+\frac{1}{\rho_{2}}\right)
$$

mit $\frac{1}{\rho_{1}}$ und $\frac{1}{\rho_{2}}$ den Hauptkrümmungen an jeder Position der Kontur. Sind $\Delta P$ und $T$ konstant, so folgt automatisch, dass die Gesamtkrümmung $\left(\frac{1}{\rho_{1}}+\frac{1}{\rho_{2}}\right)$ auch konstant an jedem Punkt der Kontur ist.

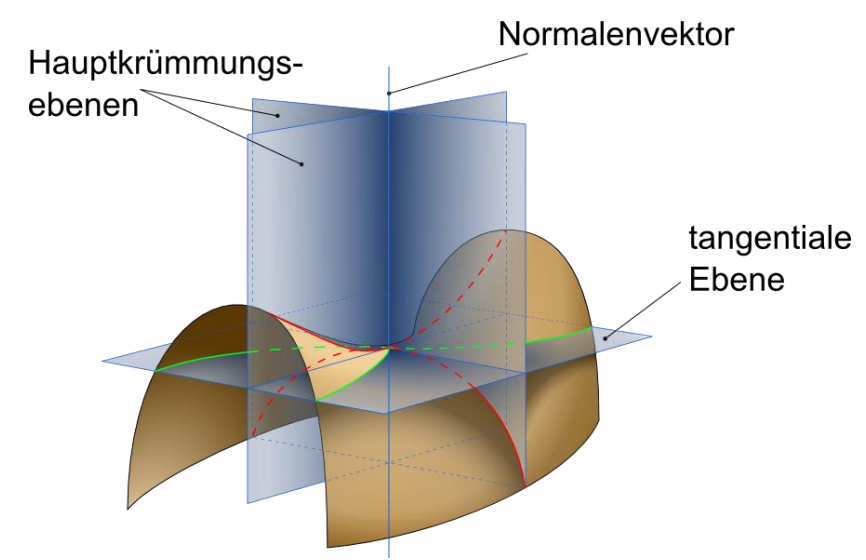

Abbildung 3.24: Schematische Darstellung einer gebogenen Fläche (braune Fläche) mit den zwei extremen (minimaler und maximaler) Hauptkrümmungsradien $\rho_{1}$ und $\rho_{2}$ (rote Linien). ${ }^{31}$

Unter der Annahme, dass $d s$ ein infinitesimales Linienelement von einem Meridian an einem beliebigen Punkt $O(r, z)$ ist, so ist die Projektion von $d s$ auf die $r$-Achse $d r=d s \cos \theta$ (Abbildung 3.25). Dementsprechend ist $r=\rho_{2} \sin \theta$ und mit der Näherung für kleine Winkel $\sin d \theta \approx d \theta=\frac{d s}{\rho_{1}}$ ergibt sich $d s=\rho_{1} d \theta$. Die Hauptkrümmungen lassen sich nach Eliminierung von $d s$ folgendermaßen beschreiben

\footnotetext{
${ }^{31}$ In Anlehnung an:

http://de.wikipedia.org/wiki/Hauptkr\%C3\%BCmmung (15.08.2012.)
} 


$$
\begin{gathered}
\frac{1}{\rho_{1}}=\frac{d \theta}{d s}=\frac{d \theta}{d r} \cos \theta=\frac{d u}{d r} \\
\frac{1}{\rho_{2}}=\frac{1}{r} \sin \theta=\frac{u}{r}
\end{gathered}
$$

mit $u=\sin \theta$.

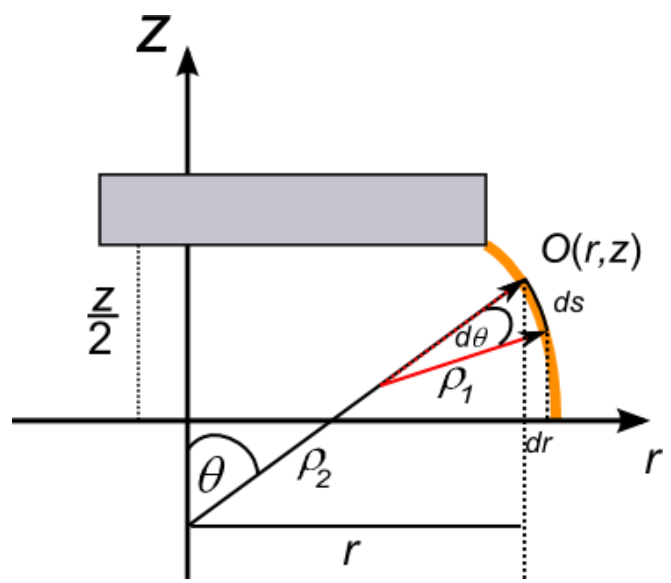

Abbildung 3.25: Schema zur Bestimmung der Frenet-Formeln.

Durch Einsetzen dieser Gleichungen in die Young-Laplace Gleichung erhält man

$$
\frac{\Delta P}{T}=\frac{d \theta}{d r} \cos \theta+\frac{1}{r} \sin \theta=\frac{1}{r} \frac{d}{d r} r \sin \theta
$$

beziehungsweise bei Substitution mit dem Parameter $u$

$$
\frac{\Delta P}{T}=\frac{d u}{d r}+\frac{u}{r}
$$

Da $\frac{\Delta P}{T}$ konstant ist $\left(\frac{\Delta P}{T}=C_{1}\right)$, erhält man durch Integration der Gleichung 3.10

$$
u=A r+\frac{B}{r}
$$

Über die Randbedingungen für den möglichen minimalen und maximalen Winkel

$$
\theta=\frac{\pi}{2} \quad \text { bei } \quad r=R_{0}
$$




$$
\theta=0 \quad \text { bei } \quad r=R_{\mathrm{i}}
$$

lassen sich $\mathrm{A}$ und $\mathrm{B}$ durch Einsetzen in Gleichung 3.11 in Abhängigkeit des Äquatorialradius $R_{0}$ und des Kontaktradius $R_{\mathrm{i}}$ ausdrücken

$$
\begin{gathered}
1=A R_{0}+\frac{B}{R_{0}} \\
0=A R_{\mathrm{i}}+\frac{B}{R_{\mathrm{i}}} \\
A=\frac{R_{0}}{R_{0}^{2}-R_{\mathrm{i}}^{2}} \\
B=\frac{-R_{\mathrm{i}}^{2} R_{0}}{R_{0}^{2}-R_{\mathrm{i}}^{2}}=-A R_{\mathrm{i}}^{2} .
\end{gathered}
$$

Solange der Punkt $O(r, z)$ im ersten Quadranten liegt, gilt unter Verwendung von $\cos ^{2} \theta+\sin ^{2} \theta=1$ und $\tan \theta=\frac{\sin \theta}{\cos \theta}$

$$
\frac{d z}{d r}=\tan \theta=\frac{\sin \theta}{\sqrt{1-\sin ^{2} \theta}}=\frac{u}{\sqrt{1-u^{2}}}
$$

Durch Integration der Gleichung 3.18 erhält man eine numerische Lösung für die frei-stehende Kontur des Vesikels $z(r)$, wenn die Kompressionstiefe $z_{\mathrm{d}}=2 R_{\mathrm{V}}-z$ und die Radien $R_{\mathrm{i}}$ und $R_{0}$ bekannt sind:

$$
z=2 \int_{R_{\mathrm{i}}}^{R_{0}} \frac{A r+\frac{B}{r}}{\sqrt{1-\left(A r+\frac{B}{r}\right)^{2}}} d r .
$$

Die Berechnungen einer Kraft-Abstandskurve für die Kompression eines Vesikels erfolgt unter der Annahme, dass es sich um eine freie, nicht-adhärente Membran handelt. Des Weiteren kann in erster Näherung die meridiane Kontur des komprimierten Vesikels, wie in Abbildung 3.26 gezeigt ist, als kreisförmig erachtet werden. Dies vereinfacht die numerische Berechnung der Kraft-Abstandskurven erheblich, da keine nummerischen Integrale gelöst werden müssen. Die Konturen des komprimierten 
Vesikels, mit der Annahme die Krümmung der freien Membran sei ein Kreisausschnitt (schwarze Linie), zeigt erst in der Vergrößerung geringe Abweichungen von der korrekt berechneten Kontur eines zwischen planparallelen Platten komprimierten Vesikels (grüne Linie).
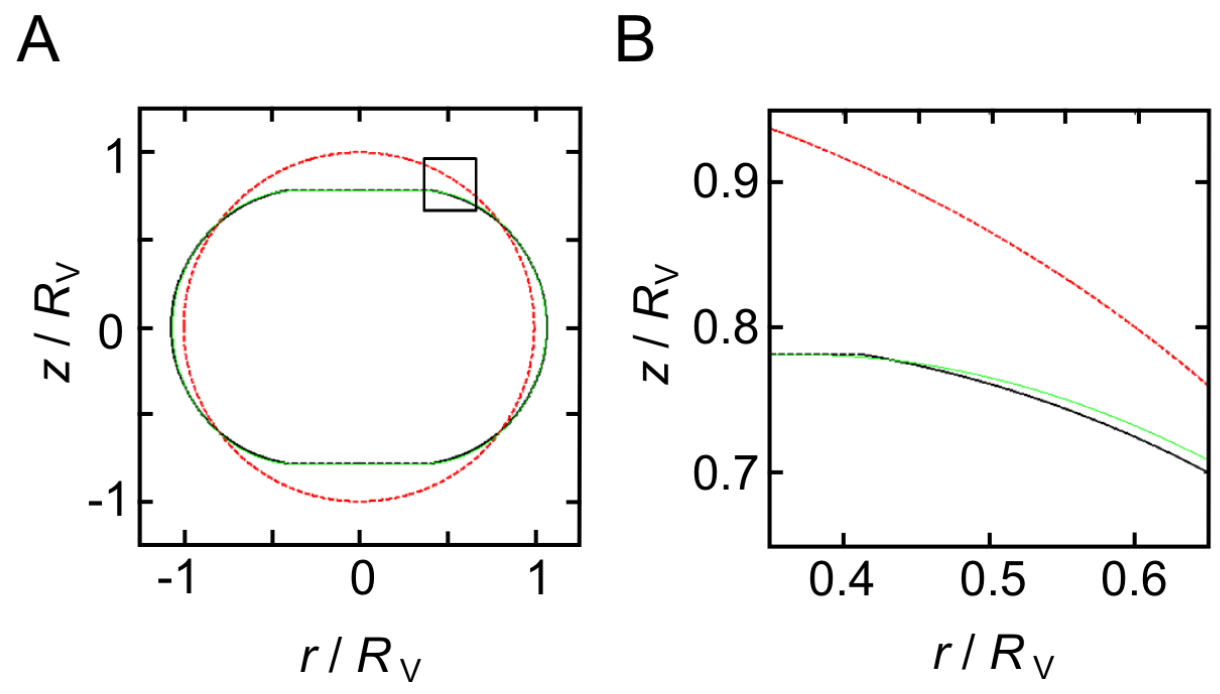

Abbildung 3.26: A) Auftragungen der Kontur eines um $25 \%$ des Durchmessers komprimierten Vesikels mit der real berechneten Form (grüne Linie) und der Kontur mit der Annahme einer kreisförmigen Krümmung (schwarze Linie) der freien Kontur des Vesikels. Die Vesikelkontur vor der Deformierung ist in rot dargestellt. Der schwarze Kasten markiert den Bereich, der vergrößert in (B) gezeigt ist. Die Kompression und die Radien sind im Verhältnis zu dem ursprünglichen Vesikelradius $\left(R_{\mathrm{V}}\right)$ aufgetragen.

Daher kann in guter Näherung die Kontur der freien Membran durch den Radius $R_{2}$ beschrieben werden. Die Kontur des komprimierten Vesikels kann somit über den Kontaktradius $R_{\mathrm{i}}$, den Äquatorialradius $R_{0}$ und den meridianen Radius der freien Membranfläche $R_{2}$ beschreiben werden (Abbildung 3.23).

Das Ziel ist es nun, einen Ausdruck für $R_{0}, R_{2}$ und $R_{\mathrm{i}}$ als Funktion der Distanz $(z)$ zwischen den zwei Platten zu finden. Um das System für einen komprimierten Vesikel vollständig zu beschreiben, werden somit drei Bedingungen benötigt. Die Lösung der daraus folgenden drei, das System vollständig beschreibenden Gleichungen führt zur gewünschten Kraft-Abstandskurve.

\subsubsection{Erste Bedingung: Konstante Krümmung}

Da die Spannung der Membran $T=\sigma_{0}+K_{\mathrm{A}} \frac{\Delta A}{A_{\mathrm{V}}}$ ist, bestehend aus dem Vorspannungsterm $\left(\sigma_{0}\right)$ und dem Dehnungsterm $\left(K_{\mathrm{A}} \frac{\Delta A}{A_{\mathrm{V}}}\right)$, und der innere und der äußere Druck auf das Vesikel $(\Delta P)$ konstant 
und gleichmäßig über der gesamten Oberfläche ist, ändert sich die Gesamtkrümmung während der Kompression des Vesikels nicht. Anders ausgedrückt, durch die Vernachlässigung der Krümmungsenergie (Kapitel: 3.4.6) und der Voraussetzung, dass die Dehnung nur in einer Ebene stattfindet, bleibt die Gesamtkrümmung in dem freien Bereich der Lipiddoppelschicht konstant. Da die Krümmung jedoch abhängig von der Stärke der Kompression $\left(z_{\mathrm{d}}\right)$ ist, ist die resultierende Energie aus der Kompression ausschließlich ein Ergebnis der Flächendehnung der Membran. Die Konsequenz ist Gleichung 3.20, die die Erhaltung der Krümmung für den freien Konturbereich der Membran ausdrückt

$$
C_{1}=\frac{1}{R_{0}}+\frac{1}{R_{2}}
$$

Dieser Zusammenhang ist gegeben, wenn die Spannung während der gesamten Kompression konstant ist. Für die Krümmungsradien der Kontur des komprimierten Vesikels ist der meridiane Radius $R_{2}$ und der äquatoriale Radius $R_{0}$ verwendet $\left(\rho_{1}=R_{0}\right.$ und $\rho_{2}=R_{2}$ ).

Da $C_{1}=2 A=2 \frac{R_{0}}{R_{0}^{2}-R_{\mathrm{i}}^{2}}$ ist, kann die erste Bedingung für die konstante Krümmung in Abhängigkeit der Variablen $R_{0}, R_{2}$ und $R_{\mathrm{i}}$ wie folgt ausgedrückt werden

$$
2 \frac{R_{0}}{R_{0}^{2}-R_{\mathrm{i}}^{2}}=\frac{1}{R_{0}}+\frac{1}{R_{2}}
$$

\subsubsection{Zweite Bedingung: Konstantes Volumen}

Unter der Annahme, dass sich das Volumen des Vesikels während der Kompression nicht ändert, kann das konstante Volumen für die zweite benötigte Bedingung verwendet werden. Das Volumen des sphärischen Vesikels vor der Kompression wird als $V_{v}$ und das Volumen des abgeflachten, komprimierten Vesikels als $V_{\mathrm{kV}}$ bezeichnet.

$$
V_{\mathrm{v}}=\frac{4}{3} \pi R_{\mathrm{V}}^{3}=V_{\mathrm{kV}}
$$

Das Volumen $V_{\mathrm{kV}}$ kann mit Hilfe der Washer-Methode für die Berechnung der Volumina von Rotationskörpern, bestimmt werden

$$
V_{\mathrm{kV}}=\pi \int_{-\frac{z}{2}}^{\frac{z}{2}} R_{0}-R_{2}+{\sqrt{R_{2}^{2}-z^{2}}}^{2} d z
$$


Durch Ersetzen von $R_{0}-R_{2}=R$ erhält man

$$
\begin{gathered}
V_{\mathrm{kV}}=\pi \int_{-\frac{z}{2}}^{\frac{z}{2}} R^{2}+2 R \sqrt{R_{2}^{2}-z^{2}}+R_{2}^{2}-z^{2} d z \\
V_{\mathrm{kV}}=\pi \int_{-\frac{z}{2}}^{\frac{z}{2}} R^{2}+R_{2}^{2}-z^{2} d z+\pi \int_{-\frac{z}{2}}^{\frac{z}{2}} 2 R \sqrt{R_{2}^{2}-z^{2}} d z .
\end{gathered}
$$

Diese Integrale lassen sich analytisch lösen zu

$$
\begin{aligned}
V_{\mathrm{kV}} & =2 \pi R\left[\frac{z}{2} \sqrt{R_{2}^{2}-z^{2}}+\frac{R_{2}^{2}}{2} \arcsin \frac{z}{R_{2}}\right]_{-\frac{z}{2}}^{\frac{z}{2}}+\frac{\pi z 12 R^{2}+12 R_{2}^{2}-z^{2}}{12} \\
& =2 \pi R\left[\frac{z}{2} \sqrt{R_{2}^{2}-\frac{z^{2}}{4}}+R_{2}^{2} \arcsin \frac{z}{2 R_{2}}\right]+\frac{\pi z 12 R^{2}+12 R_{2}^{2}-z^{2}}{12} .
\end{aligned}
$$

Demnach ergibt sich für die zweite Bedingung des konstanten Volumens folgender Ausdruck:

$$
\frac{4}{3} \pi R_{\mathrm{V}}^{3}=2 \pi R\left[\frac{z}{2} \sqrt{R_{2}^{2}-\frac{z^{2}}{4}}+R_{2}^{2} \arcsin \frac{z}{2 R_{2}}\right]+\frac{\pi z 12 R^{2}+12 R_{2}^{2}-z^{2}}{12}
$$

\subsubsection{Dritte Bedingung: Geometrie}

Abbildung 3.27 zeigt den geometrischen Zusammenhang von $R_{0}, R_{2}$ und $R_{\mathrm{i}}$, aus dem die dritte Gleichung resultiert, die das Gleichungssystem zur Bestimmung von $R_{0}, R_{2}$ und $R_{\mathrm{i}}$ vervollständigt.

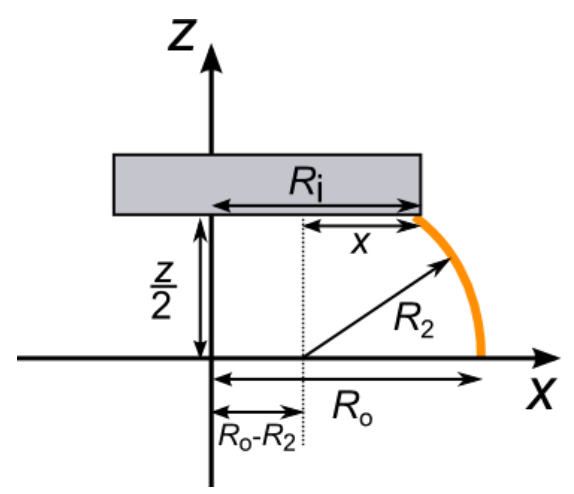

Abbildung 3.27: Geometrische Beziehung zwischen $\boldsymbol{R}_{0}, \boldsymbol{R}_{\mathbf{2}}$ und $\boldsymbol{R}_{\mathrm{i}}$. 
Nach dem Satz des Pythagoras gilt folgender Zusammenhang

$$
x^{2}+\left(\frac{z}{2}\right)^{2}=R_{2}^{2}
$$

Des Weiteren gilt

$$
R_{\mathrm{i}}=R_{0}-R_{2}+x
$$

Gleichung 3.29 und 3.30 kombiniert, ergibt für die Bedingung der Geometrie folgenden Ausdruck

$$
R_{\mathrm{i}}=R_{0}-R_{2}+\sqrt{R_{2}^{2}-\left(\frac{z}{2}\right)^{2}}
$$

\subsubsection{Bestimmung der auf das Vesikel wirkenden Kraft}

Die Rückstellkraft wird nur von der Spannung $T=\sigma_{0}+K_{A} \frac{\Delta A}{A_{\mathrm{V}}}$ des Vesikels verursacht. [89] Die auf das sphärische Vesikel applizierte Kraft durch die Kompression, kann über den Druck, der auf die Kontaktfläche des Vesikels $\pi R_{\mathrm{i}}^{2} \quad$ wirkt, berechnet werden

$$
F=\Delta P \pi R_{\mathrm{i}}^{2}
$$

Für das Kräftegleichgewicht am Äquator des komprimierten Vesikels gilt

$$
\begin{gathered}
\int_{0}^{2 \pi R_{0}} T d s+F=\Delta P \pi R_{0}^{2} \\
2 \pi R_{0} T+F=\Delta P \pi R_{0}^{2} .
\end{gathered}
$$

Durch Einsetzen der Gleichung 3.32 in 3.34 und anschließendes Auflösen nach der Kraft wird eine Gleichung erhalten, mit der man die Kraft in Abhängigkeit eines bestimmten Paares an $R_{0}$ und $R_{\mathrm{i}}$ Werten berechnen kann

$$
F=\frac{2 \pi R_{0} R_{\mathrm{i}}^{2} T}{R_{0}^{2}-R_{\mathrm{i}}^{2}}
$$




$$
=\frac{2 \pi R_{0} R_{\mathrm{i}}^{2}\left(\sigma_{0}+K_{\mathrm{A}} \frac{\Delta A}{A_{\mathrm{V}}}\right)}{R_{0}^{2}-R_{\mathrm{i}}^{2}} .
$$

Da $R_{0}$ und $R_{\mathrm{i}}$ von der Eindringtiefe abhängig sind, kann man Kraft-Abstandskurven $\left(F\left(z_{\mathrm{d}}\right)\right)$ berechnen, sofern man die beiden Radien über die Lösung des Gleichungssystems (Gleichung 3.21, 3.28 und 3.31) bestimmt hat.

\subsubsection{Bestimmung der Oberfläche eines komprimierten Vesikels}

Die Spannung des Vesikels während der Kompression ist von der Veränderung der Oberfläche $\Delta A=A_{\mathrm{kV}}-A_{\mathrm{V}}$ abhängig. Die Oberfläche des Vesikels vor Kompression $\left(A_{\mathrm{V}}\right)$ ist einfach die Oberfläche einer Kugel: $4 \pi R_{\mathrm{V}}^{2}$. Die aktuelle Oberfläche des komprimierten Vesikels $\left(A_{\mathrm{kv}}\right)$ setzt sich aus der freien Membran und den Flächen in Kontakt mit den zwei Platten zusammen

$$
A_{\mathrm{kV}}=2 \pi R_{\mathrm{i}}^{2}+2 \pi \int_{-\frac{z}{2}}^{\frac{z}{2}} R+\sqrt{R_{2}^{2}-z^{2}} \sqrt{1+\left(\frac{-z}{\sqrt{R_{2}^{2}-z^{2}}}\right)^{2}} d z
$$

Der zweite Term entstammt der Oberfläche für rotierende Körper $\left(A_{\text {Rev }}\right)$ bei Rotation um die z-Achse

$$
A_{\mathrm{Rev}}=2 \pi \int_{a}^{b} g z \sqrt{1+\left(\frac{d g z}{d z}\right)^{2}} d z
$$

Gleichung 3.38 konnte analytisch gelöst werden zu

$$
A_{\mathrm{kV}}=2 \pi R_{\mathrm{i}}^{2}+2 \pi\left(R R_{2} 2 \arcsin \left(\frac{z}{2 R_{2}}\right)+R_{2} z\right)
$$

Grundsätzlich wird zur Anpassung von Kraft-Abstandskurven an die experimentell erhaltenen Daten wie folgt verfahren: Für jeden Plattenabstand $z$ wird die Kontur beziehungsweise die Radien $R_{0}, R_{2}$ und $R_{\mathrm{i}}$ durch lösen des Gleichungssystems (Gleichung 3.21, 3.28 und 3.31) bestimmt. Anschließend 
wird die daraus resultierende Flächendehnung (Gleichung 3.39) berechnet und damit die verbundenen Kräfte als Funktion der Kompression $\left(z_{d}\right)$ ermittelt (Gleichung 3.36).

\subsubsection{Beitrag der Krümmungsenergie}

Die Biegeenergie $\left(E_{\mathrm{K}}\right)$ pro Fläche ist von der Krümmung und der Schichtdicke $(d)$ abhängig.

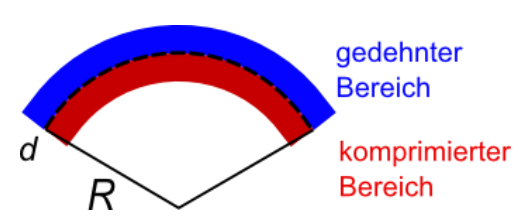

Abbildung 3.28: Schematische Darstellung der in Gleichung 3.40 angenommenen Situation einer gekrümmten Schicht.

$$
\begin{gathered}
E_{\mathrm{K}}=\frac{1}{L^{2}} \int_{0}^{L} \int_{0}^{L} \int_{-\frac{d}{2}}^{\frac{d}{2}} \frac{E_{\mathrm{Y}}}{2}\left(\frac{R+z}{R} d x d y d z-d x d y d z\right)^{2} \frac{1}{d x d y d z} \\
E_{\mathrm{K}}=\frac{E_{\mathrm{Y}}}{2} \int_{-\frac{d}{2}}^{\frac{d}{2}} \frac{z}{R} d z=\frac{1}{24} E_{\mathrm{Y}} \frac{d^{3}}{R^{2}}
\end{gathered}
$$

Ersetzt man $E_{\mathrm{Y}}=K_{\mathrm{A}} / d$, ergibt sich folgende Gleichung

$$
E_{\mathrm{K}}=\frac{1}{24} K_{\mathrm{A}}\left(\frac{d}{R}\right)^{2}
$$

Da $E_{\mathrm{K}}=\frac{1}{2} \kappa \frac{1}{R^{2}}$ ist, kann das Biegemodul einer einzelnen elastischen Schicht durch

$$
\kappa=\frac{K_{\mathrm{A}} d^{2}}{12}
$$

berechnet werden.

Eine Lipidmembran, wie sie ihm Rahmen dieser Arbeit verwendet wurde, besteht jedoch aus zwei Schichten. Das Aufspalten der Lipiddoppelschicht in zwei Schichten mit jeweils der halben Dicke führt zu wesentlichen Unterschieden für die aufzuwendende Energie während der Krümmung und Gleichung 3.43 muss daher angepasst werden. [20] 
Mit der Annahme, dass es sich um zwei getrennte Schichten handelt, die aufeinander gleiten können, ohne das hierzu Scherenergie benötigt wird [34], kann die Verbiegung einer Lipiddoppelschicht mit der Krümmung von zwei unabhängig voneinander gekrümmten Schichten der halben Schichtdicke gleichgesetzt werden. Hierdurch reduziert sich die Biegeenergie im Vergleich zu einer einzelnen, elastischen Schicht mit derselben Dicke um den Faktor 4. Die Beziehung zwischen Flächenkompressions- und Krümmungsmodul modifiziert sich für ein Zwei-Schichten-Modell zu

$$
\kappa=\frac{K_{\mathrm{A}} d^{2}}{48} .
$$

Würde man anstelle des Modells von zwei separaten Schichten ein Lipiddoppelschichtmodell verwenden, bei dem die Membran zwar aus zwei Schichten aufgebaut ist, die jedoch durch Reibung in Kontakt zueinander stehen, müsste der Nenner in Gleichung 3.44 durch den Wert 24 ausgetauscht werden. [20]

Bei den sonst häufig durchgeführten Ansaugexperimenten von Vesikeln oder Zellen mit Mikropipetten oder Eindrückexperimenten mit spitzen Indentern, wie sie normalerweise bei kraftmikroskopischen Versuchen verwendet werden, wird eine nennenswerte Krümmung der Membran an den Enden verursacht [90-91], die eine messbare Rückstellkraft verursacht. Im Gegensatz dazu entsteht bei der im Rahmen dieser Arbeit angewendeten Kompression von Vesikeln zwischen zwei parallelen Platten nur eine minimale Erhöhung der Krümmung. Die dabei auftretende Biegeenergie kann vernachlässigt werden, wie die nachfolgende Abschätzung zeigt.

M. Yoneda zeigte, dass die Krümmung einer Platte mit der einheitlichen Dicke $d$ in eine gebogene Oberfläche eine Verformungsenergie $d E$ erfordert, die im Flächenelement $d A$ gespeichert wird [92]

$$
d E=\frac{E_{\mathrm{Y}} d^{3}}{241-v^{2}}\left(\frac{1}{\rho_{1}^{2}}+\frac{1}{\rho_{2}^{2}}+\frac{2 v}{\rho_{1} \rho_{2}}\right) d A .
$$

$\rho_{1}$ und $\rho_{2}$ sind wieder die Hauptkrümmungsradien, $E_{Y}$ das Youngsche Modul der Doppelschicht und $v$ die Poissonzahl. Die Verformungsenergie die im komprimierten Vesikel durch die Verbiegung gespeichert wird, ist $E_{\mathrm{kV}}-E_{\mathrm{V}}$. Für den ursprünglich runden Vesikel mit $\rho_{1}=\rho_{2}=R_{\mathrm{V}}$ und der Oberfläche $A_{\mathrm{V}}=4 \pi R_{\mathrm{V}}^{2}$ kann die Energie des sphärischen Vesikels berechnet werden ( $v=0.5$ )

$$
E_{\mathrm{V}}=\frac{2 \pi}{3} E_{\mathrm{Y}} d^{3}
$$


Für die Bestimmung der Krümmungsenergie der komprimierten Vesikel muss die Membranfläche in zwei Bereiche eingeteilt werden. Die Kontaktfläche $A_{\text {Kont }}$ der Membran mit den zwei parallelen Platten ist nicht gekrümmt $\rho_{1}=\rho_{2}=\infty$. Für die Oberfläche der freien Kontur $A_{\mathrm{kV}}-2 A_{\text {Kont }}$ beträgt die Hauptkrümmung $\frac{1}{\rho_{1}}+\frac{1}{\rho_{2}}=\frac{1}{R_{0}}+\frac{1}{R_{2}}$. Für den Krümmungsterm der Energiedichte (Gleichung 3.45) folgt daraus

$$
\frac{1}{\rho_{1}^{2}}+\frac{1}{\rho_{2}^{2}}+\frac{2 v}{\rho_{1} \rho_{2}}=\left(\frac{1}{\rho_{1}}+\frac{1}{\rho_{2}}\right)^{2}-2 \frac{1-v}{\rho_{1} \rho_{2}} \leq\left(\frac{1}{R_{0}}+\frac{1}{R_{2}}\right)^{2} .
$$

Hieraus kann die maximal benötigte Biegeenergie für das komprimierte Vesikel ( $\left.E_{\mathrm{kV} \text { max }}\right)$ bestimmt werden. Beispielhaft wird die aufzuwendende Biegeenergie für ein Vesikel berechnet, das bis zur Hälfte des ursprünglichen Durchmessers zusammengedrückt wird. Dies entspricht einer stärkeren Kompression, als sie in den praktischen Experimenten durchgeführt wurde.

Durch Berechnung der Kontur für ein um $50 \%$ zusammengedrücktes Vesikel konnte die von M. Yoneda gefundenen Veränderungen für komprimierte Seeigeleizellen auch bei Vesikeln gezeigt werden. Dazu wurde gemäß Gleichung 3.19 die Kontur des komprimierten Vesikels exakt berechnet. Die Zunahme der Krümmung durch das Komprimieren beträgt $34 \%\left(\frac{1}{R_{0}}+\frac{1}{R_{2}}=1,34 \frac{2}{R_{\mathrm{V}}}\right)$, der Anteil der Fläche in Kontakt mit den Platten beläuft sich auf $16 \% A_{\text {kont }}=0,16 A_{\mathrm{V}}$ und die Zunahme der gesamten Membranoberfläche entspricht $13 \% \quad A_{\mathrm{kV}}=1,13 A_{\mathrm{V}}$. [92] Hieraus lässt sich mit Hilfe der folgenden Gleichung die maximale Biegeenergie des Vesikels berechnen, das auf den halben Anfangsdurchmesser komprimiert ist

$$
E_{\mathrm{kV} \max }=\frac{E_{\mathrm{Y}} d^{3}}{241-v^{2}}\left(\frac{1}{R_{0}}+\frac{1}{R_{2}}\right)^{2} A_{\mathrm{kV}}-2 A_{\mathrm{kont}}=1.3 \pi E_{\mathrm{Y}} d^{3}
$$

Für ein Youngsches Modul von $10 \mathrm{MPa}$ und einer Membrandicke von $5 \mathrm{~nm}$ ergibt dies eine zusätzliche Biegeenergie durch das Komprimieren von $E_{\mathrm{kV} \max }-E_{\mathrm{V}}=0,63 \pi E_{\mathrm{Y}} d^{3} \approx 10^{-18} \mathrm{~J}$.

Die Energie, die für die zusätzliche Krümmung der Lipidmembran benötigt wird, ist im Vergleich zu der Arbeit, die auf das Vesikel ausgeübt wird $\int F d z \approx 10^{-15} \mathbf{J}$, um Größenordnungen kleiner. Daher kann die Annahme, dass die Biegeenergie das mechanische Verhalten des Vesikels während der Kompression nicht beeinflusst, bedenkenlos getroffen werden. 


\subsubsection{Modellrechnungen}

Im folgenden Kapitel sollen die Einflüsse von verschiedenen Parametern auf das aufgestellte Plattenmodell genauer erläutert werden. Hierzu werden Plots von Kraft-Abstandskurven bei vorgegebenen Parametern gemacht und die Änderungen des Äquatorialradius $\left(R_{0}\right)$ und des Kontaktradius mit den Platten $\left(R_{\mathrm{i}}\right)$ in Abhängigkeit von der Kompression gezeigt.

\subsubsection{Einfluss der Kompression auf die Vesikelkontur}

Die Form eines Vesikels, der um $25 \%$ des ursprünglichen Vesikeldurchmessers komprimiert ist, ist in Abbildung 3.29 gezeigt.

A

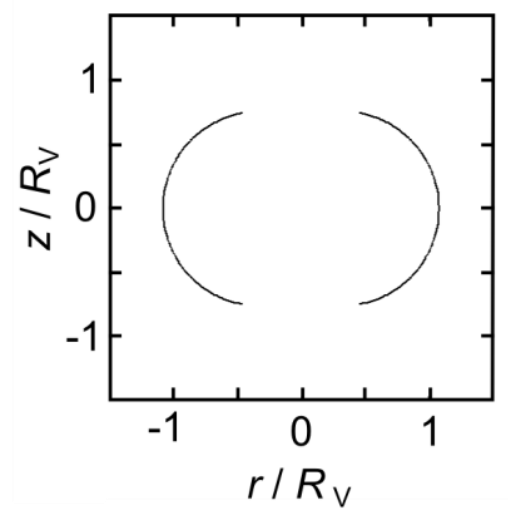

B

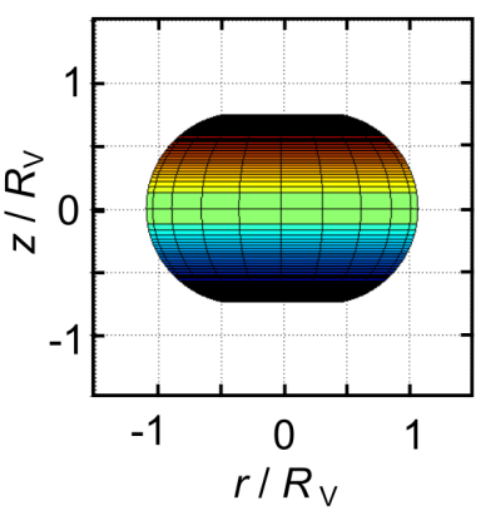

C

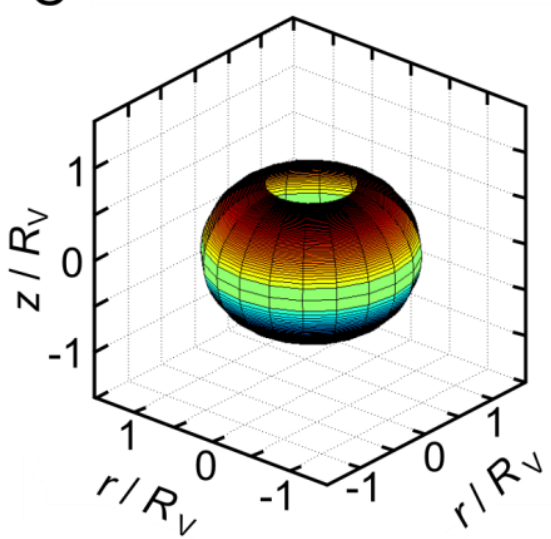

Abbildung 3.29: Kontur eines um $25 \%$ komprimierten Vesikels. A) Zweidimensionale Kontur des freien Membranbereiches. B und C) Dreidimensionale Struktur in der Seitenansicht und von schräg oben auf das Vesikel. Die Achsen sind in Abhängigkeit des ursprünglichen Vesikelradius $\left(R_{\mathrm{V}}\right)$ aufgetragen. Die vorgegebenen Parameter sind: $\sigma_{0}=0.5 \mathrm{mN} / \mathrm{m}$ und $K_{\mathrm{A}}=0.1 \mathrm{~N} / \mathrm{m}$.

Die Hauptkrümmung $\left(C_{1}=2 A=\frac{R_{0}}{R_{0}^{2}-R_{i}^{2}}\right)$ ändert sich im Vergleich zu der ursprünglichen Krümmung des Vesikels $\left(\frac{2}{R_{\mathrm{V}}}\right)$ dabei um $10.5 \%$. Der Kontaktradius nimmt insbesondere bei geringen Kompressionstiefen deutlich zu, wo hingegen der äquatoriale Radius quasi linear mit der Kompression ansteigt (Abbildung 3.30). 
A

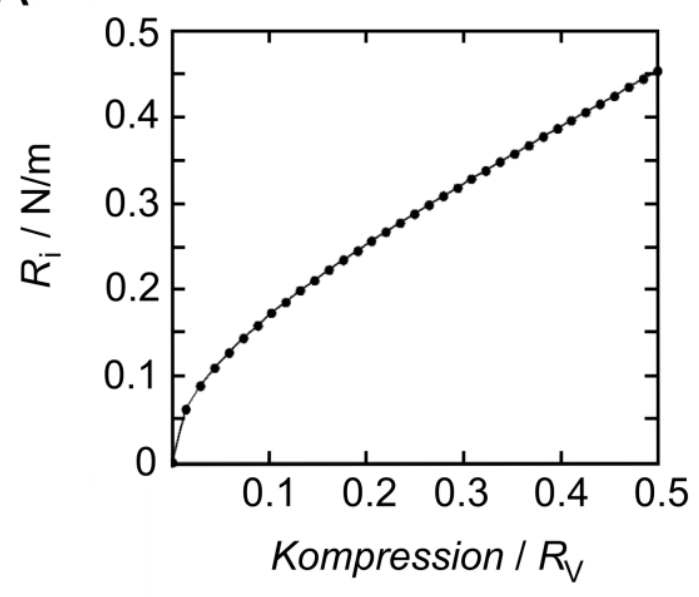

B

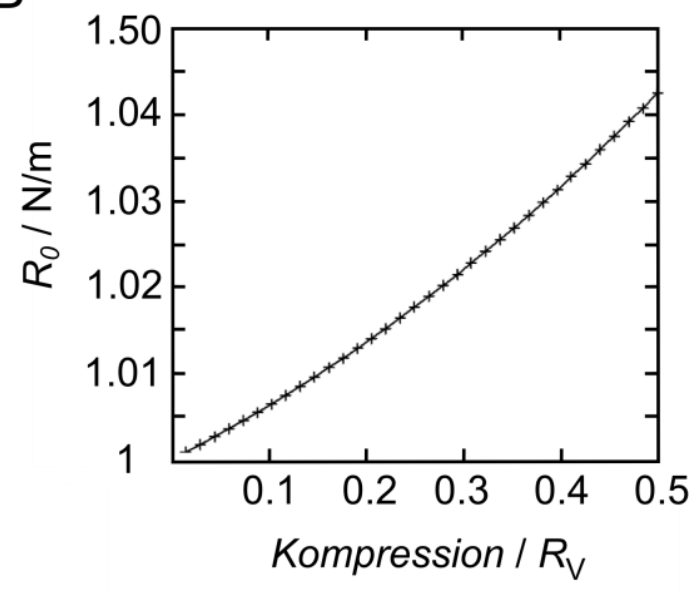

Abbildung 3.30: Veränderung A) des Kontaktradius $\left(R_{i}\right)$ und B) des Äquatorialradius $\left(R_{0}\right)$ als Funktion der Kompressionstiefe. Die Kompression und die Radien sind im Verhältnis zu dem ursprünglichen Vesikelradius $\left(R_{\mathrm{V}}\right)$ aufgetragen. Die vorgegebenen Parameter sind $\sigma_{0}=0.5 \mathrm{mN} / \mathrm{m}$ und $K_{\mathrm{A}}=0.1 \mathrm{~N} / \mathrm{m}$.

\subsubsection{Kraft-Abstandskurven in Abhängigkeit von $\sigma_{0}$ und $K_{\mathrm{A}}$}

Die beiden folgenden Plots zeigen den Einfluss der Vorspannung $\sigma_{0}$ beziehungsweise des Flächenkompressionsmoduls $K_{\mathrm{A}}$ auf den Verlauf von Kraft-Abstandskurven bei einem Vesikel mit einem Ausgangsradius von $8 \mu \mathrm{m}$.

Durch Erhöhung der Vorspannung und des Flächenkompressionsmoduls steigen die Kräfte, die benötigt werden, ein Vesikel zu komprimieren. Die Vergrößerung der Vorspannung zeigt schon bei geringer Kompression einen starken Anstieg in den Kraft-Abstandskurven. Hingegen wirken sich die Veränderungen des Flächenkompressionsmoduls eher bei größeren Kompressionen aus. 
A

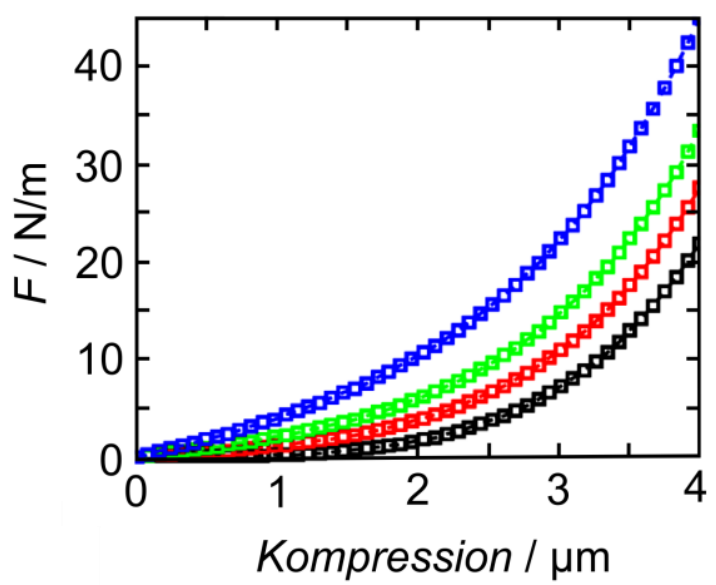

B

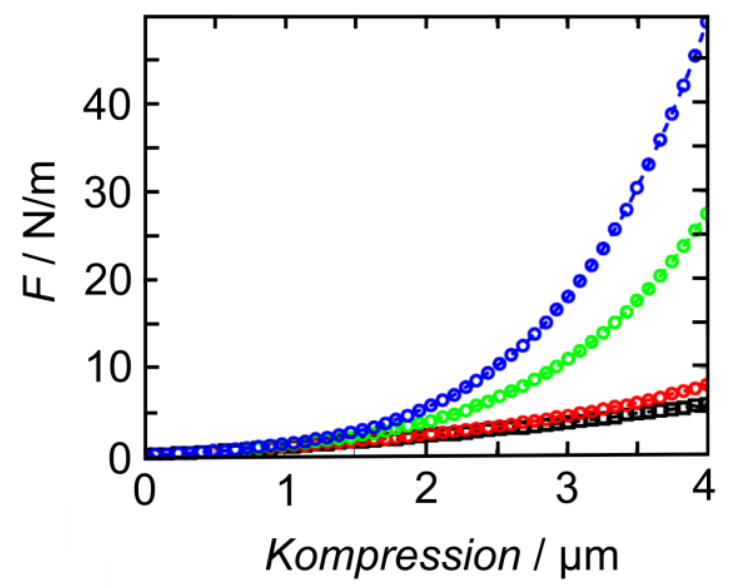

Abbildung 3.31: A) Einfluss der Vorspannung auf eine Kraft-Abstandskurve bei einem vorgegebenen $K_{\mathrm{A}}$-Wert von $0.1 \mathrm{~N} / \mathrm{m}$. Schwarze Symbole: $\sigma_{0}=0.01 \mathrm{mN} / \mathrm{m}$, rote Symbole: $\sigma_{0}=0.5 \mathrm{mN} / \mathrm{m}$, grüne Symbole: $\sigma_{0}=1 \mathrm{mN} / \mathrm{m}$, blaue Symbole: $\sigma_{0}=2 \mathrm{mN} / \mathrm{m}$. B) Einfluss des Flächenkompressionsmoduls auf den Verlauf einer Kraft-Abstandskurve bei einem vorgegebenen $\sigma_{0}$-Wert von $0.50 \mathrm{mN} / \mathrm{m}$. Schwarze Symbole: $K_{\mathrm{A}}=0$, rote Symbole: $K_{\mathrm{A}}=0.01 \mathrm{~N} / \mathrm{m}$, grüne Symbole: $\kappa_{\mathrm{A}}=0.1 \mathrm{~N} / \mathrm{m}$, blaue Symbole: $\kappa_{\mathrm{A}}=0.2 \mathrm{~N} / \mathrm{m}$. Beide Plots sind jeweils gegen die Kompression $z_{\mathrm{d}}$ aufgetragen und der Radius $R_{V}$ beträgt jeweils $8 \mu \mathrm{m}$.

\subsubsection{Einfluss der Näherung einer kreisförmigen Kontur des Meridians}

Bei der Berechnung der Kontur eines komprimierten Vesikels wird die Näherung vorgenommen, dass die meridiane Kontur des freien Bereiches der Membran kreisförmig ist. In Abbildung 3.32 ist gezeigt, dass sich die daraus resultierende Kontur von der realen Kontur kaum unterscheidet. Die Auswirkungen dieser Näherung auf eine Kraft-Abstandskurve für ein Vesikel zeigt der folgende Plot.

Durch die Näherung einer kreisförmigen, meridianen Krümmung werden etwas kleinere Rückstellkräfte bei der Komprimierung der Vesikel berechnet. Bei einer Kompression von zirka $1 \mu \mathrm{m}$, wie sie in den praktischen Versuchen vorzufinden ist, sind die Unterschiede jedoch vernachlässigbar. 


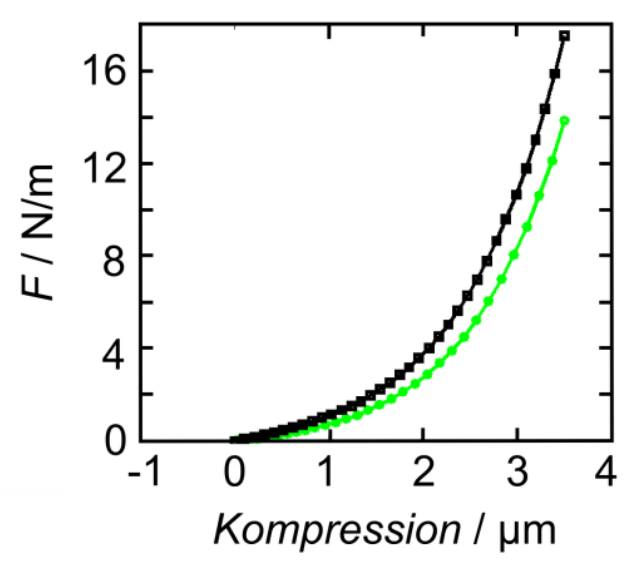

Abbildung 3.32: Unterschied in den Kraft-Abstandskurven, wenn die Vesikelkontur des freien Membranbereiches real berechnet wird (grüne Linie) oder mit der Näherung einer kreisförmigen Krümmung (schwarze Linie). Die vorgegebenen Parameter sind: $R_{\mathrm{V}}=8 \mu \mathrm{m}, \sigma_{0}=0.5 \mathrm{mN} / \mathrm{m} \mathrm{und}$ $K_{\mathrm{A}}=0.1 \mathrm{~N} / \mathrm{m}$.

\subsubsection{Zusammenfassende Diskussion}

Die Bestimmung der Vorspannung und des Flächenkompressionsmoduls der Lipidmembran von Vesikeln wird sowohl aus experimentellen als auch aus theoretischen Gründen am besten anhand der Kompression von Vesikels zwischen planparallelen Platten durchgeführt. Bei der Alternative, den kraftspektroskopischen Versuchen mit einem pyramidalen Indenter ist zwar in den Fluoreszenzaufnahmen der Vesikel keine Verschiebung zu erkennen, die geringe Anfangssteigung der Kraft-Abstandskurven ohne deutlich erkennbaren Kontaktpunkt lassen jedoch vermuten, dass das Vesikel der Indenterspitze ausweicht. Insbesondere besteht die Problematik des Verfälschens der gemessenen Daten bei nicht mittiger Berührung des Vesikels. Das Ausweichen der Vesikel könnte daher die Erklärung sein für die um eine Zehnerpotenz zu kleinen Flächenkompressionsmodule, die durch Ausgleichsrechnungen mit einem von M. J. Rosenbluth et al. entwickelten Modell [88] zur Indendation von Flüssigkeitstropfen mit einer pyramidalen Spitze erhalten werden. S. Li et al. ermittelten bei kleinen Vesikeln, die nicht in der Mitte mit der Spitze eines Cantilevers indentiert wurden, ebenfalls eine zu gering Steifigkeit der Lipidmembran. [93]

Bei der Kompression eines Vesikels zwischen einem Cantilever ohne Spitze und einer Probenoberfläche, die parallel zum Cantilever steht, können kraftspektroskopische Untersuchungen an Riesenvesikeln durchgeführt werden, ohne dass das Vesikel der applizierten Kraft ausweichen kann. Durch das Eindrücken des Vesikels mit einer größeren Fläche als bei den Eindrückexperimenten mit einem spitzen Indenter wird zwar die Adhäsionsfläche zwischen dem Cantilever und dem Vesikel vergrößert, aber durch die großflächigere Kompression des Vesikels wird auch die Membrandehnung erhöht. Eine Änderung der Membranfläche des Vesikels ist entscheidend für die Bestimmung des 
Flächenkompressionsmoduls, wobei die Genauigkeit der Bestimmung des Flächenkompressionsmoduls über das Kurvenanpassen durch eine größere Zunahme der Fläche verbessert wird.

Modelle für die Kompression eines Flüssigkeitstropfens zwischen zwei parallelen Platten wurden bereits von M. Yoneda und C. Norotte et al. aufgestellt. $[92,94]$ Im Rahmen dieser Arbeit werden diese Modelle auf die gegebene Fragestellung der Untersuchung der Membraneigenschaften von Riesenvesikeln angepasst und weiterentwickelt. Es wird von einem kleinen, kurgelförmigen Tropfen ausgegangen, auf den der Effekt der Gravimetrie vernachlässigbar ist und der nicht an den Oberflächen adhäriert. [94] Bei der Modellberechnung einer durch die Kompression eines Vesikels zwischen planparallelen Platten resultierenden Kraft-Abstandskurve kann die Biegeenergie aufgrund des geringen Energiebeitrages bei einer Lipiddoppelschicht vernachlässigt werden. Da der Hin- und Rückweg bei den gemessenen Kraft-Abstandskurven kaum Hysterese zeigt, ist davon auszugehen, dass die Vesikel während der Kompression nicht beschädigt werden und das Volumen des Vesikels konstant bleibt. $[90,93]$

Für die Modellberechnungen müssen zunächst sowohl die Anfangsgeometrie als auch die Geometrie des komprimierten Vesikels bestimmt werden. Die freie Membrankontur des komprimierten Vesikels wird dabei näherungsweise als Kreisausschnitt behandelt. Somit wird die anfängliche Geometrie des kugelförmigen Vesikels durch den Vesikelradius $\left(R_{\mathrm{V}}\right)$ vorgegeben und die Form des komprimierten Vesikels durch drei Radien beschrieben: Kontaktradius $\left(R_{\mathrm{i}}\right)$, Äquatorialradius $\left(R_{0}\right)$ und meridianer Radius der freien Membranfläche $\left(R_{2}\right)$. Die Kontur des komprimierten Vesikels in Abhängigkeit von der Vesikelkompression kann bei Vorgabe eines Vesikelradius durch drei Bedingungen vollständig definiert werden. Für das System wird erstens nach der Laplace-Gleichung eine konstante Krümmung der freien Membran vorausgesetzt, zweitens ein konstantes Volumen während der Kompression angenommen und die dritte Bedingung wird aus der vorgegebenen Geometrie zwischen den Radien $R_{\mathrm{i}} R_{0}$ und $R_{2}$ abgeleitet.

Da die Rückstellkraft der Membran von der Spannung des Vesikels dominiert wird und die Kraft bei der Kompression nur auf die Kontaktflächen eines Vesikels appliziert wird, kann eine KraftAbstandskurve $\left(F\left(z_{\mathrm{d}}\right)\right)$ für ein von der Eindringtiefe abhängiges Paar an $R_{0}$ und $R_{\mathrm{i}}$ Werten aufgestellt werden.

Der dabei verwendete Spannungsterm $T=\sigma_{0}+K_{A} \frac{\Delta A}{A_{\mathrm{V}}}$ ist von der Veränderung der Oberfläche $\Delta A=A_{\mathrm{kV}}-A_{\mathrm{v}}$ und den beiden Systemgrößen: Vorspannung und Flächenkompressionsmodul abhängig. [89] 
Mit Hilfe der im Modell aufgestellten Gleichungen ist es möglich, für einen vorgegebenen Vesikelradius eine Kraft-Abstandskurve zu bestimmen, die durch Veränderung der Parameter $\sigma_{0}$ und $K_{\mathrm{A}}$ dem Kurvenverlauf einer experimentellen Kraft-Abstandskurve aus der Rasterkraftmikroskopie angepasst werden kann. Durch diese Ausgleichsrechnungen können die Vorspannung und das Flächenkompressionsmodul für jede Kraftkurve bestimmt werden. Der entsprechende Quellcode hierzu ist im Anhang aufgeführt. 



\subsection{Kraftspektroskopie an Riesenvesikeln}

Membraneigenschaften wie Flächenkompressionsmodul, Biegemodul und Youngsches Modul sind von der Zusammensetzung der Lipiddoppelschicht abhängig. Die Vorspannung der Membran wird zusätzlich noch durch äußere Bedingungen wie zum Beispiel den Aufbau des Messsystems oder den auf die Membran wirkenden osmolaren Druck beeinflusst. Die Charakteristik von Membranen im natürlichen oder artifiziellen Systemen kann zum Beispiel durch MikropipettenAspirationsexperimente [95-96], Fluktuationsanalysen [47, 58] oder Indentationsversuche [97-98] untersucht werden.

Im Rahmen dieser Arbeit wurden verschiedene Arten von Riesenvesikeln zwischen planparallelen Platten komprimiert. Anhand der zuvor vorgestellten KVPP-Theorie lässt sich aus den dabei erhaltenen Kraft-Abstandskurven die Vorspannung sowie das Flächenkompressionsmodul von Membranen in der $L_{\alpha}$-Phase bestimmen, sowie der Einfluss eines Aktinnetzwerks im Inneren der Vesikel auf das Membranverhalten analysieren. Des Weiteren wird das Verhalten von Vesikeln in der $L_{\beta^{\prime}}$-Phase während Kompressionsexperimenten untersucht und mit dem der Vesikel in der $L_{\alpha}$-Phase verglichen.

\subsubsection{Vesikel in der $\mathrm{L}_{\alpha}$-Phase}

Als Modellsystem für eine reine Zellmembran ohne den Einfluss des Cytoskeletts dienen Lipidvesikel in der flüssig-kristallinen Phase. Diese Vesikel bestehen aus einer Mischung von DOPC/DOPE/DOPEBiotin/A23187/TR-DHPE und sind über Biotin an Avidin gebunden, dass auf der Probenoberfläche adsorbiert ist. Durch kraftmikroskopische Untersuchungen mit einem Cantilever ohne Spitze und der parallel dazu geneigten Probenoberfläche ist es möglich, das Vesikel zu komprimieren, ohne dass dieses sich dabei verschiebt. Ein Beispiel für eine auf diese Weise gewonnene Kraft-Abstandskurve ist in Abbildung 3.33 gezeigt. In blau dargestellt ist die Annäherungskurve des Cantilevers an das Vesikel und in rot der Rückweg des Cantilevers. Über weite Bereiche der Kraft-Abstandskurve sind die Kurven quasi identisch, im Bereich des Kontaktpunktes kommt es jedoch bei dem Rückweg auf Grund der Adhäsion zwischen der Membran und dem Cantilever zu detektierten negativen Kräften. 
A

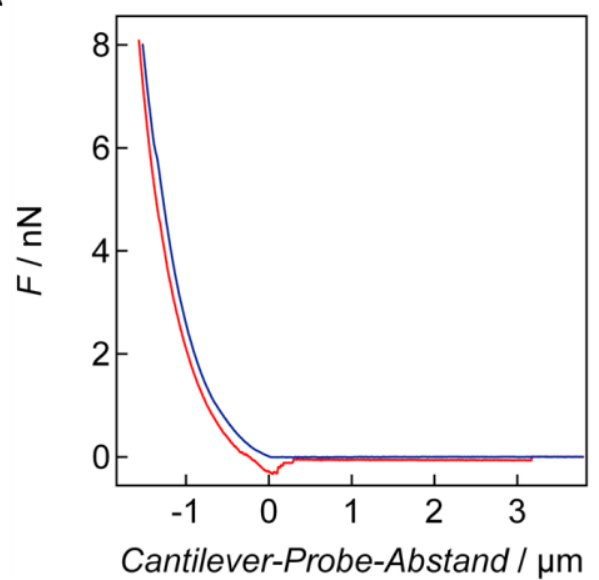

B

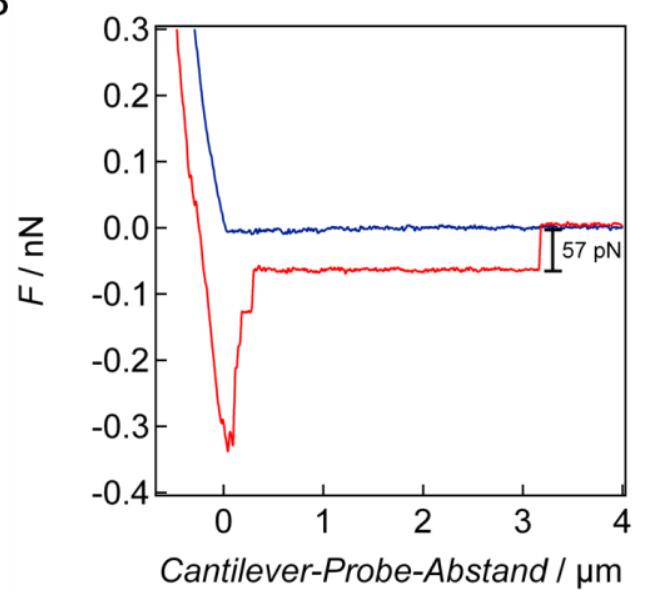

Abbildung 3.33: A) Kraft-Abstandskurve bei der Kompression eines Vesikels in der $L_{\alpha}$-Phase (Annäherung in blau, Rückweg in rot dargestellt) mit einem Cantilever ohne Spitze. B) Vergrößerung des Bereiches um den Kontaktpunkt der in (A) gezeigten Kraft-Abstandskurve. Der Radius des untersuchten Vesikels beträgt $3.8 \mu \mathrm{m}$.

Die Adhäsion im Bereich des Peakminimums wird unter anderem von Van-der-WaalsWechselwirkungen oder elektrostatischen Interaktionen zwischen der Probe und dem Cantilever verursacht, die als unspezifische Wechselwirkungen zusammengefasst werden. Weiter weg von der Probenoberfläche ist in der gezeigten Rückwegskurve ein Plateau zu erkennen, also ein Bereich, der parallel zur Basislinie der Hinwegskurve mit konstanter Kraft verläuft und unvermittelt durch einen Sprung in der detektierten Kraft auf die Basislinie beendet wird. Eine solche Kurvencharakteristik wird durch ein Tether verursacht, also einer röhrenförmigen Lipiddoppelschichtstruktur mit einem Radius im Nanometerbereich. Diese lassen sich ohne Aufwendung von Energie aus der Membran ziehen. Anhand der Differenz der Kraft, die am Sprung der Rückkurve durch die Lyse des Tethers auftritt, kann die Spannung der Vesikelmembran $\left(T_{\mathrm{T}}\right)$ berechnet werden [99-101]

$$
T_{\mathrm{T}}=\frac{\Delta F^{2}}{8 \pi^{2} \kappa} .
$$

Wird ein Biegemodul $(\kappa)$ von $10^{-19} \mathrm{Nm}$ angenommen, erhält man für den letzten Tether der in Abbildung 3.33 dargestellten Rückkurve eine Membranspannung von 0.42 mN/m.

Nach der Kompression des Vesikels nimmt dieses seine ursprüngliche Form wieder an. Dieses elastische Verhalten kann zum einen durch die quasi identischen Kurvenverläufe des Hin- und Rückweges im Kontaktbereich des Vesikels mit dem Cantilever erkannt werden also einer geringen Hysterese zwischen den Kurven. Zum anderen zeigen die Kraft-Abstandskurven bei mehrmaliger Kompression eines Vesikels eine große Übereinstimmung (Abbildung 3.34). 
A

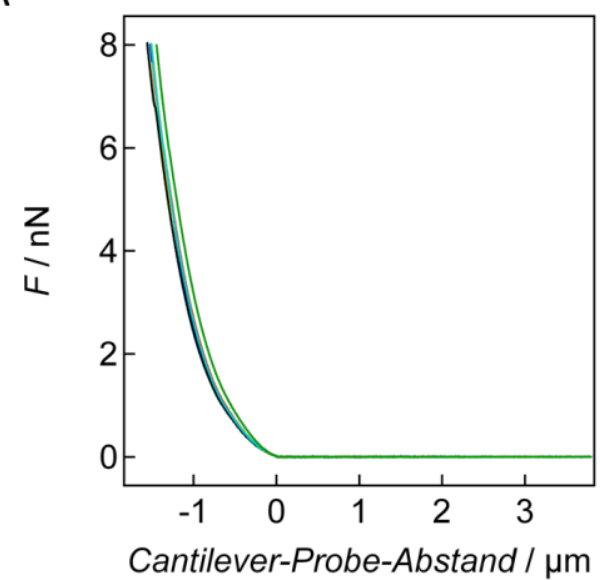

B

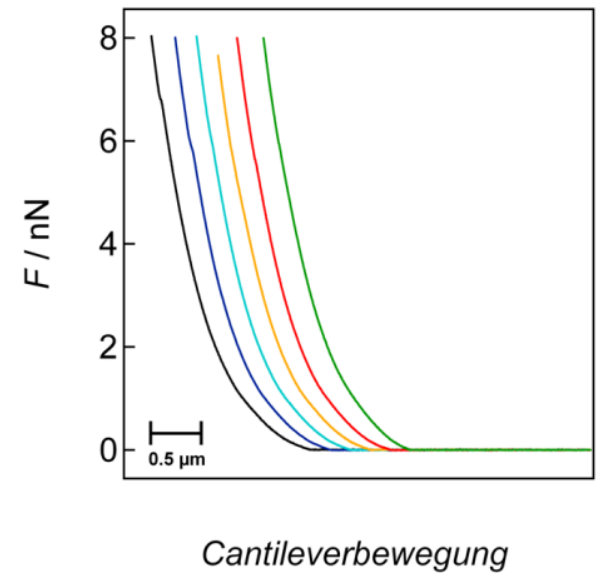

Abbildung 3.34: A) Darstellung von sechs Kraft-Abstandskurven, die nacheinander auf dem identischen Vesikel aufgenommen wurden $\left(R_{V}=3.8 \mu \mathrm{m}\right)$. Die zeitliche Reihenfolge der Kurven lautet: 1. grün, 2. rot, 3. orange, 4. hellblau, 5. dunkelblau, 6. schwarz. Zur besseren Übersicht der einzelnen Kurven wurden die sechs Kraft-Abstandskurven in (B) um -0.2 $\mu \mathrm{m}$ zur jeweils vorher aufgenommenen Kurve verschoben.

Diese hohe Reproduzierbarkeit der Kraft-Abstandskurven auf einem identischen Vesikel ist ein charakteristisches Verhalten für die vermessenen Vesikel in der flüssig-kristallinen Phase und zeigt, dass die Messmethode generell sehr gut geeignet ist.

Mit Hilfe der Kurvenanpassung auf Grundlage der in Kapitel 3.4 aufgestellten Membrantheorie für die Kompression eines Vesikels zwischen planparallelen Platten können aus den KraftAbstandskurven Werte für die Vorspannung der Membran und das Flächenkompressionsmodul ermittelt werden. Abbildung 3.35 zeigt den Hinweg der Kraft-Abstandskurve im Bereich der Kompression des Vesikels und die zugehörige Ausgleichsrechnung des KVPP-Modells.

Die angepasste Kurve zeigt den Verlauf einer Kraft-Abstandskurve mit einer Vorspannung der Vesikelmembran von $0.65 \mathrm{mN} / \mathrm{m}$ und einem Flächenkompressionsmodul von $0.14 \mathrm{~N} / \mathrm{m}$. Dieser mit dem VKPP-Modell berechnete Kurvenverlauf gibt den experimentellen Kurvenverlauf fast exakt wieder und das Flächenkompressionsmodul stimmt annähernd mit dem Literaturwert für DOPCMembranen $\left(K_{\mathrm{A}}=0.265 \mathrm{~N} / \mathrm{m}\right)$ überein. [46] 


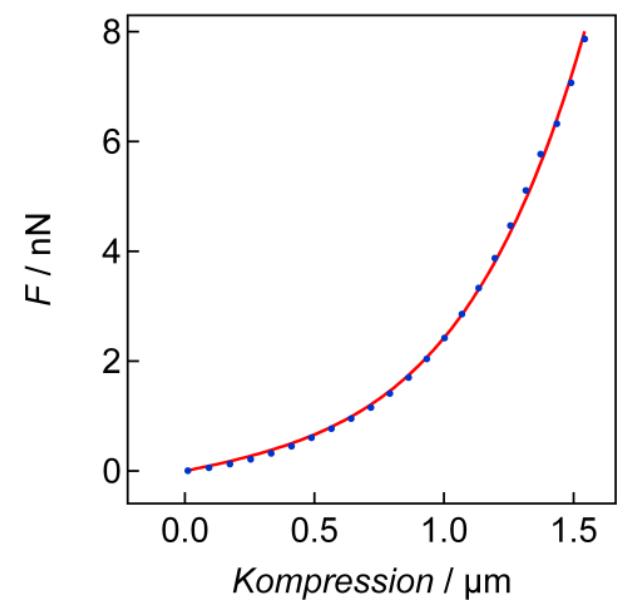

Abbildung 3.35: Auftragung der Kraft-Abstandskurve (blau Punkte) von Abbildung 3.33 im Bereich der Vesikelkompression $\left(R_{\mathrm{V}}=\mathbf{3 . 8} \mu \mathrm{m}\right)$ und der an diese Kurve angepasste Kurvenverlauf mit dem KVPP-Modell (rote Linie). Die aus dem Modell ermittelten Werte sind $\sigma_{0}=0.65 \mathrm{mN} / \mathrm{m}$ und $K_{\mathrm{A}}=0.14 \mathrm{~N} / \mathrm{m}$.

Die über die Ausgleichsrechnung ermittelten Vorspannungswerte der Membran und die Membranspannungen, die aus den Tethern bei den Rückkurven ermittelt werden, geben beide die Spannung der Membran des nicht komprimierten Vesikels an und sollten daher identisch sein. Im vorliegenden Beispiel ist der Werte der Vorspannung nur um $0.23 \mathrm{nN} / \mathrm{m}$ größer als die Spannung, die aus dem Tether bestimmt wird.

Bei dem Vergleich von Kraft-Abstandskurven, die durch Kompression von verschiedenen Vesikeln in der $L_{\alpha}$-Phase erhalten werden, zeigen sich ähnliche Verläufe. Die Abweichungen der Kurven zueinander ist jedoch größer, als bei den verschiedenen Kraft-Abstandskurven, die auf einem identischen Vesikel gemessen werden. In Abbildung 3.36 sind drei Kraftkurven gezeigt, die auf Vesikeln mit einem vergleichbaren Radius erhalten wurden.

Die in schwarz dargestellte Kurve zeigt die geringste Anfangssteigung der drei gezeigten Kurven, bei einer stärkeren Kompression ist die Steigung jedoch ähnlich zu den Steigungen der anderen beiden gezeigten Kraft-Abstandskurven. Die Divergenz in der Vorspannung der Vesikel, die durch die unterschiedlichen Steigungen im Anfangsbereich der Kraft-Abstandskurven deutlich werden, resultiert vermutlich aus den Unterschieden bei der Adhäsion der Vesikel an der 


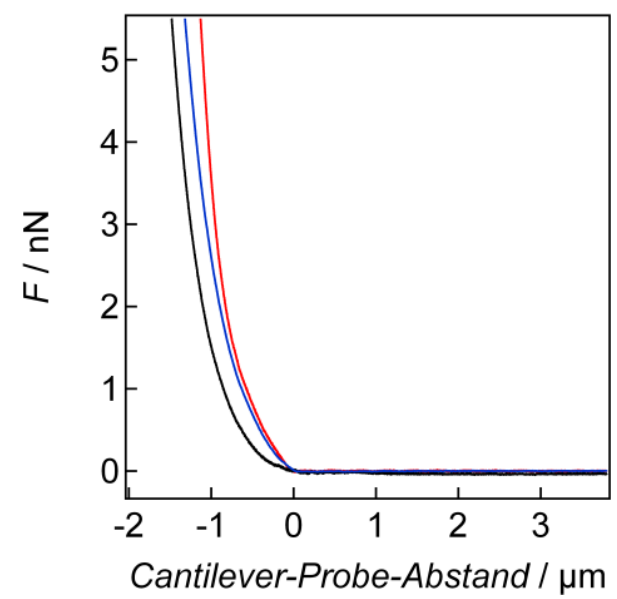

Abbildung 3.36: Drei Kraft-Abstandskurven, die bei der Kompression von drei verschiedenen Vesikeln mit vergleichbaren Radien gemessen wurden (rote Linie: $R_{V}=3.6 \mu \mathrm{m}$, blaue Linie: $R_{\mathrm{V}}=3.8 \mu \mathrm{m}$, schwarze Linie: $R_{\mathrm{V}}=3.7 \mu \mathrm{m}$ ).

Probenoberfläche. In Abbildung 3.37 A sind Fluoreszenzaufnahmen eines Vesikels dargestellt, der nur eine geringe Adhäsionsfläche zur Glasoberfläche ausbildet und daher sowohl im horizontalen, wie im vertikalen Querschnitt durch das Vesikel eine kreisrunde Form zeigt. Die Seitenansichten des in Abbildung 3.37 B illustrierten Vesikels zeigen hingegen einen größeren Auflagebereich des Vesikels auf der Oberfläche. Diese Abweichung von der Kugelform wird von einer stärkeren Adhäsion der Vesikelmembran an der Glasoberfläche bewirkt. Die bei der Verformung des Vesikels benötigte Energie für die Vergrößerung der resultierenden Membranspannung und die größere Krümmungsenergie wird hierbei durch die Bindungsenergie kompensiert, die bei der Adhäsion der Membran an der Oberfläche entsteht. [47] Aufgrund der elastischen Krümmungsenergie der Membran wird bei der Adhäsion kein scharfer Kontaktwinkel zwischen der Membran und der Oberfläche gebildet. [47, 102] Die elastische Reaktion des freien Membranbereiches auf die applizierte Spannung durch die Adhäsion ist zunächst eine Reduktion der thermalen Fluktuationen der Membran, woraus eine Vergrößerung der zu Verfügung stehenden Membranfläche resultiert. Bei stärkeren applizierten Spannungen findet eine Dehnung der Membran durch Vergrößerung des intermolekularen Abstands der Lipide in der Membran statt. [46-47] 

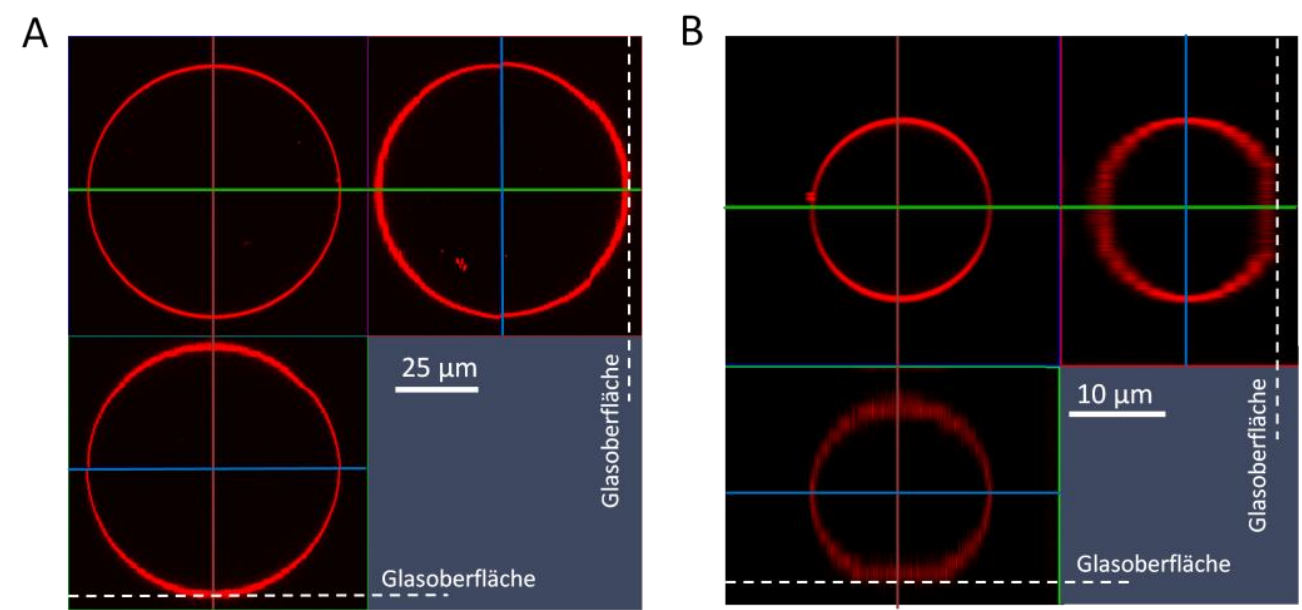

Abbildung 3.37: Fluoreszenzaufnahmen (konfokale Laserrastermikroskopie) der TR-DHPE markierten Lipidmembran zwei verschiedener Vesikel, die an einer Glasoberfläche adhäriert sind. Links oben ist jeweils die mittlere horizontale Fokusebene des Vesikels gezeigt, rechts daneben und unten links senkrecht zueinander verlaufende vertikale Schnitte, die durch zusammensetzen der einzelnen horizontalen Fokusebenen gebildet werden. A) Kugelförmiger Vesikel. B) Abgeflachter Vesikel.

Innerhalb einer Vesikelpopulation ist die Adhäsionsintensität der biotinfunktionalisierten Vesikelmembran an der Oberfläche unterschiedlich, was mutmaßlich aus einer heterogenen Verteilung der Avidin- und Caseinmoleküle auf der Glasfläche entsteht.

Mit Hilfe der fluoreszenzmikroskopischen Aufnahmen, die während der Kraftmikroskopie von den vermessenen Vesikeln erhalten werden, können die Adhäsionsintensitäten der Vesikel auf der Glasoberfläche optisch nicht bestimmt werden. Die Mikroskopiemöglichkeiten und die Qualität der Fluoreszenzaufnahmen sind wegen der geneigten Probenoberfläche eingeschränkt. Mit Hilfe der Ausgleichsrechnung mit dem KVPP-Modell lässt sich jedoch aus der experimentellen KraftAbstandskurve die Vorspannung der Membran ermitteln und daraus kann der Grad der Adhäsion abgeschätzt werden. In Abbildung 3.38 sind die drei in Abbildung 3.36 gezeigten KraftAbstandskurven mit dem jeweilig dazu angepassten Kurvenverlauf gezeigt. Der Kurvenverlauf, der für die in schwarz dargestellte Kraft-Abstandskurve ermittelt wird, spiegelt den gemessen Verlauf exakt wieder. Der in der Simulation angenommene Verlauf entspricht also dem Verhalten des gemessenen Vesikels während der Kompression.

Bei der in rot dargestellten Kurve verläuft die Anpassung des Kurvenverlaufs im Anfangsbereich deutlich unterhalb der experimentellen Werte. Das Verhalten dieses Vesikels kann daher mit der KVPP-Theorie für die Berechnung der Ausgleichskurve nicht exakt wiedergegeben werden. Hieraus resultiert ein unterbestimmter Wert für die Vorspannung dieses Vesikels. Da der an die blaue KraftAbstandskurve angepasste Kurvenverlauf oberhalb des angepassten Verlaufs der roten Kurve liegt, 
ist die aus der Ausgleichsrechnung ermittelte Vorspannung des in blau dargestellten Vesikels $\left(\sigma_{0}=0.65 \mathrm{mN}\right)$ größer als die Vorspannung des in rot gezeigten Vesikels $\left(\sigma_{0}=0.39 \mathrm{mN} / \mathrm{m}\right)$, obwohl die rot dargestellte, experimentelle Kraft-Abstandskurve eine größere Anfangssteigung zeigt als die der blauen Kurve.

Die berechneten Werte für die Membranvorspannung von biotinfunktionalisierten Vesikeln auf einer avidinbeschichteten Oberfläche liegen alle im erwarteten Spannungsbereich. Kraft-Abstandskurven, die auf Vesikeln gemessen wurden, deren Membran thermisch fluktuiert, zeigen keinen eindeutigen Kontaktpunkt, da bei geringer Kompression zuerst die Ondulationen zu Gunsten der dabei freiwerdenden Membranfläche unterdrückt werden. Der geringe Anstieg solcher KraftAbstandskurven resultiert aus der geringen Kraft die appliziert werden muss zur Gewinnung von Membranfläche aus Ondulationen im Verhältnis zu der Kraft, die für das Dehnen der Membran benötig wird. [46] Die Ausgleichsrechnung für die Kraft-Abstandskurven wird nur durchgeführt, wenn diese einen eindeutigen Kontaktpunkt zeigen. Daher werden nur Kraftkurven ausgewertet, die auf Vesikeln gemessen wurden, deren Membran durch Adhäsion an die Glasoberfläche soweit vorgespannt ist, dass die Ondulationen bereits unterdrückt sind. Nach W. Rawicz et al. wird hierzu eine Spannung von zirka $0.5 \mathrm{mN} / \mathrm{m}$ benötigt. $[46,90]$ Daher liegen die aus den Ausgleichsrechnungen ermittelten Werte zirka zwei Zehnerpotenzen höher als die von J. Rädler et al. bestimmten Vorspannungswerte aus der Fluktuationsanalyse der Membran für ondulierende Vesikel ohne Bindung zur Oberfläche $(0.001-0.08 \mathrm{mN} / \mathrm{m})$ [47] aber unter den typischen Spannungswerten für die Lyse von Vesikeln (zirka $10 \mathrm{mN} / \mathrm{m}$ ) [40].

Durch die Notwendigkeit der starken Adhäsion der Vesikel an der Glasoberfläche zur Ermittlung eines angepassten Kurvenverlaufs über das KVPP-Modell wird die in der KVPP-Theorie angenommene kugelförmige Struktur des zu komprimierenden Vesikels und den identischen Kontaktradien zwischen dem Vesikel und der Glasoberfläche beziehungsweise dem Cantilever nicht gewährleistet. Da der angepasste Kurvenverlauf den experimentellen Kurvenverlauf jedoch über weite Bereiche charakteristisch wiedergibt, sind die daraus resultierenden Fehler voraussichtlich vernachlässigbar. 
A

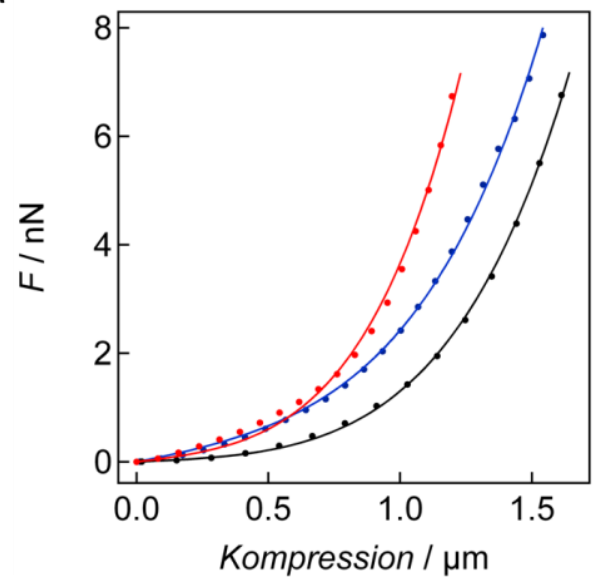

B

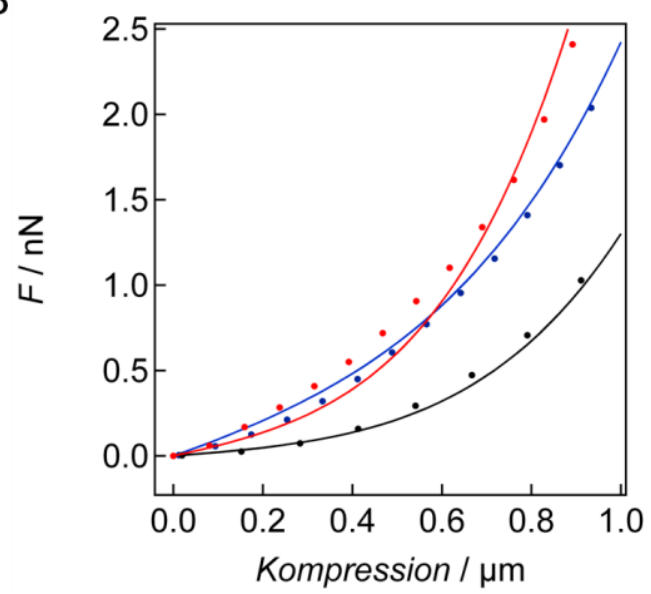

Abbildung 3.38: A) Experimentell bestimmte Kurvenverläufe der Kraft als Funktion der Kompression drei verschiedener Vesikel (rote Punkte: $R_{V}=3.6 \mu \mathrm{m}$, blaue Punkte: $R_{V}=3.8 \mu \mathrm{m}$, schwarz Punkte: $R_{\mathrm{V}}=3.7 \mu \mathrm{m}$ ) und jeweils an die Kurven angepasster Kurvenverlauf mit dem KVPPModell (Linien in der gleichen Farbe wie die jeweilige experimentell besptimmte KraftAbstandskurve). B) Vergrößerung des Anfangsbereiches der in (A) dargestellten Kurven. Die aus den Ausgleichsrechnungen ermittelten Werte sind: rot: $\sigma_{0}=0.39 \mathrm{mN} / \mathrm{m}, K_{A}=0.29 \mathrm{~N} / \mathrm{m}$; blau $\sigma_{0}=0.65 \mathrm{mN} / \mathrm{m}, K_{\mathrm{A}}=0.14 \mathrm{~N} / \mathrm{m}$; schwarz: $\left.\sigma_{0}=0.45 \mathrm{mN} / \mathrm{m}, \kappa_{\mathrm{A}}=0.19 \mathrm{~N} / \mathrm{m}\right)$.

Bei größerer Kompression spiegeln alle drei angepassten Kurvenverläufe die gemessenen KraftAbstandskurven fast exakt wieder und die bestimmten Flächenkompressionsmodule liegen im erwarteten Größenbereich für Lipidmembranen in der flüssig-kristallinen Phase. Das aus der Ausgleichsrechnung bestimmte Flächenkompressionsmodul für die in rot dargestellte Kraftkurve $\left(K_{\mathrm{A}}=0.29 \mathrm{~N} / \mathrm{m}\right)$ weicht nur um $0.025 \mathrm{~N} / \mathrm{m}$ von dem aus Mikropipetten-Aspiratonsversuchen ermittelten Wert für eine Lipidmembran aus DOPC ab $\left(K_{\mathrm{A}}=0.265 \mathrm{~N} / \mathrm{m}\right)$. [46]

Im folgenden wird eine Übersicht der ermittelten Vorspannungswerte und der Flächenkompressionsmodule von Vesikeln präsentiert, die keine Membranondulationen gezeigt haben und sich während der Kompression nicht verschoben haben (eindeutige Position des Kontaktpunktes und stetiger Anstieg in der Kraft-Abstandskurve). Des Weiteren sind nur die ermittelten Werte berücksichtigt, bei denen der aus der Ausgleichsrechnung ermittelte Kurvenverlauf den Verlauf der gemessenen Kraft-Abstandskurve wiedergibt (Abweichungen wie bei der in rot dargestellten Kurve in Abbildung 3.38 eingeschlossen). Es werden jeweils die aus den Ausgleichsrechnungen bestimmten Durchschnittswerte für die Vorspannungen beziehungsweise den Flächenkompressionsmodulen gezeigt, die durch Mittelung der Werte der einzelnen gemessenen Kraft-Abstandskurven auf jeweils einem Vesikel erhalten wurden. Ein Datenpunkt besteht somit aus 4 bis 6 Werten. 
In Abbildung 3.39 sind die Vorspannungswerte beziehungsweise das Flächenkompressionsmodul einzelner Vesikel anhand von Boxplots gezeigt mit deren Median, dem Bereich in dem die Hälfte der berechneten Werte liegt (Box) und des minimalen beziehungsweise maximalen Wertes (Antenne).

A

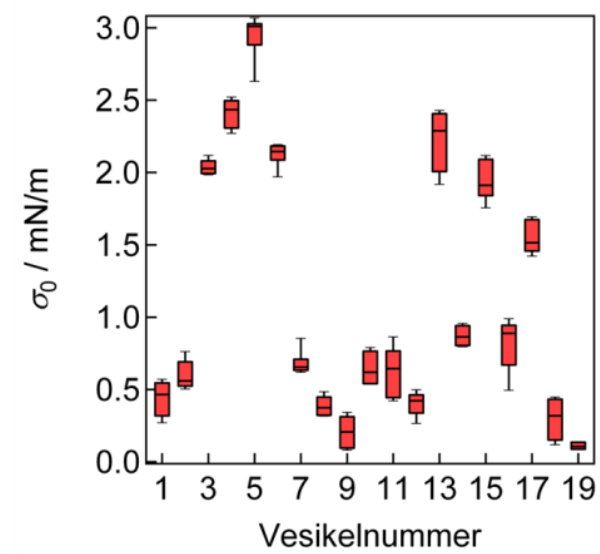

B

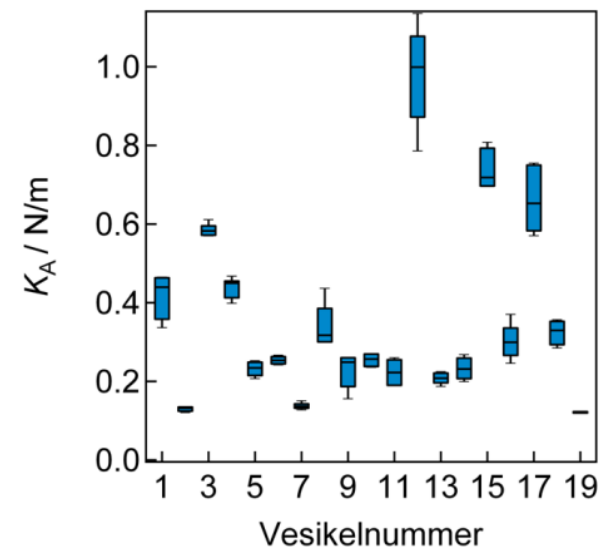

Abbildung 3.39: Boxplots der Vorspannung (A) und des Flächenkompressionsmoduls (B) die mit Hilfe der Ausgleichsrechnung mit dem KVPP-Modell ermittelt wurden. Jede Boxeinheit stellt die Verteilung der errechneten $\sigma_{0}$ beziehungsweise $K_{A}$-Werte dar, die aus den Kraftkurven (4 bis 6 Kurven) eines identischen Vesikels erhalten wurden.

Die Vorspannung der vermessenen Vesikel variiert wie oben beschrieben wegen der variablen Adhäsion der Membranen an der Glasoberfläche und liegt im Bereich von 0.1-3 mN/m. Der Mittelwert der Flächenkompressionsmodule für die einzelnen Vesikel liegt im Bereich von 0.1-1 N/m, wobei auffällig ist, dass die Streubreite der ermittelten Werte für ein Vesikel mit steigendem Wert zunimmt. Eventuell handelt es sich bei den Vesikeln mit den ermittelten hohen Flächenkompressionsmodulen ( $K_{\mathrm{A}}>0.6 \mathrm{~N} / \mathrm{m}$, Vesikel $\left.12,15,17\right)$ nicht um unilamellare Vesikel, da das Flächenkompressionsmodul in Abhängigkeit der Oberflächenspannung zwischen der Wasser-LipidGrenzfläche $(\gamma)$ linear mit der Anzahl an Lipiddoppelschichten $(N)$ zunimmt $\left(K_{\mathrm{A}}=4 \gamma N\right)$. [20] Es könnte sich also um Vesikel mit drei (zirka $0.8 \mathrm{~N} / \mathrm{m}$ ) oder vier (zirka $1.0 \mathrm{~N} / \mathrm{m}$ ) Lipidschichten handeln. Wird ein mittleres Flächenkompressionsmodul aller Vesikel ohne diese drei Vesikel berechnet, beträgt $\left\langle K_{\mathrm{A}}\right\rangle=0.28 \pm 0.12 \mathrm{~N} / \mathrm{m}$ und weicht damit nur gering von dem Literaturwert für eine DOPCLipidmembran $\left(K_{\mathrm{A}}=0.265 \mathrm{~N} / \mathrm{m}\right)$ ab. [46]

Bei der Auftragung der Flächenkompressionsmodule gegen die jeweils bestimmte Vorspannung des Vesikels ist keine Korrelation zwischen den beiden Werten zu erkennen. Eine geringe Standardabweichung des einen Parameters bedeutet auch nicht in allen Fällen eine geringe Standardabweichung des zweiten Parameters. Es ist jedoch auffällig, dass es eine Häufung von 
Vesikeln gibt, dessen aus der Ausgleichsrechnung ermittelten Vorspannungen im Bereich von 0.1-1 mN/m liegt, bei gleichzeitigem Flächenkompressionsmodul im Bereich von 0.15-0.45 N/m.

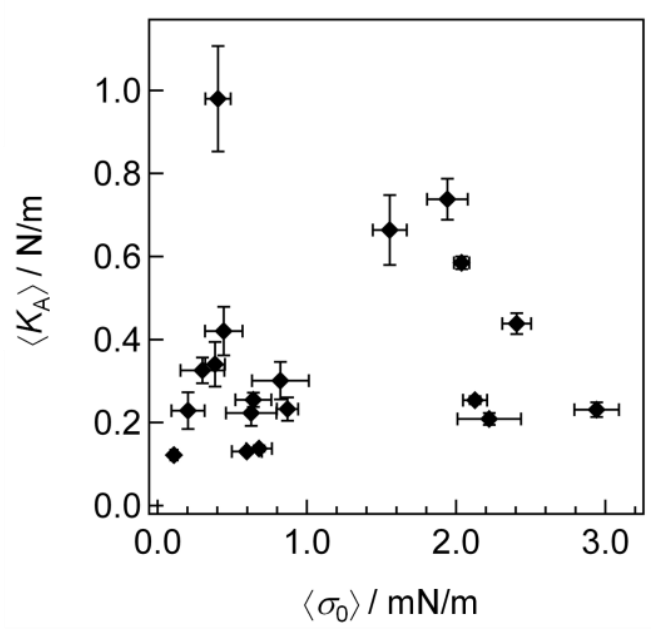

Abbildung 3.40: Auftragung der aus den Ausgleichsrechnungen berechneten Mittelwerte des Flächenkompressionsmoduls der verschiedenen, gemessenen Kraft-Abstandskurven eines Vesikels als Funktion der jeweilig bestimmten mittleren Vorspannung. Die Fehlerbalken zeigen jeweils die Standardabweichung der ermittelten $\sigma_{0}$-Werte und $K_{\mathrm{A}}$-Werte eines Vesikels an.

Das Flächenkompressionsmodul ist eine Membraneigenschaft und somit von der Größe des zu untersuchenden Systems unabhängig. Auch die Membranspannung sollte keine Korrelation mit der Größe des vermessenen Vesikels zeigen. Da bei der Berechnung der Ausgleichskurve mit dem KVPPModell die Größe des untersuchten Messsystems durch die Angabe des Vesikelradius und somit der Membranfläche berücksichtigt wird, sollten die daraus ermittelten Werte unabhängig von der Größe des vermessenen Vesikels sein. In Abbildung 3.41 ist gezeigt, dass diese Unabhängigkeit der ermittelten Werte für die Vorspannung der Vesikelmembran sowie für das Flächenkompressionsmodul von dem Radius des komprimierten Vesikels gegeben ist. 
A

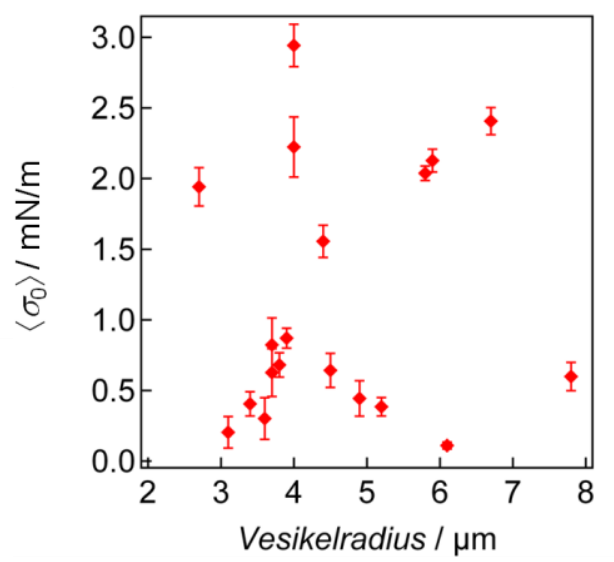

B

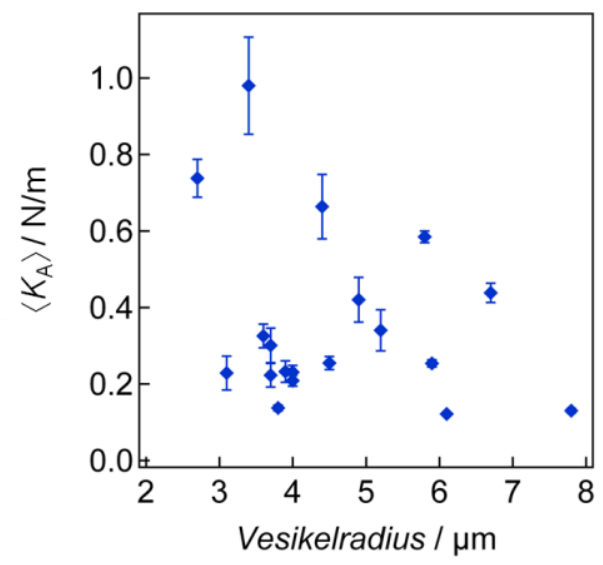

Abbildung 3.41: Mittelwerte der Vorspannung (A) und des Flächenkompressionsmoduls (B) als Funktion der Radien der vermessenen Vesikel. Die Fehlerbalken geben jeweils die Standardabweichung der ermittelten $\sigma_{0}$-Werte beziehungsweise $K_{\mathrm{A}}$-Werte von den auf dem identischen Vesikel gemessenen Kraft-Abstandskurven an.

Wie am Anfang dieses Unterkapitels beschrieben, kann aus der Lyse eines Tether bei der Rückkurve die Membranspannung des Vesikels berechnet werden, die mit der Vorspannung des Vesikels gleichzusetzen ist. Da sich jedoch nicht nach jeder Kompression eines Vesikels ein Tether zwischen

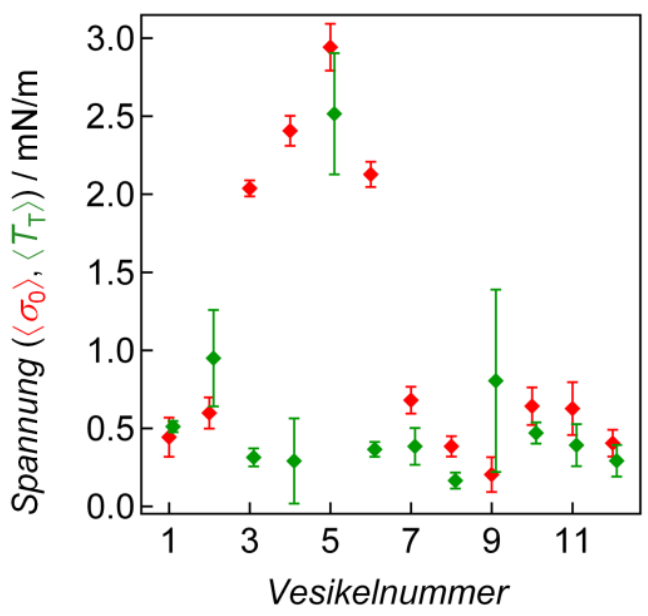

Abbildung 3.42: Auftragung der Mittelwerte der aus den Ausgleichsrechnungen ermittelten Vorspannung (rot) und der Mittelwert aus dem jeweiligen letzten Tether des Rückweges berechneten Membranspannung (grün) jeweils eines Vesikels. Aus Darstellungsgründen sind die Messwerte von einem Vesikel leicht zueinander versetzt. Die Fehlerbalken stellen die Standardabweichung der Vorspannungswerte beziehungsweise der aus den Tethern ermittelten Spannung eines Vesikels dar.

dem Cantilever und dem Vesikel bildet, kann nicht für alle vermessenen Vesikel die Membranspannung gleichzeitig über den letzten reißenden Tether ermittelt werden. In 
Abbildung 3.42 sind die Mittelwerte der Membranspannungen der einzelnen Vesikel zusammengefasst, die über die Ausgleichsrechnung der Hinkurve, sowie über die Lyse des Tether bei der Rückkurve ermittelt wurden. Die Mittelwerte für die aus den Tethern bestimmten Membranspannungen sind zum Teil quasi identisch mit der aus der Ausgleichsrechnung ermittelten Vorspannung der Membran. Außer für Vesikel 3, 5 und 6 liegen die Werte immer nahe beieinander. Die aus den Tethern berechneten Spannungen aus verschiedenen Kraft-Abstandskurven eines Vesikels zeigen zum Teil jedoch eine geringere Reproduzierbarkeit als die mit der Ausgleichsrechnung mit Hilfe der KVPP- Theorie bestimmten Membranspannungen.

Bei der Anpassung der Kurven mit dem KVPP-Modell an eine experimentelle Kraft-Abstandskurve wird die Kontur des komprimierten Vesikels über den Radius der Kontaktfläche, den Radius der freien Membrankontur und dem äquatorialen Radius erhalten. Wie in Abbildung 3.43 zu erkennen ist, nehmen erwartungsgemäß alle drei Radien mit steigendem Radius des untersuchten Vesikels bei maximal detektierter Kompression zu.

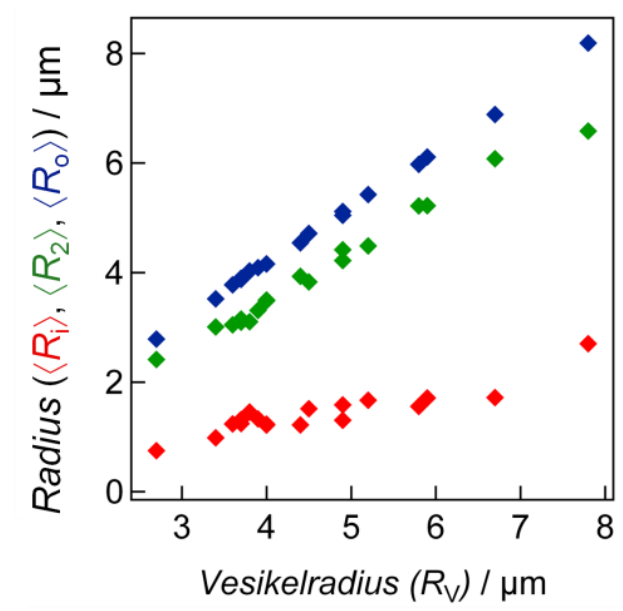

Abbildung 3.43: Bei maximal detektierter Kompression der Vesikel über die Ausgleichsrechnung ermittelte Mittelwerte für den Radius der Kontaktfläche ( $R_{i}:$ rote Karos), den Radius der Kontur des freien Membranbereiches ( $R_{2}$ : grüne Karos) und den äquatorialen Radius des komprimierten Vesikels ( $\boldsymbol{R}_{0}$ : blaue Karos) als Funktion des ursprünglichen Vesikelradius $\left(\boldsymbol{R}_{\mathrm{v}}\right)$.

\subsubsection{Vesikel in der $\mathrm{L}_{\beta}$-Phase}

Lipidmembranen, die sich in der Gelphase befinden, zeigen eine sehr viel höhere Membransteifigkeit als die zuvor beschriebenen Membranen in der flüssig-kristallinen Phase. $L_{\beta}$-Membranen lassen sich nicht über die zuvor verwendete Membrantheorie beschreiben, sondern eher über ein Schalenmodell. [103-104] Hierbei verursacht die Verformung einer Schale im Bereich der Größenordnung der Schalendicke eine linear elastische Antwort, wird jedoch eine stärkere 
Verformung bewirkt, bilden sich plastische Einbeulungen (englisch: buckling) in der Schale um eine Verbiegung auszuweichen. [103] Zur Charakterisierung der Messmethode wurden daher Gelphasenvesikel, die eine deutlich höhere Rückstellkraft als die zuvor beschriebenen flüssigkristallinen Vesikel zeigen sollten, zwischen dem Cantilever und der parallel dazu geneigten Probenoberfläche komprimiert. Es werden hierzu Vesikel verwendet, die hauptsächlich aus dem Lipid DPPC besteht.

Ein Beispiel für die typischerweise erhaltenen Kraft-Abstandskurven bei der Kompression eines $\mathrm{L}_{\beta^{\prime}}$-Phasenvesikels ist in Abbildung 3.44 gezeigt. Alle drei Kurven wurden durch Kompression des identischen Vesikels gewonnen. Die zuerst gemessene Kurve (blau) ist quasi identisch mit der anschließenden Kurve (rot). Anhand der Hysterese zwischen Hinweg (durchgezogene Linie) und

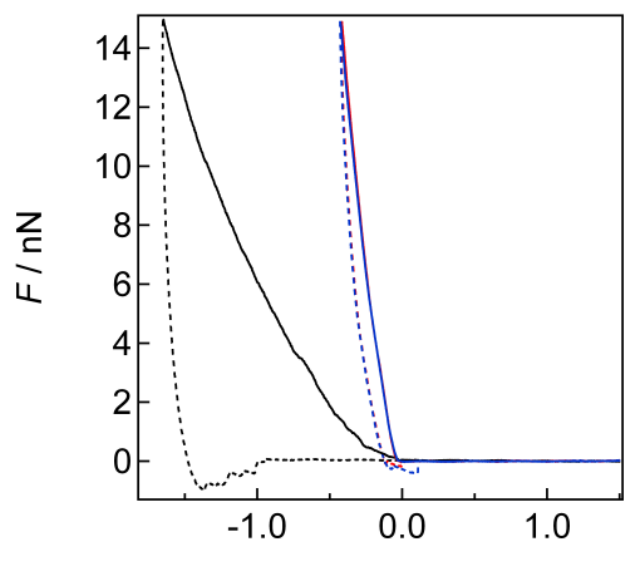

Cantilever-Probe-Abstand / $\mu \mathrm{m}$

Abbildung 3.44: Drei Kraft-Abstandskurven (Hinweg: durchgezogene Linie, Rückweg: gestrichelte Linie), die auf einem Vesikel $\left(R_{\mathrm{V}}=4.0 \mu \mathrm{m}\right)$ mit einer Gelphasenmembran (DPPC) aufgenommen wurden. Die gezeigten Kurvenverläufe entsprechen der zweiten (blaue Kurve), dritten (rote Kurve) und fünften (schwarze Kurve) Kompression des Vesikels.

Rückweg (gestrichelte Linie) ist jedoch zu erkennen, dass es sich nicht um eine rein elastische Vesikelkompression handelt. Durch mehrmaliges Komprimieren des Vesikels, wird die Membranschale zunehmend beschädigt. Die detektierte Kraft-Abstandskurve nach zuvor viermaliger Kompression (schwarze Kurve) zeigt eine deutlich geringere Steigung und dementsprechend einen geringeren Widerstand der Membran gegenüber Verformung. Der Anteil der Hysterese nimmt im Vergleich zu den vorherigen Kurvenverläufen deutlich zu.

Im Vergleich zu den Kraftkurven von Vesikeln in der flüssig-kristallinen Phase ist zu erkennen, dass bei gleicher applizierter Kraft, die Vesikel in der Gelphase deutlich weniger komprimiert werden. Zum 
Beispiel wird bei einer Kraft von $2 \mathrm{nN}$ das Gelphasenvesikel nur um zirka $0.1 \mu \mathrm{m}$ komprimiert im Gegensatz zu zirka $1 \mu \mathrm{m}$ Kompression des Vesikels in der flüssig-kristallinen Phase.

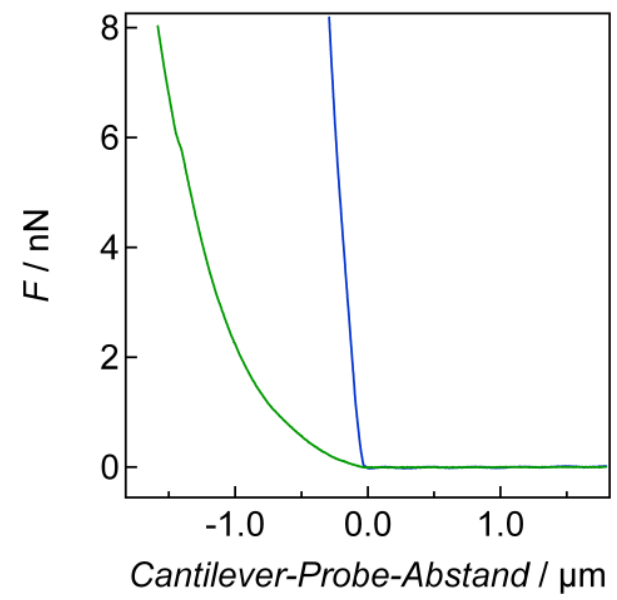

Abbildung 3.45: Vergleich der Kraft-Abstandskurven eines Gelphasenvesikels (blaue Linie: zweite gemessene Kraftkurve auf dem Vesikel, $R_{\mathrm{V}}=4.0 \mu \mathrm{m}$ ) mit einer Kraft-Abstandskurve von einem flüssig-kristallenen Vesikel (grüne Linie, $R_{\mathrm{V}}=3.8 \mu \mathrm{m}$ ).

Da die KVPP-Theorie für Vesikel in der flüssig-kristallinen Phase entwickelt wurde, lassen sich für spröde Vesikelmembranen in der Gelphase keine Membranspannungen oder Flächenkompressionsmodule über die im Rahmen dieser Arbeit verwendete Ausgleichsrechnung mit dem KVPP-Modell ermitteln.

\subsubsection{Aktin gefüllte Vesikel}

Zur Untersuchung des Einflusses des Cytoskeletts auf die elastischen Eigenschaften von Zellen wird ein Modell mit flüssig-kristallinen Vesikeln verwendet, die einen Aktincortex im Inneren besitzen. Das Aktin wird während der Vesikelpräparation als Monomer in die Vesikel eingeschlossen. Die Polymerisation des Aktins wird anschließend über die Zugabe von Magnesiumionen, die über einen Ionentransporter ins Innere der Vesikel transportiert werden, initiiert. Dabei kann das Aktin in verschiedenen Strukturen innerhalb des Vesikels polymerisieren. Die ausgebildete Struktur des Aktinnetzwerks ist abhängig von der Länge der gebildeten Aktinfilamente, da die Persistenzlänge von Aktin (zirka 10-20 $\mu \mathrm{m}$ ) [20] im Größenbereich des Durchmessers von den Vesikeln liegt. [57-58] Die mechanischen Eigenschaften der aktincortexunterstützten Membran der Vesikel wird durch Kompression zwischen planparallelen Platten untersucht. Mit Hilfe der Ausgleichsrechnung für die Kompression von flüssig-kristallinen Vesikeln wird die Vorspannung und das 
Flächenkompressionsmodul dieser Vesikel ermittelt und mit denen von Vesikeln ohne Aktin verglichen.

Fluoreszenzmikroskopische Untersuchungen zeigen, dass die Polymerisation des Aktins in den Vesikeln nach Magnesiumionenzugabe innerhalb einer Probe nicht gleichmäßig verläuft. Es können sich verschiedene Strukturen von Aktinnetzwerken ausbilden. Zum einen kann sich das F-Aktin entlang der Lipidmembran anordnen, wobei es entweder eine gleichmäßige Schicht oder eine lückenhafte Aktinhülle ausbildet. Zum anderen kann sich ein Netzwerk aus Aktinfilamenten im Lumen des Vesikels formen (Abbildung 3.46). In jeder Probe kommen jedoch auch Vesikel vor, in denen kein polymerisiertes Aktin zu erkennen ist. Die Ursachen für diese Unterschiede wurden nicht genauer analysiert. Aus der Literatur ist jedoch bekannt, dass es zu Unterschieden in der vom Vesikel eingeschlossenen Aktinkonzentration im Verlauf der Vesikelherstellung kommt. [9, 57] Einen Zusammenhang der F-Aktin-Struktur zum Vesikelradius, wie er bei L. Limonzin et al. beschrieben wird, dass Vesikeln mit einem Radius $<9 \mu \mathrm{m}$ bevorzugt einen Aktincortex entlang der Membran ausbilden, konnte nicht beobachtet werden. [57]

Durch Zugabe einer höheren Magnesiumionenkonzentration wird der Anteil an Vesikeln mit F-Aktin im Inneren gesteigert. Jedoch kommt es auch zur stärkeren Adhäsion zwischen den Vesikeln und der Glasoberfläche und deshalb zu vermehrtem Spreiten der Vesikel. Dies könnte zum einen durch F-Aktin selbst verursacht werden, das die Spreitdynamik des Vesikels verändert [49] oder aber durch Veränderungen des osmotischen Druckes. Die zugegebene Magnesiumchloridlösung besitzt zwar dieselbe Osmolarität wie die verwendeten Puffer innerhalb und außerhalb der Vesikel, aber durch den exklusiven Einstrom der Magnesiumionen in die Vesikel kommt es zwangsläufig zu einer Erhöhung der Osmolarität im Inneren der Vesikel und dem Aufbau eines elektrochemischen Potenzials.

Bei einigen Vesikeln konnten bei fluoreszenzmikroskopischen Analysen Aktinfilamente am äußeren Rand der Vesikel beobachtet werden. Diese entstehen durch Aktinmonomere, die bei Zugabe der Vesikellösung in die Probenschale mit in die Probe gelangen und sich bevorzugt an der Glasoberfläche oder an der Lipidmembran anlagern. 


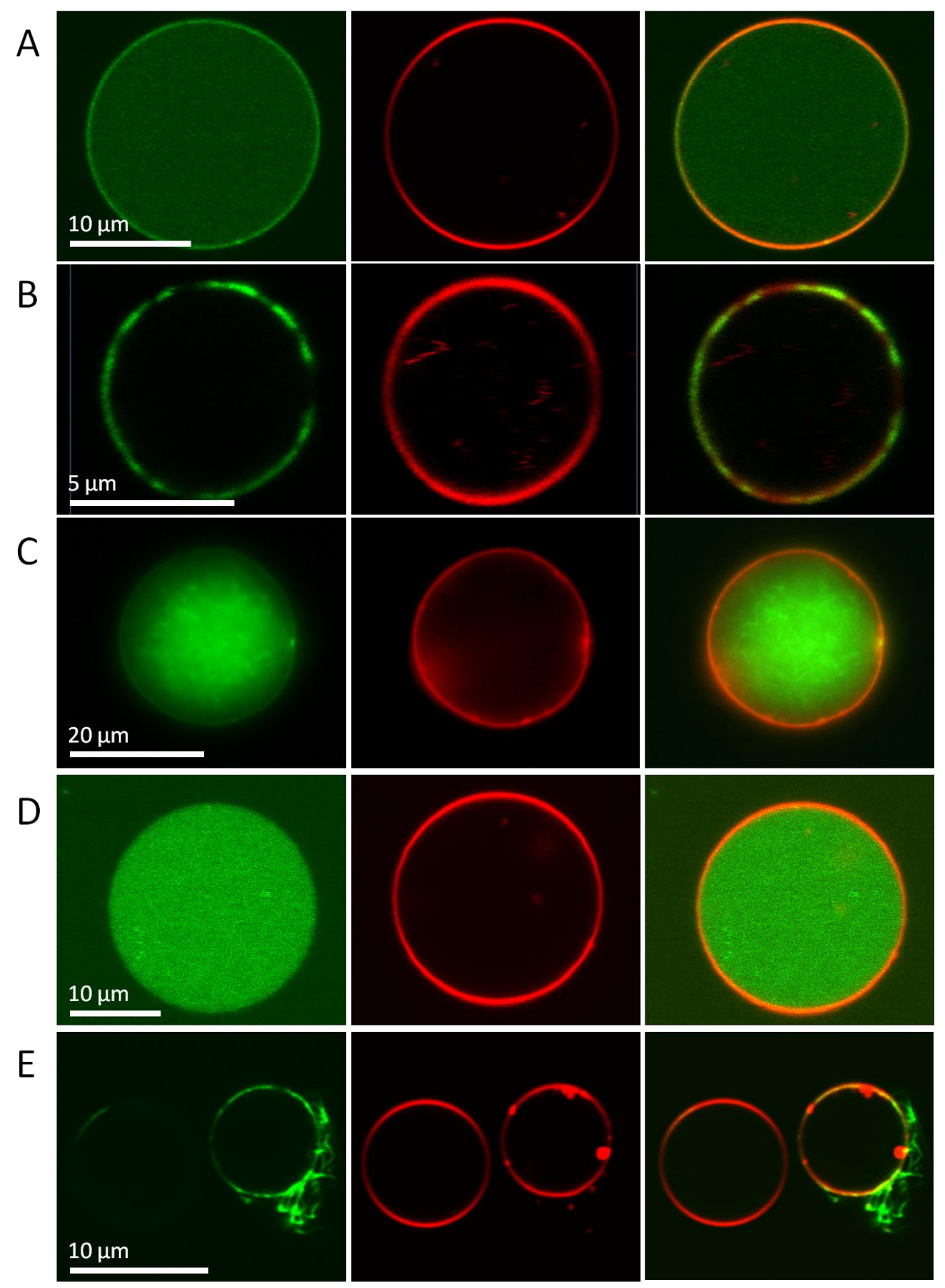

Abbildung 3.46: Fluoreszenzaufnahmen von fünf verschiedenen Vesikeln mit Aktin. In der ersten Spalte ist jeweils das Aktinnetzwerk mit eingebautem, grün leuchtenden, Alexa Fluor 488 konjungiertem Aktin zu sehen. In der zweiten Spalte ist die rot fluoreszierende TR-DHPE-markierte Lipidmembran abgebildet und in der dritten Spalte die Überlagerung der beiden Farbkanäle. A) Gleichmäßig polymerisierte Aktinschale am Rand der Lipidmembran. B) Lückenhaft ausgebildete Aktinhülle an der Lipidmembran. C) Aktinnetzwerk im Inneren des Vesikels. D) Unpolymerisiertes Aktin. E) Außen am Vesikel polymerisiertes Aktin. (A, B, D, E: CLSM-Aufnahmen, C: Aufrechtes Mikroskop). 
Dem natürlichen Aktincytoskelett einer Zelle am ähnlichsten sind die Vesikel, die im Inneren eine Aktinschicht entlang der Lipidmembran besitzen. Zur Charakterisierung der Dichte dieser Aktinnetzwerke unterhalb der Membran wurden FRAP-Experimente durchgeführt. Abbildung 3.47 zeigt Fluoreszenzaufnahmen eines Vesikels, dessen Aktinhülle durch einen Laserpuls photooxidiert wird und die Rückkehr der Fluoreszenzintensität in diesem Bereich mit der Zeit, sowie den dazugehörigen Recovery-Graphen.
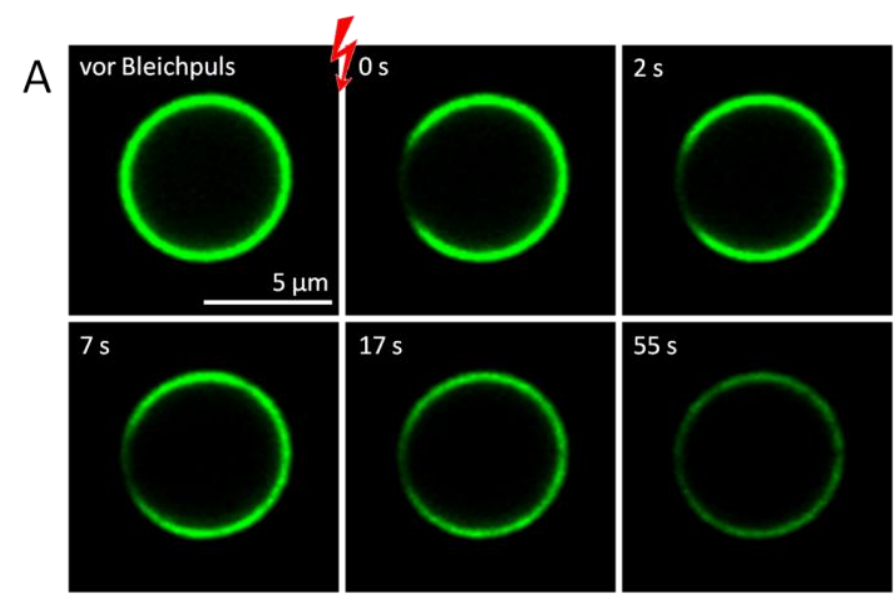

B

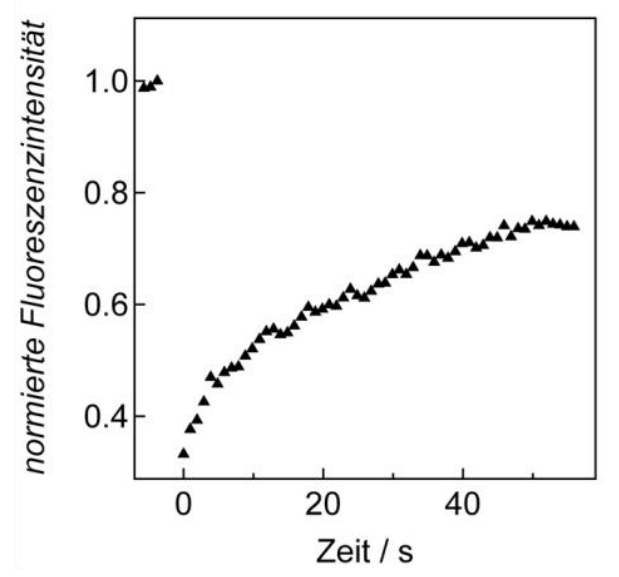

Abbildung 3.47: A) Fluoreszenzmikroskopische Aufnahmen der Aktinschale eines Vesikels (Alexa Fluor 488 konjungiertes Aktin) während einer FRAP-Messung. Die Bilder zeigen verschiedene Zeitpunkte nach dem Bleichpuls zwischen der ersten und der zweiten Aufnahme (Dauer des Bleichpuls: 3 s). B) Recovery-Graph der Fluoreszenzintensität an der gebleichten Stelle des gezeigten FRAP-Experimentes in (A). Der mobile Anteil es Aktins in diesem Vesikel beträgt $60 \%$.

Durch die nach dem Bleichen maximal zurückkehrende Fluoreszenzintensität der Aktinhülle kann der mobile Anteil des Aktins in der Schicht bestimmt werden. [78] Dieser ermittelte mobile Anteil ist vermutlich abhängig von der Maschengröße des Aktinnetzwerks, der Länge der Aktinfilamente und der Konzentration an verbleibendem G-Aktin im Vesikel. Für die vermessenen Vesikel zeigt sich eine 
große Varianz der ausgebildeten Struktur der Aktinschichten und es werden mobile Anteile von $30-90 \%$ bestimmt.

Bei den mechanischen Untersuchungen der aktingefüllten Vesikel kann die Art des Aktinnetzwerks bei den vermessenen Vesikeln wegen der eingeschränkten mikroskopischen Möglichkeiten durch das notwendige Schrägstellen der Probe nicht bestimmt werden. Die Vesikel sind nur anhand der stark leuchtenden TR-DHPE-markierten Membran durch die zeitlich parallel durchgeführte Fluoreszenzmikroskopie zu lokalisieren. Die in Abbildung 3.48 gezeigte Kraft-Abstandskurve entstammt jedoch einer Probe, in der fast alle Vesikel bei der Fluoreszenzuntersuchung mit einem aufrechten Mikroskop ein Aktinnetzwerk im gesamten Lumen und am Rand der Vesikel zeigten.

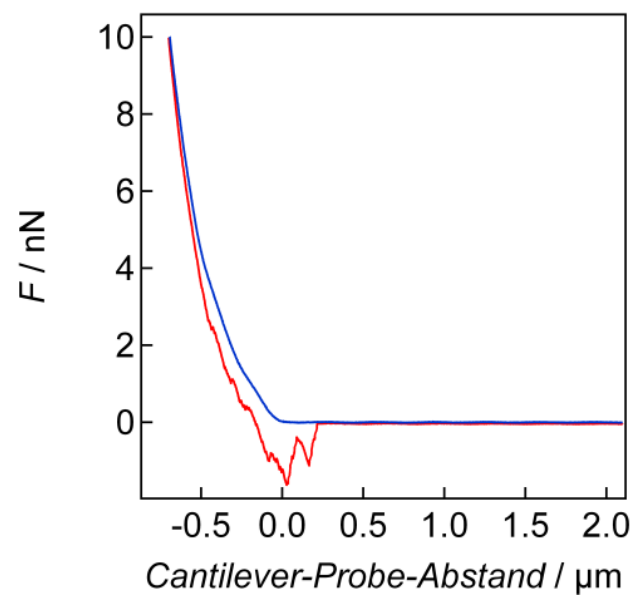

Abbildung 3.48: Kraft-Abstandskurve (Hinweg: blau, Rückweg: rot) bei der Kompression eines Vesikels mit polymerisiertem Aktin $\left(2 \mathrm{mM} \mathrm{Mg}^{2+}\right)$ mit einem Cantilever ohne Spitze. Der Radius des untersuchten Vesikels beträt $9.8 \mu \mathrm{m}$.

Mit einer Kraft von $10 \mathrm{nN}$ lässt sich das Vesikel mit polymerisiertem Aktin $\left(R_{\mathrm{V}}=9.8 \mu \mathrm{m}\right)$ um zirka $0.7 \mu \mathrm{m}$ zusammendrücken. Die Kompression der aktingefüllten Vesikeln stellt eine nicht vollständig elastische Verformung dar, die sich bei mehrmaligen Komprimieren eines Vesikels zum Teil in einer geringen Abnahme der Anfangssteigung äußert oder durch größere Kompression bei gleichbleibenden applizierten Kräften (zirka $100 \mathrm{~nm}$ ). Dies wird vermutlich durch Verschiebungen der nicht miteinander verbundenen Aktinfilamente durch die applizierten Kräfte während den Kompressionen verursacht.

Bei dem Vergleich von Kraft-Abstandskurven auf Vesikeln in denen Aktin polymerisiert ist mit Kraftkurven von flüssig-kristallinen Vesikeln ohne Aktin, ist zu erkennen, dass der Anstieg der Kurven bei den aktingefüllten Vesikeln deutlich steiler verläuft. Verglichen mit dem Anstieg der Kraft- 
Abstandskurven die auf Gelphasenvesikeln gemessen wurden, lassen sich die Vesikel mit Aktin jedoch leichter komprimieren (Abbildung 3.49).

Die Vorspannung der Vesikel und das Flächenkompressionsmodul der aktincortexunterstützten Membran werden mit der gleichen Ausgleichsrechnung unter Verwendung des KVPP-Modells ermittelt wie bei $L_{\alpha}$-Phasenvesikeln ohne Aktin. Als Beispiel hierfür sind in Abbildung 3.50 die drei in Abbildung 3.49 gezeigten Kraft-Abstandskurven von aktingefüllten Vesikeln mit den angepassten Kurvenverläufen dargestellt.

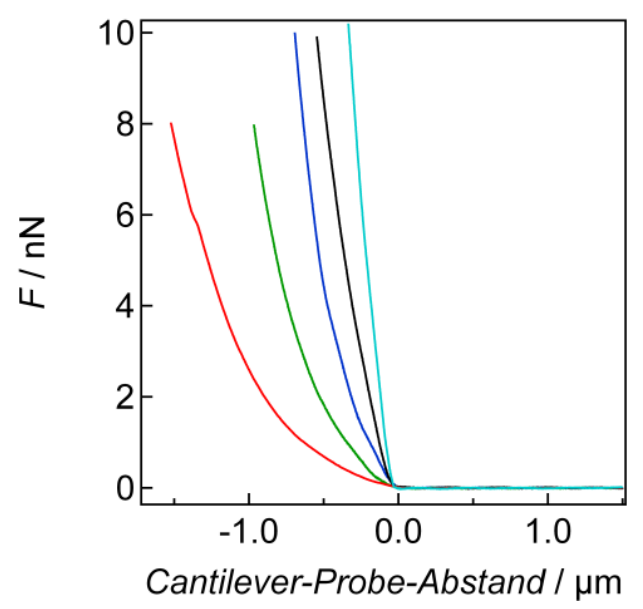

Abbildung 3.49: Vergleich von Kraft-Abstandskurven, die auf Vesikeln mit polymerisiertem Aktin (schwarze Kurve: $R_{0}=6.0 \mu \mathrm{m}, 2 \mathrm{mM} \mathrm{Mg}{ }^{2+}$; blaue Kurve: $R_{0}=9.8 \mu \mathrm{m}, 2 \mathrm{mM} \mathrm{Mg}{ }^{2+}$; grüne Kurve: $R_{0}=5.1 \mu \mathrm{m}, 6 \mathrm{mM} \mathrm{Mg}{ }^{2+}$ ), auf einem Vesikel in der flüssig-kristallinen Phase ohne Aktin (rote Kurve: $R_{\mathrm{V}}=3.8 \mu \mathrm{m}$ ) und in der Gelphase (hellblaue Kurve: $R_{\mathrm{V}}=4.0 \mu \mathrm{m}$ ) zwischen planparallelen Platten aufgenommen wurden. 


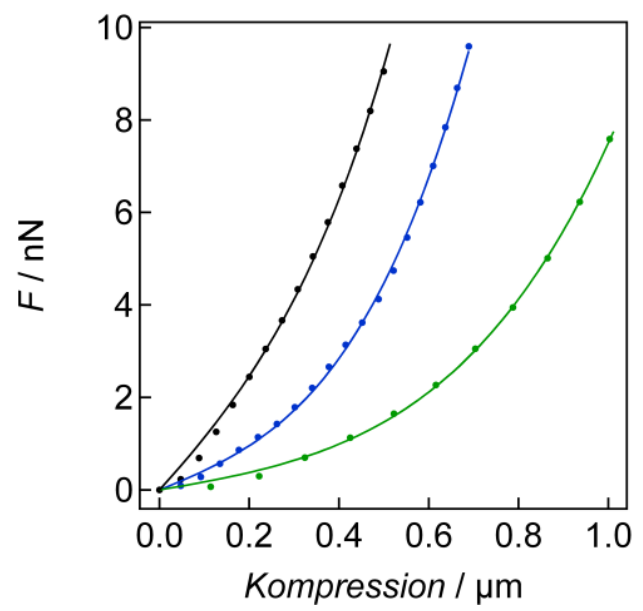

Abbildung 3.50: Experimentell bestimmte Kurvenverläufe der Kraft als Funktion der Kompression von drei verschiedenen Vesikeln mit polymerisiertem Aktin (schwarze Punkte: $R_{0}=6.0 \mu \mathrm{m}, 2 \mathrm{mM}$ $\mathrm{Mg}^{2+}$; blaue Punkte: $R_{0}=9.8 \mu \mathrm{m}, 2 \mathrm{mM} \mathrm{Mg}{ }^{2+}$; grüne Punkte: $R_{0}=5.1 \mu \mathrm{m}, 6 \mathrm{mM} \mathrm{Mg}^{2+}$ ) und an die Kurven jeweils angepasste Kurvenverläufe mit dem KVPP-Modell (Linien in der gleichen Farbe wie die jeweilige Kraft-Abstandskurve). Die aus den Ausgleichsrechnungen ermittelten Werte sind: schwarz: $\sigma_{0}=6.90 \mathrm{mN} / \mathrm{m}, K_{\mathrm{A}}^{\mathrm{app}}=10.42 \mathrm{~N} / \mathrm{m} ;$ blau: $\sigma_{0}=2.50 \mathrm{mN} / \mathrm{m}, K_{\mathrm{A}}^{\mathrm{app}}=\mathbf{2 3 . 8 1} \mathrm{N} / \mathrm{m}$; grün: $\sigma_{0}=1.00 \mathrm{mN} / \mathrm{m}, K_{\mathrm{A}}^{\mathrm{app}}=1.25 \mathrm{~N} / \mathrm{m}$.

Bei den Vesikeln, mit einem Aktinnetzwerk im Inneren ist die Kompression dieser bei vergleichbaren applizierten Kräften zu den Vesikeln ohne Aktin deutlich geringer. Die Rückstellkraft der Vesikel wird durch die eher hoch einzuschätzende Kompressibilität der Aktinnetzstruktur [20, 105] deutlich vergrößert. Aus den resultierenden steileren Kurvenverläufen der Kraft-Abstandskurven ergeben sich daher für das ermittelte Flächenkompressionsmodul aus den Ausgleichsrechnungen mit dem KVPPModell zum Teil unphysikalisch große Werte.

Zur theoretischen Beschreibung des Verhaltens von Vesikeln mit einem engen Aktinnetzwerk im Inneren, müsste ein weiterer Term, der das elastische Verhalten der Aktinfilamente während der Kompression berücksichtigt, in das KVPP-Modell implementiert werden. Die zusätzliche Biegeenergie

$$
E_{\mathrm{K}}=\int \frac{1}{2} \kappa\left(\frac{1}{\rho_{1}}+\frac{1}{\rho 2}\right)+\frac{\bar{\kappa}}{\rho_{1} \rho_{2}} d A
$$

wird von dem Biegemodul $\kappa$, dem Gaußschen Biegemodul $\bar{\kappa}$ und den Krümmungsradien $\rho_{1}, \rho_{2}$ beeinflusst. Da das Biegemoduls von der Schichtdicke abhängig ist $\left(\kappa \propto d^{3}\right)$, wächst mit zunehmender Schalendicke des Aktincortexes auch die benötigte Biegeenergie. [20, 106]

Die ermittelten Werte für das Flächenkompressionsmodul aus den Ausgleichsrechnungen mit dem KVPP-Modell von Vesikeln mit Aktinschalen beinhalten daher nicht nur das Flächenkompressionsmodul der aktincortexunterstützten Membran sondern auch das Biegemodul, 
welches die Krümmungen der kompositen Schale aus Vesikelmembran und Aktincortex beinhaltet. Die Flächenkompressionsmodule werden daher im Folgenden als apparente Flächenkompressionsmodule bezeichnet $\left(K_{\mathrm{A}}^{\mathrm{app}}\right)$. Des Weiteren sind durch die Vereinfachung der KVPP-Theorie die größeren Abweichungen zwischen simulierter und experimenteller KraftAbstandskurve bei Vesikeln mit stark ausgeprägten Aktinnetzwerken zu erklären.

Die schwarz und die blau dargestellten Kraft-Abstandskurven stammen aus derselben Probe, bei der die Fluoreszenzaufnahmen einen hohen Anteil an Vesikeln mit einem Aktinnetzwerk im gesamten Innenbereich zeigen. Bemerkenswert ist, dass diese Netzstruktur des Aktins bei einer Probe mit geringer Magnesiumionenkonzentration erreicht wurde. Die großen berechneten Werte für das apparente Flächenkompressionsmodul dieser Kurven ( $K_{\mathrm{A}}^{\mathrm{app}}=10.42 \mathrm{~N} / \mathrm{m}$ und $K_{\mathrm{A}}^{\mathrm{app}}=23.81 \mathrm{~N} / \mathrm{m}$ ) lassen sich somit durch Einbeziehen der Biegeelastizität des Aktins in den ermittelten Parameter erklären. Da die KVPP-Theorie für diese besonders stark polymerisierten aktingefüllten Vesikel das realen Verhalten des Vesikels während der Kompression nicht korrekt beschreibt, werden die ermittelten Parameter von den Vesikeln aus dieser Probe im Folgenden verworfen.

Bei der in grün dargestellten Kraft-Abstandskurve (Abbildung 3.50) ist die Steigung, insbesondere im Anfangsbereich geringer als bei den beiden anderen Kurven. Wird an die gemessene KraftAbstandskurve ein Kurvenverlauf über die Ausgleichsrechnung mit dem KVPP-Modell angepasst, wird daraus eine Vorspannung von $1.00 \mathrm{mN} / \mathrm{m}$ und ein apparentes Flächenkompressionsmodul der Membran mit Aktincortex von $1.25 \mathrm{~N} / \mathrm{m}$ ermittelt. Somit ist das berechnete apparente Flächenkompressionsmodul für die Membran mit Aktincortex dieses Vesikels zirka viermal größer als das mittlere Flächenkompressionsmodul für eine reine Lipidmembran in der $L_{\alpha}$-Phase. Die Vorspannung dieses Vesikels verändert sich hingegen in Bezug auf Vesikel ohne Aktin nicht.

Im folgenden werden die aus den Ausgleichsrechnungen bestimmten Durchschnittswerte für die Vorspannung beziehungsweise das apparente Flächenkompressionsmodul für die Membran von aktingefüllten Vesikeln gezeigt, die durch Mittelung von den Werten der einzelnen experimentellen Kraft-Abstandskurven auf jeweils einem Vesikel erhalten wurden. Hierbei wird nicht berücksichtigt, ob das Aktin als F-Aktin vorliegt und welche Netzstruktur sich gegebenenfalls ausgebildet hat, sondern nur zwischen den Proben mit $2 \mathrm{mM} \mathrm{Mg}^{2+}$ und $>4 \mathrm{mM} \mathrm{Mg}^{2+}$ unterschieden.

In Abbildung 3.51 ist zu erkenne, dass die berechneten mittleren Vorspannungen der Vesikel im Bereich von 0.2-2.0 mN/m liegen. Eine höhere Magnesiumionenkonzentration in der Probe und damit eine größere Wahrscheinlichkeit, Vesikel mit einem ausgebildeten Aktinnetzwerk oder stärker an der Glasoberfläche adhärierte Vesikel zu vermessen, zeigt keinen Einfluss auf die mittleren Vorspannungswerte. Lediglich die Reproduzierbarkeit der Kraft-Abstandskurven eines Vesikels ist bei 
den niedrigen Magnesiumionenkonzentrationen höher als bei den hohen Konzentrationen, wie an der geringeren Boxhöhe zu erkennen ist.

A

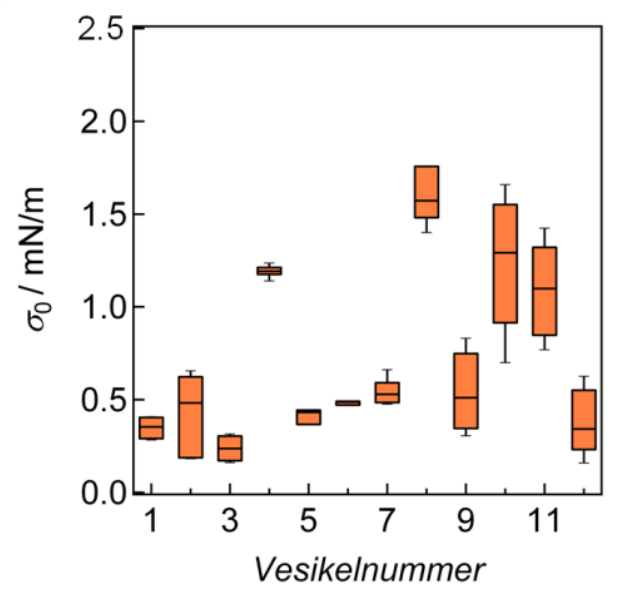

B

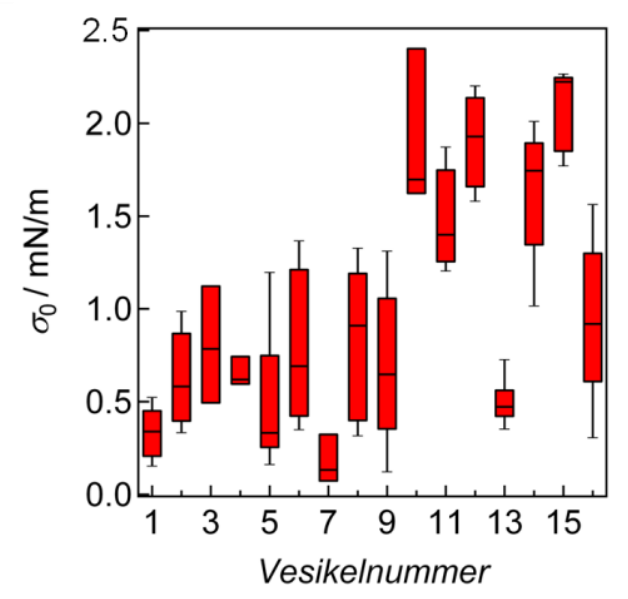

Abbildung 3.51: Boxplot der Vorspannungen aktingefüllter Vesikel, die mit Hilfe der Ausgleichsrechnung des KVPP-Modells ermittelt wurden. Jede Boxeinheit gibt die Verteilung der errechneten Vorspannung wieder, die aus den Kraftkurven ( 3 bis 6 Kurven) eines Vesikels erhalten wurden. Die Polymerisation des Aktins in den Vesikeln wurden durch die Erhöhung der $\mathbf{M g}^{2+}$ lonenkonzentration in der Lösung auf $2 \mathrm{mM}$ (A) oder $>4 \mathrm{mM}$ (B) initiiert.

Die durch Ausgleichsrechnung ermittelten apparenten Flächenkompressionsmodule für aktingefüllte Vesikel zeigen eine breite Verteilung der Mittelwerte aller auswertbarer Kraft-Abstandskurven, bei denen das KVPP-Modell annähernd gilt (Abbildung 3.52). Insbesondere für die Proben mit hohen Magnesiumionenkonzentrationen wurden große Werte für das apparente Flächenkompressionsmodul erhalten. Die Reproduzierbarkeit der aus den Kraft-Abstandskurven ermittelten apparenten Flächenkompressionsmodule nimmt mit steigendem Flächenkompressionsmodul deutlich ab. 
A

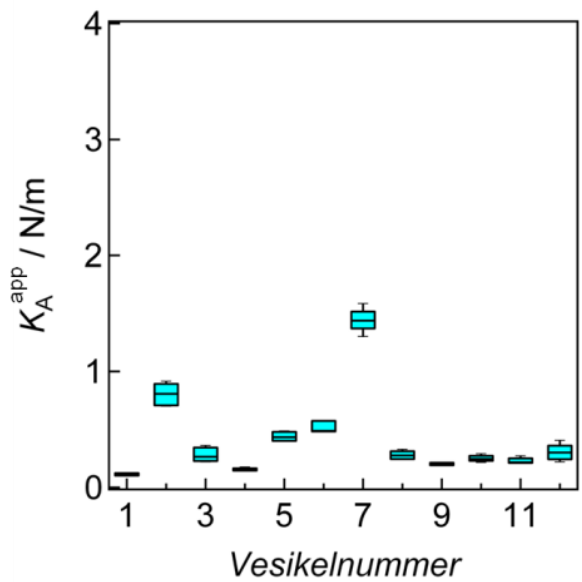

B

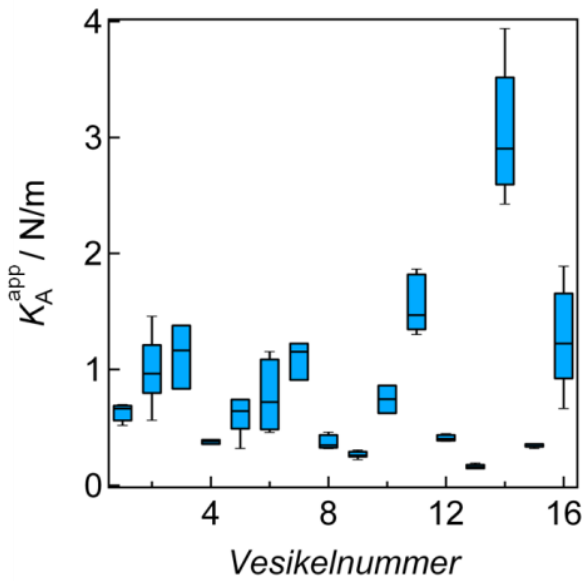

Abbildung 3.52: Boxplot der apparenten Flächenkompressionsmodule für aktingefüllte Vesikel, die mit Hilfe der Ausgleichsrechnung des KVPP-Modells ermittelt wurden. Jede Boxeinheit gibt die Verteilung der errechneten $K_{\mathrm{A}}^{\text {app }}$ wieder, die aus den Kraftkurven ( 3 bis 6 Kurven) eines Vesikels erhalten wurden. Die Polymerisation des Aktins in den Vesikeln wurde durch Erhöhung der Magnesiumionenkonzentration in der Lösung auf $2 \mathrm{mM}(\mathrm{A})$ oder $>4 \mathrm{mM}(\mathrm{B})$ initiiert.

Die Varianz in den berechneten mittleren apparenten Flächenkompressionsmodulen resultiert aus den unterschiedlich stark ausgeprägten Aktinnetzwerkten in den Vesikeln. Ein Teil der Vesikel zeigt vermutlich kein oder nur ein lückenhaftes Aktinnetzwerk im Inneren, wodurch die Membraneigenschaft im Vergleich zu Vesikeln ohne Aktin nicht beziehungsweise kaum beeinflusst wird $\left(K_{\mathrm{A}}^{\text {app }}<0.5 \mathrm{~N} / \mathrm{m}\right)$. Bei Vesikeln mit niedrigen Magnesiumionenkonzentrationen liegen die Flächenkompressionsmodule der meisten Vesikel in diesem Bereich. Bei den hohen Magnesiuminonenkonzentrationen, mit der begünstigten Aktinpolymerisation und dadurch engeren Aktinnetzwerken, steigt der ermittelte Anteil an großen apparenten Flächenkompressionsmodulen deutlich an. Die Rückstellkraft der Membran wird demnach von den Aktinfilamenten im Inneren der Vesikeln beeinflusst. Aufgrund der eingeschränkten Mikroskopiemöglichkeiten kann nicht unterschieden werden zwischen Aktinschalen an der inneren Membran oder Aktinnetzwerken im Lumen der Vesikel. Des Weiteren kann nicht ausgeschlossen werden, dass sich unter den vermessenen Vesikeln auch solche befinden, bei denen sich ein Aktinnetzwerk an der äußeren Membranseite gebildet hat.

In Abbildung 3.53 sind zum Vergleich die berechneten mittleren Vorspannungswerte und das mittlere (apparente) Flächenkompressionsmodul der vermessenen Vesikel ohne und mit Aktin gegenübergestellt. Für keine der aufgetragenen Vesikelkategorien gibt es eine Korrelation der ermittelten Werte des Flächenkompressionsmoduls mit der entsprechenden Vorspannung des Vesikels. 
Die Mittelwerte der Vorspannung der Proben mit aktingefüllten Vesikeln liegen im gleichen Bereich wie die der reinen Lipidvesikel. Die zum Teil stärkere Adhäsion der Vesikel mit Aktincortex und die hohen Magnesiumchloridkonzentrationen wirken sich demnach nicht signifikant auf die Vorspannung der Membran aus. Die ermittelten Vorspannungswerte liegen jedoch zum Teil nur knapp unterhalb der Lysisspannung einer Lipidmembran. Die Proben mit hohen Magnesiumionenkonzentrationen zeigen vermehrt bereits gespreitete Vesikel bei der Fluoreszenzmikroskopie. Eine Erklärung für das Fehlen größerer Vorspannungen könnte also die Lysis von Vesikeln mit einer höheren Vorspannung der Membran sein. Die Lyse eines Vesikels während der Kompression konnte jedoch nur selten beobachtet werden.

Die Verteilung der Mittelwerte des (apparenten) Flächenkompressionsmoduls für Vesikel ohne und mit Aktin bei niedrigen Magnesiumionenkonzentrationen ist identisch. Bei aktingefüllten Vesikeln mit einer hohen Magnesiumionenkonzentration werden vergleichsweise mehr Vesikel gefunden, bei denen die Ausgleichsrechnungen apparente Flächenkompressionsmodule von über $0.5 \mathrm{~N} / \mathrm{m}$ ergeben. Die Verteilung von Vesikeln mit einem (apparenten) Flächenkompressionsmodul $>0.5 \mathrm{~N} / \mathrm{m}$ beträgt zirka $21 \%$ bei Vesikeln ohne Aktin, $23 \%$ bei Vesikeln mit Aktin und niedriger Magnesiumionenkonzentration und $63 \%$ bei aktingefüllten Vesikeln mit hoher lonenkonzentration.

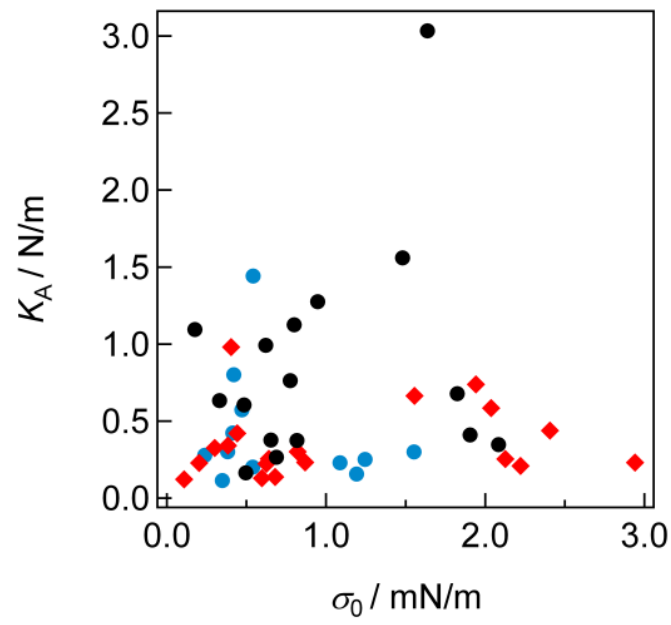

Abbildung 3.53: Vergleich der Mittelwerte des (apparenten) Flächenkompressionsmoduls als Funktion der mittleren Vorspannung für Vesikel ohne Aktin (rote Karos) und Vesikel mit Aktin und einer Magnesiumionenkonzentration von $2 \mathrm{mM}$ (blaue Punkte) beziehungsweise $>4 \mathrm{mM} \mathrm{Mg}^{2+}$ (schwarze Punkte).

Eine mögliche Erklärung für die vereinzelten hohen Flächenkompressionsmodule für Vesikel ohne Aktin ist, dass es sich hierbei um multilamellare Vesikel handelt. Es kann zwar nicht ausgeschlossen werden, dass auch bei aktingefüllten Vesikeln vereinzelt Vesikel mit mehreren Schichten vermessen wurden, aber die Vesikel in den jeweiligen Proben zeigten bei niedriger Ionenkonzentration kein 
höheres apparentes Flächenkompressionsmodul. Demzufolge handelt es sich nicht um Vesikelproben mit überdurchschnittlich vielen multilamellaren Vesikeln.

Die durchschnittlich höheren apparenten Flächenkompressionsmodule für aktingefüllte Vesikel resultieren daher aus dem gebildeten Aktincortex unter der Vesikelmembran. Die Varianz der Membransteifigkeit dieser Vesikel stammt von den unterschiedlichen Aktinnetzstrukturen im Inneren der Vesikel. Die Rückstellkraft des Vesikels während der Kompression, die auch durch das Verbiegen von Aktinfilamenten beeinflusst wird, insbesondere wenn sich ein enger, dicker Aktincortex unter der Membran bildet, spiegelt sich bei der verwendeten Ausgleichsrechnung im Wert des Flächenkompressionsmoduls wieder.

\subsubsection{Zusammenfassung und Diskussion}

In diesem Kapitel konnte gezeigt werden, dass die mechanischen Eigenschaften von Vesikelmembranen durch die Analyse von Kraft-Abstandskurven ermittelt werden können. Hierzu wurden Vesikel in der flüssig-kristallinen Phase mit einem Kraftmikroskop zwischen einem Cantilever ohne Spitze und einer parallel dazu geneigten Probenoberfläche komprimiert. Dabei zeigen die verschiedenen Kraft-Abstandskurven, die bei der Kompression eines identischen Vesikels erhalten wurden, eine sehr hohe Reproduzierbarkeit. Die Kraft-Abstandskurven, die durch Kompression verschiedener Vesikel erhalten wurden, zeigen unterschiedliche Anfangssteigungen. Bei größerer Kompression der Vesikel sind die resultierenden Steigungen in den Kraftkurven jedoch meist identisch. Die Ursache für die verschiedenen Anfangssteigungen liegt an der unterschiedlichen Adhäsion der Vesikel auf dem Glassubstrat. Durch eine stärkere Adhäsion steigt die Spannung der Vesikelmembran. Die Anfangssteigung der Kraft-Abstandskurven beeinflusst insbesondere den über die Ausgleichsrechnungen ermittelten Membranvorspannungswert der Vesikel. Er liegt im Bereich von 0.1-3.0 mN/m. Somit ergeben die Ausgleichsrechnungen mit dem hier aufgestellten KVPP-Modell Vorspannungswerte zwischen der Membranvorspannung von Vesikeln ohne Adhäsion und der Lysisspannung der Membran. [40, 47] Die ermittelten Vorspannungswerte stimmen zudem weitestgehend mit denen aus Tethern in der Rückkurve ermittelten Werten für die Membranspannung überein.

Durch Kompression wird die Oberfläche der Vesikel vergrößert. Da die Vesikel durch Adhäsion an das Substrat bereits soweit vorgespannt sind, dass die Vesikelmembranen keine beziehungsweise kaum noch Ondulationen zeigen, wird die zusätzlich benötigte Membranfläche durch Dehnung erzeugt, bei der der intermolekulare Abstand zwischen den Lipidmolekülen zunimmt. Die Energie die pro Flächenvergrößerung benötigt wird, wird durch das Flächenkompressionsmodul gemäß dem Hookschen Gesetz ausgedrückt und kann durch Kurvenanpassen an die experimentellen Kraft- 
Abstandskurven ermittelt werden. Für die vermessenen flüssig-kristallinen Vesikel ergibt sich ein Mittelwert für das Flächenkompressionsmodul von $\left\langle K_{\mathrm{A}}\right\rangle=0.28 \pm 0.12 \mathrm{~N} / \mathrm{m}$. Dieser Wert stimmt fast exakt mit dem Literaturwert aus Mikropipetten-Aspirationsexperimenten für DOPC-Lipidmembranen von $K_{\mathrm{A}}=0.265 \mathrm{~N} / \mathrm{m}$ überein. [46] Vereinzelt ermittelte Flächenkompressionsmodule im Bereich von 0.5-1.0 N/m resultieren eventuell aus multilamellaren Vesikeln.

Die aus den Ausgleichsrechnungen ermittelten Vorspannungswerte und Flächenkompressionsmodule zeigen erwartungsgemäß keine Abhängigkeit von der Größe des vermessenen Vesikels oder eine Korrelation. Hieraus und aus der Tatsache, dass die ermittelten Vorspannungswerte und Flächenkompressionsmodule gut mit den Literaturwerten übereinstimmen, kann die Schlussfolgerung gezogen werden, dass die verwendete KVPP-Theorie das Experiment korrekt beschreibt.

Gelphasenvesikel zeigten bei der Kompression zwischen planparallelen Platten deutlich größere Rückstellkräfte als flüssig-kristalline Vesikel. Aufgrund der detektierten Hysterese in den KraftAbstandskurven kann nicht von einer vollständig elastischen Kompression der Vesikel ausgegangen werden. Durch die applizierte Kraft wird die Vesikelschale plastisch deformiert oder sogar zerstört und bei mehrmaliger Kompression eines Vesikels verringert sich hierdurch dessen Rückstellkraft. Die aufgestellte Theorie zur Berechnung der Vorspannung und des Flächenkompressionsmoduls lässt sich auf die Gelphasenvesikel aufgrund des spröden Schalenverhaltens nicht anwenden.

Des Weiteren wurden flüssig-kristalline Vesikel untersucht, in deren Lumen Aktinfilamente polymerisiert wurden, wodurch der Einfluss des Cytoskeletts auf die Plasmamembran einer Zelle simuliert wird. Diese Filamente befinden sich entweder als Cortex entlang der Membran oder bilden ein Netzwerk im gesamten Innenbereich des Vesikels aus. Insbesondere durch die Zugabe von Magnesiumionen, durch die die Polymerisation des G-Aktins initiiert wurde, in einer Konzentration von > $4 \mathrm{mM}$ konnte ein hoher Anteil an mit F-Aktin gefüllten Vesikeln erzielt werden. Diese Vesikel lassen sich ebenso, wie die beiden vorher erwähnten Vesikeltypen, zwischen planparallelen Platten komprimieren. Die dabei detektierten Kraft-Abstandskurven liegen zwischen den Kurvenverläufen für Vesikel mit einer Membran in der Gelphase und denen mit einer reinen flüssig-kristallinen Membran. Die Rückstellkräfte des Vesikels während der kraftmikroskopischen Untersuchungen sind dabei von der Struktur des Aktinnetzwerks in den Vesikeln abhängig. Eine genaue Korrelation ist jedoch aufgrund der eingeschränkten optischen Mikroskopieoptionen nicht möglich.

Die Vorspannung und das Flächenkompressionsmodul der aktingefüllten Vesikel kann ebenso aus den Kraft-Abstandskurven mit Hilfe des KVPP-Modells ermittelt werden wie für die reinen Lipidvesikel in der flüssig-kristallinen Phase. Bei den ermittelten Flächenkompressionsmodulen 
handelt es sich um eine Eigenschaft der Lipidmembran zusammen mit den Aktinfilamenten. Das Flächenkompressionsmodul für Vesikel mit besonders engen Aktinstrukturen ergibt jedoch unphysikalisch große Flächenkompressionsmodule. Die Annahme des verwendeten KVPP-Modells, dass die Krümmungsenergie aufgrund ihres geringen Beitrages vernachlässigt werden kann, gilt nur für die Untersuchungen von dünnen Schichten. Zur exakten Beschreibung des Kurvenverlaufs von Vesikeln mit besonders viel F-Aktin im Lumen, müsste ein weiterer Term in die Ausgleichsrechnungen einbezogen werden, der die Elastizität des F-Aktins beziehungsweise der dickeren, kompositen Schale berücksichtigt.

Zur weiteren Analyse wurden daher nur die Kraft-Abstandskurven verwendet, die auf Vesikeln gemessen wurden, deren Kompressionsverhalten sich durch das KVPP-Modell hinreichend beschreiben lassen. Dementsprechend werden Kraft-Abstandskurven mit einer zu großen Steigung verworfen und nur die gemessenen Kurven verwendet, bei denen durch eine mittlere Konzentration von F-Aktin im Vesikel der Einfluss der Elastizität der Aktinfilamente auf das ermittelte Flächenkompressionsmodul ( $K_{\mathrm{A}}^{\text {app }}$ ) gering ist.

Bei dem Vergleich der Verteilung der Vorspannungen von Vesikeln mit und ohne Aktinfilamente können keine signifikanten Unterschiede festgestellt werden. Die in den Fluoreszenzaufnahmen erkennbare verstärkte Adhäsion der Vesikel bei höheren Magnesiumionenkonzentration zeigt demnach keine Auswirkung auf die ermittelte Vorspannung.

Das apparente Flächenkompressionsmodul von Vesikel mit Aktinfilamenten ist im Vergleich zu dem Flächenkompressionsmodul von Vesikeln ohne Aktin im Mittel deutlich größer. Es werden apparente Flächenkompressionsmodule für die Vesikelproben mit einer Magnesiumionenkonzentration von $>4 \mathrm{mM}$ im Bereich von zirka 0.1-3 N/m aus der Ausgleichsrechnung erhalten. Die geringen Werte entsprechen den Flächenkompressionsmodulen von Vesikeln ohne Aktinnetzwerk. Bei über $60 \%$ der Vesikel konnte jedoch ein apparentes Flächenkompressionsmodul ermittelt werden, bei dem der Aktincortex eine höhere Rückstellkraft während der Kompression bewirkt

Mit dem verwendeten KVPP-Modell ist es nicht möglich, das Flächenkompressionsmodul separat vom Biegemodul beziehungsweise der Elastizität des Aktinnetzwerks zu bestimmen. Einen möglichen Lösungsansatz bietet die zusätzliche Integration eines Kontaktmodells, wie folgende Überlegungen zeigen. Dabei wird zur Flächendehnung und zur Vorspannung der Membran parallel ein Hertzsches Kontaktmodell geschaltet, wie in Abbildung 3.54 gezeigt. 


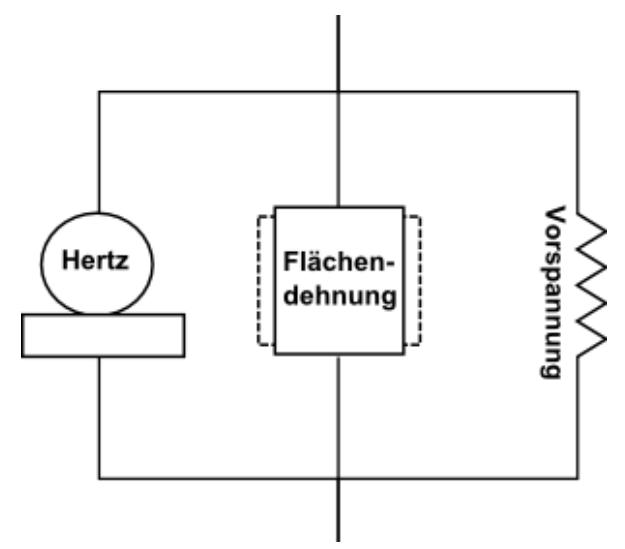

\begin{abstract}
Abbildung 3.54: Mechanisches Ersatzschaltbild, dass die Beiträge der Kompression eines aktingefüllten Vesikels nach dem Kontaktmodell von Hertz, der Flächendehnung und der linearen Vorspannung enthält.
\end{abstract}

Die elastischen Eigenschaften eines aktingefüllten Vesikels können in erster Näherung durch das gezeigte Ersatzschaltbild beschrieben werden. Für das Hertzsche Kontaktmodell wird die Kompression eines dickschaligen Vesikels im Sinne eines elastischen Kontinuums und die Extensibilität der Membran durch eine konstante Vorspannung und eine Membrandehnung im Sinne eines zweidimensionalen Hookschen Gesetzes erfasst. Wie von Discher und Mitarbeitern, Navajas und Mitarbeitern sowie Lulevich et al. gezeigt wurde, lassen sich die einzelnen Komponenten näherungsweise wie folgt zusammenfassen

$$
F=k_{\mathrm{T}} z_{\mathrm{d}}+k_{\mathrm{H}} z_{\mathrm{d}}^{3 / 2}+k_{\mathrm{FD}} z_{\mathrm{d}}^{3}
$$

mit den Konstanten $k_{\mathrm{T}} \propto \sigma_{0}, k_{\mathrm{H}}=\frac{4 E_{\mathrm{Y}}}{31-v^{2}} \sqrt{R_{\mathrm{V}}}$ und $k_{\mathrm{FD}}=\frac{2 \pi}{1-v} R_{\mathrm{V}} K_{\mathrm{A}} \cdot[91,107-109]$

Der erste Term beschreibt den Einfluss der Vorspannung auf die Kraft, der zweite die Kompression einer gefüllten Kugel nach dem Kontaktmodell von Hertz und der dritte Term erfasst die Flächendehnung der Schale bei größeren Kompressionen. Die Potenzen bei der Kompression $\left(z_{\mathrm{d}}\right)$ zeigen die Reichweite der einzelnen Kraftkomponenten. Als Ausblick ist in Abbildung 3.55 eine KraftAbstandskurve eines aktingefüllten Vesikels mit Gleichung 3.51 angepasst (rote Kurve). 


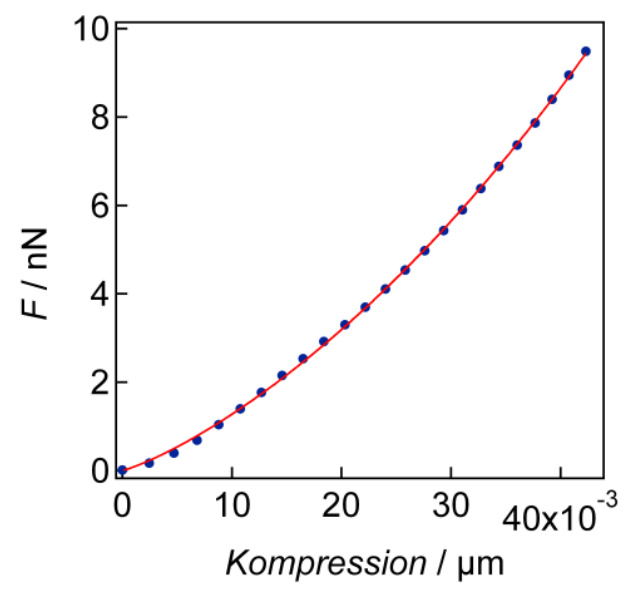

Abbildung 3.55: Kraft-Abstandskurve eines aktingefüllten Vesikels $R_{V}=6 \mu \mathrm{m}$ (blaue Punkte) und nichtlineare Anpassung der Parameter mit Gleichung 3.51 (rote Kurve). $K_{A}=0.28 \mathrm{~N} / \mathrm{m}$, $E_{\mathrm{Y}}=18.4 \mathrm{kPa}$.

Die Parameter für das Youngsche Modul entsprechen dem einer relativ steifen Zellmembran, während das Flächenkompressionsmodul dem einer Lipidmembran entspricht. Die im Vergleich zum KVPP-Modell zusätzliche elastische Komponente (Hertzsches Kontaktmodell) verringert das ermittelte apparente Flächenkompressionsmodul.

Zusammenfassend lässt sich sagen, dass mit der KVPP-Theorie das Verhalten von reinen flüssigkristallinen Lipidvesikeln während der Kompression gut beschrieben wird. Durch das Einbringen eines Aktinnetzwerks, dessen Filamente nicht miteinander verknüpft sind und das ohne Bindung zur Plasmamembran ist, konnte bereits die Rückstellkraft und somit die Membransteifigkeit der untersuchten Vesikel deutlich erhöht werden. Die Steifigkeit einer Zelle wird daher alleine durch die Existenz des Aktincortex ohne aktinbindende Proteine gesteigert. Diese Veränderungen lassen sich mit dem KVPP-Modell jedoch nur bei geringem Einfluss der Elastizität des Aktincortex beschreiben. Für Vesikel mit besonders ausgeprägten Aktinnetzwerken im Inneren bietet das Kontaktmodell einen möglichen Ansatz, der in den Grundzügen erklärt, warum die Flächenkompressionsmodule bei dicken elastischen Schalen überbestimmt werden und wie das Flächenkompressionsmodul und die Elastizität des Cortex separat bestimmt werden könnten. 



\subsection{Anhang}

\subsubsection{Computerprogramm}

Im folgenden Abschnitt ist der Quellcode aufgeführt, der zur Ausgleichsrechnung der KraftAbstandskurven für das KVPP-Modell mit der Software Matlab (The MathWorks) verwendet wird. Aus einem gegebenen Set aus $\sigma_{0}, K_{\mathrm{A}}$ und $R_{\mathrm{V}}$-Werten wird eine Kraft-Abstandskurve bestimmt.

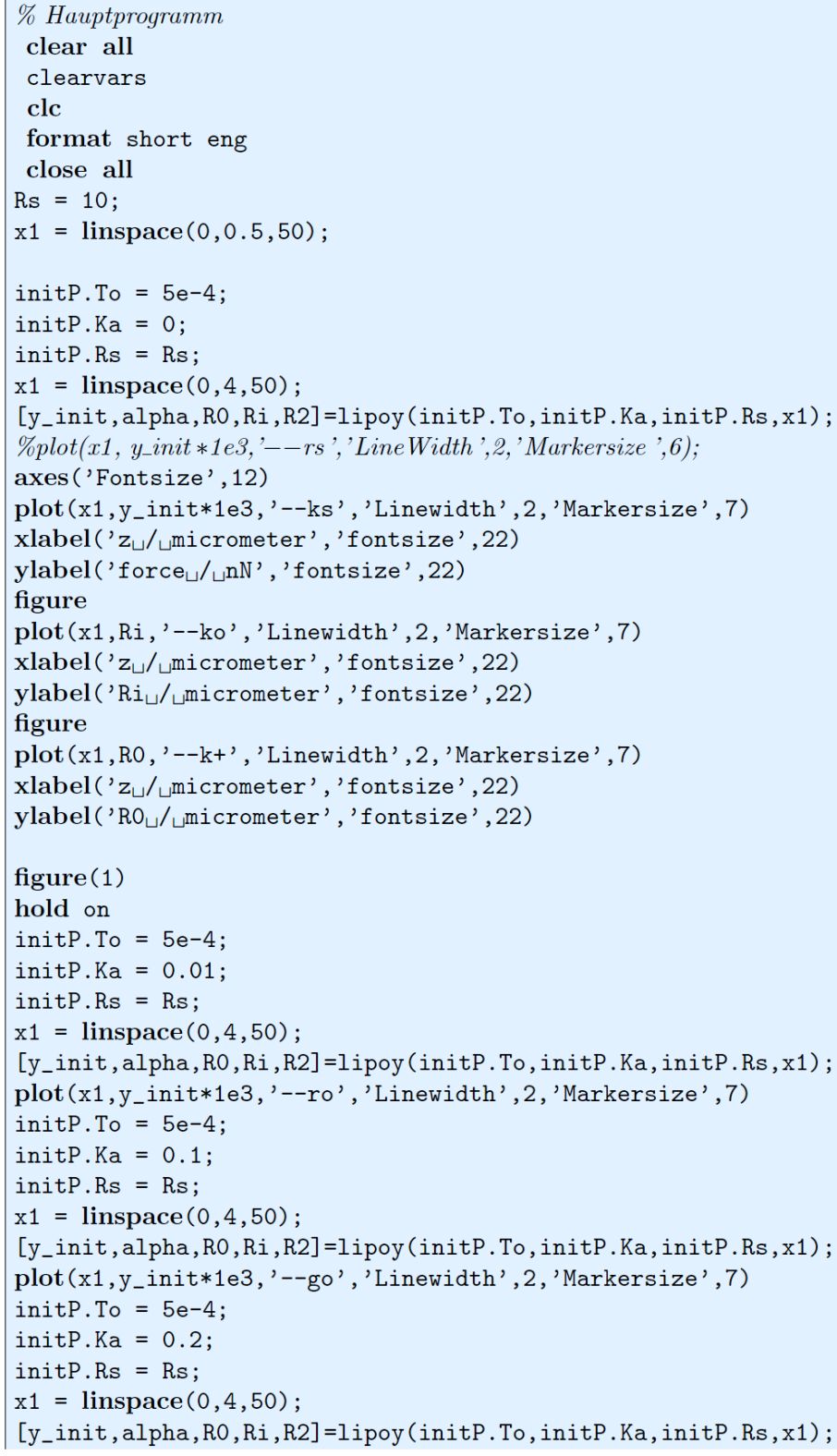




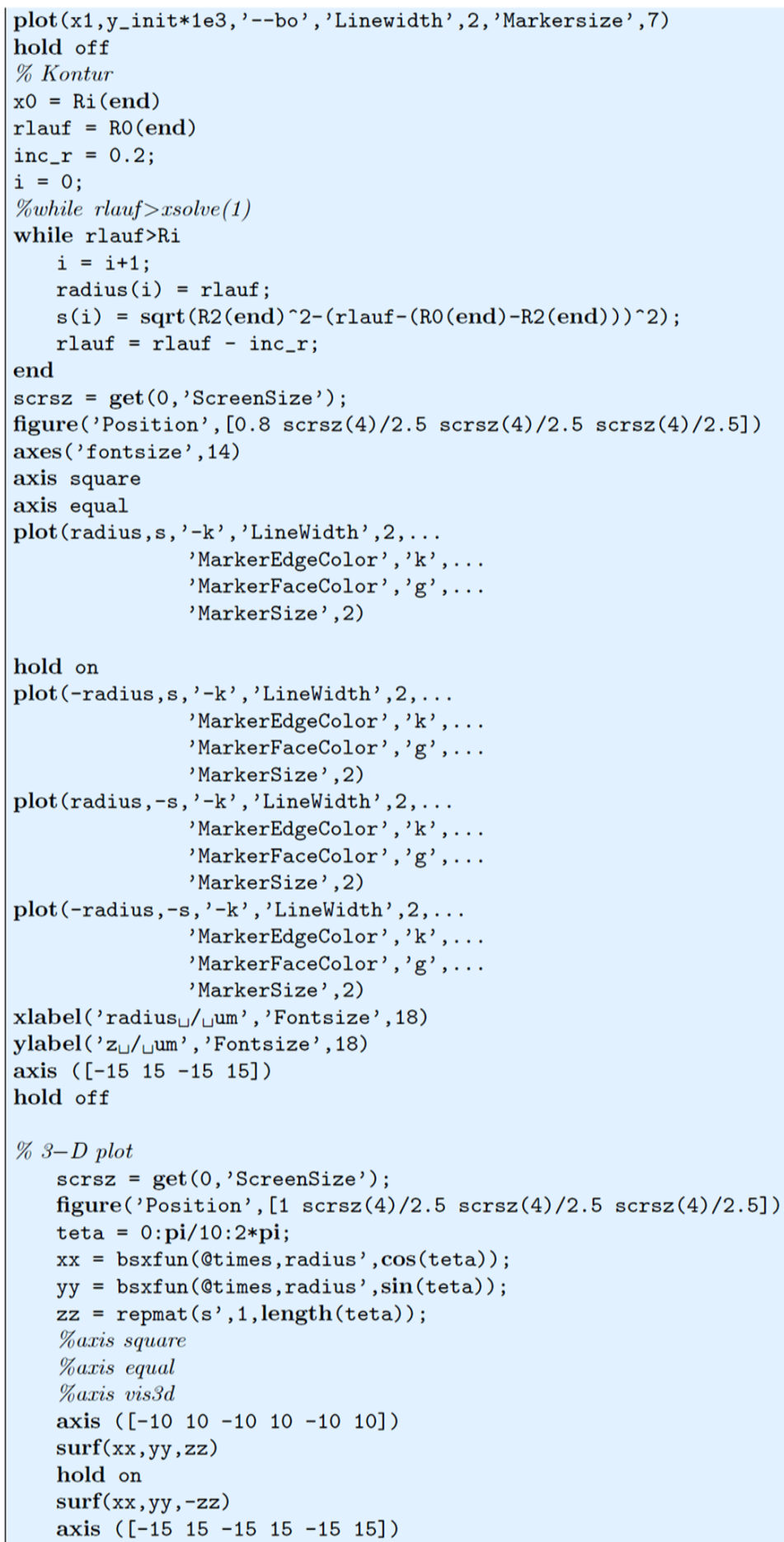


Durch Verwendung der zwei Funktionen "lipoybp.m" und "myfun.m" in einem Simplex-Verfahren werden die Parameter $\sigma_{0}(\mathrm{TO})$ und $K_{\mathrm{A}}(\mathrm{KA})$ als Funktion des Vesikelradius $R_{\mathrm{V}}(\mathrm{RS})$ bestimmt.

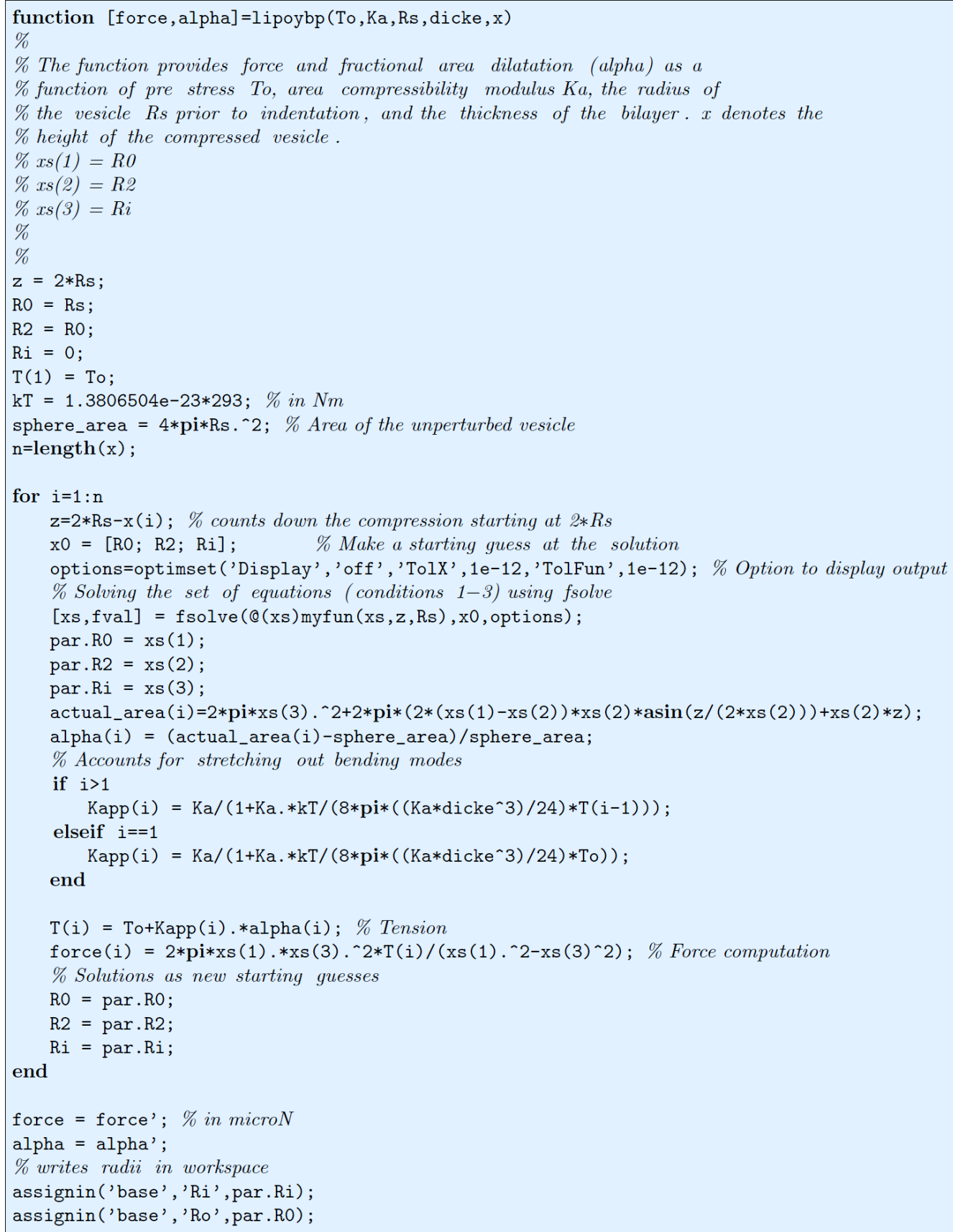


Die Funktion "lipoybp.m" benötigt die Funktion "myfun.m" zur Berechnung der drei Bedingungen für die Beschreibung der komprimierten Vesikelstruktur.

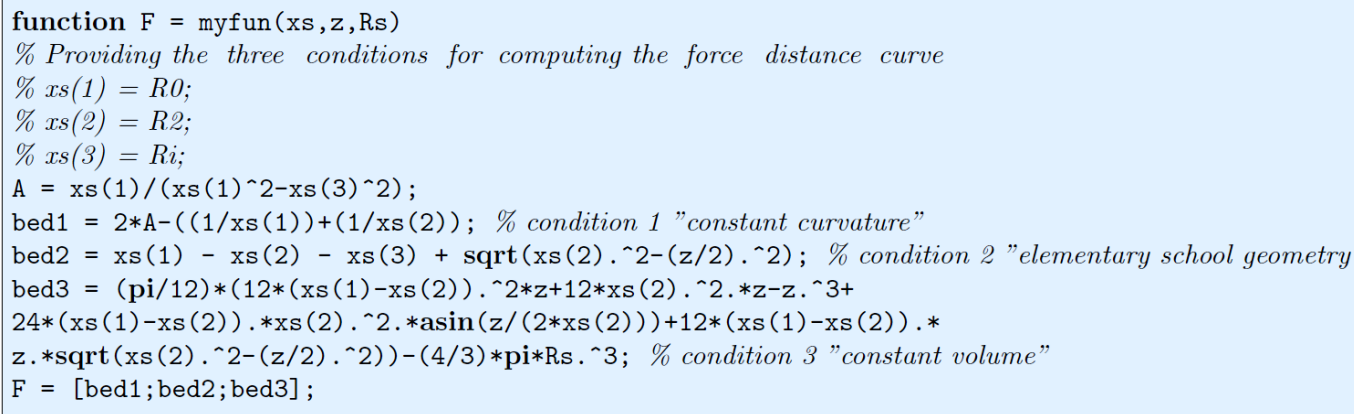




\subsection{Literaturverzeichnis}

1. Long, M. S., Jones, C. D., Helfrich, M. R., Mangeney-Slavin, L. K., und Keating, C. D. (2005) Dynamic microcompartmentation in synthetic cells, Proc. Natl. Acad. Sci. U.S.A. 102, 59205925.

2. Ruder, W. C., und LeDuc, P. R. (2011) Bioinspirations: Cell-Inspired Small-Scale Systems for Enabling Studies in Experimental Biomechanics, Integr. Comp. Biol. 51, 133-141.

3. Saetzler, K., Sonnenschein, C., und Soto, A. M. (2011) Systems biology beyond networks: Generating order from disorder through self-organization, Semin. Cancer Biol. 21, 165-174.

4. Janke, M., Herrig, A., Austermann, J., Gerke, V., Steinem, C., und Janshoff, A. (2008) Actin Binding of Ezrin Is Activated by Specific Recognition of PIP2-Functionalized Lipid Bilayers, Biochemistry 47, 3762-3769.

5. Loose, M., und Schwille, P. (2009) Biomimetic membrane systems to study cellular organization, J. Struct. Biol. 168, 143-151.

6. Barfoot, R. J., Sheikh, K. H., Johnson, B. R. G., Colyer, J., Miles, R. E., Jeuken, L. J. C., Bushby, R. J., und Evans, S. D. (2008) Minimal F-Actin Cytoskeletal System for Planar Supported Phospholipid Bilayers, Langmuir 24, 6827-6836.

7. Boulbitch, A., Simson, R., Simson, D. A., Merkel, R., Häckl, W., Bärmann, M., und Sackmann, E. (2000) Shape instability of a biomembrane driven by a local softening of the underlying actin cortex, Phys. Rev. E: Stat. Phys. Plasmas Fluids Relat. Interdisciplin. Top. 62, 3974-3985.

8. Cortese, J. D., Schwab, B., Frieden, C., und Elson, E. L. (1989) Actin polymerization induces a shape change in actin-containing vesicles, Proc. Natl. Acad. Sci. U.S.A. 86, 5773-5777.

9. Tsai, F.-C., Stuhrmann, B., und Koenderink, G. H. (2011) Encapsulation of Active Cytoskeletal Protein Networks in Cell-Sized Liposomes, Langmuir 27, 10061-10071.

10. Karp, G. (2005) Molekulare Zellbiologie, Springer 1.

11. Pollard, T. D., Earnshaw, W. C., und Lippincott-Schwartz, J. (2007) Cell Biology, Das Orginal mit Übersetzungshilfe, Spektrum Akademischer Verlag 2.

12. Mullins, R. D., Stafford, W. F., und Pollard, T. D. (1997) Structure, Subunit Topology, and Actin-binding Activity of the Arp2/3 Complex from Acanthamoeba, J. Cell Biol. 136, 331-343.

13. Pollard, T. D., Blanchoin, L., und Mullins, R. D. (2000) Molecular mechanisms controlling actin filament dynamics in nonmuscle cells, Annu. Rev. Biophys. Biomol. Struct. 29, 545-576.

14. Pollard, T. D., und Cooper, J. A. (1989) Actin and Actin-Binding Proteins. A Critical Evaluation of Mechanisms and Functions, Annu. Rev. Biochem. 55, 987-1035.

15. Pollard, T. D., und Borisy, G. G. (2003) Cellular Motility Driven by Assembly and Disassembly of Actin Filaments, Cell 112, 453-465.

16. Holmes, K. C., Popp, D., Gebhard, W., und Kabsch, W. (1990) Atomic model of the actin filament, Nature 347, 44-49.

17. Khaitlina, S. Y. (2001) Functional specificity of actin isoforms, In Int. Rev. Cytol., pp 35-98, Academic Press.

18. Rubenstein, P. A. (1990) The functional importance of multiple actin isoforms, BioEssays 12, 309-315.

19. Pantaloni, D., Clainche, C. L., und Carlier, M.-F. (2001) Mechanism of Actin-Based Motility, Science 292, 1502-1506.

20. Boal, D. (2002) Mechanics of the Cell, Cambridge Universtity Press 1.

21. Podolski, J. L., und Steck, T. L. (1990) Length distribution of F-actin in Dictyostelium discoideum, J. Biol. Chem. 265, 1312-1318.

22. Huxley, H., und Hanson, J. (1954) Changes in the cross-striations of muscle during contraction and stretch and their structural interpretation, Nature 173.

23. Higuchi, S., Tsukasaki, Y., Fukuda, N., Kurihara, S., und Fujita, H. (2011) Thin FilamentReconstituted Skinned Muscle Fibers for the Study of Muscle Physiology, J. Biomed. Biotechnol. 2011, 486021. 
24. Sheetz, M. P., Sable, J. E., und Döbereiner, H.-G. (2006) Continous membrane - Cytoskeleton adhesion requires continuous accommodation to lipid and cytoskeleton dynamics, Annu. Rev. Biophys. Biomol. Struct. 35, 417-434.

25. Machesky, L. M., und Insall, R. H. (1999) Signaling to Actin Dynamics, J. Cell Biol. 146, 267272.

26. Critchley, D. R. (2000) Focal adhesions - the cytoskeletal connection, Curr. Opin. Cell Biol. 12, 133-139.

27. Wehrle-Haller, B. (2011) Structure and function of focal adhesions, Curr. Opin. Cell Biol. 24, 116-124.

28. Condeelis, J. S., Wyckoff, J. B., Bailly, M., Pestell, R., Lawrence, D., Backer, J., und Segall, J. E. (2001) Lamellipodia in invasion, Semin. Cancer Biol. 11, 119-128.

29. Janmey, P. A., Hvidt, S., Käs, J., Lerche, D., Maggs, A., Sackmann, E., Schliwa, M., und Stossel, T. P. (1994) The mechanical properties of actin gels. Elastic modulus and filament motions, J. Biol. Chem. 269, 32503-32513.

30. Xu, J., Schwarz, W. H., Käs, J. A., Stossel, T. P., Janmey, P. A., und Pollard, T. D. (1998) Mechanical Properties of Actin Filament Networks Depend on Preparation, Polymerization Conditions, and Storage of Actin Monomers, Biophys. J. 74, 2731-2740.

31. Gittes, F., Schnurr, B., Olmsted, P. D., MacKintosh, F. C., und Schmidt, C. F. (1997) Microscopic Viscoelasticity: Shear Moduli of Soft Materials Determined from Thermal Fluctuations, Phys. Rev. Lett. 79, 3286-3289.

32. Palmer, A., Mason, T. G., Xu, J., Kuo, S. C., und Wirtz, D. (1999) Diffusing Wave Spectroscopy Microrheology of Actin Filament Networks, Biophys. J. 76, 1063-1071.

33. Pietuch, A., Fine, T., Mey, I., und Janshoff, A. Tension driven surface area regulation of epithelial cells: adaption to external stimuli, J. Cell. Sci. eingereicht.

34. Sackmann, E. (1994) Membrane bending energy concept of vesicle- and cell-shapes and shape-transitions, FEBS Letters 346, 3-16.

35. CMC.

http://avantilipids.com/index.php?option=com_content\&view=article\&id=1703\&ltemid=422 , (29.07.2012).

36. Hamai, C., Yang, T., Kataoka, S., Cremer, P. S., und Musser, S. M. (2006) Effect of Average Phospholipid Curvature on Supported Bilayer Formation on Glass by Vesicle Fusion, Biophys. J. 90, 1241-1248.

37. Luisi, P. L., und Walde, P. (2000) Giant Vesicles: Perspectives in Supramolecular Chemistry, WILEY-VCH Verlag GmbH 6.

38. Kučerka, N., Tristram-Nagle, S., und Nagle, J. (2006) Structure of Fully Hydrated Fluid Phase Lipid Bilayers with Monounsaturated Chains, J. Membr. Biol. 208, 193-202.

39. Tahara, Y., und Fujiyoshi, Y. (1994) A new method to measure bilayer thickness: Cryoelectron microscopy of frozen hydrated liposomes and image simulation, Micron 25, 141149.

40. Olbrich, K., Rawicz, W., Needham, D., und Evans, E. (2000) Water Permeability and Mechanical Strength of Polyunsaturated Lipid Bilayers, Biophys. J. 79, 321-327.

41. Yoshitani, T. (2008) Water permeability of lipid membranes of GUVs and its dependence on actin cytoskeletons inside the GUVs Micro-NanoMechatronics and Human Science, 130 - 134.

42. Becker, W. M., Kleinsmith, L. J., Hardin, J., und Bertoni, G. P. (2009) The World of the Cell, Pearson Benjamin Cummings, San Francicso 7.

43. Chiu, D. T., Wilson, C. F., Ryttsén, F., Strömberg, A., Farre, C., Karlsson, A., Nordholm, S., Gaggar, A., Modi, B. P., Moscho, A., Garza-López, R. A., Orwar, O., und Zare, R. N. (1999) Chemical Transformations in Individual Ultrasmall Biomimetic Containers, Science 283, 18921895.

44. Vitkova, V., Mader, M., und Podgorski, T. (2004) Deformation of vesicles flowing through capillaries Europhys. Lett. 68, 398. 
45. Wick, R., Angelova, M. I., Walde, P., und Luisi, P. L. (1996) Microinjection into giant vesicles and light microscopy investigation of enzyme-mediated vesicle transformations, Chem. Biol. 3, 105-111.

46. Rawicz, W., Olbrich, K. C., McIntosh, T., Needham, D., und Evans, E. (2000) Effect of Chain Length and Unsaturation on Elasticity of Lipid Bilayers, Biophys. J. 79, 328-339.

47. Rädler, J. O., Feder, T. J., Strey, H. H., und Sackmann, E. (1995) Fluctuation analysis of tension-controlled undulation forces between giant vesicles and solid substrates, Phys. Rev. E: Stat. Phys. Plasmas Fluids Relat. Interdisciplin. Top. 51, 4526-4536.

48. Evans, E. A. (1974) Bending Resistance and Chemically Induced Moments in Membrane Bilayers, Biophys. J. 14, 923-931.

49. Murrell, M., Pontani, L.-L., Guevorkian, K., Cuvelier, D., Nassoy, P., und Sykes, C. (2011) Spreading Dynamics of Biomimetic Actin Cortices, Biophys. J. 100, 1400-1409.

50. Miyata, H., und Hotani, H. (1992) Morphological changes in liposomes caused by polymerization of encapsulated actin and spontaneous formation of actin bundles, Proc. Natl. Acad. Sci. U.S.A. 89, 11547-11551.

51. Honda, M., Takiguchi, K., Ishikawa, S., und Hotani, H. (1999) Morphogenesis of liposomes encapsulating actin depends on the type of actin-crosslinking, J. Mol. Biol. 287, 293-300.

52. Li, S., und Palmer, A. F. (2004) Structure of Small Actin-Containing Liposomes Probed by Atomic Force Microscopy: Effect of Actin Concentration \& Liposome Size, Langmuir 20, 79177925.

53. Maemichi, H., Shikinaka, K., Kakugo, A., Furukawa, H., Osada, Y., und Gong, J. P. (2008) Morphogenesis of Liposomes Caused by Polycation-Induced Actin Assembly Formation, Langmuir 24, 11975-11981.

54. Miyata, H., Nishiyama, S., Akashi, K.-i., und Kinosita, K. (1999) Protrusive growth from giant liposomes driven by actin polymerization, Proc. Natl. Acad. Sci. U.S.A. 96, 2048-2053.

55. Miyata, H., und Kinosita Jr, K. (1994) Transformation of actin-encapsulating liposomes induced by cytochalasin D, Biophys. J. 67, 922-928.

56. Limozin, L., und Sackmann, E. (2002) Polymorphism of Cross-Linked Actin Networks in Giant Vesicles, Phys. Rev. Lett. 89, 168103.

57. Limozin, L., Bärmann, M., und Sackmann, E. (2003) On the organization of self-assembled actin networks in giant vesicles, Eur Phys J E Soft Matter 10, 319-330.

58. Häckl, W., Bärrmann, M., und Sackmann, E. (1998) Shape Changes of Self-Assembled Actin Bilayer Composite Membranes, Phys. Rev. Lett. 80, 1786-1789.

59. Merkle, D., Kahya, N., und Schwille, P. (2008) Reconstitution and Anchoring of Cytoskeleton inside Giant Unilamellar Vesicles, ChemBioChem 9, 2673-2681.

60. Pontani, L.-L., van der Gucht, J., Salbreux, G., Heuvingh, J., Joanny, J.-F., und Sykes, C. (2009) Reconstitution of an Actin Cortex Inside a Liposome, Biophys. J. 96, 192-198.

61. Takiguchi, K., Yamada, A., Negishi, M., Tanaka-Takiguchi, Y., und Yoshikawa, K. (2008) Entrapping Desired Amounts of Actin Filaments and Molecular Motor Proteins in Giant Liposomes, Langmuir 24, 11323-11326.

62. Ito, T., und Yamazaki, M. (2006) The "Le Chatelier's Principle"-Governed Response of Actin Filaments to Osmotic Stress, J Phys Chem B 110, 13572-13581.

63. Herman, I. M. (1993) Actin isoforms, Curr. Opin. Cell Biol. 5, 48-55.

64. Khaitlina, S. (2007) Mechanisms of spatial segregation of actin isoforms, Cell and Tissue Biol. 1, 293-304.

65. Aktin Alexa-Fluor488. http://products.invitrogen.com/ivgn/product/A12373, (28.07.2012).

66. DPPC. http://avantilipids.com/index.php?option=com_content \&view=article\&id=216\&ltemid=206\& catnumber $=850355,(28.07 .2012)$.

67. DOPC.

http://avantilipids.com/index.php?option=com_content\&view=article\&id=231\&Itemid=207\& catnumber $=850375,(28.07 .2012)$. 
68. DOPE.

http://avantilipids.com/index.php?option=com_content\&view=article\&id=565\&ltemid=228\& catnumber $=850725,(28.07 .2012)$.

69. Livnah, O., Bayer, E. A., Wilchek, M., und Sussman, J. L. (1993) Three-dimensional structures of avidin and the avidin-biotin complex, Proc. Natl. Acad. Sci. U.S.A. 90, 5076-5080.

70. TR-DHPE. http://products.invitrogen.com/ivgn/product/T1395MP, (28.07.2012).

71. Abbott, B. J., Fukuda, D. S., Dorman, D. E., Occolowitz, J. L., Debono, M., und Farhner, L. (1979) Microbial transformation of A23187, a divalent cation ionophore antibiotic, Antimicrob Agents Chemother 16, 808-812.

72. Angelova, M. I., und Dimitrov, D. S. (1986) Liposome electroformation, Faraday Discuss. Che. Soc. 81, 303-311.

73. Pott, T., Bouvrais, H., und Méléard, P. (2008) Giant unilamellar vesicle formation under physiologically relevant conditions, Chem. Phys. Lipids 154, 115-119.

74. Walde, P., Cosentino, K., Engel, H., und Stano, P. (2010) Giant Vesicles: Preparations and Applications, ChemBioChem 11, 848-865.

75. Mathivet, L., Cribier, S., und Devaux, P. F. (1996) Shape change and physical properties of giant phospholipid vesicles prepared in the presence of an AC electric field, Biophys. J. 70, 1112-1121.

76. De Smedt, S. C., Remaut, K., Lucas, B., Braeckmans, K., Sanders, N. N., und Demeester, J. (2005) Studying biophysical barriers to DNA delivery by advanced light microscopy, Adv. Drug Delivery Rev. 57, 191-210.

77. Wang, Y., Shyy, J. Y.-J., und Chien, S. (2008) Fluorescence Proteins, Live-Cell Imaging, and Mechanobiology: Seeing Is Believing, Annu. Rev. Biomed. Eng. 10, 1-38.

78. Zeizz. (2005) Photomanipulation with Laser Scanning Microscopes, Photomanipulation techniques.

79. Butt, H.-J., Cappella, B., und Kappl, M. (2005) Force measurements with the atomic force microscope: Technique, interpretation and applications, Surf. Sci. Rep. 59, 1-152.

80. Canale, C., Jacono, M., Diaspro, A., und Dante, S. (2010) Force spectroscopy as a tool to investigate the properties of supported lipid membranes, Microsc. Res. Tech. 73, 965-972.

81. Fisher, T. E., Marszalek, P. E., und Fernandez, J. M. (2000) Stretching single molecules into novel conformations using the atomic force microscope, Nat. Struct. Mol. Biol. 7, 719-724.

82. Müller, D. J., und Dufrêne, Y. F. (2011) Atomic force microscopy: a nanoscopic window on the cell surface, Trends Cell Biol. 21, 461-469.

83. Cappella, B., und Dietler, G. (1999) Force-distance curves by atomic force microscopy, Surf. Sci. Rep. 34, 1-104.

84. Janshoff, A., Neitzert, M., Oberdörfer, Y., und Fuchs, H. (2000) Force Spectroscopy of Molecular Systems-Single Molecule Spectroscopy of Polymers and Biomolecules, Angew. Chem. Int. Ed. 39, 3212-3237.

85. Hutter, J. L., und Bechhoefer, J. (1993) Calibration of atomic-force microscope tips Rev. Sci. Instrum. 64, 1868-1973.

86. Schäfer, E., Kliesch, T.-T., und Janshoff, A. Mechanical properties of giant liposomes compressed between two parallel plates - impact of artificial actin shells, Langmuir eingereicht.

87. Yeung, A., und Evans, E. (1989) Cortical shell-liquid core model for passive flow of liquid-like spherical cells into micropipets, Biophys. J. 56, 139-149.

88. Dong, C., Skalak, R., Sung, K.-L. P., Schmid-Schonbein, G. W., und Chien, S. (1988) Passive Deformation Analysis of Human Leukocytes, J. Biomech. Eng. 110, 27-36.

89. Rosenbluth, M. J., Lam, W. A., und Fletcher, D. A. (2006) Force Microscopy of Nonadherent Cells: A Comparison of Leukemia Cell Deformability, Biophys. J. 90, 2994-3003.

90. Sen, S., Subramanian, S., und Discher, D. E. (2005) Indentation and Adhesive Probing of a Cell Membrane with AFM: Theoretical Model and Experiments, Biophys. J. 89, 3203-3213.

91. Evans, E., und Rawicz, W. (1990) Entropy-driven tension and bending elasticity in condensedfluid membranes, Phys. Rev. Lett. 64, 2094-2097. 
92. Hategan, A., Law, R., Kahn, S., und Discher, D. E. (2003) Adhesively-Tensed Cell Membranes: Lysis Kinetics and Atomic Force Microscopy Probing, Biophys. J. 85, 2746-2759.

93. Yoneda, M. (1964) Tension at the Surface of Sea-Urchin Egg: A Critical Examination of Cole's Experiment, J. Exp. Biol. 41, 893-906.

94. Li, S., Eghiaian, F., Sieben, C., Herrmann, A., und Schaap, I. A. T. (2011) Bending and Puncturing the Influenza Lipid Envelope, Biophys. J. 100, 637-645.

95. Norotte, C., Marga, F., Neagu, A., Kosztin, I., und Forgacs, G. (2008) Experimental evaluation of apparent tissue surface tension based on the exact solution of the Laplace equation Europhys. Lett. 81, 46003.

96. Evans, E., und Rawicz, W. (1997) Elasticity of "Fuzzy" Biomembranes, Phys. Rev. Lett. 79, 2379-2382.

97. Evans, E. A., Waugh, R., und Melnik, L. (1976) Elastic area compressibility modulus of red cell membrane, Biophys. J. 16, 585-595.

98. Mey, I., Stephan, M., Schmitt, E. K., Müller, M. M., Ben Amar, M., Steinem, C., und Janshoff, A. (2009) Local membrane mechanics of pore-spanning bilayers, J. Am. Chem. Soc. 131, 70317039.

99. Dao, M., Lim, C. T., und Suresh, S. (2003) Mechanics of the human red blood cell deformed by optical tweezers, J. Mech. Phys. Solids 51, 2259-2280.

100. Derényi, I., Jülicher, F., und Prost, J. (2002) Formation and Interaction of Membrane Tubes, Phys. Rev. Lett. 88, 238101.

101. Powers, T. R., Huber, G., und Goldstein, R. E. (2002) Fluid-membrane tethers: Minimal surfaces and elastic boundary layers, Phys. Rev. E: Stat. Nonlinear Soft Matter Phys. 65, 041901.

102. Hochmuth, F. M., Shao, J. Y., Dai, J., und Sheetz, M. P. (1996) Deformation and flow of membrane into tethers extracted from neuronal growth cones, Biophys. J. 70, 358-369.

103. Seifert, U., und Lipowsky, R. (1990) Adhesion of vesicles, Phys. Rev. A: At. Mol. Opt. Phys. 42, 4768-4771.

104. Fery, A., und Weinkamer, R. (2007) Mechanical properties of micro- and nanocapsules: Single-capsule measurements, Polymer 48, 7221-7235.

105. Knoche, S., und Kierfeld, J. (2011) Buckling of spherical capsules, Phys. Rev. E: Stat. Nonlinear Soft Matter Phys. 84, 046608.

106. Chaudhuri, O., Parekh, S. H., und Fletcher, D. A. (2007) Reversible stress softening of actin networks, Nature 445, 295-298.

107. Helfrich, W. (1973) Elastic properties of lipid bilayers: theory and possible experiments, $Z$. Naturforsch. 28, 693-703.

108. Roca-Cusachs, P., Almendros, I., Sunyer, R., Gavara, N., Farré, R., und Navajas, D. (2006) Rheology of Passive and Adhesion-Activated Neutrophils Probed by Atomic Force Microscopy, Biophys. J. 91, 3508-3518.

109. Lulevich, V. V., Andrienko, D., und Vinogradova, O. I. (2004) Elasticity of polyelectrolyte multilayer microcapsules, J. Chem. Phys. 120, 3822.

110. Lulevich, V. V., und Vinogradova, O. I. (2004) Effect of pH and Salt on the Stiffness of Polyelectrolyte Multilayer Microcapsules, Langmuir 20, 2874-2878. 



\section{Kapitel}

\section{Zusammenfassung}

Im Rahmen der vorliegenden Arbeit wurden kollektive Veränderungen der Zellkontakte synchronisierter Zellen und mechanische Eigenschaften von Plasmamembranen anhand von zwei verschiedenen Modellsystemen detailliert untersucht. Im ersten Teil der Arbeit war die zelluläre Adhäsion von Dictyostelium discoideum Zellen zwischen den Amöben sowie insbesondere zum Substrat von entscheidender Bedeutung. Einen wichtigen Einfluss auf die Ausbildung von zellulärer Adhäsion haben dabei die Plasmamembran und das damit verbundene Aktincytoskelett der Zellen. Im zweiten Teil wurde daher das mechanische Verhalten von artifiziellen Membranen mit und ohne Aktincortex anhand von Vesikelkompressionsexperimenten mit dem Rasterkraftmikroskop analysiert. Impedanzmessungen im Mikrokanal und in ECIS-Messkammern zeigen bei einem Ensemble von Dictyostelium discoideum Zellen nach 3-5 Stunden Nahrungsentzug Oszillationen mit einer Periodendauer von wenigen Minuten. Durch Beeinflussung der Oszillation konnte bewiesen werden, dass die Ursache für diesen periodischen Signalverlauf die cAMP-abhängige Chemotaxis der Zellen während der Aggregation ist. Als (bio)physikalische Ursache für den detektierten, oszillierenden Impedanzverlauf konnten zwei verschiedene synchrone Veränderungen des Zellenkontaktes ermittelt werden. Zum einem korreliert die Oszillation des Impedanzsignals mit dem periodischen Auf- und Abbau von kleinen Zellverbänden. Der Zeitpunkt der lokalen Maxima des Impedanzverlaufs entspricht dabei der maximalen Clusterbildung. Zum anderen konnten D-QCM-Messungen und zeitabhängige TIRF-Mikroskopie zeigen, dass es zu zyklischen Veränderungen des Zell-SubstratAbstands kommt, wobei es sich hauptsächlich um eine Verlagerung des Zellkörpers zum Substrat handelt. Die parallel zur TIRF-Mikroskopie- und ECIS-Messung aufgenommenen hellfeldmikroskopischen Aufnahmen ermöglichten die Korrelation zwischen dem Zeitpunkt der größten Kontaktfläche der Zelle mit dem Substrat und den maximalen Impedanzwerten.

Zur Untersuchung der mechanischen Eigenschaften von Membranen wurde eine neue Messmethode entwickelt, bei der Riesenvesikel zwischen einem Cantilever ohne Spitze und einer parallel dazu geneigten Probenoberfläche komprimiert werden. Mit Hilfe der dabei vom Rasterkraftmikroskop detektierten Rückstellkraft der Membran kann die Vorspannung und das Flächenkompressionsmodul der Lipidmembran durch Ausgleichsrechnungen mit dem hierfür entwickelten KVPP-Modell bestimmt werden. Dieses basiert auf der Membrantheorie unter Annahme eines konstanten Volumens des Vesikels während der Kompression. 
Vesikel mit einer Membran in der flüssig-kristallinen Phase zeigen ein elastisches Kompressionsverhalten. Die Membran der Vesikel ist durch Adhäsion an die Glasoberfläche bereits soweit vorgespannt, dass keine Ondulationen mehr auftreten. Die durch Anpassungen an die KraftAbstandskurven berechneten Vorspannungswerte liegen daher im Bereich von 0.1-3 mN/m und das mittlere Flächenkompressionsmodul der Vesikelmembran beträgt zirka $0.28 \mathrm{~N} / \mathrm{m}$.

Zur Simulation der Plasmamembranen mit dem Cytoskelett wurden aktingefüllte Vesikel hergestellt, wobei die Aktinfilamente im Inneren keine einheitliche Struktur ausbilden, wie Fluoreszenzaufnahmen darlegen. Aktingefüllte Vesikel ohne F-Aktin oder einer nur lückenhaften Aktinschale verhalten sich bei der Kompression identisch zu den Vesikeln ohne Aktin und es dominiert die Extensibilität der Membran. Die Rückstellkräfte von Vesikeln mit einem ausgebildeten Aktincortex am Rand oder einem Aktinnetzwerk im Lumen sind hingegen deutlich größer. Bei gleichbleibender Vorspannung der Membran erhöht sich das Flächenkompressionsmodul der aktinfilamentunterstützten Membran auf 0.1-3 N/m. Der erhöhte Wert für das „apparente“ Flächenkompressionsmodul resultiert vermutlich aus zusätzlichen elastischen Beiträgen, wie einem erhöhten Biegemodul. 


\section{Anhang}

\section{Abkürzungsverzeichnis}

\begin{tabular}{|c|c|}
\hline$\langle A\rangle$ & durchschnittlichen Fläche einer Zelle \\
\hline$A C$ & Adenylycyclase \\
\hline ACA & Adenylycyclase Adenosiontriphosphat \\
\hline ADP & Adenosindiphosphat \\
\hline ATP & Adenosiontriphosphat \\
\hline$A_{\mathrm{kV}}$ & kompremierte Vesikeloberfläche \\
\hline$A_{V}$ & Vesikeloberfläche \\
\hline AX & Dictyostelium discoideum-Stämme die keimfrei überleben können \\
\hline A23187 & Magnesiumionophor \\
\hline BEN & polarisierten, angeregten Netzwerkes \\
\hline BF & Hellfeldmikroskopie \\
\hline$\langle C\rangle$ & durchschnittliche Zirkularität einer Zelle \\
\hline CAMP & zyklischen Adenosinmonophosphat \\
\hline CAR & cAMP Rezeptor \\
\hline$\gamma$ & Oberflächenspannung \\
\hline$\delta$ & Dissipationsfaktor Delta \\
\hline$d$ & Schichtdicke \\
\hline D-QCM & Quarzkristall-Mikrowaage mit Dissipation \\
\hline DIC-Mikroskopie & Differentialinterferenzkontrast-Mikroskopie \\
\hline DPPC & 1,2-Dipalmitoyl-sn-glycero-3-phosphocholin \\
\hline DOPC & 1,2-Dioleoyl-sn-glycero-3-phosphocholin \\
\hline DOPE & 1,2-Dioleoyl-sn-glycero-3-phosphoethanolamin \\
\hline DOPE-Biotin & 1,2-Dioleoyl-sn-glycero-3-phosphoethanolamin- $\mathrm{N}$-(cap biotinyl) \\
\hline DTT & Dithiothreitol \\
\hline ECIS & electric cell-substrate impedance sensing \\
\hline$E_{\mathrm{K}}$ & Biegeenergie \\
\hline et al. & und andere \\
\hline$E_{\mathrm{Y}}$ & Youngsches Modul \\
\hline$F$ & Kraft \\
\hline F-Aktin & Aktinfilamente \\
\hline FFT & Schnellen-Fourier-Transformationsanalyse \\
\hline FRAP & fluorescence recovery after photobleaching \\
\hline FRET & Förster-Resonanzenergietransfer \\
\hline G-Aktin & monomeres / globuläres Aktin \\
\hline G-B-Puffer & Glucose haltiger Basispuffer \\
\hline GFP & grün fluoreszierendes Protein \\
\hline GUV & große, unilamellare Vesikel \\
\hline
\end{tabular}


h

ITO

$\kappa$

$K_{\mathrm{A}}$

I

$\mathrm{L}_{\alpha}$-Phase

$\mathrm{L}_{c}$-Phase

LEGI

$\mathrm{MgCl}_{2}$

min

$\mathrm{Na}_{2} \mathrm{HPO}_{4}$

NC4-Stamm

$N_{\mathrm{P}}$

QCM

PDMS

$\mathrm{Pl}_{3} \mathrm{~K}$

$\mathrm{PIP}_{2}$

$\mathrm{PIP}_{3}$

PTEN

ReZ

$R_{\mathrm{i}}$

$R_{\mathrm{V}}$

$R_{0}$

$R_{2}$

Vesikels

S-Puffer

S-A-Puffer

$\sigma_{0}$

Tris $\mathrm{HCl}$

$T$

$\mathrm{t}$

TIRF

TIRFM

TR-DHPE

$T_{\mathrm{T}}$

$\langle U\rangle$

UK

Z

Z

$z_{\mathrm{d}}$

$\left|Z_{\text {detrend }}\right| 4 \mathrm{kHz}$

$\left|Z_{\text {normd }}\right|_{4 \mathrm{kHz}}$

$\%$ Vol.

$\varnothing$
Stunden

Iridium-Zinn-Oxidschicht

Biegemodul

Flächenkompressionsmodul

Liter

flüssig-kristallinen, lamellaren Phase

Gelphase

lokalen Anregungs- und globalen Inhibitionsmodels

Magnesiumchlorid

Minuten

Dinatriumhydrogenphosphat

Dictyostelium discoideum Zellstamm aus dem Norden Kaliforniens

kritischer Packungsparameter

Quarzkristall-Mikrowaage

Polydimethylsiloxan

Phosphoinositid-3-Kinase

Phosphatidylinositol $(3,4$,$) -Diphosphat$

Phosphatidylinositol $(3,4,5)$-Trisphosphat

Phosphatase und Tensin Homolog auf Chromosom zehn

realer Anteil der Impedanz

Kontaktradius eines komprimierten Vesikels

Vesikelradius

äquatorialer Radius eines komprimierten Vesikels

meridiander Radius der freien Membranfläche eines komprimierten

Sörensen-Phosphatpuffer (nährstofffrei)

Sucrose haltiber und für Polymerisation geeigneter Puffer

Membranvorspannung

Tris(hydroxymethyl)aminomethan Hydrochlorid

Spannung

Zeit

Interne Totalreflexionsfluoreszenz

Interne Totalreflexionsfluoreszenzmikroskopie

Texas Red ${ }^{\circledR}$-1,2-Dihexydecanoyl-sn-glycero-3-phosphoethanolamin

Membranspannung aus Tether bestimmt

durchschnittlichen Umfang einer Zelle

Großbritannien

Impedanz

Abstand zwischen planparallelen Platten

Kompression

vom Langzeittrend bereinigte Impedanzverlauf bei einer Frequenz von $4 \mathrm{kHz}$ normierter Impedanzverlauf bei einer Frequenz von 4 kHz

Volumenprozent

Durchmesser 


\section{Chemikalienverzeichnis}

\begin{tabular}{|c|c|}
\hline Agarose NEEO & Carl Roth, Karlsruhe, Deutschland \\
\hline Aktin & Cytoskeleton, Denver, USA, Vertrieb: tebu-bio, Offfenbach, \\
\hline \multicolumn{2}{|l|}{ Deutschland } \\
\hline Alexa Fluor ${ }^{\circledR} 488$ Aktin & Life Technologies, Carlsbad, USA \\
\hline Ammoniak $30 \%$ Vol & Sigma-Aldrich, St. Louis, USA \\
\hline ATP & Sigma-Aldrich, St. Louis, USA \\
\hline Avindin & CalBioChem (Merck-Gruppe), Darmstadt, Deutschland \\
\hline A23187 & Sigma-Aldrich, St. Louis, USA \\
\hline BSA & Sigma-Aldrich, St. Louis, USA \\
\hline CAMP & Sigma-Aldrich, St. Louis, USA \\
\hline Casein & Merck, Darmstadt, Deutschland \\
\hline Chloroform & Carl Roth, Karlsruhe, Deutschland \\
\hline DOPC & Avanti Polar Lipids, Alabaster, USA \\
\hline DOPE & Avanti Polar Lipids, Alabaster, USA \\
\hline DOPE-Biotin & Avanti Polar Lipids, Alabaster, USA \\
\hline DPPC & Avanti Polar Lipids, Alabaster, USA \\
\hline DTT & Sigma-Aldrich, St. Louis, USA \\
\hline Ethanol, p.a. & Sigma-Aldrich, St. Louis, USA \\
\hline Geneticin $^{\circledast}$ & Roche, Mannheim, Deutschland \\
\hline Glucose & Carl Roth, Karlsruhe, Deutschland \\
\hline Hellmanex-II & Hellma, Mühlheim, Deutschland \\
\hline HL5-Medium mit Glucose & ForMedium, Norfolk, UK \\
\hline $\mathrm{KH}_{2} \mathrm{PO}_{4}$ & Fluka, Buchs, Schweiz \\
\hline Koffein & Sigma-Aldrich, St. Louis, USA \\
\hline Magesiumchlorid & Fluka, Buchs, Schweiz \\
\hline $\mathrm{Na}_{2} \mathrm{HPO}_{4}$ & Appli Chem, Darmstadt, Deutschland \\
\hline Sucrose & Acros Organics, Geel, Belgien \\
\hline Tirs-HCl & Sigma-Aldrich, St. Louis, USA \\
\hline TR-DHPE & Life Technologies, Darmstadt, Deutschland \\
\hline Wasserstoffperoid(35\%) & Grüssing, Filsum, Deutschland \\
\hline
\end{tabular}





\section{Veröffentlichungen}

E. Schäfer, C. Westendorf, E. Bodenschatz, C. Beta, B. Geil, und A. Janshoff Shape Oscillations of Dictyostelium discoideum Cells on Ultramicroelectrodes Monitored by Impedance Analysis. Small, (2011), 7, 723-126.

E. Schäfer, M. Tarantola, E. Polo, C. Westendorf, N. Oikawa, E. Bodenschatz, B. Geil, und A. Janshoff, Chemotaxis of Dictyostelium discoideum: collective oscillation of cellular contacts. PLoS One, (2013), 8, e54172.

E. Schäfer, T.-T. Kliesch und A. Janshoff, Mechanical properties of giant liposomes compressed between two parallel plates - impact of artificial actin shells. Langmuir, eingereicht.

E. Schäfer, D. Aue, M. Tarantola, E. Polo, C. Westendorf, N. Oikawa, E. Bodenschatz, B. Geil, und A. Janshoff, Impedance analysis of collective oscillations of Dictyostelium discoideum.

Commun. Integr. Biol., eingereicht. 